\title{
Erythrotoxicity of aliphatic hydroxylamines : mechanic aspects and parameters for biological effect monitoring
}

Citation for published version (APA):

Spooren, A. A. M. G. (2000). Erythrotoxicity of aliphatic hydroxylamines : mechanic aspects and parameters for biological effect monitoring. [Doctoral Thesis, Maastricht University]. UM. https://doi.org/10.26481/dis.20001026as

Document status and date:

Published: 01/01/2000

DOI:

10.26481/dis.20001026as

Document Version:

Publisher's PDF, also known as Version of record

\section{Please check the document version of this publication:}

- A submitted manuscript is the version of the article upon submission and before peer-review. There can be important differences between the submitted version and the official published version of record. People interested in the research are advised to contact the author for the final version of the publication, or visit the DOI to the publisher's website.

- The final author version and the galley proof are versions of the publication after peer review.

- The final published version features the final layout of the paper including the volume, issue and page numbers.

Link to publication

\footnotetext{
General rights rights.

- You may freely distribute the URL identifying the publication in the public portal. please follow below link for the End User Agreement:

www.umlib.nl/taverne-license

Take down policy

If you believe that this document breaches copyright please contact us at:

repository@maastrichtuniversity.nl

providing details and we will investigate your claim.
}

Copyright and moral rights for the publications made accessible in the public portal are retained by the authors and/or other copyright owners and it is a condition of accessing publications that users recognise and abide by the legal requirements associated with these

- Users may download and print one copy of any publication from the public portal for the purpose of private study or research.

- You may not further distribute the material or use it for any profit-making activity or commercial gain

If the publication is distributed under the terms of Article $25 \mathrm{fa}$ of the Dutch Copyright Act, indicated by the "Taverne" license above, 


\section{Erythrotoxicity of Aliphatic Hydroxylamines}

Mechanistic aspects and parameters for biological effect monitoring 
(C) A.A.M.G. Spooren, Montfoort 2000

ISBN $90-9014120-0$

Subject headings: hydroxylamines / human erythrocytes / toxicology

All rights reserved. No part of this thesis may be reproduced in any form or by any means without permission of the holder of the copyright.

Financial support by the Saal van Zwanenberg foundation and the dr. ir. J.H.J. van der Laar foundation for the advancement of biochemical research for the publication of this thesis is gratefully acknowledged. 


\title{
Erythrotoxicity of Aliphatic Hydroxylamines
}

\author{
Mechanistic aspects and parameters \\ for biological effect monitoring
}

\section{PROEFSCHRIFT}

ter verkrijging van de graad van doctor aan de Universiteit Maastricht, op gezag van de Rector Magnificus, Prof. dr. A.C. Nieuwenhuijzen Kruseman, volgens het besluit van het College van Dekanen, in het openbaar te verdedigen op donderdag 26 oktober 2000 om 14.00 uur

door

Antonette Allegonda Maria Gerarda Spooren

geboren te Vught op 1 april 1968 


\section{Promotores:}

Prof. Dr. H.A.J. Struijker Boudier

Prof. Dr. A. Bast

\section{Co-promotor:}

Dr. ir. C.T.A. Evelo

\section{Beoordelingscommissie:}

Prof. Dr. M.P. van Dieijen-Visser (voorzitter)

Dr. B.J. Blaauboer (Universiteit Utrecht)

Prof. Dr. P.J. van Bladeren (Wageningen Universiteit)

Prof. Dr. H.F.P. Hillen 
De waarheid is zelden zuiver en nooit eenvoudig

Oscar Wilde 



\section{Contents}

Abbreviations used

Chapter 1 General Introduction

Chapter 2 Two mechanisms for toxic effects of hydroxylamine in human erythrocytes: Involvement of free radicals and risk of potentiation

Chapter 3 In vitro hematotoxic effects of three methylated hydroxylamines

Chapter 4 Only the glutathione dependent antioxidant enzymes are inhibited by hematotoxic hydroxylamines

Chapter 5 Hydroxylamine treatment increases glutathione-protein and protein-protein binding in human enthrocytes

Chapter $6 \quad$ A study on the interaction between hydroxylamine analogues and oxyhemoglobin in intact erythrocytes

Chapter 7 Occupational handling of O-methyl hydroxylamine: adoption of an integrated strategy for risk prevention

Chapter 8 General discussion and conclusions

Chapter 9 Summary

Chapter 10 Samenvatting

Dankwoord

Curriculum Vitae

List of Publications 
alnatro 


\section{Abbreviations used}

\begin{tabular}{|c|c|}
\hline ADP & Andenine diphosphate \\
\hline ATP & Adenine triphosphate \\
\hline BEM & Biological effect monitoring \\
\hline CDNB & 1-chloro-2,4-dinitrobenzene \\
\hline $\mathrm{CO}$ & Carbon monoxide \\
\hline CPD & Citrate-phosphate-dextrose \\
\hline DPG & Diphosphoglycerate \\
\hline $\mathrm{DTT}$ & Dithiothreitol \\
\hline DTNB & 5,5'-dithio-bis(2-nitrobenzoic acid) \\
\hline EC-SOD & Extracellular superoxide dismutase \\
\hline EDTA & Ethylenediaminetetraacetic acid \\
\hline FAD & Flavin adenine dinucleotide \\
\hline $\mathrm{Fe}^{2+}$ & Ferrous iron \\
\hline $\mathrm{Fe}^{3+}$ & Ferric iron \\
\hline G6P & Glucose 6-phosphate \\
\hline G6PDH & Glucose 6-phosphate dehydrogenase \\
\hline GPX & Glutathione peroxidase \\
\hline GR & Glutathione reductase \\
\hline $\mathrm{GR}_{\text {coeff }}$ & Glutathione reductase riboflavin activity coefficient \\
\hline $\mathrm{GS}^{\bullet}$ & Thiyl radical \\
\hline GSH & Glutathione (reduced) \\
\hline GSOO & Peroxysulphenyl radical \\
\hline GSSG & Glutathione (oxidized) \\
\hline GST & Glutathione S-transferase \\
\hline GT & Glutathione (total) \\
\hline $\mathrm{H}_{2} \mathrm{O}_{2}$ & Hydrogen peroxide \\
\hline $\mathrm{Hb}$ & Hemoglobin \\
\hline $\mathrm{Hb}^{+}$ & Methemoglobin \\
\hline $\mathrm{HbSH}$ & Free sulfhydryl groups in hemoglobin \\
\hline HbS-SG & Hemogobin-hemoglobin mixed disulfides \\
\hline $\mathrm{HbS}-\mathrm{SHb}$ & Hemoglobin-glutathione mixed disulfides \\
\hline HYAM & Hydroxylamine \\
\hline LDL & Low-density lipoprotein \\
\hline LP & Lipid peroxidation \\
\hline MAC & Maximum acceptable concentration \\
\hline MDA & Malondialdehyde \\
\hline Mem ProtS-SG & Membrane protein-hemoglobin mixed disulfides \\
\hline Mem ProtS-SHb & Membrane protein-glutathion mixed disulfides \\
\hline MHbR & NADPH methemoglobin reductase \\
\hline
\end{tabular}




$\begin{array}{ll}\text { MW } & \text { Molecular weight } \\ \text { NADH } & \text { B-nicotinamide adenine dinucleotide (reduced) } \\ \text { NADH-HbR } & \text { NADH methemoglobin reductase } \\ \text { NADPH } & \text { B-nicotinamide adenine dinucleotide phosphate (reduced) } \\ \text { NADPH-HbR } & \text { NADPH methemoglobin reductase } \\ \text { NF-KB } & \text { Nuclear factor kB } \\ \text { NO } & \text { Nitric oxide } \\ \text { NDMH } & \text { N-dimethyl hydroxylamine } \\ \text { NMH } & \text { N-methyl hydroxylamine } \\ \text { NODMH } & \text { N,O-dimethyl hydroxylamine } \\ { }^{1} \mathrm{O}_{2} & \text { Singlet oxygen } \\ \mathrm{O}_{2}^{-} . & \text {Superoxide radical } \\ \text { OH } & \text { Hydroxyl radical } \\ \text { OEH } & \text { O-ethyl hydroxylamine } \\ \text { OMH } & \text { O-methyl hydroxylamine } \\ 6 \text { PGDH } & \text { 6-phosphogluconate dehydrogenase } \\ \text { PBS } & \text { Phosphate-buffered saline } \\ \text { SD } & \text { Standard deviation } \\ \text { SDS-PAGE } & \text { Sodium dodecyl sulphate polyacrylamide gel electrophoresis } \\ \text { Se } & \text { Selenium } \\ \text { SE } & \text { Standard error } \\ \text { SEMD } & \text { Standard error of the mean difference } \\ \text { SH } & \text { Sulfhydryl groups } \\ \text { SOD } & \text { Superoxide dismutase } \\ \text { STEL } & \text { Short-term exposure limits } \\ \text { TBA } & \text { Thiobarbituric acid } \\ \text { TBARS } & \text { Thiobarbituric acid reactive substances } \\ \text { TCA } & \text { Trichloroacetic acid } \\ \text { TLV } & \text { Threshold limit values } \\ \text { TLV-C } & \text { Threshold limit value ceiling } \\ \text { TT } & \text { Thioltransferase } \\ \text { TWA } & \text { Time weighted average } \\ & \end{array}$




\section{Chapter 1}

\section{General Introduction}

Toxicology is the study of the adverse effects of chemicals on living organisms. The toxicologist is specially trained to examine the nature of these adverse effects and to assess the probability of their occurrence. The combination of a variety of potential adverse effects and the diversity of chemicals present in our environment makes toxicology a very broad science [77]. Therefore, toxicologists are usually specialised to work in one area of toxicology.

As occupational toxicologists we are concerned with the prevention of health impairments in workers who may be exposed to industrial chemicals. The working environment may present the risk of workers' overexposure to various chemicals. It is obvious that the control of these risks cannot wait until epidemiological studies have defined the no-adverse-effect level in man. However, extrapolation from animal data or even from human tissue data also has its limitations. Man is not a big rodent and is more than a jigsaw puzzle of tissue fragments. To overcome this problem, toxicity studies in animals and human tissue can be combined with insights in structure activity relationships. As a next step monitoring techniques can be used to check exposure levels and for early evaluation of effects that occur during actual use of a compound in the industry.

Monitoring activities has an important role in occupational and environmental practice. Most obvious are the methods related to the evaluation of the presence of chemical agents either in the contaminated environment or in the exposed organism. In the first case the procedures are indicated as environmental monitoring, and in the latter case the procedures are defined as biological monitoring [41]. Lately the arsenal of monitoring techniques has been extended with test methods directed to the assessment of early, possibly reversible, biological effects (biological effect monitoring). In order to use such effects for monitoring, the relationship to health impairment does not need to be established. The proposal of tests capable of detecting early adverse biological effects of industrial chemicals requires a detailed knowledge of their mechanism of action. Unfortunately, for many chemicals, such information is still missing. In such cases, the available screening tests are frequently too insensitive for detecting health effects at a reversible stage. Further fundamental research on the mechanism of action of industrial chemicals is needed for development of more useful health surveillance procedures for workers [77].

In this thesis the attention is directed to the toxicity of aliphatic hydroxylamines. Several derivatives of the parent compound hydroxylamine $\left(\mathrm{H}_{2} \mathrm{NOH}\right)$ are currently in use in the chemical industry. However, the availability of toxicity and mechanistic data is limited and almost restricted to data for the parent compound itself. To obtain information for risk assessment a better understanding of the mechanism by which different hydroxylamines 
exert their toxic effects is necessary. Literature data suggest that the primary target for hydroxylamine toxicity is the red blood cell $[72,96,120,132,134,157,167]$. Since human blood is relatively readily available and well suited for biological evaluations it was used in in vitro experiments. The use of human cells foregoes the necessity for interspecies extrapolation that is normally needed when animals or animal derived cells are used. It also offers extra possibilities for mechanistic studies for instance because conditions can be used that would not be possible in vivo; such as the use of high concentrations of hydroxylamines, pretreatment with toxic substances like carbon monoxide, sodium borohydride, diethyldithiocarbamate and aminotriazole, assessment of remaining antioxidant capacity with strong oxidants like hydrogen peroxide and so on. The use of isolated human material also has its disadvantages though. Isolated cells do not always have a normal physiological state and effects on other tissues like the vascular wall or other neighbouring cells like white blood cells are absent.

Despite these disadvantages, the results of the in vitro studies were expected to improve our insights in the toxic effects of hydroxylamines, to aid in better toxicological risk evaluations and to provide us with parameters for biological effect monitoring studies. The toxicological information obtained from the mechanistic in vitro studies was indeed used to determine the most critical aspects of the hematotoxic process and to define a critical exposure level below which there is no reasonable doubt that adverse effects will occur in man. Furthermore, these mechanistic studies were used to develop a potency ranking method for the different hydroxylamines, and, as mentioned above, to provide some useful parameters for biological effect monitoring of hydroxylamine exposure.

\section{Toxicity of hydroxylamines}

Hydroxylamines are chemicals belonging to the family of alkoxyamines. All hydroxylamines studied in this thesis are derivatives of the parent compound hydroxylamine. Hydroxylamines are used as intermediates in the production of pharmaceuticals and pesticides, as reducing agents in the dye-, perfume- and photographic industry, in aldehyde and ketone purification, as oxidants for fatty acids and soaps, or as tanning agents $[35,60]$. Organic hydroxylamines are also formed as intermediates by the enzymatic reduction of nitrates or nitrites or by the oxidation of ammonia as a product of normal cell metabolism. These reactions are components of an intracellular detoxification system $[3,11,23]$. Although hydroxylamine is a product of normal cell metabolism, it is nevertheless moderately toxic to man, animals, and even plants. However, its toxic reactions become manifest only at concentrations substantially greater than those resulting from normal cell metabolism. Hydroxylamines are also formed in the body from drugs such as amphetamine, ephedrine, and norephedrine [60].

In this thesis we were interested in the following structurally related hydroxylamines: hydroxylamine (HYAM), O-methyl hydroxylamine (OMH), O-ethyl hydroxylamine (OEH), 
$\mathrm{N}, \mathrm{O}$-dimethyl hydroxylamine (NODMH), N-methyl hydroxylamine (NMH) and $\mathrm{N}$-dimethyl hydroxylamine (NDMH). In figure 1 the structures of these hydroxylamine analogues are depicted. Most of these hydroxylamines are currently in use in the chemical industry.<smiles>CONO</smiles><smiles>NOO</smiles><smiles>CNON</smiles><smiles>CCONC</smiles><smiles>CN(C)ON</smiles>

Figure 1: Structure analogues of hydroxylamine (HYAM). O-methylhydroxylamine (OMH); O-ethyl hydroxylamine (OEH); $\mathrm{N}$-methyl hydroxylamine (NMH); $\mathrm{N}$-dimethyl hydroxylamine (NDMH); N,Odimethyl hydroxylamine (NODMH).

\section{Animal data}

Information on the toxicity of the above mentioned hydroxylamines is very limited. Therefore, the toxicity of the parent compound HYAM is mainly discussed.

\section{Acute and subacute toxicity}

Studies on the acute toxicity of HYAM and its salts have given variable results and are listed in table 1. An oral $L_{50}$ for HYAM (free base) in the dog of $200 \mathrm{mg} / \mathrm{kg}$ has been established. For the hydrochloride a range from 192 to $600 \mathrm{mg} / \mathrm{kg}$ was found in rats and mice, while in these species a range of $500-1000 \mathrm{mg} / \mathrm{kg}$ was observed for the sulphate $[14,60,82,120]$. The latter compound is the only one for which dermal $L D_{50}$ 's are known: a range of 1500 to 2000 $\mathrm{mg} / \mathrm{kg}$ has been reported for the rabbit [14]. No inhalation studies are available for the different compounds. The inhalation of vapour from saturated aqueous solutions of HYAM hydrochloride or HYAM sulphate for 1 hour (no details of concentration) is tolerated by rats without any signs of toxicity [14]. Contact of HYAM with the skin results in slight irritation that may eventually culminate in dermatitis and sensitisation in man as well as in animals 
$[4,47,55]$. In contact with more delicate tissues such as those of the eyes, it is corrosive and the corrosive effect or the damage is only slightly reversible within 1-week [35].

Effects on the blood have predominantly been observed in mice, rats, rabbits and cats after single and repeated oral, intraperitoneal, subcutaneous or dermal administration of HYAM $(5-75 \mathrm{mg} / \mathrm{kg})[4,14,35,134]$. The major effect seen in blood was elevation of methemoglobin levels, with the added features of methemoglobinemia, sulfhemoglobinemia and moderate anemia. Heinz bodies were also observed. At necropsy high incidence of enlarged and darkened spleens were found in these species, regardless of the dose level or route of exposure.

Table 1: Acute toxicity of hydroxylamine and its salts

\begin{tabular}{lcccc}
\hline Species & Compound tested & $\begin{array}{c}\text { Route of } \\
\text { administration }\end{array}$ & $\begin{array}{c}\mathbf{L D}_{50} \\
(\mathbf{m g} / \mathbf{k g})\end{array}$ & Reference \\
\hline Mouse & Chloride & Oral & 420 & {$[120]$} \\
Mouse & Chloride & Oral & 400 & {$[82]$} \\
Mouse & Sulphate & Oral & 1000 & {$[14]$} \\
Mouse & Chloride & Intraperitoneal & 127 & {$[134]$} \\
Mouse & Chloride & Intraperitoneal & 100 & {$[82]$} \\
Mouse & Chloride & Intraperitoneal & 180 & {$[14]$} \\
Mouse & Chloride & Intraperitoneal & 250 & {$[60]$} \\
Mouse & Free base & Intraperitoneal & 60 & {$[82]$} \\
Mouse & Sulphate & Intraperitoneal & 142 & {$[14]$} \\
Rat & Chloride & Oral & 192 & {$[60]$} \\
Rat & Chloride & Oral & 600 & {$[14]$} \\
Rat & Sulphate & Oral & 545 & {$[60]$} \\
Rat & Sulphate & Oral & $500-1000$ & {$[14]$} \\
Rat & Sulphate & Oral & 642 & {$[14]$} \\
Rat & Chloride & Intraperitoneal & 140 & {$[60]$} \\
Rat & Free base & Intraperitoneal & 59 & {$[82]$} \\
Rat & Free base & Subcutane & 29 & {$[82]$} \\
Rabbit & Sulphate & Dermal & $1500-2000$ & {$[14]$} \\
Guinea pig & Chloride & Intraperitoneal & 70 & {$[60]$} \\
Dog & Free base & Oral & 200 & {$[60]$} \\
Dog & Chloride & Subcutane & 70 & {$[14]$} \\
\hline
\end{tabular}

Subchronic and chronic toxicity

After administration of HYAM sulphate in the drinking water of rats for 3 months (maximum concentration $20 \mathrm{mg} / \mathrm{kg}$ bw/day), the animals had developed anemia (dose-related), with corresponding hematological changes and hemosiderosis [14]. Athropy of the thyroid gland and a 4- to 5-fold enlargement of the spleen have been described in rats given milk containing $350 \mathrm{mg} / \mathrm{kg}$ bw/day HYAM hydrochloride for 6 months. This daily feeding of HYAM hydrochloride had no influence on the general condition and the growth-rate of the rats [120]. 
In a large-scale study, 172 rabbits were injected intravenously with $2.5 \mathrm{mg} / \mathrm{kg}$ HYAM hydrochloride 6 days per week, for a period as long as 19 months. The rabbits showed methemoglobin formation, anemia and reticulocytosis. The hematological effects were present in all animals, but there were no symptoms that could be interpreted with certainty as dysfunction or blocking of the erythropoietic system [72]. A similar study, conducted more than 20 years later, involving rabbits injected intravenously daily with as little as $1 \mathrm{mg} / \mathrm{kg}$ HYAM hydrochloride also resulted in anemic animals [4]. Long-term administration of HYAM sulphate (52 weeks) to mice in their drinking water, at a concentration of $3 \mathrm{~g} / \mathrm{l}$ resulted in splenomegaly, a decrease in red blood cells, and an increase in white blood cells. These effects were reversible after 8 and 18 weeks. There was also bone formation (osseous metaplasia) in the spleen of about $50 \%$ of the mice. These effects were also seen for $\mathrm{OMH}$ at a concentration of $6 \mathrm{~g} / \mathrm{l}$, although the effects were somewhat less pronounced [167].

\section{Carcinogenicity}

Although $\mathrm{N}$-nitroso-O-, and $\mathrm{N}$-diethyl-hydroxylamine given orally caused multiple carcinomas of paranasal sinuses, lung, and stomach in 25 out of 28 male rats [155], HYAM, itself, has been shown to be noncarcinogenic after chronic administration to mice [167]. In this same study it was also demonstrated that $\mathrm{OMH}$ did not cause tumour formation in mice. Other reports confirm that HYAM does not show any carcinogenic activity in a variety of tests [143]. In certain cases some carcinostatic effects of HYAM have been described $[60,66,117,118,167]$. However, in another study with rats, HYAM caused excessive growth and secretory activity of the mammary gland [14].

\section{Mutagenicity}

Numerous studies have investigated the genotoxic potential of HYAM and its salts $[21,37,38,48,49,61,85,97,110,116,131,135,137,146,149]$. The results of these tests are not consistent. Both positive and negative results have been obtained in in vitro tests for the induction of point mutations, but two Salmonella tests which were carried out independently of each other gave negative results both with and without metabolic activation $[97,131]$. Tests for clastogenic activity and DNA exchange have proved positive, almost without exception $[21,48,49,61,135,137]$. From these studies it is known that HYAM reacts with pyrimidine bases, such as cytosine and uracil. Cell transformation tests have again given both positive and negative results $[37,116,149]$. In vivo, most studies on Drosophilia melanogaster have been positive $[15,22,43,58,73,126,127,166]$, while in the dominant lethal assay in mice HYAM sulphate was without effect $[39,40]$.

\section{Reproductive toxicity and teratogenicity}

No foetal abnormalities were found in rats which have been dosed with amounts of HYAM that were capable of causing some maternal deaths $[26,80]$. When dairy heifers were fed daily amounts of HYAM with their feed $(40$ to $60 \mathrm{mg}$ ) from the time they were 2 months pregnant throughout their pregnancy -a dose sufficient to produce methemoglobin- no detrimental effect was observed on the calves [157]. Although, one report indicated that no 
teratogenic effects of HYAM were noted in chicken [141], another study observed abnormalities in the lower extremities of developing chicken embryos [142]. Using mice as test subjects, HYAM sulphate was listed as one of the agents producing early foetal deaths and preimplantation losses [40]. No mutations were noted. In a study of pregnant rabbits injected intravenously with HYAM, abnormalities in cephalic development were observed [169].

\section{Human data}

It is reported that in workers working with HYAM (concentration unknown), methemoglobin levels up to $25 \%$ have occurred at the end of the working day [14]. According to another report quoted by Gross [60], the accidental ingestion of "two swallows" of a HYAM solution caused nausea, vomiting, cyanosis and hemolytic anemia that was only slowly reversible. Martin et al [96] described the development of serious anemia in five laboratory workers working with methylated hydroxylamines (O-methyl, N,O-dimethyl and trimethyl hydroxylamine). In the most acute patient lowered hemoglobin and increased serum iron levels were found, indicating hemolytic anemia. All exposed workers had increased numbers of bone marrow erythroblasts and the reticulocyte numbers were increased in two out of five exposed workers. Heinz bodies were not found and methemoglobin could not be detected. Skin irritation due to HYAM hydrochloride or sulphate has also been described in humans $[47,55,56]$.

\section{Human Erythrocytes}

Blood cells are among the easiest available cells from within the body. They can be obtained with hardly invasive techniques, and therefore volunteers can easily be found. The erythrocyte is an extremely specialised cell and many organelles normally present in human cells are not present in mature erythrocytes (e.g. nucleus, ribosomes, mitochondria). In other words, the erythrocyte is a cell that can be thought of as composed of two parts, the cytoplasm and the membrane. The cytoplasm is so packed with hemoglobin that $90 \%$ to $95 \%$ of the dry weight of the cell is hemoglobin [16]. The actual hemoglobin concentration is usually 320 to $360 \mathrm{~g} / \mathrm{l}$ of cytoplasm. The cytoplasm also contains all of the glycolytic enzymes and enzymes involved in protection against oxidative stress.

The other major component of the erythrocyte is the membrane. The membrane is essentially a lipid bilayer containing cholesterol and certain intrinsic membrane proteins embedded in it [62]. The lipid bilayer consist of phospholipids with the hydrophilic heads oriented to the outside and the hydrophobic tails oriented to the inside. One of the intrinsic membrane proteins is called band 3, so named because of its relative electrophoretic position. Other intrinsic membrane proteins include a set of three proteins called glycophorins [91-93]. Underlying the lipid bilayer on the cytoplasmic surface is a network of proteins called the cytoskeleton. One of the major proteins in the cytoskeleton is called spectrin. Spectrin is a large molecule that forms a tetramer with head-to-head association of 
dimers. Near the head junction, spectrin is linked to band 3 protein of the membrane through a protein referred to as ankyrin. Near the tail end of the spectrin there is a complex of proteins involving an oligomer of actin subunits together with another protein called band 4.1 $[9,57,92]$.

The structure of the red cell membrane is responsible for the well known biconcave disc shape of the red blood cell. Normal human red cells have a diameter of 7.5 to $8.7 \mu \mathrm{m}$, which decreases slightly with cell age. They have an average volume of $90 \times 10^{-15} \mathrm{~L}$ and a surface area of approximately $136 \mu \mathrm{m}^{2}[24,79]$. Under flow circumstances in the circulation the cell actually develops more of a helmet shape. This shape results from the force of blood flow, producing shear deformation of the cell. The requirement to yield to shear deformation means that the red cell membrane has to be remarkably flexible. The flexibility and excess membrane surface are such to allow the cell to swell to a sphere of approximately $150 \mathrm{x}$ $10^{-15} \mathrm{~L}$ or to enter a capillary of $2.8 \mu \mathrm{m}$ in diameter [16].

Human erythrocytes have a longevity of about 120 days [28], and new cells are continuously being formed in the hematopoietic tissues located mainly in the bone marrow. Their main function is the transport of oxygen from the lungs to the other tissues and carbon dioxide in the opposite direction. This binding, transport, and delivery of oxygen do not require the expenditure of metabolic energy by the red blood cell. However, if the red blood cell is to perform its function efficiently, and to survive in the circulation for its full life-span, it must have a source of energy. This energy is needed to maintain the following: (1) the iron of hemoglobin in the divalent form; (2) the high potassium and low calcium and sodium levels within the cell against a gradient imposed by the high plasma calcium and sodium and low plasma potassium levels; (3) the sulfhydryl groups of red cell enzymes, hemoglobin, and membranes in the active, reduced form; and (4) the biconcave shape of the cell $[13,16]$.

\section{Energy source}

The erythrocyte does not have an oxidative phosphorylation system, a cytochrome system, nor a Krebs cycle. It cannot synthesize lipids, and, of course, it cannot synthesize proteins since it loses its nucleus before it enters the circulation and most of its RNA within 1 or 2 days of its release into the circulation [144]. The energy supply is totally dependent on the enzyme-controlled glycolytic system in which glucose is converted to lactic acid. The erythrocyte cannot further utilise either pyruvate or lactate, and these substances diffuse out into the plasma. ATP is the main product of glycolysis and two molecules of ATP are generated from ADP for each glucose molecule metabolised. The ATP formed is sufficient to maintain shape, volume and flexibility of the red blood cells $[13,16]$. Another major product of glycolysis is DPG (diphosphoglycerate). This compound plays an important role in oxygen dissociation. After releasing oxygen, DPG assumes a position in between two $\beta$-chains of the hemoglobin molecule, and by doing so reduces the affinity for oxygen and facilitates the release of oxygen to tissues [8]. 
Another pathway that branches off the main glycolytic pathway is the hexose monophosphate shunt. The first step of this pathway is catalysed by the enzyme glucose 6-phosphate dehydrogenase (G6PDH). Both this step and the subsequent step cause the reduction of NADP to NADPH [144]. This is required for the reduction of oxidised glutathione (GSSG) to reduced glutathione (GSH) and for the reduction of mixed disulphides of hemoglobin and GSH [138]. GSH is required to protect the cell against oxidative stress, which is illustrated in Figure 2. This figure shows that the production of NADPH is linked through a series of reactions to the eventual detoxification of peroxide. Oxidant-type stress is a constant feature of the life of the red cell, partly because of its role in oxygen transport. Thus, the intactness of this pathway is important for the defence of the cell against this type of stress.

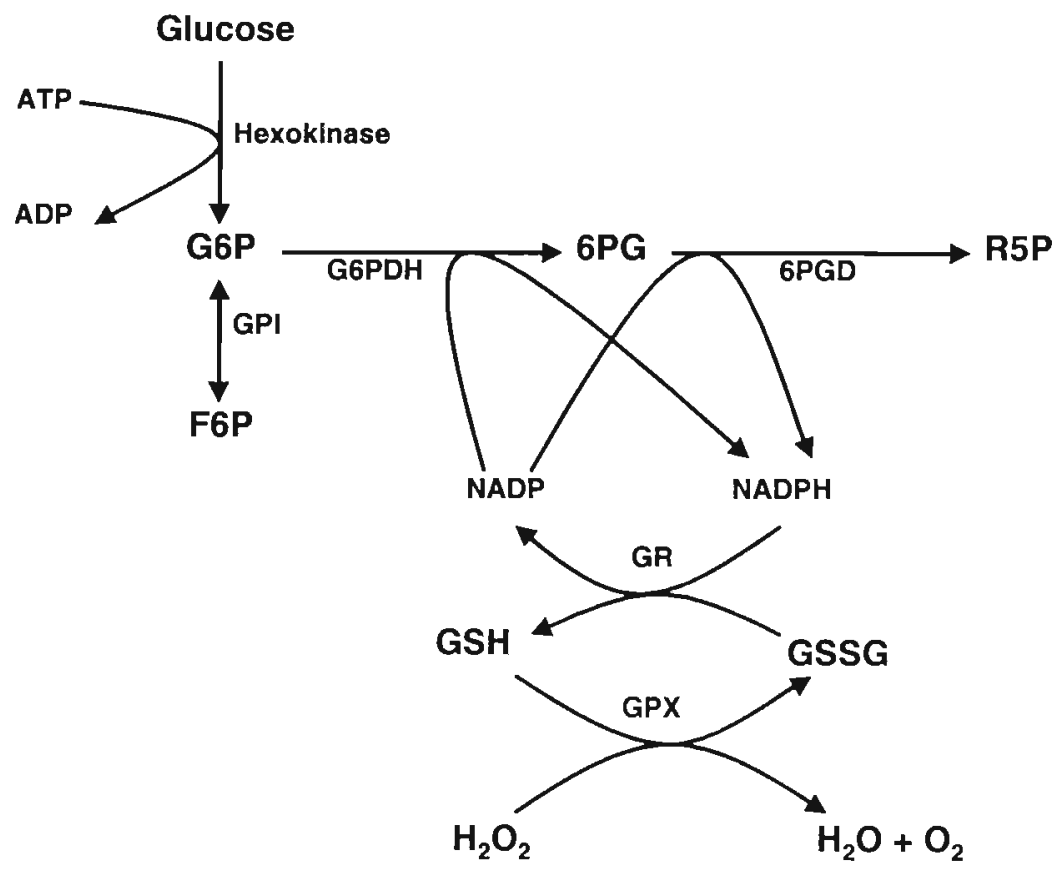

Figure 2: The antioxidant cascade stemming from the hexose monophosphate shunt.

\section{Hemoglobin}

As mentioned before the primary function of the red cell is to transport oxygen, and hemoglobin is the molecule that transports that oxygen. The hemoglobin molecule in normal adults has a molecular weight of 68,000 and consists of four polypeptide chains, two $\alpha$ and two $\beta$ chains. The $\alpha$ and $\beta$ chains have different sequences of amino acids but fold up to form similar three-dimensional structures. Each chain harbours one heme, which gives blood its red colour. The heme consist of a ring of carbon, nitrogen, and hydrogen atoms called 
porphyrin, with an atom of iron at its centre (see figure 3) [115]. The four polypeptide chains fit together in a precise way, primarily by hydrophobic bonding; that is, the amino acid residues that provide the contact points between the chains are primarily hydrophobic. On the other hand, those amino acid residues that are on the surface of the tetrameric molecule are largely hydrophilic $[13,16]$.

The conformation of the oxygenated hemoglobin tetramer is different from that of the deoxygenated form. Certain residues are protonated in the Oxy conformation but at the time of deoxygenation lose a proton. This allows the formation of salt bridges between the charged groups of different chains. The residues involved are called the Bohr groups, and the loss of protons during deoxygenation is called the Bohr effect. The additional rigidity of the tetrameric structure caused by the salt bridges has led to the term tense, or $T$, for the deoxy structure as opposed to the relaxed, or $R$, structure for the Oxy conformation [53].

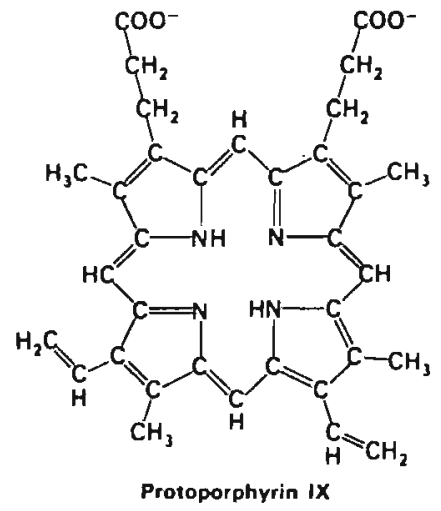

Figure 3: Structure of heme (ferroprotoporphyrin IX)

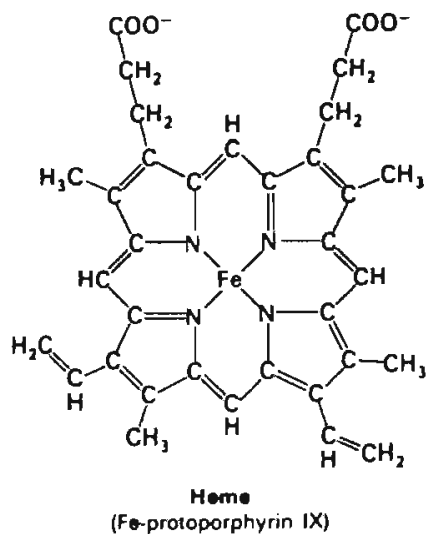

(Fe-protoporphyrin IX)

Carbon monoxide (CO) and nitiric oxide (NO) combine with heme iron and have a much higher affinity for it than oxygen, which they are therefore able to displace $[75,107]$. If the CO affinity of hemoglobin were as high as that of free ferrous heme, vertebrate life could not exist. Steric factors in the heme pocket of hemoglobin lower the $\mathrm{CO}$ affinity relative to the oxygen affinity sufficiently to reduce the fraction of hemoglobin poisoned with endogenously produced $\mathrm{CO}$. Moreover, the combination of one of the four hemes in any hemoglobin molecule with $\mathrm{CO}$ raises the oxygen affinity of the remaining three hemes by heme-heme interaction [115]. However, a higher oxygen affinity of the remaining heme groups also means that less oxygen is transported and released to tissues, which is not advantageous.

Methemoglobin is the form of hemoglobin in which the iron of the heme has been oxidised to the ferric $\left(\mathrm{Fe}^{3+}\right)$ state compared with the usual ferrous $\left(\mathrm{Fe}^{2+}\right)$ state. Methemoglobin is nonfunctional because it cannot bind and therefore cannot transport oxygen. About $1 \%$ to $3 \%$ of 
the hemoglobin is converted into methemoglobin every day, and without a reducing system the cell would soon become non-functional [25]. The red cell contains both NADH and NADPH methemoglobin reductases for regulation of the conversion of methemoglobin to oxyhemoglobin. The NADH methemoglobin reductase is the principal reductase for the enzymatic conversion of methemoglobin to oxyhemoglobin and is dependent on the glycolytic pathway for NADH reduction [148]. The activity of the NADPH methemoglobin reductase -depending on the hexose monophosphate shunt for NADPH reduction-accounts for only about $20 \%$ of total methemoglobin reduction under normal conditions [168]. However, during stress conditions it may be of much more importance [123]. Thus the properties which prevent the formation of methemoglobin in excessive quantities in normal circumstances are the structural integrity of the hemoglobin molecule, the activity of NADH methemoglobin reductase and the reserve activity of NADPH methemoglobin reductase.

Sulfhemoglobin is a compound in which the irons are in the ferrous state but the oxygen affinity is about 100 times lower than that of normal hemoglobin [13]. The sulphur is not liganded to the iron but is found in the porphyrin ring.

\section{Oxidative damage in erythrocytes}

The human erythrocyte is a cell that one might expect to be at risk for free radical damage $[27,32,67]$. The combination of several factors such as an active metalloprotein, hemoglobin, that can function as an oxidase and a peroxidase [101,102], high oxygen tension in many areas of the circulation, membrane proteins and other functional proteins that can become cross-linked, and unsaturated fatty acids that can be oxidised provides an environment for potentially deleterious reactions to the red cell. These reactions could lead to normal cell ageing but under certain pathological conditions, or under conditions of oxidative stress, this will lead to premature loss of cellular function and integrity.

\section{Oxidation of hemoglobin}

Most free radical reactions in the red cell are initiated through hemoglobin, which can reductively activate $\mathrm{O}_{2}$, as well as oxidise or reduce other compounds to radical intermediates. It is well known that superoxide $\left(\mathrm{O}_{2}^{-}\right)$is produced when oxyhemoglobin autoxidises $[25,106,153]$. Normally the heme iron electron binding $\mathrm{O}_{2}$ returns to the iron when oxygen is released, and the iron remains in its ferrous state. When water or other small anions enter the heme pocket -which is normally prevented due to the hydrophobic nature of this pocket- oxygen can be displaced with an extra electron, i.e. as superoxide (eq. 1.1). As a result of this phenomenon there is a continual spontaneous source of activated oxygen within the erythrocyte.

$$
\mathrm{HbFe}^{2+}-\mathrm{O}_{2}+\mathrm{H}_{2} \mathrm{O} \rightarrow \mathrm{HbFe}^{3+}-\mathrm{OH}+\mathrm{O}_{2}^{-}
$$


Superoxide can both oxidise oxyhemoglobin to methemogiobin, and reduce methemoglobin

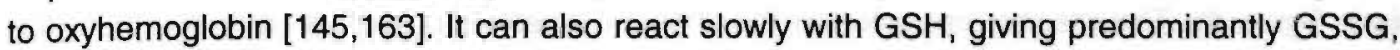
with the sulphonate and possibly singlet oxygen as minor products [154]. However, the rate of reactions of superoxide with hemoglobin are slow, so that less than $1 \%$ of any superoxide formed in the erythrocyte is likely to react with hemoglobin rather than with superoxide dismutase (SOD) [145]. Considering the high concentration of hemoglobin, other reactions of superoxide in the bulk cytoplasm are probably of minor significance.

Superoxide can dismutate spontaneously and this process can be catalyzed enzymatically by SOD [50]. In the latter case, in addition to $\mathrm{H}_{2} \mathrm{O}_{2}$ also the highly reactive singlet oxygen $\left({ }^{\prime} \mathrm{O}_{2}\right)$ is formed. Superoxide and $\mathrm{H}_{2} \mathrm{O}_{2}$ are involved in the formation of the hydroxyl radical $\left(\mathrm{OH}^{\circ}\right)$, which is the most reactive oxygen radical known [65]. This redox reaction occurs in the presence of transition metal ions such as iron and copper salts. This metal catalysed reaction is known as the Haber-Weiss reaction (eq. 1.4) [63].

$$
\begin{aligned}
& \mathrm{O}_{2}^{-\bullet}+\mathrm{Fe}^{3+} \rightarrow \mathrm{Fe}^{2+}+\mathrm{O}_{2} \\
& \mathrm{Fe}^{2+}+\mathrm{H}_{2} \mathrm{O}_{2} \rightarrow \mathrm{Fe}^{3+}+\mathrm{OH}^{-}+\mathrm{OH}^{\bullet} \\
& \mathrm{O}_{2}^{-}+\mathrm{H}_{2} \mathrm{O}_{2} \rightarrow \mathrm{O}_{2}+\mathrm{OH}^{-}+\mathrm{OH}^{-}
\end{aligned}
$$

Another source of radicals is the interaction of hemoglobin with redox active compounds. These compounds can be either reducing agents or oxidising agents, and the reactions are predominantly of two types: either oxidation of the former by the heme-bound oxygen (eq. 1.5), or reduction of the latter by the heme iron (eq. 1.6) [159].

$$
\begin{aligned}
& \mathrm{HbFe}^{2+}-\mathrm{O}_{2}+\mathrm{RH}+\mathrm{H}^{+} \rightarrow \mathrm{HbFe}^{3+}+\mathrm{R}^{\cdot}+\mathrm{H}_{2} \mathrm{O}_{2} \\
& \mathrm{HbFe}^{2+}-\mathrm{O}_{2}+\mathrm{R} \rightarrow \mathrm{HbFe}^{3+}+\mathrm{O}_{2}+\mathrm{R}^{\cdot}
\end{aligned}
$$

The products formed in reaction 1.5 are all capable of undergoing further reactions, with themselves, with the initial reactants, and with $\mathrm{O}_{2}$, giving rise to other radicals such as superoxide and hemoglobin-peroxide complexes (ferryl species). The free radical intermediate, produced in reaction 1.6, is in most cases a reducing radical and can react with oxygen to give superoxide. Hydrogen peroxide can then be produced by dismutation of superoxide [29]. Again a mixture of radicals, $\mathrm{H}_{2} \mathrm{O}_{2}$ and consequently hemoglobin-peroxide complexes are obtained. These hemoglobin-peroxide complexes are strong oxidising species which are capable of at least some of the reactions of the high reactive hydroxyl radical $\left(\mathrm{OH}^{\circ}\right)$ [159]. On the whole, these reactions generate a complex mixture of products which oxidise hemoglobin. The characteristic effect of excessive oxidation of hemoglobin is denaturation of the molecule with precipitation, condensation and attachment of the denatured protein to the inside of the membrane. The insoluble precipitates are Heinz bodies 
[140]. The overall outcome of this reaction is frequently early destruction of the erythrocytes (see figure 4). The results presented in this thesis indicate that such a complex, multistep process can certainly be applied for the different hydroxylamines.

\section{Oxidation of the red cell membrane}

As mentioned above, the red cell membrane consist of a lipid bilayer made up of phospholipids and cholesterol with a complicated membrane skeleton of proteins, to which various carbohydrate or lipid groups are attached. The phospholipids have fatty acids side chains of which some are unsaturated fatty acids. These reduced, double-bonded groups play a part in membrane flexibility but are also susceptible to lipid peroxidation $[27,129]$. Especially the methyl groups between two cis double bonds in polyunsaturated lipids are sensitive to lipid peroxidation [124].

Free radicals react with the polyunsaturated lipids in a chemical process involving three stages: initiation, propagation, and termination. In the initiation phase a hydrogen atom is abstracted from a carbon atom. Since a hydrogen atom has only one electron, this leaves behind an unpaired electron on the carbon. This carbon-centred radical undergoes a molecular rearrangement to form a conjugated diene which then combines with oxygen to form a peroxy radical [129]. This peroxy radical is able to abstract a hydrogen atom from another fatty acid and so propagates a chain reaction. In the final step two unpaired electrons come together to form an electron pair thereby terminating the chain reaction [27]. Since the probability for two radicals colliding is much smaller than that for each of the radicals to hit another molecule, lipid peroxidation does not usually terminate until considerable numbers of radicals have been formed. In other words, once initiated, lipid peroxidation will most likely not terminate until extensive damage to lipid molecules has occurred.

The red cell membrane may be damaged in other ways than by lipid peroxidation. Reduced sulfhydryl groups (SH) are present mainly on the inner surface of the membrane [44]. Oxidation and the formation of mixed disulphides is associated with hemolytic mechanism $[100,160]$. Several studies have shown that oxidation of membrane proteins occurs independently of lipid peroxidation $[34,54,150]$. As such, protein oxidation (intrachain and interchain) can also be an important step in membrane damage (see also next paragraph on oxidation of cellular proteins).

\section{Oxidation of cellular proteins}

A consequence of free radical attack on proteins can be loss of function, for example loss of catalytic activity for enzymes. Enzymes will be especially sensitive to radicals when reactive species are formed at the active sites. Superoxide and hydroxyl radicals can inhibit catalase $[78,156]$. SOD loses enzymatic activity when exposed to $\mathrm{H}_{2} \mathrm{O}_{2}$, probably due to the formation of $\mathrm{OH}^{*}$ radicals near the active site $[69,87]$. Glutathione peroxidase (GPX) is inhibited by superoxide radicals. This inhibition is thought to involve oxidation of the selenocysteine residue at the active site of the enzyme [19]. The activity of glutathione S-transferase $\pi$ 
(GST $\pi$ ) in human enythrocyles is known to be inactivated by $\mathrm{H}_{2} \mathrm{O}_{2}$. The first stage of the latter inactivation is reversible since GST could be reactivated with purified rat liver thioltransferase (TT) [125]. Human GST $\pi$ is known to contain 4 cysteine residues at the $14^{\text {th }}$, $47^{\text {th }}, 101^{\text {th }}$ and $169^{\text {th }}$ positions [89]. The cysteine residues at the $47^{\text {th }}$ and $101^{\text {th }}$ position were found to be critical for the observed inactivation of GST $\pi$. Disulphide formation between these residues, resulting in steric hindrance, was considered the most probable cause for the inactivation.

The inhibition of GST by oxidative stress seems to be more or less specific for GST $\pi$. Nishinaka et al. [112] showed that class $\pi$ porcine lens GST could be inactivated by a xanthine-xanthine oxidase system and by $\mathrm{H}_{2} \mathrm{O}_{2}$. On the other hand, bovine lens GST - which belongs to class $\mu$ - was not sensitive to these factors. In fact, class $\mu$ GST as well as microsomal GST, can even be activated by active oxygen species $[2,84,109]$. GSTs from the $\alpha$ class can be inactivated by active oxygen species [109], but they are less sensitive than $\pi$ class GST.

In general, any enzyme bearing an accessible thiol group essential for activity is susceptible to formation of protein-mixed disulphides or intramolecular disulphides by reacting with small disulphides, this being accompanied by an increase or decrease in the enzyme activity [128]. The results presented in the next chapters indicate that the activity loss of GST and GPX after exposure to hydroxylamines is likely to involve such an oxidation of critical cysteine residues.

The reaction of the tripeptide glutathione with free radicals is of special importance. This is related to its abundance in the cell and its function as a free radical scavenger. Under oxidative stress conditions GSH is oxidised to the disulphide GSSG via different processes: (a) direct oxidation of GSH into GSSG by oxidative compounds, (b) peroxidase activity of both GPX and GST with concomitant oxidation of GSH, (c) reduction of vitamin $\mathrm{C}$ and $\mathrm{E}$ leading to increased GSH oxidation and (d) the formation of mixed disulphides of GSH and proteins by TT (see also next section). Since the erythrocytes must keep their reduced state, GSSG must be reduced. At normal physiological conditions, GSSG is reduced into GSH by glutathione reductase (GR) at the expense of NADPH. The regeneration of NADPH is coupled to the hexose-monophosphate shunt, which has a high reserve capacity. Under oxidative stress conditions up to $92 \%$ of the phosphorylated glucose can pass through this pathway (normally about 11\%) [1]. Under such conditions the turnover is no longer limited by G6PDH but by phosphorylation of glucose itself, catalysed by hexokinase [147]. When the reductive capacity of the erythrocyte is not high enough, erythrocyte GSSG will be exported from erythrocytes by two separate ATP dependent transport systems [12]. Even under normal conditions glutathione removal from mature erythrocytes is considerable, leading to a turnover half-time of 2-4 days [68]. This export rate confronts erythrocytes with a problem since GSH cannot be imported into the erythrocyte [158], but is synthetised in erythrocytes by means of the glutathione synthetising enzymes $\gamma$-glutamylcysteine synthetase and glutathione synthetase [86]. Furthermore, erythrocytes lack $\gamma$-glutamyltranspeptidase activity 
which hampers the uptake of amino acids [139]. The availability of substrates, mainly of glutamate since the permeability of the erythrocyte membrane for this amino acid is very low, is considered to be a serious limiting factor in erythrocyte glutathione synthesis [12]. Altogether, this can mean that the erythrocyte is not able to keep its reduced state. Under serious stress conditions GR activity may become insufficient to hold the high GSH/GSSG ratio needed for optimum protection. The GSSG export system described above will then remove part of the GSSG and as such compete with GR. Moreover, under severe stress conditions the GSSG level will become high enough to allow formation of mixed proteinglutathione disulphides by the reversal of the $T$ catalysed reaction shown in eq. 2.2. Since GSSG export is ATP dependent, insufficient supply of ATP might also stimulate this pathway. As stated above, import of GSH is not possible and the GSH synthesis can be limited by slow amino acid uptake. Eventually this process will lead to damaged erythrocytes and consequently to premature sequestration (see figure 4).

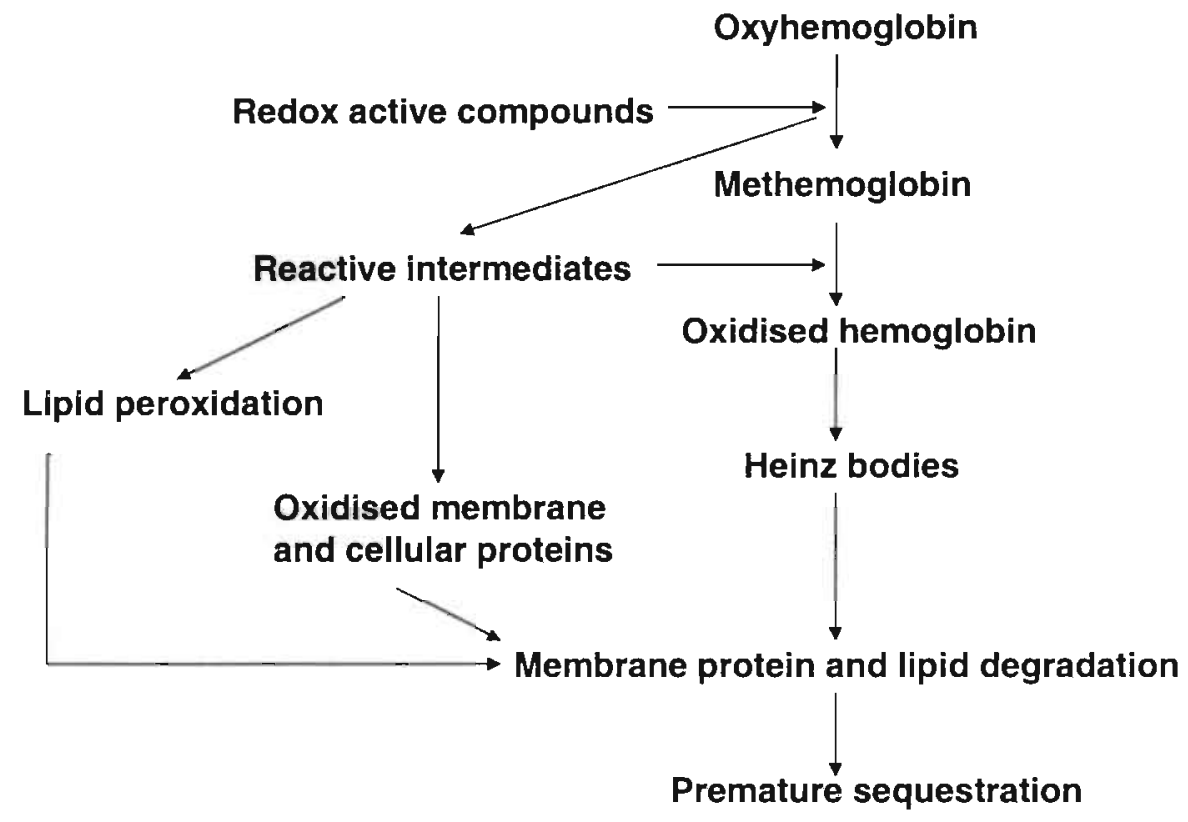

Figure 4: Process of oxidative denaturation in erythrocytes

\section{Antioxidant defence in erythrocytes}

Human erythrocytes possess enzymatic antioxidant mechanisms as well as non-enzymatic antioxidants to cope with the toxic effects of oxidative stress. SOD, catalase, and GPX are considered the primary antioxidant enzymes, since they are involved in the direct elimination of reactive oxygen species. GST, GR, TT and G6PDH are secondary antioxidant enzymes 
which help in the detoxification of reactive oxygen species by decreasing peroxide levels (GST) or by maintaining a steady supply of metabolic intermediates like glutathione (GR and TT) and NADPH (G6PDH) for the primary antioxidant enzymes. The non-enzymatic small molecular anitoxidants include among others sulfhydryl compounds such as GSH and thiols, $\mathrm{NADPH}$, ascorbic acid (vitamin C), uric acid and tocopherol (vitamin E).

\section{Enzymatic antioxidant defence}

Superoxide dismutase (EC 1.15.1.1) was first discovered by McCord and Fridovich in 1969 [99]. The enzyme dismutates two molecules of superoxide $\left(\mathrm{O}_{2}^{-*}\right)$ to form $\mathrm{H}_{2} \mathrm{O}_{2}$ and $\mathrm{O}_{2}$ (eq. 1.7).

$$
2 \mathrm{O}_{2}^{-\cdot}+2 \mathrm{H}^{+} \stackrel{S O D}{\longrightarrow} \mathrm{H}_{2} \mathrm{O}_{2}+\mathrm{O}_{2}
$$

In eukaryotic cells there are several forms of the metalloprotein SOD, a Cu/Zn SOD, a Mndependent SOD and an extracellular SOD (EC-SOD) [51]. Cu/Zn SOD is mainly found in the cytosol and has a MW of 32,000 with two identical subunits. The copper ion is catalytically active, undergoing cyclic reduction and oxidation during catalysis. The EC-SOD also contains copper and zinc, however, it has a MW of 135,000 . EC-SOD is composed of four equal noncovalently bound subunits [94]. Mn SOD (MW 88,000) is found in the mitochondrial matrix and as such is not present in erythrocytes. As mentioned before, the $\mathrm{Cu} / \mathrm{Zn}$ SOD can be inactivated by $\mathrm{H}_{2} \mathrm{O}_{2}$, the dismutation product of superoxide radicals. This is due to the formation of site-specific hydroxyl radicals, which react at the copper ion in the active site $[69,87]$.

Catalase (EC 1.11.1.6) is one of the oldest known enzymes; it was named by Loew in 1901 [114]. The enzyme catalyses the breakdown of $\mathrm{H}_{2} \mathrm{O}_{2}, \mathrm{H}_{2} \mathrm{O}_{2}$ can be dangerous despite its non-radical character, because it can react with reduced metal ions to form $\mathrm{OH}^{*}$ radicals (Fenton reaction; eq. 1.3).

$$
\mathrm{H}_{2} \mathrm{O}_{2} \stackrel{\text { caualase }}{\longrightarrow} 2 \mathrm{H}_{2} \mathrm{O}+\mathrm{O}_{2}
$$

The usual form of catalase has a MW of about 240,000 and consists of four protein subunits, each containing a heme [Fe(III)-protoporphyrin] group bound to its active site. Dissociation of the molecule into its subunits causes loss of activity. Inhibition of catalase can occur due to superoxide radicals [78] and $\mathrm{OH}^{\circ}$ radicals [156]. As such, SOD and catalase protect each other since superoxide inhibits catalase, while hydrogen peroxide may inhibit SOD $[69,78,87]$.

Glutathione peroxidase (EC 1.11.1.9) was first described by Mills in 1957 [105]. Organic hydroperoxides are removed by GPX, which uses GSH as a hydrogen donor. 


$$
\mathrm{ROOH}+2 \mathrm{GSH} \stackrel{G P X}{\longrightarrow} \mathrm{GSSG}+\mathrm{H}_{2} \mathrm{O}+\mathrm{ROH}
$$

This leads to the interconversion of GSH into its oxidised form GSSG. Adequate levels of GSH are maintained by the NADPH-dependent enzyme GR that generates GSH from GSSG (see eq. 2.0). By its selenium (Se) dependency, GPX can be divided into two forms: Se-dependent GPX and Se-independent GPX (similar to GST). The Se-dependent GPX is able to reduce $\mathrm{H}_{2} \mathrm{O}_{2}$ and organic hydroperoxides. The Se-independent GPX (GST) is only able to reduce organic hydroperoxides. GPX is a tetramer of MW 84,000 with one residue of selenocysteine per mole at each of the active sites and is found in both cytosol $(70 \%)$ and mitochondria (30\%) [46]. As the organic hydroperoxides must be liberated form the cellular membrane before it can be reduced by GPX, the action of phospholipase is a requirement [81]. GPX activity is sensitive to superoxide anions which can react with the selenoate in the active site of the enzyme [19].

Glutathione S-transferase (EC 2.5.1.18) were originally observed in the catalysis of the first step in the formation of the mercapturic acids [20]. The enzymes are dimers of approximately MW 50,000 with at least 7 different forms of subunits and 8 isoenzymes. The enzymes have relatively low activity towards organic hydroperoxides but none at all towards $\mathrm{H}_{2} \mathrm{O}_{2}$. They have multiple functions, but are mainly involved in the biotransformation of xenobiotics $[74,76]$ and detoxification of carcinogens [133]. The intracellular distribution was found to be cytosolic and mitochondrial. The majority of the human erythrocyte GST consist of GST $\rho$ $(90-95 \%)$ which is a GST $\pi$ class enzyme $[18,89]$. Apart from GST $\rho$, erythrocytes contain another GST which has been designated GST $\sigma(5 \%)$ [6]. More recently another erythrocyte GST has been described, GST $\theta$ [122]. This GST $\theta$ is important for the conjugation of methylene chloride. Expression of this $\theta$-class enzyme is known to be polymorfic [64]. As mentioned before, inactivation of GST by oxidative stress seems to be more or less specific for class $\pi$ GSTs and this class of GSTs can be inactivated by superoxide and $\mathrm{H}_{2} \mathrm{O}_{2}$ $[89,109,112]$.

Glutathione reductase (EC 1.6.4.2) was initially observed in livers from various animals by Hopkins and Elliott in 1931 [70], and later isolated form ox, sheep, and rabbit liver by Mann in 1932 [88]. The MW of the enzyme is about 120,000 with 2 subunits, each with the flavin adenine dinucleotide (FAD) at its active site. It has a binding site for GSSG, NADPH and FAD $[83,90]$. Electrons are supplied by NADPH and transported via FAD to the active site, which is a disulphide [42]. As a result GSSG is reduced to GSH.

$$
G S S G+N A D P H+H^{+} \stackrel{G R}{\longrightarrow} 2 G S H+N A D P^{+}
$$

The enzyme is found in cytosol and in mitochondria. GR activity is strongly decreased at normal physiological conditions since it is inactivated by NADPH by modification of the reduced enzyme [83]. GSSG protects GR against inactivation and is also able to reactivate the enzyme. In case of oxidative stress, the GSSG concentration increases which activates 
GR to reduce GSSG into GSH, with concomitant increase of the NA.DP ${ }^{+}$concentration. This increased NADP ${ }^{+}$concentration activates G6PDH, so that NADP+ is converted into NADPH, which can be used for the reduction of GSSG by GR [83].

Thioltransferase (EC 1.8.4.1) belongs to the family of thiol-disulphide oxidoreductases. The MW of the enzyme is about 11,000 with four cysteine residues per protein molecule $[103,104]$. The reduction of a cysteine bridge would be a two step process [152], in which the disulphide bridge is reduced at the expense of glutathione oxidation. In human erythrocytes this type of reactions are catalysed by thioltransferase $[103,104]$.

$$
\begin{aligned}
& R S S R+G S H \stackrel{\pi}{\longleftrightarrow} R S S G+R S H \\
& R S S G+G S H \stackrel{\pi}{\longleftrightarrow} G S S G+R S H
\end{aligned}
$$

$\Pi$ along with GR and G6PDH may play a crucial role in erythrocytes sulfhydryl homeostasis by protecting $\mathrm{SH}$-groups on enzymes, hemoglobin and proteins important for membrane integrity. Moreover, at high intracellular GSSG concentrations, $\Pi$ is also able to store GSSG in the form of mixed disulphides [90].

The existence of a direct oxidative pathway for the oxidation of glucose-6-phosphate was demonstrated in yeast extract in 1936 [36]. The purification of G6PDH (EC 1.1.1.49), however, was not successful until 1961 [95]. The native human erythrocyte G6PDH exists in a rapid equilibrium between a tetramer of $M W 210,000$ and a dimer of $M W 105,000$. The subunits are identical in charge [30]. The hexose monophosphate shunt start with the dehydrogenation of glucose 6-phosphate (G6P), a reaction catalysed by G6PDH. This enzyme is highly specific for $\mathrm{NADP}^{+}$; the $\mathrm{K}_{\mathrm{M}}$ for $\mathrm{NAD}^{+}$is about a thousand times as great as that for NADP ${ }^{+}$[144]. The product is 6-phosphoglucono- $\delta$-lactone, which is an intramolecular ester between the C-1 carboxyl group and the C-5 hydroxylgroup. The next step is the hydrolysis of 6-phosphoglucone- $\delta$-lactone by a specific lactonase to give 6 -phosphogluconate. This six-carbon sugar is then oxidatively decarboxylated by 6-phosphogluconate dehydrogenase (6PGDH) to yield ribulose-5-phosphate. NADP ${ }^{+}$is again the electron acceptor [144].

$$
\begin{aligned}
& G 6 P+N A D P^{+} \stackrel{66 P D H}{\longrightarrow} 6-\text { phosphoglucono- } \delta \text {-lactone }+N A D P H \\
& 6 \text { - phosphglucono- } \delta \text {-lactone }+\mathrm{H}_{2} \mathrm{O} \stackrel{\text { tactonase }}{\longrightarrow} 6-\text { phophogluconate } \\
& 6 \text { - phosphogluconate }+\mathrm{NADP}^{+} \stackrel{{ }_{6} \mathrm{PGOH}}{\longrightarrow} \text { ribulose }-5-\text { phosphate }+\mathrm{NADPH}
\end{aligned}
$$

In other words, the hexose monophosphate shunt provides reducing equivalents in the form of NADPH and pentose sugars for nucleotide metabolism. In human erythrocytes, flux through the hexose monophosphate shunt maintains glutathione in the reduced form as one of the main cellular anti-oxidative mechanisms [59]. Red cells are regularly subjected to high oxygen tension and are among the first body cells exposed to exogenous oxidative 
substances that are ingested, injected or inhaled. The importance of this anti-oxidative function is shown by the massive oxidant-induced hemolysis seen in subjects with a marked deficiency of G6PDH [59]. This G6PDH deficiency in red cells, a sex-linked trait, is not a rare disease. Female heterozygotes have two populations of red cells: one has normal enzymatic activity, whereas the other is deficient. This inherited enzymatic deficiency is relatively benign until exposure to certain xenobiotics (e.g. antimalarial drugs, oxidising or reducing xenobiotics) [144].

\section{Non-enzymatic antioxidant defence.}

Thiol groups act as intracellular antioxidants by scavenging free radicals and through enzymatic reactions. The tripeptide glutathione (L- $\gamma$-glutamyl-L-cysteinyl-glycine) is the most important cellular thiol with an intracellular concentration of $2 \mathrm{mM}$ in erythrocytes [45]. As seen above, GSH has a multifaceted role in antioxidant defence. It is a cosubstrate for peroxide detoxification by GPX, for conjugation by GST and, through disulphide exchange reactions via $T$, it can reduce protein disulphides and regulate the thiol/disulphide status of the cell. Furthermore, it can reduce vitamin $C$ and $E$ as will be discussed later on in this chapter. GSH can also be important as a direct radical scavenger. It is considered to be a major contributor to radioprotection and radical repair [136], and to protect against xenobiotic radicals and endogenous oxidants [121]. GSH can react with a wide variety of radicals with consequent generation of another radical, the thiyl radical (GS ${ }^{*}$; eq. 2.6), as is characteristic of radical reactions $[121,136,151]$. Therefore, depending on the properties of the secondary radical, such scavenging is not necessarily a defence or protective process.

$$
R^{*}+\left(\text { SSH } \longleftrightarrow R H+G S^{*}\right.
$$

GS $^{*}$ radicals have been historically considered as biologically benign. However, GS ${ }^{*}$ is a reactive radical that can oxidise compounds such as NADH and ascorbate, and abstract hydrogen from polyunsaturated fatty acids to initiate lipid peroxidation [33]. To rationalise these pro-oxidant properties with GSH being an efficient radical scavenging antioxidant, it is necessary to consider alternative reactions of $\mathrm{GS}^{\circ}$ and in particular the influence of oxygen. For most radicals, equation 2.6 is thermodynamically unfavourable and the equilibrium lies far to the left. It can, however, be kinetically driven by efficient removal of the thiyl radical product $[151,162]$. This can occur via a reaction with the thiolate ion, followed by the fast reaction of the disulphide radical ion with oxygen [162].

$$
\begin{aligned}
& G S^{-}+G S^{-} \longleftrightarrow G S S G^{-} \\
& G S S G^{-}+O_{2} \longrightarrow G S S G+O_{2}^{-}
\end{aligned}
$$

Whether this sequence is favoured over either thiyl radical combination or reaction with oxygen to give the peroxysulphenyl radical (GSOO') will depend on the concentration of GSH and on the $\mathrm{pH}$ and $\mathrm{pO}_{2}$ [5]. However, at physiological $\mathrm{pH}$ and $\mathrm{pO}_{2}$ reactions 2.7 and 2.8 
have been shown to be the major route for thiyl radical decay in a number of studies $[161,164]$ and provide the necessary driving force for GSH to act as an efficient scavenger $[108,162]$. The implication is that GSH would be a poor scavenger in the absence of oxygen, and superoxide would always be produced as a consequence of its scavenging activity. This is important when considering the reaction of GSH with superoxide itself.

$$
\mathrm{O}_{2}^{-{ }^{*}}+G S H+H^{+} \longrightarrow H_{2} O_{2}+G S^{*}
$$

The thiyl radical then reacts via reactions 2.7 and 2.8 to regenerate superoxide and set up a chain. Chain termination is predominantly caused by SOD (eq. 1.7).

Vitamin E, a term that encompasses a small group of related tocopherols (alpha-, beta, gamma-, and delta-tocopherol), is the major lipid-soluble antioxidant responsible for protecting the polyunsaturated fatty acids in membranes against lipid peroxidation [71]. The heterocyclic ring of the chroman-head group is important for the antioxidative action; the phythyl group is necessary for the intercalation into membranes. Vitamin $E$ acts in the lipid phase by trapping peroxy radicals [165].

$$
V i t E+R O O^{\bullet} \longleftrightarrow R O O H+V i t E^{*}
$$

The vitamin $E$ radical is relatively unreactive and if the vitamin $E$ radical can be repaired, and by itself does not lead to further propagation reactions, the effect is that the radical chain of lipid peroxidation is interrupted. The hydroperoxide generated from the peroxyl radical may undergo further non-radical repair reactions, for example, the reduction to the corresponding alcohol by peroxidase reactions and the excision of the peroxidised fatty acid from the phospholipids in the membrane [130]. Several possibilities exist to regenerate vitamin $E$ : the radical might react with another peroxyl radical to form a non-radical product, the radical may interact with another vitamin $E$ radical, forming a vitamin $E$ dimer, and the radical may be reduced to regenerate the vitamin $E$ itself. Vitamin $C$ (ascorbic acid) and GSH have been shown to be able to generate vitamin $E[10,31,111]$. This directly reduction of vitamin $E$ radicals by GSH is known to involve a membrane-bound GSH-dependent vitamin $E$ freeradical reductase $[7,98,119]$. Vitamin $E$ can also react directly with superoxide and hydroxyl radicals $[52,113]$.

Vitamin $C$, a water-soluble antioxidant, plays an essential role in numerous biological mechanisms. One of its functions it to quench free radicals. Vitamin $C$ is a two electron/hydrogen reductant with a stable one-electron oxidised form, the monodehydroascorbate (ascorbyl radical), which is readily formed on reaction with radicals (e.g. peroxy radicals, vitamin $E$ radicals, oxygen derived radicals) [17]. This makes vitamin $C$ a good chain breaking antioxidant. The ascorbyl radical can react with another radical or disproportionate to form ascorbic acid and dehydroascorbic acid $[10,17]$. The formation of 
dehydroascorbic acid can be reduced by GSH, a reaction that may be catalysed by $\Pi$ [152]. In this way GSH directly or indirectly assist the radical scavenging effect of vitamin $\mathrm{E}$ and $\mathrm{C}$.

\section{Outline of the thesis}

This thesis describes the use of in vitro studies to elucidate some aspects of the mechanism of hydroxylamine erythrotoxicity and to evaluate the potency in this respect of some important chemicals from this group. This supplied the insight that interaction with hemoglobin is the most critical step in the erythrotoxic mechanism for all hydroxylamines studied. The outcome of these studies was used to set a critical exposure level for one of the compounds studied. Furthermore it provided some insights necessary for potency ranking and some useful parameters for biological effect monitoring of exposed workers.

Firstly, the effects of hydroxylamines on human red blood cells were studied. In chapter 2 the in vitro effects of the parent compound hydroxylamine and two of its derivatives, O-ethyl and N,O-dimethyl hydroxylamine, are described. In this chapter effects are studied on a cellular level, on hemoglobin and its reduction, on systems supplying reducing factors on glutathione and accessory systems and on lipid peroxidation. In chapter 3 the in vitro effects of the other three industrially used hydroxylamines were studied (i.e. O-methyl, $\mathrm{N}$-methyl and $\mathrm{N}$-dimethyl hydroxylamine). In chapter 4 the possible effects of hydroxylamines on the enzymatic antioxidant defence system in human erythrocytes are described. A primary effect of hydroxylamine exposure in man and animals is hemolytic anemia that is probably a result of oxidative stress within erythrocytes. For this reason, the in vitro study described in chapter 5 was directed to the effect of hydroxylamine on the sulfhydryl status, morphology and membrane skeletal proteins of human erythrocytes. In chapter 6 the hemoglobin dependence of the toxicity, the occurrence of cell damaging products, and the cellular kinetics of the hydroxylamine analogues were investigated to elucidate the difference in toxicity profiles between the six tested hydroxylamines.

In the following chapter -chapter 7- an occupational health study was carried out. In this study information obtained from the above described in vitro studies was used to adopt an integrated strategy to prevent risks related to O-methyl hydroxylamine exposure in a recently started production facility.

The findings from chapter 2 to 7 are discussed in chapter 8. A summary in English and Dutch is included in chapter 9 and 10 respectively (Een samenvatting in het Engels en Nederlands is respectievelijk te vinden in hoofdstuk 9 en 10). 


\section{References}

1 Albrecht $V$, Roigas $\mathrm{H}$, Schultze $\mathrm{M}$, Jacobasch $\mathrm{G}$ and Rapoport $\mathrm{S}$. The influence of $\mathrm{pH}$ and methylene blue on the pathways of glucose utilization and lactate formation in erythrocytes of man. Eur. J. Biochem. 20: 44-50, 1971

2 Aniya $Y$ and Naito $A$, Oxidative stress-induced activation of microsomal gluathione S-transferase in isolated rat liver. Biochem. Pharmacol. 45: 37-42, 1993

3 Armarger $\mathrm{N}$ and Alexander $\mathrm{M}$, Nitrite formation from hydroxylamine and oximes by pseudomonas aeruginaso. J Bacteriol. 95: 1651-5, 1968 Arnoldova KA and Speransky NN, Some aspects of the effect produced by muriatic hydroxylamine on the animal body. Gig. Tr. Prof. Zabol. 7: 38-42, 1963 Asmus KD, Sulfur-centered radicals. Meth. Enzymol. 186: 168-80, 1990

Awasthi YC and Singh SV, Purification and characterization of a new form of glutathione S-transferase from human erythrocytes. Biochem. Biophys. Res. Commun. 125: 1053-60, 1084

Bast $A$ and Haenen GRMM, Cytochrom P-450 and vitamin $E$ free radical reductase: formation of and protection against free radicals. In: Free radicals, lipoproteins and membrane lipids. (eds. Crastes de Paulet A, Douste Blazy L and Paoletti R), pp. 108-15. New York: Plenum Press. 1990

Benesch RE and Benesch R, Mechanisms of interaction of red cell organic phosphates with hemoglobin. Adv. Protein Chem. 28: 211-4, 1974

Bennet $\mathrm{V}$, The molecular basis for membrane - cytoskeleton association in human erythrocytes. J. Cell. Biochem. 18: 49-65, 1982

Berg van den JJM, Kuypers FA, Roelofsen B and Op den Kamp JAF, The cooperative action of vitamine $E$ and $C$ in the protection against peroxidation in human erythrocyte membranes. Chem. Phys. Lipids 53: 309-20, 1990

Bernheim MLC, Hydroxylamine reductase of mitochondria. Arch. Biochem. Biophys. 134: 40812,1969

Beutler E and Dale GL, Erythrocyte glutathione: function and metabolism. In: Glutathione chemical biochemical and medical aspects. Part B. (eds. Dolphin D. Avramovic $O$ and Poulson R), pp. 291-317. New York: Wiley and Sons, 1989

13 Beutler E, Lichtman MA, Coller BS and Kipps TJ, Williams Hematology. New York: McGrawHill, Inc., 1995

14 BG Chemie: Hydroxylamin und seine salze. (Berufsgenossenschaft der Chemischen Industrie. Toxikologische bewertung Ausgabe 05/91 Nr 62, Heidelberg ISSN-0937-4248), 1991

Bhattacharya AK, Biswas $A$ and Haldar $G_{1}$ Genotoxicity of amino-acids, a probe. Indian J. Exp. Biol. 24: 460-3, 1986

Bick RL, Bennet JM, Brynes RK, Cline MJ, Kass L, Murano G, Shohet SB and Ward PCJ, Hematology. Clinical and laboratory practice. St. Louis, USA: Mosby, Inc, 1993

7 Bielski BHJ and Richter HW, Some properties of the ascorbate free radical. Ann. N.Y. Acad. Sci. 258: 231-7, 1975

8 Bladeren PJ and Ommen B. The inhibition of glutahione S-transferases; mechanisms, toxic consequences and therapeutic benefits. Pharmac. Ther. 51: 35-46, 1991

9 Blum $J$ and Fridovich I, Inactivation of glutathione peroxidases by superoxide radical. Arch. Biochem. Biophys. 240: 500-8, 1985

20 Booth $J$, Boyland $E$ and Sims $P$, An enzyme from rat liver catalysing conjugations with glutathione. Biochem. J. 79: 516-24, 1961 
21 Borenfreund $E$, Krim M and Bendlich $A$, Chromosomal aberrations induced by hyponitrite and hydroxylamine derivatives. J. Natl. Cancer Inst. 32: 667-79, 1964

22 Brusick DJ and Stetka D, Mutagenic assessment of hydroxylamine sulfate in the mouse micronucleus assay. Proc. Symp. Ind. Approach. Chem. Risk Assess. 1: 229-32, 1984

23 Budowsky El, The mechansim of the mutagenic action of hydroxylamines. Prog. Nucleic Acid Res. Mol. Biol. 16: 125-30, 1976

24 Bull BS and Hay KL, Are red cell indices international? Arch. Pathol. Lab. Med. 109: 604-10, 1985

25 Carrell RW, Winterbourn CC and Rachmilewitz EA, Activated oxygen and haemolysis. Br. J. Haematol. 30: 368-89, 1975

26 Chaube S and Murphy ML. The effects of hydroxyurea and related compounds on the rat fetus. Cancer Res. 26: 1448-57, 1966

27 Chiu D, Kuypers F and Lubin B, Lipid peroxidation in human red cells. Semin. Hematol. 26: 25776, 1989

28 Clark MR, Senescence of red blood cells: progress and problems. Physiol. Rev. 68: 503-54, 1988

29 Cohen $G$ and Hochstein P. Generation of hydrogen peroxide in erythrocytes by hemolytic agents. Biochem. 3: 895-900, 1964

30 Cohen P and Rosemeyer MA, Glucose-6-phosphate dehydrogenase from human erythrocytes. In: Methods in enzymology. (eds. Wood WA), pp. 188-96. New York: Academic Press, 1975

31 Constantinescu A, Han D and Packer L, Vitamine E recycling in human erythrocyte membranes. J. Biol. Chem. 268: 10906-13, 1993

32 Cross CE, Halliwell B, Borish ET, Pryor WA, Ames BN, Saul RL and McCord JM, Oxygen radicals and human disease. Ann. Intern. Med. 107: 526-45, 1987

33 D'Aquino $M$, Bullion $C$ and Choprs $M$, Sulfhydryl free radical formation enymatically by sonolysis, by radiolysis, and thermally: Vitamin $A$, curcumin, muconic acid, and related conjugated olefins as references. Meth. Enzymol. 233: 34-46, 1994

34 De Goeij AFPM, Van Straalen RJC and Van Steveninck J, Photodynamic modificatioon of proteins in human red blood cell membrances, induced by protoporphyrin. Clin. Chim. Acta 71: 485-94, 1976

35 Derelanko MJ, Gad SC, Gavigan FA, Babich PC and Rinehart WE, Toxicity of hydroxylamine sulfate following dermal exposure: Variability with exposure method and species. Fund. Appl. Toxicol. 8: 583-94, 1987

36 Dickens $F$ and Glock GE, Direct oxidation of glucose 6-phosphate, 6-phosphogluconate and pentose-5-phosphates by enzymes of animal origin. Biochem. J. 50: 81-95, 1951

37 Dunkel VC, Pienta RJ, Sivak A and Traul KA, Comparative neoplastic transformation responses of Balb/3T3 cells, Syrian hamster embryo cells, and Rauscher murine leukemia virus-infected Fischer 344 rat embryo cells to chemical carcinogens. J. Natl. Cancer Inst. 67: 1303-15, 1981

38 Engel $W$, Krone $W$ and Wolf $U$, Die Wirkung von Thioguanin, Hydroxylamin und 5-Bromdesoxyuridin auf menschliche Chromosomen in vitro. Mutat. Res 4: 353-68, 1967

39 Epstein SS, Arnold E, Andria J, Bass W and Bishop $Y$, Detection of chemical mutagens by the dominant lethal assay in the mouse. Toxicol. Appl. Pharmacol. 23: 288-325, 1972

40 Epstein SS and Rohrborn G, Recommenden procedures for testing genetic hazards from chemicals, based on the induction of dominant lethal mutatuions in mammals. Nature 230: 45960, 1971 
41 Evelo CTA and Henderson PT, Biological effect monitoring. Arch. Toxicol. Suppl. 15: 268-77, 1992

42 Fahey RC and Sundquist AR, Evolution of glutathione metabolism. Adv. Enzymol. Rel. Areas Mol. Biol. 64: 1-53, 1991

43 Fahmy CG and Fahmy MJ, Hydroxylamine and derivatives: Cytotoxicity without mutagenicity in cellular genetic systems. Chem. Biol. Interact. 2: 331-48, 1970

44 Fairbanks G, Steck TL and Wallach DFH, Electrophoretic analysis of the major polypeptides of the human erythrocyte membrane. Biochem. 10: 2606-17, 1971

45 Fazi A, Mancini U, Piatti E, Accorsi A and Magnani M, Human red blood cells as bioreactors for the inactivation of harmful xenobiotics. Biotechnol. Appl. Biochem. 14: 60-8, 1991

46 Flohè L, The selenoprotein glutathione peroxidase. In: Glutathione chemical, biochemical and medical aspects. (eds. Dolphin D, Avramocic O and Poulson R), pp. 643-731. New York: J. Wiley \& Sons, 1989

47 Folesky $H$, Nickel $H$, Rothe $A$ and Zschunke $E$, Allergic eczema due to hydroxylamine salts (oxammonium). Z. Gesamte Hyg. Ihre Grenzgeb. 17: 353-5, 1971

48 Freese $E$, Bautz $E$ and Bautz-Freese $E$, The chemical and mutagenic specificity of hydroxylamine. Proc. Natl. Acad. Sci. USA 47: 845-55, 1961

49 Freese $E$ and Bautz-Freese $E$, The oxygen effect on deoxyribonucleic acid inactivation by hydroxylamine. Biochem. 4: 2419-33, 1965

50 Fridovich I, Editorial: Superoxide radical and the bactericidal action of phagocytes. N. Engl. J. Med. 290: 624-5, 1974

51 Fridovich I, Superoxide dismutases. Ann. Rev. Biochem. 44: 147-59, 1975

52 Fuzuka K, Tokumura A, Suchi S and Tsuka-Tani H, Antioxidant activation of tocopherol on Feascorbate induced lipid peroxidation in lecithin liposomes. Lipids 17: 511-3, 1982

53 Gibson $\mathrm{QH}$, The reactionof oxygen with hemoglobin and the kinetic basis of the effect of salt on binding of oxygen. J. Biol. Chem. 245: 3285-90, 1970

54 Girotti AW, Photodynamic action of protoporphyrin IX on human erythrocytes: Cross linking of membrane proteins. Biochem. Biophys. Res. Commun. 72: 1367-74, 1976

Gobbi A, Topic eczema due to hydroxylamine in workers engaged in the production of cycloserine. Med. Lav. 61: 387-90, 1970

Goh CL, Allergic contact dermatitis and onycholysis from hydroxylamine sulfate in colour developer. Contact Dermatitis 22: 109-15, 1990

Goodman SR and Shiffer K, The spectrin membrane skeleton of normal and abnormal human erythrocytes: a review. Am. J. Physiol. 244: C121-41, 1983

Graf U, Juon H, Katz AJ, Frei HJ and Wurgler FE, A pilot study on a new Drosophila spot test. Mutat. Res. 120: 233-9, 1983

Grimes AJ, Human red cell metabolism. Oxford: Blackwell Scientific Publications, 1980

Gupta P and Sharma T, Effect of mitomycin C, hydroxylamine and bromodeoxyuridin on cell cycle kinetics and sister chromatide exchange frequency of muntjac lymphocytes. Indian J. Exp. Biol. 20: 726-30, 1982 Haber $F$ and Weiss J, The catalytic decomposition of hydrogen peroxide by iron salts. Proc. Roy. Soc. Biol. Sci. 147: 332-51, 1934 $H M$, Polymorphism of glutathione conjugation in methyl bromide, ethylene oxide and 
dichloromethane in human blood: influence on the induction of sister chromatid exchange (SCE) in lymphocytes. Arch. Toxicol. 67: 173-8, 1993

65 Halliwell $B$ and Cross $C E$, Oxygen-derived species: Their relation to human disease and environmental stress. Env. Health Perpect 102 (suppl 10): 5-12, 1994

66 Harman D, Prolongation of the normal lifespan and inhibition of spontaneous cancer by antioxidants. J. Gerontol. 16: 247-54, 1961

67 Hatherill R, Till GO and Ward PA, Mechanisms of oxidant-induced changes in erythrocytes. Agents and Actions 32: 351-8, 1991

68 Hochberg A, Rigbi M and Dimant E, The incorporation in vitro of glycine and L-glutamic acid into glutathione of human erythrocytes. Biochim. Biophys. Acta 90: 464-71, 1964

69 Hodgson EK and Fridovich I, The interaction of bovine erythrocyte superoxide dismutase with hydrogen peroxide: inactivation of the enzyme. Biochem. 14: 5294-9, 1975

70 Hopkin FG and Elliott KAC, The relation of glutathione to cell respiration with special reference to hepatic tissue. Proc. Roy. Soc. Biol. Sci. 109: 58-88, 1931

71 Horwitt MK, The promotion of vitamin E. J. Nutr. 116: 1371-7, 1986

72 Jacobson $\mathrm{E}$, Plum $\mathrm{CM}$ and Milwertz I, Experimental anemias with hydroxylamine and their relation to human pernicious anemia. Nord. Med. 3: 2851-8, 1939

73 Jain HK and Shukla PT, Locus specificity of mutagens in Drosophila. Mutat. Res. 14: 440-2, 1972

74 Jakoby WB, The glutathione S-transferases: a group of detoxification proteins. In: Advances in enzymology. (eds. Meister A), pp. 383-414. New York: John Wiley \& Sons, Inc, 1978

75 Johnson $\mathrm{ME}$ and Ho $\mathrm{C}$, Effect of ligands and organic phosphates on functional properties of human adult hemoglobin. Biochem. 13: 365-70, 1974

76 Ketterer B, Tan KH, Meyer DJ and Coles B, Glutathione transferases: a possible role in the detoxification of DNA and lipid hydroperoxides. In: Glutathione S-transferases and carcinogenisis. (eds. Mantle TJ, Pickett CB and Hayes JD), pp. 149-63. New York: Taylor \& Francis, 1987

77 Klaassen CD, Amdur MO and Doull J, Casarett and Doull's Toxicology: The basic science of poisons. New York: Macmillan Publishin Company, 1986

78 Kono $Y$ and Fridovich I, Superoxide radical inhibits catalase. J. Biol. Chem. 257: 5751-4, 1982

79 Korpman RA, Dorrough DC, Brailsford JD and Bull BS, The red cell shape as an indicator of membrane structure: Ponder's rule reexamined. Blood Cells 3: 315-20, 1977

80 Kreybig TH, Chemical composition and teratogenic effect of several groups of compounds. Naunyn-Schmiedeberg's Arch. Pharmacol. 257: 296-310, 1967

81 Kuijk van FJGM, Sevanian A, Handelman GJ and Dratz EA, A new role for phospholipase A2: protection of membranes from lipid peroxidation damage. Trends in Biochemical Sciences 12: $31-4,1987$

82 Lewis RJ and Tatken RL, Registry of toxic effects of chemical substances. : U.S. Department of Health and Human Services, 1982

83 Lopez-Barea J, Barcena JA, Bocanegra JA, Florindo J, Garcia-Alfonso C, Lopez-Ruiz A, Martinez-Galisteo $\mathrm{E}$ and Peinado $\mathrm{J}$, Structure, mechanism, functions, and regulatory properties of glutathione reductase. In: Gluathione: metabolism and physiologcial functions. (eds. Vina J), pp. 105-16. Boca Raton: CRC Press, 1990

84 Lundqvist $G$ and Morgenstern R, Mechanism of activation of rat liver microsomal gluathione transferase by noradrenaline and xanthine oxidase. Biochem. Pharmacol. 43: 1725-8, 1992 
Mahma SK, Transfection assay test system: Assay of four chemical mutagens. Indian J. Exp. Biol. 22: 338-9, 1984

86 Majerus PW, Brauner MJ, Smith MB and Minnich V, Glutathione synthesis in human erythrocytes. II Purification and properties of the enzymes of glutathione biosynthesis. J. Clin. Invest. 50: 1637-43, 1971

87 Malivelli I, Cirilio MR and Rotilio G, Multiple electrophoretic variants of $\mathrm{Cu}$, Zn superoxide dismutase as expression of the enzyme aging. Effects of hydrogen peroxide, ascorbate and metal ions. Biochem. Biophys. Res. Commun. 117: 677-81, 1983

Mann PJG, The reduction of glutathione by a liver system. Biochem. J. 26: 785-90, 1932

Mannervik $B$ and Danielson $\mathrm{UH}_{1}$ Glutathione Transferases - structure and catalytic activity. Crit. Rev. Biochem. 23: 283-337, 1988

90 Mannervik B, Widersten $M$ and Board PG, Glutathione linked enzymes in detoxification reactions. In: Gluathione centennial: molecular perspectives and clinical implications. (eds. Taniguchi N, Higashi T, Sakamoto $Y$ and Meister A), pp. 23-34. San Diego: Academic Press, 1989

91 Marchesi VT, Structure and fucntion of the erythrocyte membrane skeleton. Recent clinical and experimental advances : 1-12, 1984

Marchesi VT, Stabilizing infrastructure of cell membranes. Ann. Rev. Cell Biol. 1: 531-61, 1985 Marchesi VT and Furthmayr $H$, The red cell membrane. Ann. Rev. Biochem. 45: 667-98, 1976. Marklund SL, Human copper-containing superoxide dismutase of high molecular weight. Proc. Natl. Acad. Sci. USA 79: 7634-8, 1982

Marks PA, Szeinberg A and Banks J, Erythrocyte glucose 6-phosphate dehydrogenase of normal and mutant human subjects: properties of the purified enzymes. J. Biol. Chem. 236: 10-7, 1961

Martin $H$, Wörner $W$ and Rittmeister $B$, Hämolytische anämie durch inhalation von hydroxylaminen. Zugleich ein beitrag zur frage der Heinz-Körper-Bildung. Klin. Wochenschr. 15: 725-31, 1964

97 McCann J, Choi E, Yamasaki E and Ames BN, Detection of carcinogens ass mutagens in the Salmonella/microsome test assay of 300 chemicals. Proc. Natl. Acad. Sci. USA 72: 5135-9, 1975

98 McCay PB and Powell SR, Relationship between glutathione and chemically induced lipid peroxidation. In: Gluathione chemical biochemical and medical aspects. Part B. (eds. Dolphin D, Avramovic O and Poulson R), pp. 111-51. New York: J Wiley \& Sons, 1989

99 McCord JM and Fridovich I, Superoxide Dismutase: an enzymic function for erythrocuprein (hemocuprein). J. Biol. Chem. 244: 6049-55, 1969

100 McMillan DC, Simson JV, Budinsky RA and Jollow DJ, Dapsone-induced hemolytic anemia: effect of dapsone hydroxylamine on sulfhydryl status, membrane skeletal proteins and morphology of human and rat erythrocytes. J. Pharmacol. Exp. Ther. 274: 540-7, 1995

101 Mieyal JJ, Monooxygenase activity of hemoglobin and myoglobin. In: Reviews in biochemical toxicology. (eds. Hodgson E, Bend JR and Philpot RM), pp. 1-66. Amsterdam: Elsevier, 1985

102 Mieyal JJ, Ackerman RS, Blumer JL and Freeman LS, Characterization of enzyme-like activity of human hemoglobin: properties of the hemoglobin-P-450 reductase-coupled aniline hydroxylase system. J. Biol. Chem. 251: 3436-41, 1976

103 Mieyal JJ, Starke DW, Gravina SA, Dothey C and Chung JS, Thioltransferase in human red blood cells: purification and properties. Biochem. 30: 6088-97, 1991 
104 Mieyal JJ, Starke DW, Gravina SA and Hocevar BA, Thioltransferase in human red blood cells: kinetics and equilibrum. Biochem. 30: 8883-91, 1991

105 Mills GC, Hemoglobin catabolism. I. Glutahione peroxidase, an erythrocyte enzyme which protects hemoglobin from oxidative breakdown. J. Biol. Chem. 229: 189-97, 1957

106 Misra HP and Fridovich 1. The generation of superoxide radical during the autoxidation of hemoglobin. J. Biol. Chem. 247: 6960-2, 1972

107 Moncada S, Palmer RM and Higgs EA, Nitric oxide: Physiology, pathophydiology and pharmacology. Pharmacol. Rev. 43: 109-20, 1991

108 Munday R and Winterboume $\mathrm{CC}$, Reduced glutathione in combination with superoxide dismutase as an important biological anitoxidant defence mechanism. Biochem. Pharmacol. 38 : 4349-52, 1989

109 Murata T, Hatayama I, Satoh K, Tsuchida S and Sato K, Activation of rat glutathione transferases in class mu by active oxygen species. Biochem. Biophys. Res. Commun. 171: 845-51, 1990

110 Nagata $\mathrm{C}$ and Martensson $\mathrm{O}$, On the mechanism of mutagenic action of hydroxylamine. $\mathrm{J}$. Theoret. Biol. 19: 133-46, 1968

111 Niki E, Tsuchiya J, Tanimura R and Kamiya Y, Regeneration of vitamine E from alphachromanoxyl radical by glutathione and vitamine $C$. Chem. Lett. 9: 789-92, 1982

112 Nishinaka T, Terada T, Nanjo $H$, Mizoguchi $T$ and Nishihara T, Difference in gluathione Stransferase response to oxidative stress between porcine and bovine lens. Exp. Eye Res. 56: 299-303, 1993

113 Ozawa $T$, Hanaki $A$ and Matsuo $M_{1}$ Reactions of superoxide ion with tocopherol and its model compounds: correlations between the physiological activities of tocopherols and the concentration of chromanoxyl-type radicals. Biochem. Int. 6: 685-92, 1983

114 Percy ME, Catalase: an old enzyme with a new role? A review. Can. J. Biochem. Cell. Biol. 62: 1006-14, 1984

115 Perutz MF, Molecular anatomy, physiology, and pathology of hemoglobin. In: The molecular basis of blood diseases. (eds. Dyson J), pp. 127-78. Philadelphia: W.B. Saunders Company, 1987

116 Pienta RJ, Transformation of Syrian-hamster embryo cells by diverse chemicals and correlation with their reported carcinogenic and mutagenic activities. Chem. Mutagens 6: 175-202, 1980

117 Poukka Evarts R and Brown CA, Morphology of mammary gland, ovaries and pituitary gland of hydroxylamine-fed C3H/HeN mice. Lab. Invest. 37: 53-63, 1977

118 Poukka Evarts R, Brown CA and Atta GJ, The effect of hydroxylamine on the morphology of the rat mammary gland and on the induction of mammary tumors by 7,12-dimethylbenz(a)anthracene. Exp. Mol. Pathol. 30: 337-48, 1979

119 Reddy CC, Scholz RW, Thomas CE and Massaro EJ, Vitamine E dependent reduced glutathione inhibition of rat microsomal lipid peroxidation. Life Sci. 31: 571-6, 1982

120 Riemann $\mathrm{H}$, On the toxicity of hydroxylamine. Acta Pharmacol. 6: 285-92, 1950

121 Ross D, Glutathione, free radicals and chemotherapeutic agents. Mechanism of free-radical induced toxicity and gluathione-dependent protection. Pharmacol. Ther. 37: 231-49, 1988

122 Schroder KR, Hallier E, Peter H and Bolt HM, Dissociation of a new glutahione S-transferase activity in human erythrocytes. Biochem. Pharmacol. 43: 1671-4, 1992

123 Scott MD, Zuo L, Lubin BH and Chiu DTY, NADPH, not glutathione, status modulates oxidant sensitivity in normal and glucose-6-phosphate dehydrogenase deficient erythrocytes. Blood 77 : 2059-64, 1991 
124 Sevanian A and Hochstein P. Mechanisms and consequence of lipid peroxidation in biological system. Am. Rev. Nutr. 5: 365-90, 1985

125 Shen H, Tamai K, Satoh K, Hatayama I, Tsuchida S and Sato K, Modulation of class Pi glutathione transferase activity by sulfhydryl group modification. Arch. Biochem. Biophys. 286: 178-82, 1991

126 Shuka PT, Analysis of mutagen specificity in Drosophila melanogaster. Mutat. Res. 16: 363-71, 1972

127 Shukla PT and Auerbach C, The delayed mutagenic action of hydroxylamine in Drosophila. Mutat. Res. 61: 399-400, 1979

128 Sies H, Oxidative stress. London: Academic Press, 1985

129 Sies H, Biochemistry of oxidative stress. Angew. Chem. Int. Ed. Engl. 25: 1058-71, 1986

130 Sies $H_{1}$ Relationship between free radicals and vitamins: An overvies. Int. J. Vit. Nutr. Res. 30: 215-23, 1989

131 Simmon VF, In vitro mutagenicity assays of chemical carcinogens and related compounds with Salmonella thyphimurium. J. Natl. Cancer Inst. 62: 893-9, 1979

132 Sinha D and Sleigh SD, Experimental production of Heinz Bodies in the pig. Toxicol. Appl. Pharmacol. 12: 435-9, 1986

133 Smith GT, Ohl VS and Litwack G, Ligandin, the glutathione S-transferases, and chemically induced hepatocarcinogenesis: a review. Cancer Res. 37: 8-14, 1977

134 Smith RP and Layne WR, A comparison of the lethal effects of nitrite and hydroxylamine in the mouse. J. Pharmacol. Exp. Ther. 165: 30-5, 1969

135 Somers CE and Hsu TC, Chromosome damage induced by hydroxylamine in mammalian cells. Proc. Natl. Acad. Sci. USA 48: 937-43, 1962

136 Sonntag von $C$ and Schuchmann $H$, Sulphur compounds and chemical repair in radiation biology. In: Sulfur-centered reactive intermediates in chemistry and biology. (eds. Chatgilialoglu $C$ and Asmus KD), pp. 409-14. New York: Plenum Press, 1990

137 Speit $\mathrm{G}$, Wick $\mathrm{C}$ and Wolf $\mathrm{M}$, Induction of sister chromatid exchanges by hydroxylamine, hydrazine and isoniazid and their inhibition by cysteine. Hum. Genet. 54: 155-8, 1980

138 Srivastava SK and Beutler E, Glutathione metabolism of the erythrocyte. The enzymic cleavage of glutathione-hemoglobin preparations by glutathione reductase. Biochem. J. 119: 353-60, 1970

139 Srivastave SK, Absence of gamma-glutamyl transpeptidase and the role of GSSG transport in the turnover of GSH in erythrocytes. Blood 49: 668-9, 1977

140 Stern A, Drug-induced oxidative denaturation in red blood cells. Semin. Hematol. 26: 301-6, 1989

141 Stoll $R$, Bodit $F$ and Maraud $R$, Effect on the chick embryo of various antimitotic agents related to hydroxyurea and semicarbazide. C. R. Soc. Biol. 161: 1963-7, 1967

142 Stoll $R$, Bodit $F$ and Maraud $R$, Teratogenic action of hydrazine and related compounds on chick embryo. C. R. Soc. Biol. 161: 1680-4, 1967

143 Stoltz DR, Poirier LA, Irving CC, Stich HF, Weisburger JH and Grice HC, Evaluation of shortterm tests for carcinogenicity. Toxicol. Appl. Pharmacol. 29: 157-60, 1974

144 Stryer L, Biochemistry. New York: W.H. Freeman and company, 1988

145 Sutton HC, Roberts PB and Winterbourn CC, the rate of reaction of superoxide radical ion with oxyhaemoglobin and methaemoglobin. Biochem. J. 155: 503-10, 1976 
146 Taylor WD, Mudgett JS, Bonneau R, Wilt S, Kroekel N, Brontz PC and Heicklen J, Toxic and mutagenic effects on bacteria and mammalian cells of hydroxylamines. Environ. Mutagen. 7 : 86,1985

147 Thornburn DR and Kuchel PW, Regulation of the human-erythrocyte hexose-monophosphate shunt under conditions of oxidative stress. A study using NMR spectroscopy, a kinetic isotope effect, a reconstituted system and computer simulation. Eur. J. Biochem. 150: 371-86, 1985

148 Tomoda A, Imoto M, Hirano $M$ and Yoneyama $Y$, Analysis of met-form haemoglobins in human erythrocytes of normal adults and of a patient with hereditary methemoglobinaenemia due to deficiency of NADH-cytochrome $b_{5}$ reductase. Biochem. J. 181: 505-7, 1979

149 Traul KA, Takayama K, Kachevsky V, Hink RJ and Wolff JS, A rapid in vitro assay for carcinogenicity of chemical substances in mammalian cells utilizing an attachmentindependence endpoint. J. Appl. Toxicol. 1: 190-5, 1981

150 Verweij $H$, Dubbelman TMAR and Van Steveninck $J$, Photodynamic protein cross-linking Biochim. Biophys. Acta 647: 87-94, 1981

151 Wardman $\mathrm{P}$, Conjugation and oxidation of glutathione via thiyl radicals. In: Glutathione conjugation: mechanism and biological significance. (eds. Sies $\mathrm{H}$ and Ketterer B), pp. 43-72. New York: Academic Press, 1988

152 Wells WW, Yang $Y$ and Deits TL, Thioltransferases. Adv. Enzymol. Rel. Areas Mol. Biol. 60: 149-201, 1993

153 Wever R, Oudega B and van Gelder BF, Generation of superoxide radicals during the autoxidation of mammalian oxyhemoglobin. Biochim. Biophys. Acta 302: 475-8, 1973

154 Wevers $\mathrm{H}$ and Sies $\mathrm{H}$, Oxidation of glutathione by the superoxide radical to the disulfide and the sulfonate yieldinng singlet oxygen. Eur. J. Biochem. 137: 29-35, 1983

155 Wiessler $M$ and Schmahl $D$, The carcinogenic action of $\mathrm{N}$-nitroso-compounds. Fourth communication: N-nitroso-o, N-diethyl-hydroxylamine. Z. Krebsforsch. 83: 205-9, 1975

Willson RL, Hydroxyl radicals and biological damage in vitro: what relevance in vivo? In: Oxygen-free radicals and tissue damage. (eds. Fitzsimons DW), pp. 19-42. Amsterdam: Elsevier, 1979

157 Winter AJ and Hokanson JF, Effects of long-term feeding of nitrate, nitrite, or hydroxylamine on pregnant dairy heifers. Am. J. Vet. Res. 25: 335-61, 1964

158 Winter CG and Christensen HN, Migration of amino acids across the membrane of the human erythrocyte. J. Biol. Chem. 239: 872-8, 1964

159 Winterbourn CC, Free-radical production and oxidative reactions of hemoglobin. Environ. Health Perspect. 64: 321-30, 1985

160 Winterbourn CC and Carrell RW, The attachment of Heinz bodies to the red cell membrane. Br. J. Haematol. 25: 585-92, 1973

161 Winterbourne CC, Inhibition of autoxidation of divicine and isouramil by the combination of superoxide dismutase and reduced glutathione. Arch. Biochem. Biophys. 271: 447-55, 1989

162 Winterbourne CC, Superoxide as an intracellular radical sink. Free Rad. Biol. Med. 14: 85-90, 1993

163 Winterbourne CC, McGrath BM and Carrell RW, Reactions involving superoxide and normal and unstable haemoglobins. Biochem. J. 155: 493-503, 1976

164 Winterbourne CC and Munday R, Glutathione-mediated redox cycling of alloxan. Mechanisms of superoxide dismutase inhibition and of metal-catalyzed $\mathrm{OH}$ radical formation. Biochem. Pharmacol. 38: 271-7, 1989 
165 Witting LA, Vitamine $E$ and lipid antioxidants in free-radicals initiated reactions. In: Free radicals in biology. (eds. Pryor WA), pp. 295-320. New York: Academic Press, 1980

166 Wurgler FE, Graf $\mathrm{U}$, Frei $\mathrm{H}_{1}$ Juon $\mathrm{H}$ and Katz AJ, Mutagenicity testing with somatic cells of Drosophila melanogaste. Mutat. Res. 113: 350-1, 1983

167 Yamamoto RS, Weisburger EK and Korziz J, Chronic administration of hydroxylamine and derivatives in mice. Pro. Soc. Exp. Biol. Med. 124: 1217-20, 1967

168 Yubisui $T$, Takeshita $M$ and Yoneyama $Y$, Reduction of methemoglobin through flavin at the physiological concentrations by NADPH-flavin reductase of human erythrocytes. J. Biochem. 87: $1715-20,1980$

169 Zimmerman W and Gottschewski GHM, Effect of specific substances on DNA and protein synthesis in the early embryonic development of rabbits. Bull. Schweiz. Akad. Med. Wiss. 22, 166-183, 1966 


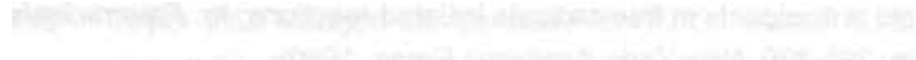

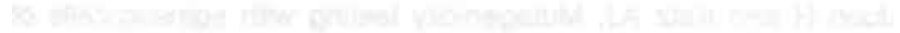

in

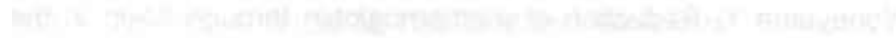


Chapter 2

Two Mechanisms for Toxic Effects of Hydroxylamines in Human Erythrocytes: Involvement of Free Radicals and Risk of Potentiation

Published in: Blood Cells, Molecules, and Diseases 24: 280-295, 1998 


\section{Two Mechanisms for Toxic Effects of Hydroxylamines in Human Erythrocytes: Involvement of Free Radicals and Risk of Potentiation}

Submitted 06/22/98

(communicated by Ernest R. Jaffe. M.D., 07/06/98)

Chris T.A. Evelo ${ }^{1}$, Anita A.M.G Spooren ${ }^{1}$, Rob A.G. Bisschops ${ }^{1}$, Leo G.M. Baars ${ }^{1}$, John M. Neis ${ }^{2}$

ABSTRACT: The toxic potency of three industrially used hydroxylamines was studied in human blood cells in vitro. The parent compound hydroxylamine and the O-ethyl derivative gave very similar results. Both compounds induced a high degree of methemoglobin formation and glutathione depletion. Cytotoxicity was visible as Heinz body formation and hemolysis. High levels of lipid peroxidation occurred, in this respect O-ethyl hydroxylamine was more active than hydroxylamine. In contrast $\mathrm{H}_{2} \mathrm{O}_{2}$ induced lipid peroxidation was lowered after $\mathrm{O}$-ethyl hydroxylamine or hydroxylamine treatment, this is explained by the ferrohemoglobin dependence of $\mathrm{H}_{2} \mathrm{O}_{2}$ induced radical species formation. Glutathione S-transferase (GST) and NADPH methemoglobin reductase (NADPH-HbR) activities were also impaired, probably as a result of the radical stress occurring. The riboflavin availability was decreased. Other enzyme activities glutathione reductase (GR), glucose 6-phosphate dehydrogenase (G6PDH), glucose phosphate isomerase and NADH methemoglobin reductase, were not or only slightly impaired by hydroxylamine or O-ethyl hydroxylamine treatment.

A different scheme of reactivity was found for N,O-dimethyl hydroxylamine. This compound gave much less methemoglobin formation and no hemolysis or Heinz body formation at concentrations up to and including $7 \mathrm{mM}$. Lipid peroxidase induction was not detectable, but could be induced by subsequent $\mathrm{H}_{2} \mathrm{O}_{2}$ treatment. GST and NADPH-HbR activities and riboflavin availability were not decreased. On the other hand GR and G6PDH activities were inhibited. These results combined with literature data indicate the existence of two different routes of hematotoxicity induced by hydroxylamines. Hydroxylamine as well as $\mathrm{O}$-alkylated derivatives primarily induce methemoglobin, a process involving radical formation. The radical stress occurring is probably responsible for most other effects. $\mathrm{N}$-alkylated species like $\mathrm{N}, \mathrm{O}$-dimethyl hydroxylamine primarily lead to inhibition of the protective enzymes G6PDH and GR. Since these enzymes play a key role in the protection of erythrocytes against oxidative stress a risk of potentiation during mixed exposure does exist.

Keywords: hydroxylamines, human erythrocytes, oxidizing effects, potency ranking, structure activity relations

\section{INTRODUCTION}

Hydroxylamines are derivatives of the parent compound hydroxylamine (chemical formula $\mathrm{H}_{2} \mathrm{NOH}$ ). Hydroxylamine itself is used in the synthesis of caprolactam, which is used for the production of Nylon 6 . It is also used as a reducing agent in photography, as an antioxidant for soaps and fatty acids, as a tanning agent and as an intermediate in the production of pesticides and pharmaceuticals $(1,2)$. Derivatives of hydroxylamine often serve as intermediates in chemical synthesis. The main toxic effect of hydroxylamine is of hematological nature $(1,2)$. Methemoglobin

\footnotetext{
'Deparment of Pharmacology (Toxicology section).Universiteit Maastricht. P.O. Box 616, 6200 MD Maastricht, The Netherlands: ${ }^{2}$ Corporate Department for Safety, Enivironment, Health and Technology: DSM, Heerlen. The Netherlands.

Reprint request to: Chris Evelo. Ph. D., Deparment of Pharmacology (Toxicology section). Universiteit Maastricht, P.O. Box 616.6200 MD Maasiricht. The Netherlanils, phone 31433831231 or 31433881417 , tax 31433670940 , email: c.evelo@ farmaco.unimaas.nl
} 
formation was found in vitro (3-5). In in vivo animal studies anemia with increased levels and sometimes with sulfhemoglobinemia was consistently found $(6,7)$. In some studies this was found to be accompanied by remarkable splenomegaly (8-10). In a subchronic (ninety days) study with rats, performed according to guidelines of the Organization for Economic Co-Operation and Development (OECD), exposure to $250 \mathrm{ppm}$ hydroxylamine-sulfate lead to hematological effects and increased spleen weight and some other effects (11). In the 50 ppm treated groups small increases in reticulocyte numbers and some other marginal effects were found. The "no effect level" in this study was between 10 and $50 \mathrm{ppm}$ for both sexes.

In his review Gross (2) quotes a single incidence of human hydroxylamine poisoning described in the Russian literature. A woman who had drank about "two swallows" of hydroxylamine solution in water developed rapidly progressing hemolytic anemia which required five weeks for recovery.

Martin et al. (12) described the development of serious anemia in five laboratory workers working with methylated hydroxylamines (O-methyl, N,O-dimethyl and trimethyl hydroxylamine). In the most acute patient lowered hemoglobin and increased serum iron levels were found, indicating hemolytic anemia. All patients had shown jaundice symptoms and had increased numbers of bone martow erythroblasts. Reticulocyte numbers were increased in two patients. Heinz bodies were not found and could not be detected spectrophoto-metrically. These findings prompted the authors to further in vitro studies. Interestingly trimethyl hydroxylamine in these studies gave by far the highest hemolytic activity, while it did not lead to increased methemoglobin levels. In contrast the far less hemolytic O-methyl hydroxylamine and the N,O-dimethyl compound did strongly induce methemoglobin formation. The higher hemolytic potency of trimethyl, and to a much lesser extent N,O-dimethyl hydroxylamine, was found to be accompanied with strong glucose 6-phosphate dehydrogenase
$(\mathrm{G} 6 \mathrm{PDH})$ inhibition and loss of reduced glutathione (GSH).

We recently described the in vitro hematotoxic effects of three methylated hydroxylamines: O-methyl hyüroxylarnine, N-methyl hydroxylamine and N,N-dimethyl hydroxylamine (13). This study also suggested that different mechanisms for the hematotoxicity of hydroxylamines may exist. In one route methemoglobin formation is a major effect, while G6PDH inhibition is predominant in the other. Both routes seem to be able to give rise to hemolytic anemia. The purpose of the present study was to further elucidate these two mechanisms. Three industrially used hydroxylamines were tested: hydroxylamine, O-ethyl hydroxylamine and $\mathrm{N}, \mathrm{O}$-dimethyl hydroxylamine. Next to the effects described above we were especially interested in the fact that the methemoglobin formation by hydroxylamine does involve a radical mechanism $(14,15)$, and therefore might give rise to free radical induced lipid peroxidation.

\section{MATERIALS AND METHODS}

\section{Chemicals}

The following chemicals were used: N,Odimethy! hydroxylamine (methoxymethylamine. CAS-nr 1117-97-1, purity 99.5\%) and O-ethyl hydroxylamine (ethoxyamine. CAS-nr 624-86-2, $55 \%(w / v)$ solution in water), were a gift from DSM Special Products (Geleen, NL). Brilliant cresyl blue was from BDH (Poole, UK), malonal. dehyde bis(diethylacetal) (used as precursor for malondialdehyde reference) was from Janssen Chimica (Beerse, Belgium), 2-thiobarbituric-acid (TBA) was from Merck (Darmstadt, FRG), glucose 6-phosphate dehydrogenase (grade XI from Torula yeast) (G6PDH), glutathione reductase (type III) (GR), hydroxylamine HCl (Hydroxylamine, CAS-nr: 5470-11-1 (free base CAS-nr: 7803-49-8) (ACS reagent, purity 99.1\%) and all other biochemicals were from Sigma (St. Louis, Mo., USA). All inorganic chemicals were of analytical quality. Only microfiltrated deionized water was used. 


\section{Blood Samples}

Human blood samples were collected in vacuum tubes containing $\mathrm{K}_{3}$ EDTA as an anticoagulant. For the determinations of Heinz body formation, lipid peroxidation, peroxidation resistance, glutathione S-transferase and glutathione reductase activities fresh samples from individual persons were used. For all other experiments pooled blood samples from three to five persons with blood group O-positive were used. The latter samples were checked for viral infections and stored at $4 \mathrm{C}$ until the next day.

\section{Incubations}

To $1 \mathrm{ml}$ blood $100 \mu$ hydroxylamine solution in $100 \mathrm{mM} \mathrm{KH} \mathrm{KO}_{2} / \mathrm{Na}_{2} \mathrm{HPO}_{4}$ of $\mathrm{pH} 7.4$ were added, and the samples were incubated in a shaking waterbath $(80 \mathrm{rpm})$ for 1 hour at $37 \mathrm{C}$. All experiments were performed three times on separate days and with different blood samples, each day all incubations were performed in duplicate. Except for the determinations of Heinz bodies, hemolysis and lipid peroxidation, erythrocytes were washed three times with five volumes of cold phosphate buffered saline ( $15 \mathrm{mM} \mathrm{KH}_{2} \mathrm{PO}_{4} /$ $\mathrm{Na}_{2} \mathrm{HPO}_{4}+130 \mathrm{mM} \mathrm{NaCl} ; \mathrm{pH}=7.4$ ). Where applicable the erythrocytes were lysed by addition of three to five volumes of cold water, after 15 minutes storage on ice cellular debris was removed by centrifugation at $13000 \mathrm{~g}$ for 10 $\min$.

\section{Analyses}

Heinz body formation Heinz bodies were stained by incubation of $1 \mathrm{ml}$ blood with $0.5 \mathrm{ml}$ $1 \%(\mathrm{w} / \mathrm{v})$ brilliant cresyl blue in saline. More severe cellular damage leads to detectable numbers of Heinz bodies after shorter incubation times and at lower temperatures. For this reason, one of two identical samples was incubated at room temperature and the other at $37 \mathrm{C}$ and samples were dried and evaluated by light microscopy (1000x) under oil immersion (16) after 20,60 and 120 minutes of coloring.

Hemolysis After incubation, the hemoglobin $(\mathrm{Hb})$ content of the plasma was used to determine the degree of hemolysis (17).

Methemoglobin The percentage present in hemolysates was calculated from the absorbance change after addition of KCN compared to the same change in a sample fully converted to the methemoglobin form by the addition of $\mathrm{K}_{3} \mathrm{Fe}(\mathrm{CN})_{6}$ (18).

Total glutathione (GSH+ GSSG) Total glutathione was determined after precipitation of protein $(200 \mu \mathrm{l}$ packed cells plus $200 \mu \mathrm{l} 8 \%$ (w/v) trichloroacetic acid) using the cyclic oxidationreduction method essentially as described by Anderson (19). Especially for the determination of GT, it was of interest whether the Torula yeast GR enzyme used was itself inhibited by any of the hydroxylamines studied. This was tested separately with hydroxylamine concentrations of $0,2.5$ and $7 \mathrm{mM}$, no significant inhibition of Torula yeast GR was found under the assay conditions used.

Reduced glutathione (GSH) GSH was determined as non-protein sulfhydryl after trichloroacetic acid precipitation of erythrocytes by measurement of the reactivity towards 5,5'-dithiobis(2-nitrobenzoic acid) as previously described (20).

Release of thiobarbituric-acid reactive substances (TBARS) The accumulation of lipid peroxidation products in the extracellular medium was assessed by determination of the amount of TBARS released and was expressed as malondialdehyde equivalents (21). After incubation of 1.5 $\mathrm{ml}$ fresh blood with hydroxylamines, the plasma was collected after centrifugation $(1500 \mathrm{~g}$ for 10 $\mathrm{min})$. The protein was precipitated by addition of 
an equal volume of $10 \%(\mathrm{w} / \mathrm{v})$ trichloroacetic acid and subsequent centrifugation. $1.5 \mathrm{ml}$ of the supernatant was added to $1 \mathrm{ml}$ TBA solution $(1 \%(w / v)$ in $50 \mathrm{mM} \mathrm{NaOH})$ and heated in a boiling waterbath for $15 \mathrm{~min}$. After forced cooling, $1.25 \mathrm{ml}$ butanol was added, and the two phases were thoroughly mixed. The absorbance of the butanol phase at $535 \mathrm{~nm}$ was determined and corrected for the background absorbance at $590 \mathrm{~nm}$.

Resistance to $\mathrm{H}_{2} \mathrm{O}_{2}$ forced lipid peroxidation The remaining resistance to $\mathrm{H}_{2} \mathrm{O}_{2}$ induced lipid peroxidation of erythrocytes pre-treated with hydroxylamines was assessed. After incubation of fresh blood samples with hydroxylamines the plasma was removed by centrifugation. The erythrocytes were washed three times to remove remaining hydroxylamines and were diluted in phosphate buffered saline to a cell concentration of $5 \%(\mathrm{v} / \mathrm{v})$. To $2.5 \mathrm{ml}$ erythrocyte suspension an equal volume of $20 \mathrm{mM} \mathrm{H}_{2} \mathrm{O}_{2}$ plus $1 \mathrm{mM} \mathrm{NaN} \mathrm{Nas}_{3}$ was added. TBARS release was determined after reincubation at $37 \mathrm{C}$ for $0,15,30,45$ and $60 \mathrm{~min}(22)$.

Free hemoglobin sulfhydryl (HbSH) Free hemoglobin sulfhydryl groups were determined in hemolysates from the reactivity towards $4,4^{\prime}$ dithiodipyridine as previously described (20).

NADH methemoglobin reductase (NADHHbR) NADH-HbR activity in hemolysates was determined using DEAE-cellulose purified hemoglobin converted to the methemoglobin-ferrocyanide complex as substrate with the method described by Hegesh et al. (23) and some small moditications according to Bauer (24).

NADPH methemoglobin reductase (NADPHHbR) NADPH-HbR activity in hemolysates was determined from the reduction of methylene blue by NADPH (25). Disappearance of NADPH was followed spectrophotometrically at $340 \mathrm{~nm}$. Corrections were made for spontaneous methylene blue reduction.
Glutathione S-transferase (GST) GST (EC 2.5.1.18) activity with 1-chloro-2,4-dinitrobenzene as substrate was determined in hemolysates prepared from incubates of fresh blood samples by the addition of three volumes $1.4 \mathrm{mM}$ neutralized dithiothreitol, using the method of Habig and Jakoby (26) with previously described modifications (27).

Glutathione reductase (GR) GR (EC 1.6.4.2) activity in hemolysates was determined by a modification of the method described by Carlberg and Mannervik (28). $100 \mu \mathrm{l}$ Hemolysate were added to $2 \mathrm{ml} 100 \mathrm{mM}$ potassium phosphate buffer, $50 \mu \mathrm{l} 80 \mathrm{mM}$ EDTA, $100 \mu \mathrm{l} 2 \mathrm{mM}$ NADPH and $100 \mu \mathrm{l} 0.3 \mathrm{mM}$ flavin adenine dinucleotide (FAD). After 2 min pre-incubation (37C), the reaction was started by addition of $100 \mu \mathrm{l} 7.5 \mathrm{mM}$ oxidized glutathione. After $15 \mathrm{sec}$ the reaction was followed spectrophotometrically at $340 \mathrm{~nm}$ for 2 min. The FAD was added in order to convert all enzyme to its holo form.

Glutathione reductase riboflavin activity coefficient ( $\mathbf{G R}_{\text {coeff }}$ ) The coefficient of erythrocyte GR activity with and without addition of FAD to the assay was used as an indicator of the riboflavin content. The determinations were carried out exactly as described for GR above except that FAD was left out from one of the 2 samples (18).

Glucose 6-phosphate dehydrogenase (G6PDH) G6PDH (EC 1.1.1.49) activity in hemolysates was determined spectrophotometrically; the reduction of $\mathrm{NADP}^{+}$was followed at $340 \mathrm{~nm}$ (18).

Glucose-phosphate isomerase Glucose-phosphate isomerase (EC 5.3.1.9) activity in hemolysates was determined using fructose 6-phosphate as substrate in the presence of $\mathrm{NADP}^{+}, \mathrm{G} 6 \mathrm{PDH}$ and 6-phosphogluconic dehydrogenase. Under these circumstances each molecule of fructose 6-phosphate converted will give rise to reduction of two molecules $\mathrm{NADP}^{+}$, which was followed spectrophotometrically at $340 \mathrm{~nm}$ (24). 
Hemoglobin (Hb) The Hb concentrations were determined with the hemoglobin cyanide procedure (17).

\section{Statistical Evaluation}

Significance of concentration dependent changes was evaluated using linear regression analysis. In each experiment incubations were performed with $0,1,2.5,5$ and $7 \mathrm{mM}$ hydroxylamine concentrations. All experiments were performed three times. Duplicate values obtained during a single experiment were averaged before statistical analysis since these values are not independent. This leads to a total of 3 (experiments) $\times 5$ (concentrations) $=15$ data points for each regression analysis. The regression model used corrects for interexperimental variations in control values. For this reason the standard errors shown in the figures are given as the standard error of the mean difference between sample value and its control (i.e. the corresponding value at concentration 0 ).

\section{RESULTS}

\section{Oxidative Effects}

A concentration dependent methemoglobin formation was found for all three hydroxylamines (Figure 1). The effects of hydroxylamine and O-ethyl hydroxylamine (about $8 \%$ methemoglobin formation for each $\mathrm{mM}$ addition) were much stronger than the effect caused by N.O-dimethyl hydroxylamine. GT decreased for all three hydroxylamines (Figure 2A). GT depletion caused by O-ethyl hydroxylamine 10.34 (SE 0.04) $\mu$ moles $\mathrm{GT} / \mathrm{g} \mathrm{Hb}$ decrease for each $\mathrm{mM}$ O-ethyl hydroxylamine) was much more pronounced than the effect caused by the other two hydroxylamines $(0.17$ (SE 0.03 ) and 0.12 (SE 0.02) $\mu$ moles GT/g Hb decrease for each $\mathrm{mM}$ for hydroxylamine and $\mathrm{N}, \mathrm{O}$ dimethyl hydroxylamine respectively). The decreases in reduced GSH also were strongest for O-ethyl hydroxylamine (Figure 2B). The regression coefficient of this GSH decrease amounted to

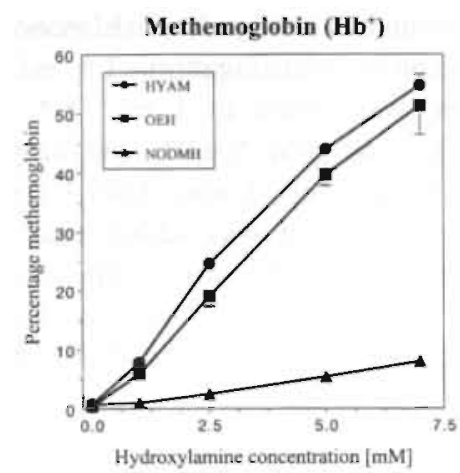

Figure 1. Formation of methemoglobin in human erythrocyles after incubation with hydroxylamines (1 hour, 37C). The error bars represent the standard error of the mean difference between the sample value and its control. Regression analyses showed significant $(P<0.0001)$ increases in methemoglobin formation with increasing concentration for all three hydroxylamines.

0.26 (SE 0.03) $\mu$ moles/g Hb for each mM O-ethyl hydroxylamine. For hydroxylamine and N,Odimethyl hydroxylamine these depletions were only about 0.1 L (SE 0.03) and 0.07 (SE 0.03) umoles/g $\mathrm{Hb}$ for each $\mathrm{mM}$ of the respective hydroxylamines added. Plasma GT was found to increase for all three hydroxylamines (Figure 2C). Contrary to what might be expected from erythrocyte depletions, the increase was strongest for $\mathrm{N}, \mathrm{O}$-dimethyl hydroxylamine (about $5.4 \mu \mathrm{M}$ increase/mM N.O-dimethyl hydroxylamine). For O-ethyl hydro-xylamine and hydroxylamine increases were not more than half that amount. Loss of hemoglobin sulfhydryl group availability was not found for any of the chemicals studied.

\section{Cell Damage}

Increased hemolysis occurred for hydroxylamine and O-ethyl hydroxylamine (Figure 3 ). Both compounds liberated about $45 \mathrm{mg} \mathrm{Hb} / \mathrm{from}$ the erythrocytes for each $\mathrm{mM}$ added. For N.Odimethyl hydroxylamine no increased hemolysis was detectable. Heinz bodies were visible in all blood samples treated with $2.5 \mathrm{mM}$ hydroxylamine or O-ethyl hydroxylamine (Table 1). In the $2.5 \mathrm{mM}$ hydroxylamine treated samples blue spots, 
normally indicating Heinz bodies, were also visible extracellularly. The same indications for cell breakdown were also present in the $2.5 \mathrm{mM}$ O-ethyl hydroxylamine treated samples, but only when they were incubated at 37C. Minor Heinz body formation was present in the $1 \mathrm{mM}$ hydroxylamine treated samples incubated at 37C or incubated for $60 \mathrm{~min}$ or more at room temperature as well as in the $1 \mathrm{mM}$ O-ethyl hydroxylamine treated samples incubated at $37 \mathrm{C}$ for $60 \mathrm{~min}$ or more. The occurrence of Heinz bodies at a lower temperature and after shorter incubation

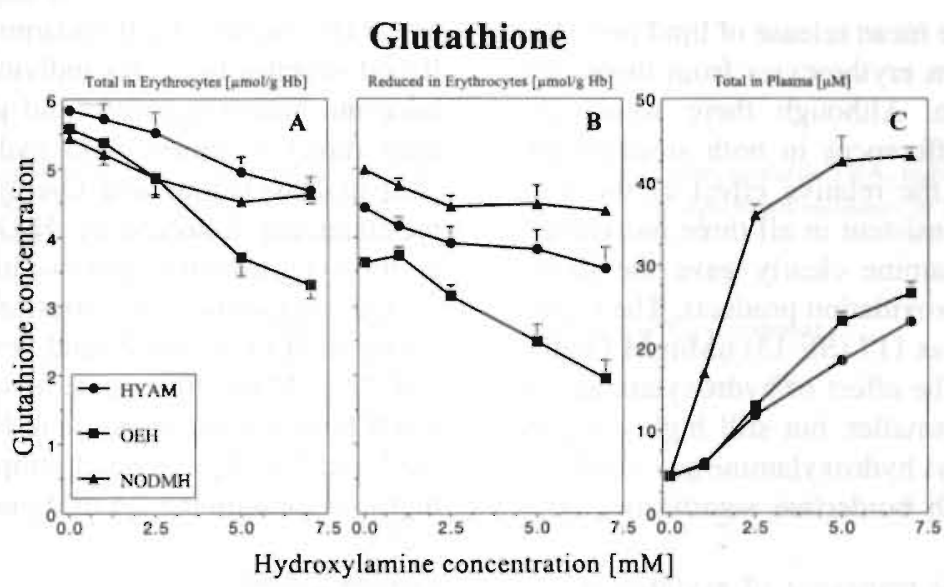

Figure 2. Availability of A: total glutathione (reduced plus oxidized) in human erythrocytes; B: reduced glutathione in human erythrocytes and $\mathrm{C}$ : total glutathione in human plasma, after incubation with hydroxylamines (1 hour, 37C). The error bars represent the standard error of the mean difference between the sample value and its control. Separate experiments were performed to obtain the data for panel A, B and C. Regression analyses showed that all concentration dependent changes were significant $(P<0.0002$ in all cases, except the decrease in reduced glutathione with increasing hydroxylamine and N,O-dimethyl hydroxylamine (panel B) where the P values were 0.007 and 0.015 respectively).

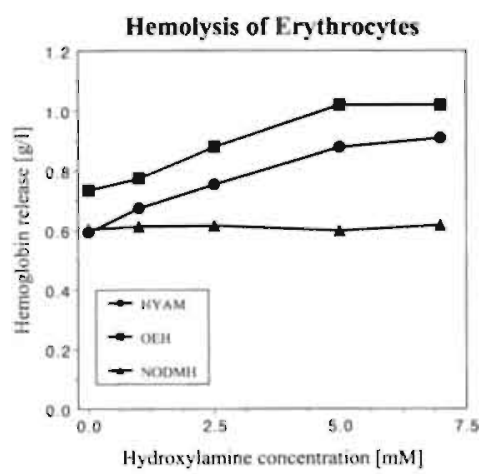

Figure 3. Occurrence of hemolysis of human erythrocytes after incubation with hydroxylamines ( 1 hour, 37C). The errors bars represent the standard error of the mean difference between sample value and its control. Regression analyses showed significant $(\mathrm{P}<0.0001)$ increases in hemolysis with increasing hydroxylamine and $\mathrm{O}$-ethyl hydroxylamine concentrations. 
times for hydroxylamine compared to O-ethyl hydroxylamine, indicates that the effect is strongest for hydroxylamine. In N,O-dimethyl hydroxylamine treated blood samples no Heinz body formation could be detected even at concentrations up to $10 \mathrm{mM}$.

\section{Lipid Peroxidation}

In Figure 4 the mean release of lipid peroxidation products from erythrocytes from three individuals is shown. Although there were clear interindividual differences in both susceptibility and background, the relative effect of the three chemicals was consistent in all three individuals. O-ethyl hydroxylamine clearly gave the largest release of lipid peroxidation products. The regression coefficient was 117 (SE 13) $\mathrm{nM} / \mathrm{mM}$ O-ethyl hydroxylamine. The effect of hydroxylamine was about two times smaller, but still highly significant. N,O-dimethyl hydroxylamine gave only minor increases with borderline significance $(\mathrm{P}=$ 0.093).

The remaining resistance of erythrocytes towards $\mathrm{H}_{2} \mathrm{O}_{2}$ induced lipid peroxidation after hydroxylamine and O-ethyl hydroxylamine pretreatment is shown in Figure 5. Fresh blood samples from three individuals were used. Although there were some interindividual differences in sensitivity the qualitative phenomena were comparable for all three persons and averaged data are shown. For both hydroxylamines pre-treatment lead to a hydroxylamine-concentration dependent decrease in the $\mathrm{H}_{2} \mathrm{O}_{2}$ induced lipid peroxidation

For N,O-dimethyl hydroxylamine the effect that occurred was more complex. The amounts of lipid peroxidation products released from erythrocytes from person $\mathrm{A}$ were not markedly influenced by $\mathrm{N}, \mathrm{O}$-dimethyl hydroxylamine pre-treatment. Blood samples from this individual did generally have the lowest induced lipid peroxidation both after direct treatment with hydroxylamines and after hydroxylamine and $\mathrm{O}$-ethyl hydroxylamine pre-treatment followed by $\mathrm{H}_{2} \mathrm{O}_{2}$ treatment. The erythrocytes from the other two individuals showed a hydroxylamine-concentration dependent increase in $\mathrm{H}_{2} \mathrm{O}_{2}$ induced lipid peroxidation after 1 and $2.5 \mathrm{mM}$ pre-treatment. In samples from person $\mathrm{B}$ however, the response to $\mathrm{H}_{2} \mathrm{O}_{2}$ was lower in the 5 and $7 \mathrm{mM}$ pre-treated samples than the (very high) response in the $2.5 \mathrm{mM}$ pre-treated samples.

\section{Enzyme Inhibitions}

GST activity was strongly decreased in both hydroxylamine and O-ethyl hydroxylamine treated samples (Figure 7). For hydroxylamine and O-ethyl hydroxylamine the GST activity decreased with about $0.35 \mathrm{U} \cdot \mathrm{g} \mathrm{Hb}^{-1} / \mathrm{mM}$ addition. As a

Table 1: Presence of Heinz bodies in human erythrocytes after incubation with hydroxylamines (1 hour, 37C). After addition of brilliant cresyl blue the erythrocytes were incubated at room temperature or $37 \mathrm{C}$ for a specified amount of time. Visibility of Heinz bodies is indieated as positive $(+)$, negative $(-)$ or visible but minor $( \pm)$.

\begin{tabular}{lcccccc}
\hline \multicolumn{1}{c}{ Sample } & \multicolumn{3}{c}{ Room Temperature } & $37 \mathrm{C}$ & \\
& $20 \mathrm{~min}$ & $60 \mathrm{~min}$ & $120 \mathrm{~min}$ & $20 \mathrm{~min}$ & $60 \mathrm{~min}$ & $120 \mathrm{~min}$ \\
\hline Blank & - & - & - & - & - & - \\
N,O-dimethyl hydroxylamine $10 \mathrm{mM}$ & - & - & - & - & - & - \\
hydroxylumine $1 \mathrm{mM}$ & - & \pm & \pm & \pm & \pm & \pm \\
hydroxylamint $2.5 \mathrm{mM}$ & \pm 1 & \pm 1 & \pm 1 & \pm 1 & \pm 1 & \pm 1 \\
O-cthyl hydroxylamine $1 \mathrm{mM}$ & - & - & - & - & \pm & \pm \\
O-ethyl hydroxylamine $2.5 \mathrm{mM}$ & + & + & + & +1 & +1 & +1 \\
\hline
\end{tabular}

'Blue spots were also visible extrace ilularly. 


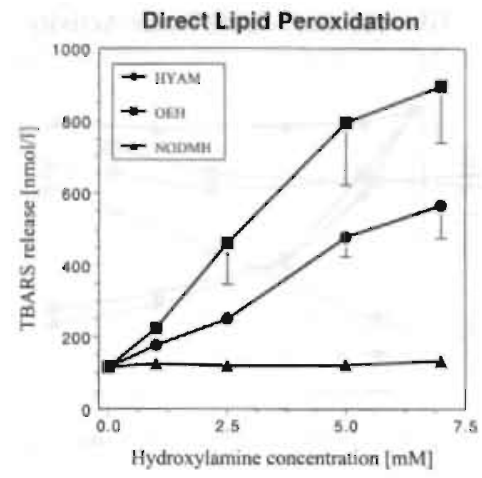

Figure 4. Lipid peroxidation, expressed as malondialdehyde equivalents in reactivity towards IBA, in blood incubated with hydroxylamines ( 1 hour, 37C). Regression analyses on the combined data showed significant increases in TBARS release with increasing O-ethyl hydroxylamine and hydroxylamine concentrations $(\mathrm{P}<0.0001)$.

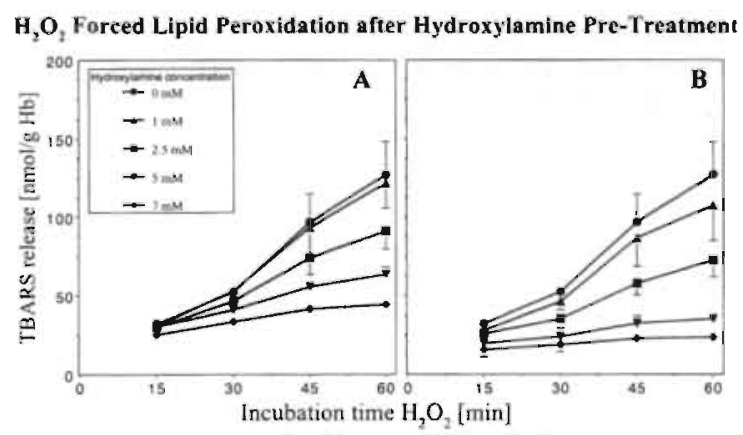

Figure 5. Hydrogen peroxide (10 $\mathrm{mM}$ ) forced lipid peroxidation, expressed as malondialdehyde equivalents in reactivity towards TBA after pre-incubation of blood with various concentrations of A: hydroxylamine and B: O-ethyl hydroxylamine (1 hour, 37C).

\section{$\mathrm{H}_{2} \mathrm{O}_{2}$ Forced Lipid Peroxidation after NODMH Pre-Treatment}

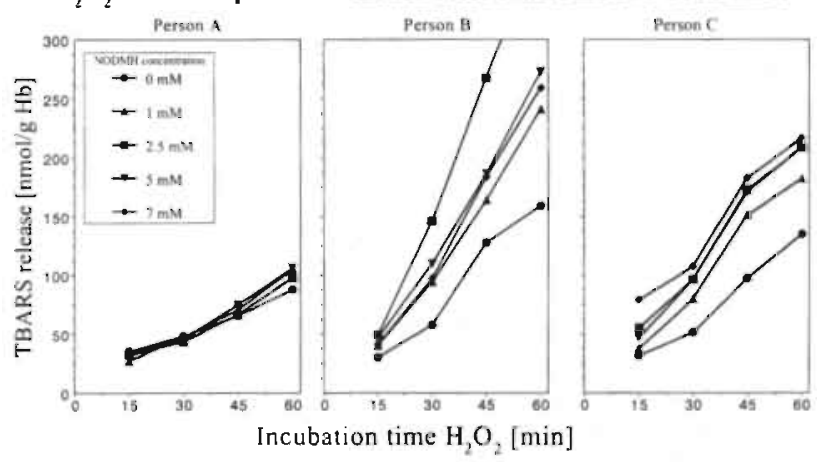

Figure 6. Hydrogen peroxide $(10 \mathrm{mM})$ forced lipid peroxidation, expressed as malondialdehyde equivalents in reactivity towards TBA, in erythrocytes of three individuals after pre-incubation of blood with various concentrations of $\mathrm{N}, \mathrm{O}$-dimethyl hydroxylamine (1 hour, 37C). 


\section{Glutathione S-Transferase Activity}

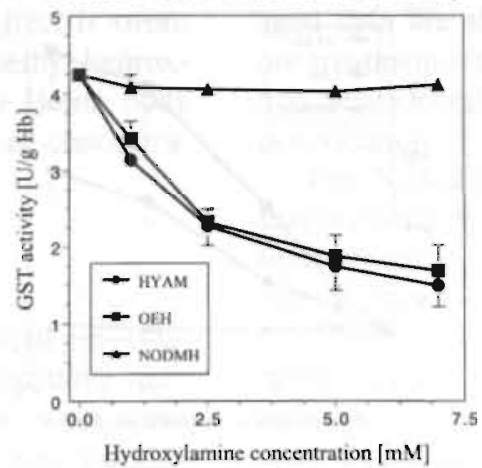

Figure 7. Activity of glutathione $S$-transferase in human erythrocytes after incubation with hydroxylamines ( 1 hour, 37C). The error bars represent the standard error of the mean difference between sample value and its control. Regression analyses showed significant decreases in GST activity with increasing hydroxylamine and O-ethyl hydroxylamine concentrations $(\mathrm{P}<0.0001$ ).

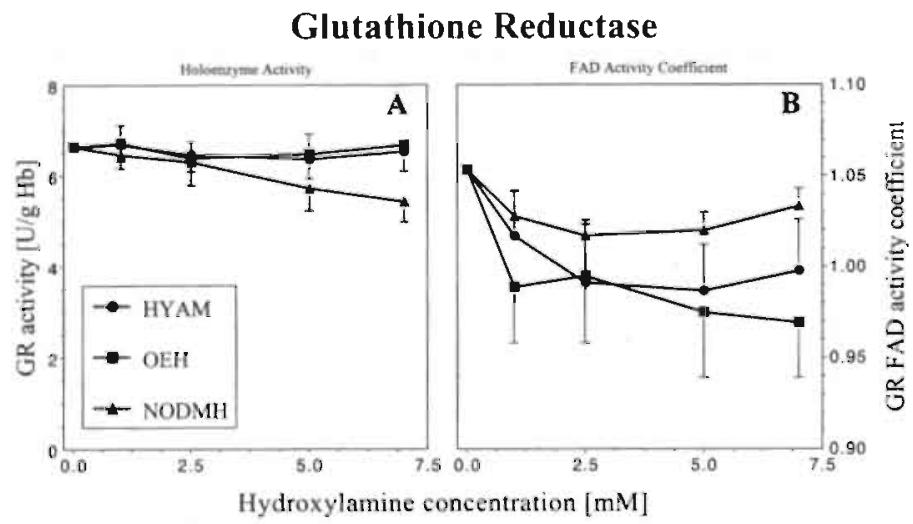

Figure 8. A: Activity of glutathione reductase (holoenzyme) and B: FAD activity coefficient of glutathione reductase in human erythrocytes after incubation with hydroxylamines ( 1 hour, 37C). The coefficients were calculated by division of the activity in the presence of $\operatorname{FAD}(11.75 \mu \mathrm{M})$ by the activities determined in a parallel assay without FAD addition. The error bars represent the standard error of the mean difference between sample value and its control. Regression analyses showed a significant decrease in GR activity with increasing $\mathrm{N}, \mathrm{O}$-dimethyl hydroxylamine concentration $(\mathrm{P}=0.0002)$ as well as significant decreases in FAD activity coefficients with increasing hydroxylamine $(P=0.025)$ and $\mathrm{O}$-ethyl hydroxylamine $(\mathrm{P}=0.010)$ concentrations. 


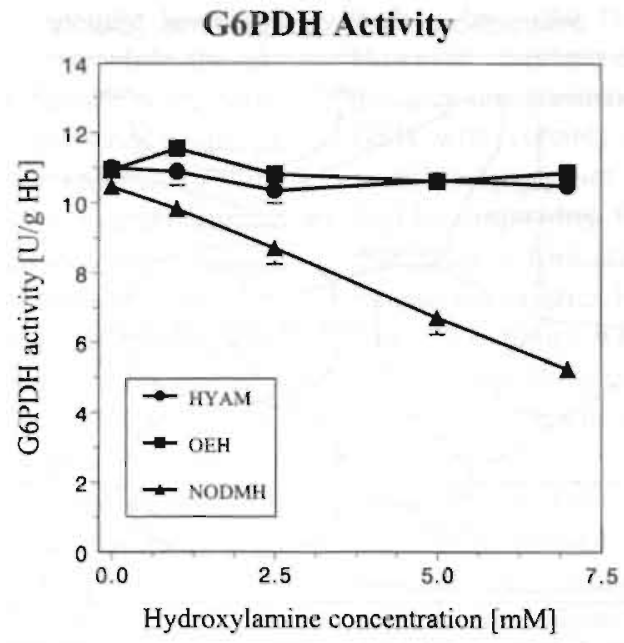

Figure 9. Activity of glucose 6-phosphate dehydrogenase in human erythrocytes after incubation with hydroxylamines (1 hour, 37C). The error bars represent the standard error of the mean difference between sample value and its control. Regression analyses showed significant decreases in G6PDH activity with increasing N,O-dirnethyl hydroxylamine concentrations $(\mathrm{P}<0.0001)$.

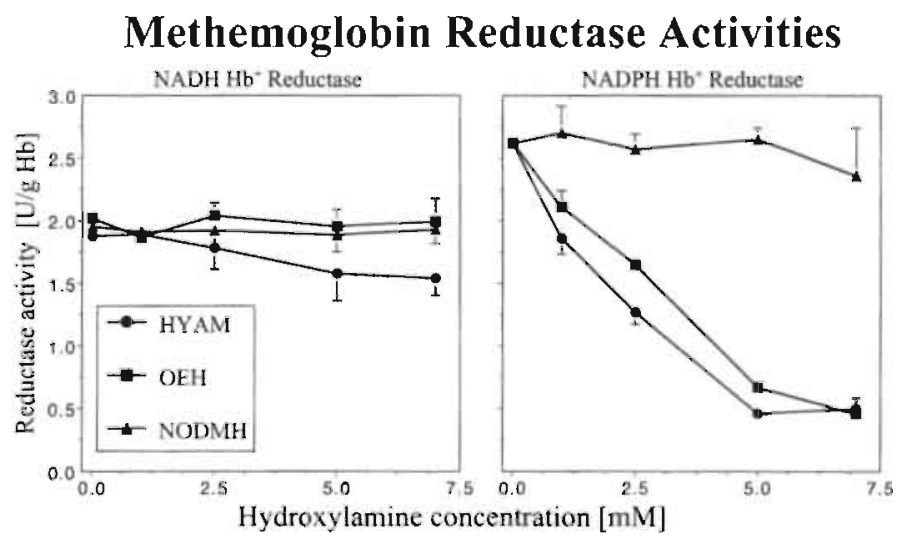

Figure 10. Activity of NADH methemoglobin reductase and NADPH methemoglobin reductase in human erythrocytes after incubation with hydroxylamines ( 1 hour, 37C). The error bars represent the standard error of the mean difference between sample value and its control. Regression analyses showed a significant decrease in NADH methemoglobin reductase with increasing hydroxylamine concentrations $(\mathbb{P}=0.002)$ and significant decreases in NADPH methemoglobin concentrations with increasing hydroxylamine and $\mathrm{O}$-ethyl hydroxylamine concentrations $(\mathrm{P}<0.0001)$. 
Interactions in Hydroxylamine Toxicity

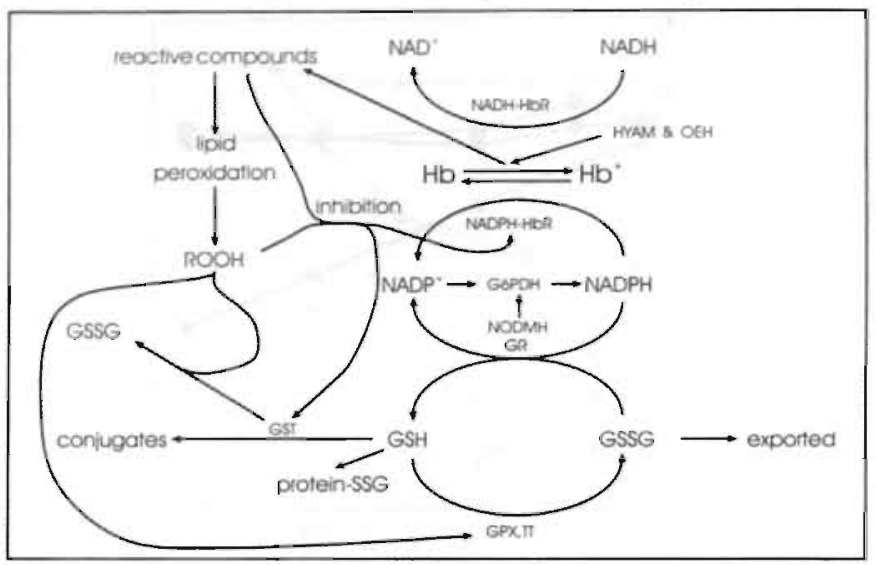

Figure 11. Schematic representation of the proposed mechanisms for hydroxylamine erythrotoxicity. hydroxylamine and the O-ethyl derivative ( $O$-ethyl hydroxylamine) induce formation of methemoglobin. During this process free radicals are formed that induce lipid peroxidation. The free radicals plus the lipid peroxides (ROOH) formed lead to inhibition of glutathione S-transferase (GST) and NADPH methemoglobin reductase (NADPH-HbR). The oxidative stress occurring leads to depletion of glutathione (GSH) by various routes. N-substituted hydroxylamines like N,O-dimethyl hydroxylamine inhibil glucose 6-phosphate dehydrogenase (G6PDH), and to a lesser extend glutathione reductase (GR). The resulting inability to reduce $\mathrm{NADP}^{+}$and glutathione renders the erythrocyte more vulnerable to oxidative stress, including that caused by hydroxylamine and O-ethyl hydroxylamine. Other abbreviations used: GPX = glutathione peroxidase, Protein-SSG = protein-glutathione mixed disulfides, $\mathrm{TT}=$ thiol transferase.

consequence about two-thirds of the initial GST activity was lost at the highest $(=7 \mathrm{mM})$ hydroxylamine and $\mathrm{O}$-ethyl hydroxylamine concentrations used. For N,O-dimethyl hydroxylamine no significant changes in the GST activity were found. In contrast the GR activity was only decreased for N,O-dimethyl hydroxylamine, for this substance GR activities in $7 \mathrm{mM}$ incubations were about $20 \%$ lower than the $6.7 \mathrm{U} \cdot \mathrm{g} \mathrm{Hb}^{-1}$ found in control incubations (Figure 8A). The GR $\mathrm{Goff}_{\text {cot }}$ was slightly decreased in both hydroxylamine $(P=0.025)$ and O-ethyl hydroxylamine ( $\mathrm{P}=0.01)$ treated samples (Figure $8 \mathrm{~B}$ ). This indicates a decrease in riboflavin availability in these samples (18).

The G6PDH activity was strongly impaired by N.O-dimethyl hydroxylamine $(0.76$ (SE 0.04$) \mathrm{U} \cdot \mathrm{g}$ $\mathrm{Hb}^{-1} \operatorname{lost} / \mathrm{mM}$ N,O-dimethyl hydroxylamine), leading to about $50 \%$ reduction at the highest $(=7$ mM) N,O-dimethyl hydroxylamine concentration tested (Figure 9). Hydroxylamine and O-ethyl hydroxylamine did not influence the G6PDH activity. The activity of another pentose-phosphate shunt enzyme tested, glucose-phosphate isomerase. was not significantly influenced by any of the three hydroxylamines. NADH-HbR activity was only impaired by hydroxylamine. The control activity of $1.9 \mathrm{U} \cdot \mathrm{g} \mathrm{Hb}^{-1}$ fell to about $1.5 \mathrm{U} \cdot \mathrm{g} \mathrm{Hb}^{-1}$ in $7 \mathrm{mM}$ hydroxylamine incubations (Figure 10A). NADPH-HbR activity was strongly decreased in incubations with both hydroxylamine and O-ethyl hydroxylamine. For both substances the decrease amounted to about $0.3 \mathrm{U} \cdot \mathrm{g} \mathrm{Hb}^{-1}$ for each $\mathrm{mM}$ addition, and as a result less than $20 \%$ of the control activity was found in the $7 \mathrm{mM}$ incubations (Figure 10B).

\section{DISCUSSION}

On the whole the effects caused by hydroxylamine and O-ethyl hydroxylamine were very 
much like the effects that we recently described for O-methyl hydroxylamine (13), while the effects of N,O-dimethyl hydroxylamine were comparable to those of $\mathrm{N}$-methyl hydroxylamine. A schematic representation of the mechanisms involved is given in figure 11. For hydroxylamine and $\mathrm{O}$-ethyl hydroxylamine massive methemoglobin formation was found, for N,O-dimethyl hydroxylamine this was much lower. Hydroxylamine forms complexes with hemoproteins, for instance leading to inactivation of catalase (29-31). Methemoglobin formation in vitro was previously described for hydroxylamine $(4,5,14,15,32)$ and N,Odimethyl hydroxylamine (4). The mechanism of methemoglobin formation by hydroxylamine is known to differ from that induced by nitrite (5). Reaction of hydroxylamine with hemoglobin involves $\mathrm{Hb} / \mathrm{Hb}^{+}$cycle reactions $(3,30)$, and leads to decomposition of hydroxylamine. The methemoglobin forming reaction, which produces $\mathrm{NH}_{3}$ from hydroxylamine, was found to be very fast, explaining the high methemoglobin concentrations found. During the other step of the cycle $\mathrm{N}_{2}$ is formed. Stolze et al. $(14,15)$ proved with electron spin resonance spectroscopy techniques that free hydronitroxide radicals $\left(\mathrm{H}_{2} \mathrm{NO} \bullet\right)$ are formed as intermediates in the methemoglobin formation induced by hydroxylamine. Stoichiometric considerations lead them to the expectation that $\mathrm{H}_{2} \mathrm{O}_{2}$ and active oxygen species might also be formed. Moreover, they proved the existence of a compound I type ferryl species, probably formed by $\mathrm{H}_{2} \mathrm{O}_{2}$ (33). This radical formation can be one of the causes for lipid peroxidation.

The reduced availability of GSH will also facilitate lipid peroxidation. GSH consumption can result from direct oxidation and from use in protective reactions catalyzed by GST and glutathione peroxidase (34). In this way lipid peroxidation may not only be facilitated by GSH depletion (35) but may also provoke it (34). This agrees with our finding that O-ethyl hydroxylamine as the substance with the highest lipid peroxidation activity also gives the highest GT depletion. I.oss of 4,4'-dithiodipyridine reactive $\mathrm{HbSH}$ groups was not found. After treatment with electrophilic agents such a loss can be clearly demonstrated (20). However, oxidative loss of $\mathrm{HbSH}$ groups for instance by formation of mixed disulfides with GSH, will probably not be picked up by this assay, as dithiodipyridines are able to break GSH sulfhydryl bindings (36). We recently provided evidence that such a formation of mixed disulfides does indeed occur after hydroxylamine treatment (37) and this explains why the increases in extracellular GT (mainly present as oxidized glutathione) did not make up for the loss of GT from the erythrocytes.

Methemoglobin formation, GT depletion and membrane damage, as indicated by lipid peroxidation, are all strongly associated with cellular damages like Heinz body formation and hemolysis. Induction of this kind of damage by the two substances with high potencies for methemoglobin formation, GT depletion and lipid peroxidation is therefore in accordance with expectations. For hydroxylamine Heinz body formation in mice (38) and in pigs (6) were previously reported.

It is well known that lipid peroxidation products can give rise to inhibition of several enzymes and to protein damage in general (39). Purified rat GST-P (7-7), which is equivalent to human GST $\pi$, the form of GST predominating in human erythrocytes $(40)$ is very vulnerable to oxidative stress (41). The human enzyme itself is also inhibited by $\mathrm{H}_{2} \mathrm{O}_{2}$ (42). This was confirmed in control experiments where erythrocytes were treated directly with $\mathrm{H}_{2} \mathrm{O}_{2}$. (data not shown). Previously we showed that GST activity in human erythrocytes is impaired by occupational exposure to coal tar products (43) and to the pesticide dichloropropene (27), in miners with early forms of pneumoconiosis (44) and after long-distance running (45). At least in the latter two cases oxidative stress is the most likely cause for GST activity loss. Therefore, activity loss of GST under conditions causing lipid peroxidation was expected beforehand. In fact these experiments were included in order to examine the possible use of GST activity loss as a biomarker for hydroxylamine exposure. As expected, GST inactivation was only found for the strong lipid peroxidation 
causing substances hydroxylamine and O-ethyl hydroxylamine and not for $\mathrm{N}, \mathrm{O}$-dimethyl hydroxylamine. NADPH-HbR was also strongly inhibited by hydroxylamine and O-ethyl hydroxylamine and not by N,O-dimethyl hydroxylamine. Inhibition of NADPH-HbR by hydroxylamine was previously shown by Layne and Smith (46), and does explain the lowered effectiveness of methylene blue treatment in case of hydroxylamine poisoning in mice (7). The absence of inhibition by $\mathrm{N}, \mathrm{O}$-dimethyl hydroxylamine indicates a possible relation between radical stress and inhibition of this reductase. Impairment of NADPH-HbR did indeed occur in control experiments where erythrocytes were treated directly with $\mathrm{H}_{2} \mathrm{O}_{2}$ (data not shown). The loss of riboflavin, as indicated by the decreases in $\mathrm{GR}_{\text {coeff }}$ after hydroxylamine and O-ethyl hydroxylamine treatment, might also be caused by consumption during radical scavenging.

N,O-dimethyl hydroxylamine showed far less activity in most aspects discussed so far. Methemoglobin formation was low, lipid peroxidation, hemolysis and Heinz body formation were not found, GST and NADPH-HbR inhibition were absent, and riboflavin loss was not found. On the other hand N,O-dimethyl hydroxylamine treatment of erythrocytes resulted in a decrease of G6PDH activity, consistent with the earlier findings by Martin et al. (12). GR activity was also decreased by N,O-dimethyl hydroxylamine, but since more than $80 \%$ of GR activity was still present at $\mathrm{N}, \mathrm{O}$-dimethyl hydroxylamine concentrations of $7 \mathrm{mM}$ this may be of less importance. Interestingly GT concentrations in erythrocytes were decreased by N.O-dimethyl hydroxylamine while GT in plasma was even more increased than for the two other hydroxylamines. GT depletion by N.O-dimethyl hydroxylamine can be the result of oxidation in glutathione peroxidase and thiol transferase reactions, combined with lower availability of NADPH reduction equivalents for GR activity, due to G6PDH inhibition. Even the G6PDH inactivation alone will render the erythrocyte more vulnerable to oxidative stress from subsequent exposure to other oxidative com- pounds. This is confirmed by the fact that N,Odimethyl hydroxylamine treated erythrocytes did show a higher vulnerability towards subsequent $\mathrm{H}_{2} \mathrm{O}_{2}$ induced lipid peroxidation. Contrary to what night have been expected hydroxylamine and O-ethyl hydroxylamine pre-treatment did not lead to an increased vulnerability to $\mathrm{H}_{2} \mathrm{O}_{2}$. This is however easily explained. For $\mathrm{H}_{2} \mathrm{O}_{2}$ induced lipid peroxidation in erythrocytes ferrous-hemoglobin is a prerequisite (47). After hydroxylamine and O-ethyl hydroxylamine treatment a large fraction of hemoglobin is converted to the ferric form, necessarily leading to a decrease in lipid peroxidation. It should be noted that changes in $\mathrm{H}_{2} \mathrm{O}_{2}$ resistance cannot be the result of catalase inhibition by the hydroxylamines, since $\mathrm{NaN}_{3}$ was added to the assays in order to obtain a full inhibition of catalase. Hydroxylamine is known to inhibit catalase both in vitro $(29,30)$ and in vivo in mouse liver (31), and this inhibition will in itself increase the vulnerability of erythrocytes to oxidative stress.

The occurrence of lipid peroxidation in erythrocytes exposed to hydroxylamine and O-ethyl hydroxylamine indicates the availability of free radicals, possibly including active oxygen species. The presence of active oxygen species and of the resulting peroxides in vivo is associated with increased cancer risks and accelerated aging (4850 ). It should be noted however that radical production in this case seems to be strongly linked to the presence of hemoglobin. In experiments with hydroxylamine we did not see any lipid peroxidation in washed erythrocyte membranes or in isolated rat hepatocytes (51). Since erythrocytes do not contain a nucleus, direct DNA damage is not possible. On the other hand reactive products formed in erythrocytes might be able to reach other cells and provoke damage there. and similar radical mechamisms might be induced by hydroxylamines at hemoproteins elsewhere. Cousidering the above, the most serious threat resulting from possible exposure of humans to hydroxylamines seems to come from the direct erythrotoxic effects. Methemoglohin formation. lipid peroxidation, GT depletion and inhibition of protective enzymes can 
lead to faster senescence of erythrocytes and increased sequestration in the spleen. Next to clinical parameters for anemia and increases in reticulocytes, determination of GST and NADPH$\mathrm{HbR}$ and assessment of lipid peroxidation in vivo (52) may be useful biomarkers to monitor human exposure to hydroxylamines with direct oxidative activity, like hydroxylamine and $\mathrm{O}$-ethyl hydroxylamine. Two special aspects should be noted: 1) due to the inhibition of NADPH-HbR by hydroxylamines like hydroxylamine and O-ethyl hydroxylamine and due to the inhibition of G6PDH by compounds like N,O-dimethyl hydroxylamine and trimethyl hydroxylamine, treatment of accidental methemoglobinemia with methylene blue may fail, 2) exposure to compounds like N,O-dimethyl hydroxylamine and trimethyl hydroxylamine will inhibit G6PDH and thereby will render the erythrocytes more vulnerable to a subsequent exposure to direct oxidative compounds. Because of the latter, determination of G6PDH activities may also serve as a valuable biomarker when exposure to this group of hydroxylamines can occur.

\section{ACKNOWLEDGMENTS}

The authors are grateful to Dr L Voluvics and Dr A Kester of the department for Methodology and Statistics for valuable advises on statistical procedures, to Astrid Feijts (MSc) for assistance with the analyses of glucosephosphate isomerase and NADPH-HbR; to Mrs. M Catsberg from the "Maasland Hospital" (Sittard, Netherlands) for her assistance with the Heinz body determinations and to the "Red Cross Bloodbank, South-Limhurg" for the blood samples used. Financial support wa" given by DSM Special Products b.v. (Geleen, Netherlands).

\section{REFERENCES}

1. BG Chemie (1991): Hydroxylamin und seine salze. (Berufsgenossenschaft der Chemischen Industrie. Toxikologische bewertung Ausgabe 05/91 Nr 62. Heidelberg ISSN-0937-4248).

2. Gross P. Biologic activity of hydroxylamine: A Review. CRC Crit Rev Toxicol 14:87-99, 1985.

3. Bazylinski DA, Arkowitz RA, Hollocher TC. Decomposition of hydroxylamine by hemoglobin. Arch Biochem Biophys 259:520-526, 1987.
4. Calabrese 3, Tilli F, Horton HM, Stoddard A. The effects of ethanol on the hematotoxicity of twelve pharmaceutical and environmental agents. $J$ Environ Sci Health A23:359-367, 1988.

5. Cranston RD, Smith RP. Some aspects of the reactions between hydroxylamine and hemoglobin derivatives. $J$ Pharmacol Exp Ther 177:440-446, 1971.

6. Sinha. D. Sleigh SD. Experimental production of Heinz Bodies in the pig. Toxicol Appl Pharmacol 12:435. 439. 1986.

7. Smith RP, Layne WR. A comparison of the lethal effects of nitrite and hydroxylamine in the mouse. $j$ Pharmacol Exp Ther 165:30-35, 1969.

8. Derelanko MI, Gad SC. Gavigan FA, Babich PC, Rinehart WE. Toxicity of hydroxylamine sulfate following dermal exposure: Variability with exposure method and species. Fund Appl Toxicol 8:583-594, 1987.

9. Riemann H. On the toxicity of hydroxylamine. Acta Pharmacol 6:285-292, 1950.

10. Yamamoto RS, Weisburger EK, Korziz J. Chronic administration of hydroxylamine and derivatives in mice. Pro Soc Exp Biol Med 124:1217-1220, 1967.

11. BASFAG (1989): Bericht Prüfung der oralen Toxicität von Hydroxylaminsulfat an Ratten, Verabreichung im Trinkwasser über 3 monate. [Projekt-Nr.32C0389/ 8474, (cited in: Berufsgenossenschaft der Chemischen Industrie 1991)].

12. Martin H. Wömer W, Rittmeister B. Hämolytische anämie durch inhalation von hydroxylaminen. $\mathrm{Zu}$ gleich ein beitrag zur fruge der Heinz-Körper-Bildung. Klin Wochenschr 15:725-731, 1964.

13. Spooren AAMG, Evelo CTA. In vitro haematotoxic effects of three methylated hydroxylamines. Arch Toxicol 71:299-305, 1997.

14. Stolze $\mathrm{K}$. Nohl $\mathrm{H}$. Detection of tree radicals as internediates in the methemoglobin formation from oxyhemoglobin induced by hydroxylamine. Biochem Pharmacel 38:3055-3059. 1989.

15. Stolze K. Dadak A, Liu Y, Nohl H. Hydroxylamine and Phenol-induced formation of methemoglobin and free radical intermediates in erythrocytes. Bioc hem Pharmacol 52:1821-1829, 1996.

16. Hak Hyun B, Gulati GL. Ashton JK. Color Allas of Clinical Hematolog: New York-Tokyo: Igaku-Shoin, 1986.

17. van Kampen EJ, Zijlstra WG. Determination of hemoglobin and its derivatives. Adv Clin Chem 8:141-1B7. 1965.

18. Tietz NW. Textbook of Clinical Chemistry: Philadelphia: W.B. Saunders, 1986.

19. Anderson ME. Determination of glutathione and gluta. thione disulphide in biological samples. Meth Enzymol 113.548-555, 1985. 
20. Evelo CTA, Henderson PT. Influence of glutathione on the formation of cysteinne alkylation products in human hemoglobin. Toxicology 52:177-186, 1988.

21. Stocks J, Dormandy TL. The autoxidation of human red cell lipids induced by hydrogen peroxide. $\mathrm{Br} J$ Haematol 20:95-111, 1971.

22. Engelen JJM, Borm PJA, van Sprundel M, Leenearts L. Blood antioxidant parameters at different stages oof pneumoconiosis in coal workers. Environ Health Perspect 84:165-172, 1990.

23. Hegesh E, Calmanovici N, Avron M. New method for determining ferri-hemoglobin reductase(NADH methemoglobin reductase) in erythrocytes. I Lab Clin Med 72:339-344, 1968.

24. Bauer JD. Laboratory investigation of hemoglobin. In: Sonnenwirth AC, Jarett L, eds. Gradwohl's Clinical Laboratory Methods and Diagnosis. St. Louis: C.V. Mosby Company, Inc., pp. 809-902, 1980.

25. Beutler E. Red Cell Metabolism (A Manual of Biochemical Methods). New York: Grune and Stratton, 1975.

26. Habig WH, Jakoby WB. Assays for the differentiation of glutathione S-transferases. Meth Enzymol 77:398405, 1981

27. Brouwer EJ, Evelo CTA, Verplanke AJW, van Welie RTH, de Wolff FA. Biological effect monitoring of exposure to 1,3-dichloropropene: effects on liver and renal function and on glutathione conjugation. $B r J$ Ind Med 48:167-172, 1991.

28. Carlberg 1, Mannervik B. Glutathione reductase. Meth Enzymol 113:484-490, 1985.

29. Adams DH, Roe FJ. The action of some chemical substances on mouse liver catalase activity in yivo. $\mathrm{Br}$ J Cancer 7:509-518, 1953.

30. Colter JS, Quastel JH. Catalytic decomposition of hydroxylamine by hemoglobin. Arch Biochem 27:368389,1950 .

31. Keilin D, Hartree EF. On some properties of catalase haematin. Proc Roy Soc B121:173-191, 1936.

32. Tomoda A, Matsukawa S. Tatkeshita M. Yoneyama Y. Opposite effects of organic phosphates on hemoglobin oxidation by hydroxylaminnne under aerobic and anaerobic conditions. $J$ Biol Chem 252:6105-6107, 1977.

33. Nohl $\mathbf{H}$. Stolze $\mathrm{K}$. Chemiluminescence from activated heme compounds detected in the reaction of various xenobiotics with oxyhemoglobin: comparison with several heme/hydrogen peroxide systems. Free Rad Biol Med 15:257-263, 1993.

34. Shan X, Aw TY, Jones DP. Glutathione-dependent protection against oxidative injury. Pharmac Ther 47:61-71, 1990.

35. Comporti $\mathbf{M}$. Three models of free radical-induced cell injury. Chem Biol Interact 72:1-56, 1989.
36. Carlsson J, Svensen A, Rydén L. Isolation of cysteine peptides from proteins by solid-phase techniques based on thiol-disulfide exchange. In: Previero A, ColettiPreviero MA. Eds. Solid Phase Methods in Protein Sequence Analysis. Amsterdarn: Elsevier, Inc., pp. 29-37, 1977.

37. Spoorerı AAMG, Evelo CTA. Hydroxylamine treatment increases glutathione-protein and protein-protein binding in human erythrocytes. Blood Cells. Molecules and Diseases 23:323-336, 1997.

38. Webster SH, Liljegren EJ, Zimmer DJ. Heinz body formation by certain chemical agents. J Pharmacol Exp Ther 95:201-211, 1949.

39. Stadtman ER. Oxidation of proteins by mixed-function oxidation systems: implications i protein tumover, ageing and neutrophil function. Trends in Biochemical Sciences 11:11-12, 1986.

40. Fazi A, Accorsi A, Piatti E, Magnani M. Cell age dependent decay of human erythrocytes glutathione S-transferase. Mech Ageing Dev 58:255-266, 1991.

41. Shen $H$, Tsuchida $S$, Tamai K, Sato K. Identification of cysteine residues involved in disulfide formation in the inactivation of glutathione transferase P-form by hydrogen peroxide. Arch Biochem Biophys 300:137-141, 1993.

42. Shen $H_{\text {, Tamai }} \mathrm{K}$, Satoh $\mathrm{K}$, Hatayama J, Tsuchida $\mathrm{S}$, Sato K. Modulation of class Pi glutathione transferase activity by sulfhydryl group modification. Arch Biochem Biophys 286:178-182, 1991.

43. Evelo CTA. Henderson PT. Biological effect monitoring. Arch Toxicol Suppl 15:268-277, 1992.

44. Evelo CTA, Bos RP, Bom PJA. Decreased gluathione content and glutathione S-transferase activity in red blood cells of coal miners with early stuge of coal miners pneumoconiosis. Br J Ind Med 50:633-636. 1993.

45. Evelo CTA, Palmen NGM, Artur Y, Janssen GME. Changes in blood glutathione concentrations, and in erythrocyte glutathione reductase and glutathione $S$-transferase activity after running training and after participation to contests. Eur J Appl Physiol 64:354358, 1992.

46. Layne WR. Smith RP. Methylene blue uptake and the reversal of chemically induced methemoglobinemias in human erythrocytes. J Pharmacol Exp Ther 165:3644. 1969.

47. Clemens MR, Einsele H, Remmer H, Waller HD. An essential requirement for ferrous-haemoglobin in the hydrogen peroxide stimulated oxidation of red blood cell membrane lipids. Biochem Pharmacol 34:13391341, 1985

48. Cutler RG. Antioxidants in aging. Am J Clin Nutr 53:373S-379, 1991. 
49. Janssen YMW, Van Houten B, Borm PJA, Mossman BT. Biology of disease. Cell and tissue responses to oxidative damage. Lab Invest 69:261-274. 1993.

50. Trush MA, Kensler TW. An overview of the relationship between oxidative stress and chemical carcinogenesis. Free Rad Biol Med 10:201-209, 1991.
51. Palmen NGM, Evelo CTA. Oxidative effects in human erythrocytes caused by some oximes and hydroxylamine. Arch Toxicol 72:270-276, 1998.

52. Pryor WA, Godber SS. Noninvasive measures of oxidative stress status in humans. Free Rad Biol Med 10:175-176, 1991. 
Chapter 3

\section{In Vitro Hematotoxic Effects of Three Methylated Hydroxylamines}

Published in: Archives of Toxicology, 71: 299-305, 1997 
Anita A.M.G. Spooren - Chris T.A. Evelo

\section{In vitro haematotoxic effects of three methylated hydroxylamines}

\begin{abstract}
Hydroxylamine (HYAM, $\mathrm{HONH}_{2}$ ) and some of its derivatives are known to cause erythrotoxic effects both in vitro and in vivo. Previous studies have shown that the primary in vitro effect of HYAM and O-ethy! hydroxylamine $(\mathrm{OEH})$ is methaemoglobin formation. leading to liberation of free radicals which cause lipid peroxidation, enzyme inhibitions and glutathione depletion. By contrast, N-substituted N,O-dimethyl hydroxylamine (NODMH), primarily induces impairment of glucose 6-phosphate dehydrogenase (G6PDH) and glutathione reductase (GR). The oxidative potency of HYAM and the O-derivative was larger than the potency of the N,O-derivative. This seemed to indicate that attachment of an alkyl group to the nitrogen atom of hydroxylamine leads to decreased reactivity. To achieve a better understanding of the structure activity relationship for hydroxylamines three methylated derivatives were tested: $\mathrm{N}$-methyl hydroxylamine (NMH), $\mathrm{N}$-dimethyl hydroxylamine (NDMH) and O-methyl hydroxylamine $(\mathrm{OMH})$. We were also interested in the erythrotoxic potency of $\mathrm{OMH}$ which recently entered industrial production. Methaemoglobin formation, high release of lipid peroxidation products, inhibition of NADPH methaemoglobin reductase and glutathione S-transferase (GST) and depletion of total glutathione (GT) were seen for OMH. The reducing enzymes G6PDH and GR were not impaired by $\mathrm{OMH}$. These findings for $\mathrm{OMH}$ are consistent with the proposed mechanism for O-derivatives. Since both the effects caused by $\mathrm{OMH}$ and its potency are comparable to those of HYAM and OEH this indicates that possible occupational exposure to this compound may be approached similarly to HYAM and OEH. NMH only inhibited G6PDH and GR activity, which is fully in accord with the proposed mechanism for $\mathrm{N}$-substituted
\end{abstract}

\footnotetext{
A.A.M.G. Spooren $(\triangle)$ C.T.A. Evelo

Department of Pharmacology (toxicology section).

University Maastrich, P.O. Bor 616 .

6200 MD Maastricht. The Netherlands
}

derivatives of HYAM. However. NDMH a double Nsubstituted compound, caused a strikingly different scheme of reactivity: inhibition of G6PDH but not of GR, severe methaemoglobin formation, only little lipid peroxidation and some impairment of NADPH methaemoglobin reductase. This study confirms that O-derivatives of HYAM are potent haemoglobin oxidators, leading to other oxidative effects. The main effect was confirmed for single $\mathrm{N}$-derivatives as inhibition of the two protective enzymes G6PDH and GR. However, the results for NDMH indicate that this simple classification of $\mathrm{O}$-derivatives and $\mathrm{N}$-derivatives has to be extended for double $\mathrm{N}$-substituted compounds which give a mixture of effects.

Key words Hydroxylamines ' Human erythrocytes Oxidizing effects P Potency ranking

Structure activity relations

\section{Introduction}

Hydroxylamine derivatives formed from the parent compound hydroxylamine ( $\mathrm{HYAM}, \mathrm{HONH}_{2}$ ), are used as intermediates in chemical synthesis (e.g. for Nylon $6^{T M}$, pesticides and pharmaceuticals). The primary target cell for HYAM in humans is the erythrocyte and exposure to HYAM leads to methaemoglobin formation, glutathione depletion and haemolytic anaemia ( $\mathrm{Ca}$ labrese et al. 1988; Gross 1985). Such haematological effects were also seen in animal studies (Smith and Layne 1969: Yamamoto et al. 1967). Increased formation of methaemoglobin alone is not necessarily accompanied by haemolysis, as evidenced by the absence of haemolysis in patients with methaemoglobinaemia induced by nitrites (Beutler 1969). Hydroxylamine has been found to alter the structure of erythrocyte membrane proteins (Kotsifopoulos 1975) and to form Heinz bodies (Sinha and Sleight 1968; Webster et al. 1949). Such modifications could provide an explanation for the haemolysis due to HYAM, which is a prominent part of its toxicity. 
Martin et al. (1964) described in vitro effects of methylated hydroxylamines (O-methyl, N,O-dimethyl and trimethyl hydrcixylamine). Their data indicated the: induced by hydroxylamines. One route primarily induces methaemoglobin (O-methyl and N,O-dimethyl hydroxylamine) and the other route mainly inhibits the: activity of glucose 6-phosphate dehydrogenase (trimethyl and N,O-dimethyl hydroxylamine); both routes. can lead to haemolytic anaemia. The existence of two possible hydroxylamine-related haematotoxic routes was also confirmed by in vitro research with hydroxylamines in our laboratory (Evelo 1995). Human blood was exposed to three hydroxylamines, which are currently in production in the chemical industry: HYAM, O-ethyl hydroxylamine $(\mathrm{OEH}$, $\mathrm{C}_{2} \mathrm{H}_{5} \mathrm{ONH}_{2}$ ) and $\mathrm{N}, \mathrm{O}$-dimethyl hydroxylamine (NODMH, $\mathrm{CH}_{3} \mathrm{ONHCH}_{3}$ ). Cytotoxic effects, oxidative effects, effects on reducing enzymes, on glutathione $S$ transferase and on some basal metabolic enzymes were determined. Some of the effects found are summarized

It was postulated that HYAM as well as the Oalkylated derivative primarily induce methaemoglobin. This one electron oxidation of ferro- to ferrihaemoglobin leads to the formation of free radicals. In spontaneous methaemoglobin formation, the electron is displaced to oxygen leading to superoxide formation (Carrell et al. 1975: Misra and Fridovich 1972). For hydroxylamines, production of a possible non-radical intermediate (hydrogen peroxide) was suggested subsequent to formation of a nitroxide $\left(R_{2} R_{1} N O \cdot\right)$ radical and methaemoglobin (Stolze and Nohl 1989, 1990) in incubations with hydroxylamines and oxyhaemoglobin. It was further postulated that the reactive products formed will induce lipid peroxidation and together with the lipid peroxidation products will induce enzyne inhibition and glutathione depletion. N-substituted

Table 1 Methaemoglobin fomation, release of lipid peroxidation products. glutathione depletion and activity decreases of some enzymes in tiuman erythrocytes after incubation with hydroxylamines ( $\mathrm{h}, 37^{\circ} \mathrm{C}$ ). These incubations were carried out with 1-day-old blood, except for the determination of lipid peroxidation products, glutathione S-transferase activity and glutathione reductase (GR) activity where fresh blood was used. Five concentrations (control, 1. 2.5.5 and $7 \mathrm{mM}$ ) were tested of which only existence of two different routes of haematotoxicity in Table 1 .

hydroxylamines primarily lead to impairment of glucose 6-phosphate dehydrogenase (G6PDH) and glutathione reductase (GR), probably because the stability of the radicals derived from these compounds are considerably higher than that of unsubstituted hydroxylamine (Stolze and Nohl 1990\%. This resulting decrease in metabolic: protection renders the erythrocyte more vulnerable to oxidative stress.

This previous study led to some ideas about structure activity relationships. It seemed that the reactivity of hydroxylamines decreases when an alky! group is attached to the nitrogen atom. To explore this idea and consequently gain more insigbt into the structure-activity relationship of hydroxylamines three methylated hydroxylamines were tested: $\mathrm{N}$-methy hydroxylamine ( $\mathrm{NMH}, \mathrm{HONHCH}_{3}$ ), $\mathrm{N}$-dimethyl hydroxylamine [NDMH, $\mathrm{HON}\left(\mathrm{CH}_{3}\right)_{2}$ ] and $\mathrm{O}$-methyl hydroxylamine $\left(\mathrm{OMH}, \mathrm{CH}_{3} \mathrm{ONH}_{2}\right.$ ) also known as methoxyamine. This particular nomenclature was chosen because then the compounds would all be related to the O-N centre. The last-mentioned compound was of special interest as it recently entered bulk production and thus might lead to occupational exposure. The in vitro work deseribed in this paper was therefore also used to compare the toxicity of $\mathrm{OMH}$ with that of HYAM and $\mathrm{OEH}$.

\section{Materials and methods}

\section{Chemicals}

$\mathrm{N}$-methyl hydroxylamine HCl (NMH: CAS-no 4229-44-2), Ndimethyl hydroxylamine $\mathrm{HCl}$ (NDMH; CAS-no 16645-06-0) and O-methy! hydroxylamine $\mathrm{HCl}$ (OMH: CAS-no 593-56-6) were purchased fiom Fluka Chemika-Bio (hemika (Buchs, Switzerland). The purity of all three compounds. was $\geq 98 \%$. 2-Thiobarbituricacid (TBA) was obtained from Merck (Darmstadt, Germany) and all biochemicals were obtained from Sigma (Si. Louis, Mo., USA). Only micro filtrated deionized water was used and all other chemicals employed were of analytical grade.

the effects of the lowest and highest concenirations are summarized. Values represent the mean difference between sample value and its control \pm SEMD. A dash indicates the parameter tested was not significantly affected by the substrate. Regression analyses showed that all changes were significatl at $P<0.0001\left(^{P}=0.0002\right.$ for $G R$ activity decreases by NODHM). (Hb Haemoglobin). See the Discussion for explanation of the shading

\begin{tabular}{|c|c|c|c|c|c|c|}
\hline \multirow[t]{2}{*}{ Parameter } & \multicolumn{2}{|c|}{$\begin{array}{l}\text { Hydroxylamine } \\
\text { (HYAM) }\end{array}$} & \multicolumn{2}{|c|}{$\begin{array}{l}\text { O-Ethyl hydroxylamine } \\
\text { (OEH) }\end{array}$} & \multicolumn{2}{|c|}{$\begin{array}{l}\text { N,O.Dimethy! hydroxylamine } \\
\text { (NODMH) }\end{array}$} \\
\hline & $1 \mathrm{mM}$ & $7 \mathrm{mM}$ & $\mathrm{I} \mathrm{mM}$ & $7 \mathrm{mM}$ & $\mathrm{I} \mathrm{mM}$ & $7 \mathrm{mM}$ \\
\hline Methaemoglobin ( $\%$ ) & $7 \pm 0.8$ & $54 \pm 2$ & $5.5 \pm .0 .5$ & $51 \pm 5$ & $0.25 \pm 0.05$ & $7.5 \pm 0.2$ \\
\hline Lipid peroxidation (nmol/1) & $60 \pm 18$ & $450 \pm 90$ & $105 \pm 16$ & $780 \pm 157$ & - & - \\
\hline NADPH methaemoglobin reductase (U/g $\mathrm{Hb}$ ) & $0.8 \pm 0.1$ & $2.1 \pm 0.02$ & $0.5 \pm 0.1$ & $2.2 \pm: 0.1$ & - & - \\
\hline Glutathione S-transferase (U/g Hb) & $1.1 \pm 0.1$ & $2.8 \pm 0.3$ & $0.8 \pm 0.2$ & $2.6 \pm 0.3$ & - & - \\
\hline Total glutathione (umol/g b) & $0.1 \pm 0.2$ & $1.2 \pm 0.2$ & $0.2 \pm 0 . \overline{3}$ & $2.3 \pm 0.2$ & $0.2 \pm 0.2$ & $0.8 i \pm 0.2$ \\
\hline Glutathione reductase (U/g Hb) & - & - & - & - & $0.3 \pm 0.3$ & $1.3 \mathrm{i} \pm 0.4$ \\
\hline Glucose 6-phosphate dehydrogenase (U/g Hb) & - & - & - & - & $0.6 \pm 0.3$ & $5.2 \pm 0.2$ \\
\hline
\end{tabular}

Data from Evelo (1995) 


\section{Incubation conditions}

Human buffy coats, containing citrate-phosphate-dextrose (CPD) as anticoagulant, were obtained from the local centre for blood transfusion and stored at $4{ }^{\circ} \mathrm{C}$ until the following day. Samples were checked for viral infections before use. Erythrocytes, after the removal of white blood cells and plasma by centrifugation, $(2000 \mathrm{~g})$ were washed twice in saline and resuspended to the original haematocrit concentration in phosphate-buffered saline (PBS) comprising $15 \mathrm{mM} \mathrm{KH_{2 }} \mathrm{PO}_{4} / \mathrm{Na}_{2} \mathrm{HPO}_{4}, 130 \mathrm{mM} \mathrm{NaCl}$, pH 7.4. The cells were incubated with hydroxylamines (final concentration 0.1 . 2.5. 5 and $7 \mathrm{mM}$ ) in a shaking water bath at $80 \mathrm{rpm}$ for $1 \mathrm{~h}$ at $37^{\circ} \mathrm{C}$. After incubation, erythrocytes were carefully washed twice with 9 volumes of PBS and packed by centrifugation $(2000 \mathrm{~g})$. Where applicable, the packed erythrocytes were lysed by adding three or fifteen volumes of ice cold water. After 15 min storage on ice, cellular debris was removed by centrifugation at $10000 \mathrm{~g}$ for $10 \mathrm{~min}$. All experiments were performed three times on separate days and all incubations were performed in triplicate each day. Haemoglobin concentrations were determined with the haemoglobin cyanide procedure (van Kampen and Zijlstra 1965).

\section{Analyses}

\section{Methaemoglobin formation}

The percentage methaemoglobin present in haemolysates was calculated from the absorbance change occurring after addition of $\mathrm{KCN}$, compared to the same change in a sample fully converted to the methatemoglobin form by the addition of $\mathrm{K}, \mathrm{Fe}(\mathrm{CN})_{6}$ (Tiet 1986).

\section{Thiobarbituric acid reactive substances (TBARS)}

The formation of lipid peroxidation products in the extracellular medium was assessed by determination of the amount of TBARS released and was expressed as malondialdehyde equivalents (Stocks and Dormandy 1971). After incubation and centrifugation (2000 g). the supernatant was collected and protein precipitated by the addition of an equal volume of $10 \%$ (w/v) trichloroacetic acid. Of the supernatant $1.5 \mathrm{ml}$ was added to $1 \mathrm{ml}$ of $1 \%(\mathrm{w} / \mathrm{v})$ TBA solution in $50 \mathrm{mM} \mathrm{NaOH}$ and heated in a boiling water bath for $15 \mathrm{~min}$. After forced cooling. $1.25 \mathrm{ml}$ butanol was added, and the two phases were thoroughly mixed. The absorbance of the butanol phase at $535 \mathrm{~nm}$ was determined and corrected for the background absorbance at $590 \mathrm{~nm}$.

\section{Total glutathione (GT)}

Protein in erythrocytes was precipitated with an equal volume of $8 \%$ (w/v) trichloroacetic acid. The clear supernatant was diluted ninefold in 100 m.M KH $\mathrm{PO}_{2} / \mathrm{Na}_{2} \mathrm{HPO}_{4}$ buffer, $\mathrm{pH} 7.4$, and stored at $-20{ }^{\circ} \mathrm{C}$ until determination. GT was measured using the cyclic oxidationreduction method essentially as described by Anderson (1985).

\section{Glutathione S-transferase (GST)}

GST (EC 2.5.1.18) activity with 1-chloro-2,4-dinitrobenzene as subsimite was determined in the haemolysate prepared from erythrocyie inctibates. Three volumes were added of ice-cold water contaning $1.4 \mathrm{mM}$ dithiothreitol and GST activity determined using the method of Habig and Jakoby (1981) with previously described modifications (Brouwer et al. 1991).

\section{Glutathione reductase $(G R)$}

GR (EC 1.6.4.2) activity in the haemolysate was determined by a modification of the method described by Carlberg and Mannervik
(1985). One-hundred microlitres of haemolysate was added to $2 \mathrm{ml}$ potassium phosphate buffer $(100 \mathrm{mM}), 50 \mu \mathrm{l}$ EDTA $(80 \mathrm{mM})$, $100 \mu \mathrm{l}$ NADPH $(2 \mathrm{mM})$ and $100 \mu \mathrm{l}$ flavin adenine dinucleotide (FAD: $0.3 \mathrm{mM}$ ). After $2 \mathrm{~min}$ preincubation at $37{ }^{\circ} \mathrm{C}$, the reaction was started by adding $100 \mu$ t oxidized glutathione (GSSG; $7.5 \mathrm{mM}$ ). After $15 \mathrm{~s}$ the reaction was followed spectrophotometrically at $340 \mathrm{~nm}$ for $2 \mathrm{~min}$. The FAD was added in order to convert all the enzyme to its holo form.

\section{Glucose 6-phosphate dehydrogenase (G6PDH)}

G6PDH (EC 1.1.1.49) activity in the haemolysate was determined using glucose 6-phosphate as substrate in the presence of NADP and $\mathrm{MgCl}_{2}$ (Beutler 1975; Tietz 1986). The rate of reduction of $\mathrm{NADP}^{2}$ was followed spectrophotometrically at $340 \mathrm{~nm}$ for $10 \mathrm{~min}$.

\section{NADPH methaemoglobin reductase}

NADPH-methaemoglobin reductase activity in the haemolysate was determined by measuring the oxidation of NADPH at $340 \mathrm{~nm}$ for 10 min (Beutler 1975; Huennekens et al. 1957). Methylene blue was used as substrate.

\section{Statistical evaluation}

The significance of the concentration dependent change was evaluated using linear regression analysis. The regression model used corrects for inter-experiment variations in control values. For this reason the standard errors shown in the figures are given as the standard error of the mean difference (SEMD) between the sample value and its control (i.e. the corresponding value at concentration 0 ).

\section{Results}

\section{Oxidative effects}

As shown in Fig. I, erythrocyte incubations with $\mathrm{OMH}$ and unexpectedly NDMH at $7 \mathrm{mM}$ resulted in high levels of methaemoglobin of $70 \%$ (SE 3.7) and $45 \%$ (SE 1.3) respectively. Both of these effects were statistically significant $(P<0.0001)$. A very low rate of methaemoglobin formation was found for NMH: $0.20 \%$ (SE 0.02) per $\mathrm{mM} N \mathrm{NMH} P<0.0001$ ). The release of lipid peroxidation products from erythroeytes, shown as TBARS release, is presented in Fig. 2. Again OMH and NDMH had a concentration dependent effect, producing significant amounts of TBARS release $(P<0.0001$ and $P<0.003$ respectively). OMH clearly gave the largest release of lipid peroxidation products: 2000 (SE 180) $\mathrm{nmol} / \mathrm{l}$ at $7 \mathrm{mM} \mathrm{OMH}$. The release of lipid peroxidation products by NDMH of 80 (SE 32) $\mathrm{nmol} / 1$ at $7 \mathrm{mM}$ is low, especially in comparison with the unexpectedly high methaemoglobin formation $(45 \%$ at $7 \mathrm{mM})$ by this compound. As expected, because of the very low methaemoglobin formation, no release of lipid peroxidation products was found for NMH. Total glutathione (Fig. 3) decreased with dependence on concentration in incubations with $\mathrm{OMH}[0.29$ (SE 0.02) $\mu \mathrm{mol} / \mathrm{g}$ haemoglobin (Hb) per $\mathrm{mM}: P<0.0001]$ but not in incubations with NDMH. GT levels were depleted by $\mathrm{NMH}$ 


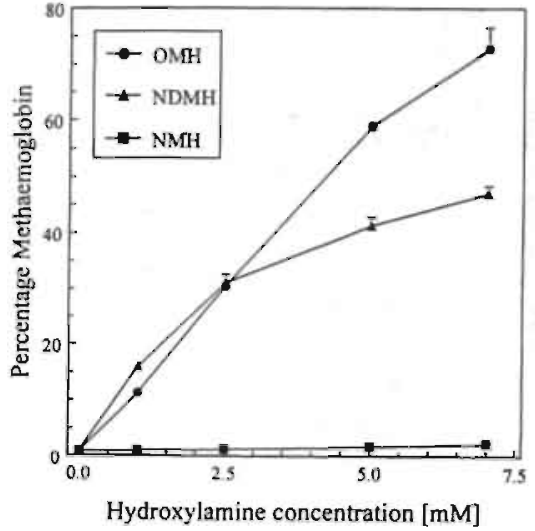

Fig. 1 Effects of $\mathrm{N}$-methyl (NMH). N-dimethyl (NDMH) and O-methyl (OMH) hydroxylamine on methaemoglobin formation in buman erythrocytes after incubation for $1 \mathrm{~h}$ at $37^{\circ} \mathrm{C}$. The etror bars represent the standard error of the mean differences between sample value and control. The error bars for some of the data fall within the data points. The control methaemoglobin value was $0.89 \%$ (SE. 0.07 ). Regression analyses showed significant increases in methaemoglobin formation with increasing OMH and NDMH concentrations $(P<0.0001)$

$(P<0.014)$ with the depletion reaching a plateau level of 0.8 (SE 0.1): $\mu \mathrm{mol} / \mathrm{g} \mathrm{Hb}$ of depleted GT at $2.5 \mathrm{mM}$ NMH.

\section{Enzyme inhibitions}

The activity of NADPH methaemoglobin reductase in erythrocytes is shown in Fig. 4. This activity was im-

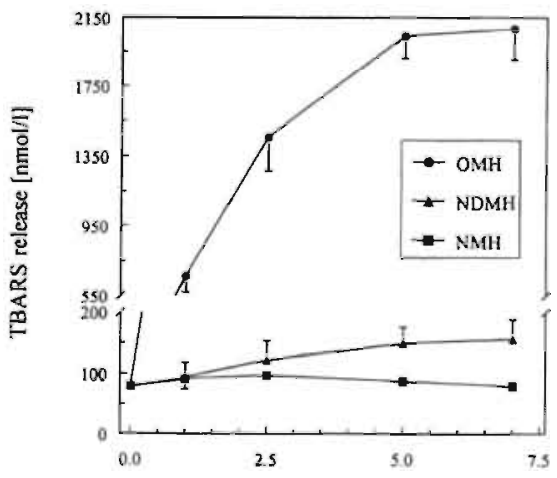

Hydroxylamine concentration [mM]

Fig. 2 Lipid peroxidation. expressed as malondialdehyde squivalents in reaclivity towards thiobarbituric acid (TBA) in human erythrocy res after incubation with NMH. NDMH and OMH for I h at $37^{\circ} \mathrm{C}$. The control release of TBA-reactive substances (TBARS) was 80 (SE 9) nmoll. Regression analyses showed significant increases in TBARS release with increasing concentrations of $\mathrm{OMH}(P<0.0001)$ and NDMH $(P<0.003)$. For explanation of error bais see the legend to Fig. I

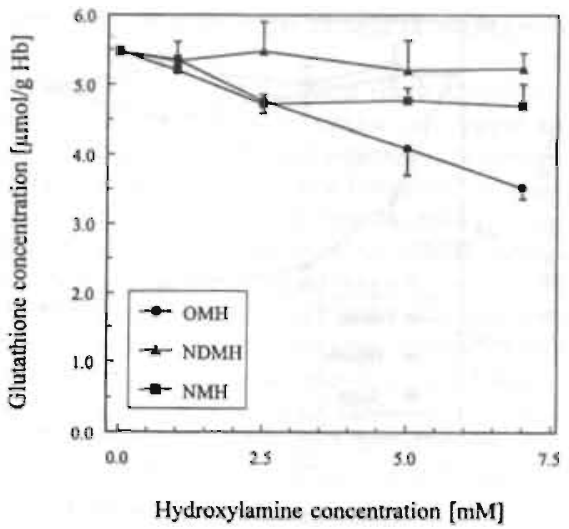

Fig. 3 Availability of total glutathione (GT) in human ergthrocyzes after incubation with NMH, NDMH and $O M H$ for 1 h at $37^{\circ} \mathrm{C}$. The control GT value was 5.5 (SE 0.3 ) $\mu \mathrm{mol} / \mathrm{g}$ haemoglobin $(\mathrm{Hb}$ ). Regression analyses showed significant decreases in GT concentrations: with increasing OMH $(P<0.0001)$ and NMH $(P<0.014)$ concentrations. For explanation of error bars see the legend to Fig. 1

paired in both $\mathrm{OMH}$ and NDMH treated samples $(P<0.0001)$. With OMH the NADPH methaemoglobin reductase activity decreased by 0.30 (SE 0.04 ) U/g Hb per $\mathrm{mM}$ addition and with NDMH the activity decreased by $0.15(0.02) \mathrm{U} / \mathrm{g} \mathrm{Hb}$ per $\mathrm{mM}$ addition. With NMH no significant change was found in the NADPH methaemoglobin reductase activity. The glutathione S-transferase activity was strongly inhibited by $\mathrm{OMH}$ leading to $\sim 65 \%$ reduction $[2.3$ (SE 0.2 ) U/g Hb] at the highest ( $7 \mathrm{mM}$ ) OMH concentration tested (Fig. 5). The

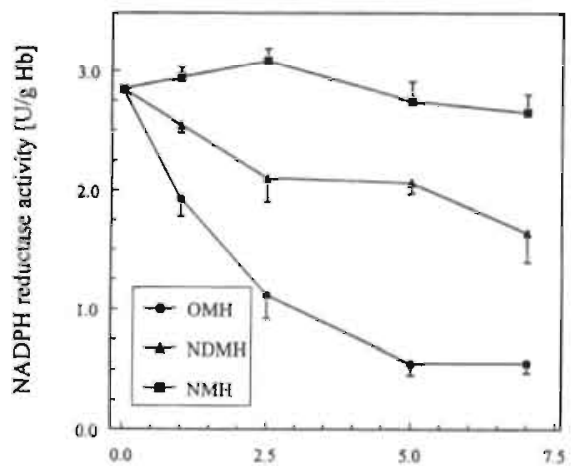

Hydroxylamine concentration [mM]

Fig. 4 Efiecs of NMIH, NDMH and OMH on the NADPH methaemoglobin reductase activity in human erythrocytes after incubation for i h, at $37^{\circ} \mathrm{C}$. The control NA.DPH methaemogiobin reductase activity was $2.85(\mathrm{SE} 0.2) \mu \mathrm{mol} / \mathrm{g} \mathrm{Hb}$. Regression analyses showed significant decreases in NADPH methaemoglobin reductase activity with increasing $\mathrm{OMH}$ and $\mathrm{NDMH}$ concentrations $(P<0.0001)$. For explanation of error bars see the legend to Fig. 1 


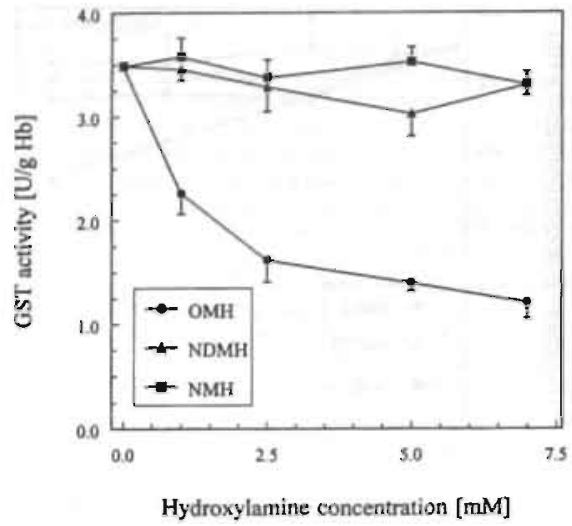

Fig. 5 Eflects of NMH, NDMH and OMH on glutathione S-transferase (GST) activity in human erythrocytes after incubation for $1 \mathrm{~h}$ at $37^{\circ} \mathrm{C}$. The control GST activity value was 3.5 (SE 0.4) $\mu \mathrm{mol} / \mathrm{g} \mathrm{Hb}$. Regression analyses showed significant decreases in GST activity with increasing $\mathrm{OMH}$ concentrations $(P<0.0002)$. For explanation of error bars see the legend to Fig. !

other two hydroxylamine derivatives tested (NDMH and $\mathrm{NMH}$ ) did not cause significant inhibition of the GST activity in erythrocytes.

Glutathione reductase activity was decreased with NMH $(P<0.0001)$ : GR activities in incubations with $7 \mathrm{mM}$ NMH were $\sim 20 \%$ lower than the $6.9 \mathrm{U} / \mathrm{g} \mathrm{Hb}$ found in control incubations (Fig. 6). The activity of GR was not impaired by NDMH while only a small tendency toward impairment of GR activity was found with OMH $(P<0.011)$. A concentration dependent decrease in glucose 6-phosphate dehydrogenase accivity

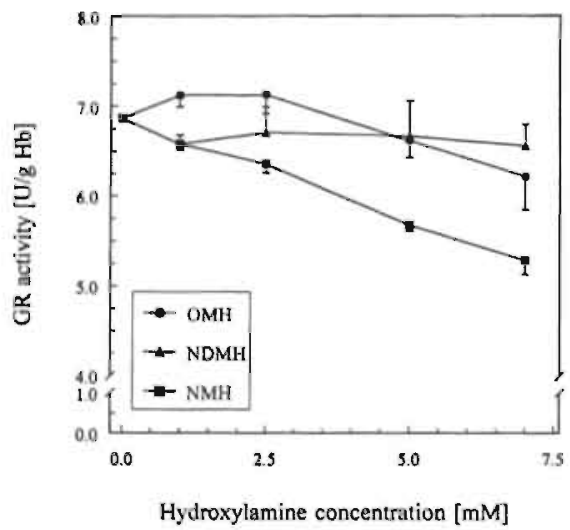

Fig. 6 Effects of NMH. NDMH and OMH on the glutathione: reductase $(G R)$ actisity in human erythrocytes after incubation for $1 \mathrm{~b}$ at $37^{\circ} \mathrm{C}$. The control GR activity value was 6.9 (SE 0.8) umol/g Hb. Regression analyses showed significant decreases in GR activity with increasing NMH concentrations $(P<0.0001)$. For explanation of error bars see the iegend to Fig. 1

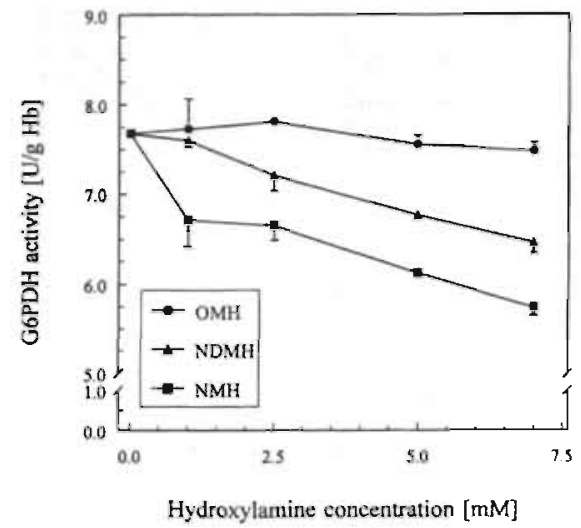

Fig. 7 Eflects of NMH. NDMH and $\mathrm{OMH}$ on the glucose 6 phosphate deliydrogenase (G6PDH) activity in human erythrocytes after incubation for $1 \mathrm{~h}$ at $37^{\circ} \mathrm{C}$. The control G6PDH activity value was 7.7 (SE 0.1) $\mu \mathrm{mol} / \mathrm{g} \mathrm{Hb}$. Regression. analyses showed significant decreases in G6PDH activity with increasing NMH and NDMH concentrations $(P<0.0001)$. For explanation of error bars see the; legend to Fig. 1

was found with NMH and NDMH $(P<0.0001$; Fig. 7): 1.9 (SE 0.1) U/g Hb at $7 \mathrm{mM} \mathrm{NMH}$ and 1.2 (SE 0.1) U/g $\mathrm{Hb}$ at $7 \mathrm{mM} \mathrm{NDMH}$. As a consequence $\sim 20 \%$ and $\sim 15 \%$ of the initial G6PDH activity was lost at $7 \mathrm{mM} \mathrm{NMH}$ and NDMH respectively. The activity of G6PDH was not significantly influenced by $\mathrm{OMH}$.

\section{Discussion}

Hydroxylamines are know to cause oxidative effects in erythrocytes (Bazylinski et al. 1987: Calabrese et al. 1988: Evelo 1995). Oxidation is a major contributor to the degenerative processes that lead to ageing andi cellular breakdown. This consideration is particularly important for the red blood cell, which is at increased risk due to both the exposure to high concentrations of oxygen and inability to replace damaged proteins by resynthesis. As a consequence. the red cell devotes much of its metabolic activity to reductive processes which combat the threat of exidation. When these reductive processes are deficient, or are overwhelmed, oxidation of cellular constituents will oceur with consequent haemolysis (Carrell et al. 1975; Stern 1989). Since hydroxylamines in vivo are able to induce haemolytio anaemia, oxidation of cellular constituents is thought to be the basis for hydroxylamine toxicity in man.

Methaemoglobin formation, high release of lipid peroxidation products and depletion of total glutathione were observed with $\mathrm{OMH}$, indicating that $\mathrm{OMH}$ is able to give rise to strong oxidative effects. Methaemoglobin formation and glutathione depletion in vitro were previously described for HYAM (Bazylinski et al. 1987; Calabrese et al. 1988; Evelo 1995). The reaction of 
HYAM with haemoglobin involves a two-step reaction in which haemoglobin cycles between oxyhaemoglobin and methaemoglobin leading to decomposition of HYAM into ammonia, nitrogen gas and small amounts of nitrous oxide (Bazylinski et al. 1987; Colter and Quastel 1950). Since the heme iron is a one-electron reactant and two electrons are required to form nitrogen gas, it is assumed that free radical intermediates are involved. Moreover. Stolze and Nohl (1989, 1990) reported the existence of a possible non-radical product, hydrogen peroxide, and a radical product, $\mathrm{R}_{2} \mathrm{R}_{1} \mathrm{NO} \bullet$, as intermediates in the formation of methaemoglobin induced by hydroxylamines. This radical formation is one of the causes for lipid peroxidation and glutathione depletion. The oxidative effects seen with $\mathrm{OMH}$ are similar to the effects previously seen with HYAM and OEH (Table 1) except for the amount of lipid peroxidation products released by OMH: 2000 (SE 180) nmol/l at $7 \mathrm{mM}$, a value which was about fourfold higher than the amount previously seen for HYAM [450 (SE 90) nmol/l at $7 \mathrm{mM}$ : Table 1]. A partial explanation for this difference could be that the earlier experiments were carried out in fresh whole blood in stead of 1-day-old washed erythrocytes (data not shown).

It is well known that free radicals are able to oxidize glutathione and interact with enzymes particularly if they contain sulphydryl groups (Sies 1986). Alternatively, these effects may be indirect; for example. exposure to oxygen radicals may cause lipid peroxidation in cell membranes which in turn may generate species that damage cell proteins. Therefore, activity loss of enzymes under conditions causing lipid peroxidation was expected beforehand, especially for a particular enzyme in the erythrocyte. GST p, which is very vulnerable to oxidative stress (Murata et al. 1990; Shen et al. 1993: Evelo et al. 1996). NADPH methaemoglobin reductase and actual GST impairment was found for the strong lipid peroxidation-forming substance $\mathrm{OMH}$; the reductive enzymes G6PDH and GR were not impaired by this compound. The latter two enzymes were inactivated by NMH and only the activity of G6PDH was inactivated by $\mathrm{NDMH}$. The activities of the protective enzymes NADPH methaemoglobin reductase and GST were not influenced by the addition of NMH. The potency of NMH in achieving oxidative effects (methae-, moglobin formation. total glutathione depletion) is small, comparable with the effects previously seen for NODMH (Table 1). A very small amount of methaemoglobin formation dependent upon concentration was seen for NMH but the effect was so small as to probably be due to impurities. NDMH not only decreased the activity of G6PDH but also decreased the NADPH methaemoglobin reductase activity. Furthermore, NDMH caused severe methaemoglobin formation with very little release of lipid peroxidation products. GST activity and GT leveis were not decreased by NDMH. However, a slight decrease in GST activity seemed to be present at NDMH concentrations up to $5 \mathrm{mM}$ isee Fig. 5 for details) possibly in accordance with the effect seen for this substance on NADPH methaemoglobin reductase activity.

As stated before, HYAM and the hydroxylamine O. ethyl derivative $(\mathrm{OEH})$ were previously found to cause severe effects on all of the parameters mentioned except G6PDH and GR (Table 1). The latter two enzymes were only inhibited by the much less oxidative compound, NODMH. The effects seen here for OMH were fully in accord with the effects found earlier for HYAM and OEH. NMH and NDMH inhibited G6PDH activity and in this respect were comparable to NODMH. For NDMH a non-typical result was found: NDMH caused. G6PDH inhibition and also severe methaemoglobin formation, with only little lipid peroxidation and inhibition of NADPH methaemoglobin reductase.

Our findings: for OMH are consistent with the proposed mechanism for $\mathrm{O}$-derivatives where methaemoglobin formation is the primary and critical step leading to the liberation of free radicals, which cause lipid peroxidation, GT depletion, inhibition of NADPH methaemoglobin reductase activity and GST activity (see light shaded area in Table 1). The inhibition of G6PDH and GR activity, and as a consequence depletion of GT, by $\mathrm{NMH}$ and NODMH indicate that this may be a general phenomenon for $\mathrm{N}$-derivatives (see dark shaded area in Table 1). The primary oxidative effects (methaemoglobin formation, lipid peroxidation and GT depletion) seem most promising for the purpose of ranking the biological activity potency of new hydroxylamines. The hazard identification and potency assessment made for $\mathrm{OEH}$ is also applicable to $\mathrm{OMH}$ since this hydroxylamine is equally potent in erythrotoxic effects as OEH. This suggests that erythrotoxicity is probably the most important effect after occupational exposure to $\mathrm{OMH}$ and other O-derivatives. For this reason, apart from classical haemaiological effects, determinations of NADPH methaemoglobin reductase and GST activity are likely to be useful biomarkers to monitor human exposure to compounds of this class.

On the whole, our data support the idea that the main oxidative activity of hydroxylamine derivatives is dependent on the availability of the nitrogen atom. Masking this atom with a single methyl group was found to decrease the oxidative potency in NMH as was previously shown for NODMH (Table 1). The presence of an alkyl group attached to the oxygen atom in $\mathrm{OMH}$ and $\mathrm{OEH}$ does not have qualitative effects. The potency of these two compounds in lipid peroxidation and GT depletion is higher than the potency of the parent compound. HYAM. This may be caused by a shift in electron density between nitrogen and oxygen or through a change in lipophilicity leading to different approaches of the heme pocket.

The di $\mathrm{N}$-substituted compound. NDMH, does not behave similarly to the mono substituted compounds. In fact, the pattern of effects for NDMH is difficult to understand: formation of methaemoglobin without simultaneous high lipid peroxidation but with inhibition of NADPH methaemoglobin reductase while the effects 
on GST are small if at all present. This finding indicates that, despite the simple structures, the structure-activity relationship is not so straightforward as was initially suggested. Moreover, NDMH would be incorrectly classified on the assumption that binding of a molecule to the nitrogen atom would decrease the oxidative toxicity of hydroxylamines. Reactions between xenobiotics and oxyhaemoglobin are complex and involve a multistep process (Winterbourn 1985). This produces many reactive intermediates, which are responsible for other reactions in the environment of the red cell. The end result can vary considerably as a result of differences in reactivity or stability of the intermediates. Furthermore, effects on haemoglobin are also related to electronic or steric properties of the different hydroxylamines. Together with the fact that methaemoglobin can act as a scavenger of reactive intermediates, inhibiting further oxidative damage to other cell components (Sullivan and Stern 1984), this can be an explanation for the different effects seen here for the hydroxylamines. The findings of this study have reinforced the idea that structure-activity relationships are useful a priori for hazard identification and potency ranking of compounds though the main effects must be verified for confirmation.

\begin{abstract}
Acknowledgements The authors are grateful to Dr L Volovics and Dr A Kesier of the Department of Methodology and Statistics for valuable advice on statistical procedures, to R Bisschops (MSc) for development of some analyses and to Dr J Neis, DSM corporate Safety. Health, Environment and Technology, for critical reading of the manuscript. Financial support was given by DSM Special Products b.v. (Geleen, Netherlands).
\end{abstract}

\section{References}

Anderson ME (1985) Determination of glutathione and glutathione disulphide in biological samples. Methods Enzymol 113: $548-555$

Buzylinski DA, Arkawitz RA. Hollocher TC (1987) Decomposition of hydroxylamine by hemoglobin. Arch Biochem Biophys 259: $520-526$

Beutier E (1969) Drug-induced hemolytic anemia. Phamacol Rev 21: $73-103$

Beutler E (1975) Red cell metabolism (A manual of biochemical methods). 2nd edn. Grune \& Stratton. New York

Brouwer EJ. Evelo CTA. Verplanke AJW, van Welie RTH, de Wolf FA (1991) Biological effect monitoring of exposure to 1.3dichloropropene: effects, on liver and renal function and on glutathione conjugation. Br J Ind Med 48: 167-172

Calabrese EJ. Tilli F. Horton HM. Stoddard A (1988) The effects of ethanol on the hematotoxicity of twelve pharmaceutical and environmental agents. J Environ Sci Health A23: 359-367

Cariberg 1, Mannervik B (1985) Glutathione reductase. Methods Enzymol 113:484-490

Carrell RW. Winterbourn CC. Rachmilewitz EA (1975) Activated oxygen and haemolysis Br J Haematol 30: 259-264

Colter JS, Quastel JH (1950) Catalytic decomposition of hydroxylamine by hemoglobin. Arch Biochem 27: 368-389
Evelo CTA (1995) Toxicological stress indicators in human red blood cells: changes in glutathione and glutathione S-transferase as biological markers for electrophilic and oxidative stress. PhD Thesis, University of Limburg. Maastricht

Evelo CTA, Hoorntje TM, Baars LGM, Boesten PD (1996) Decreased erythrocyte glutathione S-transferase activity is a useful oxidative stress parameter both in humans and in pigs. Abstract presented at the 8th SFRR Biennial Meeting, Barcelona

Gross P (1985) Biologic activity of hydroxylamine: a review. CRC Crit Rev Toxicol 14: 87-99

Habig WH, Jakoby WB (1981) Assays for the differentiation of glutathione S-transferases. Method's Enzymol 77: 398-405

Huennekens: FM, Caffrey RW, Basford RE, Gabrio BW (1957) Erythrocyte metabolism. IV. Isolation and properties of methaemoglobin reductase. J Biol Chem 227: 261-272

van Kampen EJ, Zijlstra WG (1965) Determination of hemoglobin and its derivatives. Adv Clin Chem 8: 14!-187

Kotsifopoulos PN (1975) In vitro effect of oxidizing and analgesic agents on the erychrocyte: membrane protein electiophoretic pattern. Nouv Rev Fr Hematol 15: 141-146

Martin H. Wörner W. Rittmeister B (1964) Hämolytische Anämie durch inhalation von hydroxylamine. Zugleich ein beitrag zur frage der Heinz-Körper-Bildung. Klin Wochenschr 15: 725-731

Misra HP. Fridovich I (1972) The generation of superoxide radical during the autoxidation of hemoglobin. J Biol Chem 247:69606962

Murata T, Hatayama I, Satob K. Tsuchida S, Sato K (1990) Activation of rat glutathione transferases in class $\mathrm{mu}$ by active oxygen species. Biochem Biophys Res Commun 171: 845-851

Shen H, Tsuchida S, Tamai K. Sato K (1993) Identification of cysteine residues involved in disulfide formation in the inactivation of glutathione transferase P-form by hydrogen peroxide. Arch Biochem Biophys 300: 137-141

Sies H (1986) Biochemistry of oxidative stress. Angew Chem Inı Ed Eng 25: 1058-1071

Sinha D. Sleight SD (1968) Experimental production of Heinz bodies in the pig. Toxicol Appl Pharmacol 12: 435-439

Smith RP. Layne WR (1969) A comparison of the lethal effects of nitrite and hydroxylaminc in the mouse. J Phamacol Exp Ther 165: $30-35$

Stem A (1989) Drug-induced oxidative denaturation in red blood cells. Semin Hematol 26: 301-306

Stocks J, Dormandy TL (1971) The autoxidation of human red cell lipids induced by hydrogen peroxide. $\mathrm{Br} \mathrm{J}$ Haematol 20: 95-111

Stolze K. Nohl H (1989) Detection of free radicals as intermediates in the methaemoglobin formation from oxyhemoglobin induced. by hydroxylamine. Biochem Pharmacol 38: 3055-3059

Stolze K. Nohi H (1990) Free radical intermediates in the oxidation of $\mathrm{N}$-methylhydroxylamine and $\mathrm{N}$. $\mathrm{N}$-dimethylhydroxylamine by oxyhemoglobin. Free Rad Res Commun 8: 123-13i

Sullivan SG. Stern A (1984) The protective role of methacmoglobin in red cells exposed to oxidative stress. Life Chem Rep (Suppl 2): $348-352$

Tietz NW (1986) Textbook of clinical chemistry. Saunders. Philadelphia

Webster SH, Liljegren EJ. Zimmer DJ (1949) Heinz body formation by certain chemical agents. J Pharmacol Exp Ther 95: 201-211

Winterbourn CC (1985) Free-radical production and oxidative re. actions of hemoglobin. Environ Health Perspect 64: 321-330

Yamamoto RS. Wersburger EK. Korziz J (1967) Chronic administration of hydroxylamine and derivatives in mice. Proc Soc Exp Biol Med 124: 1217-1220 
Chapter 4

\section{Only the Glutathione Dependent Antioxidant Enzymes Are Inhibited by Hematotoxic Hydroxylamines}

Published in: Human \& Experimental Toxicology 17: 554-559, 1998 


\title{
Only the glutathione dependent antioxidant enzymes are inhibited by haematotoxic hydroxylamines
}

\author{
Anita AMG Spooren and Chris TA Evelo \\ Department of Pharmacology, Toxicology Section, Universiteit Maastricht, PO Box 616, 6200 MD Maastricht. \\ The Netherlands
}

\begin{abstract}
Hydroxylamine and some of its derivatives are known to cause oxidative effects both in vitro and in vivo. In the current study we investigated the effects of hydroxylamines on the enzymatic antioxidant defense system in human erythrocytes. The activity of catalase and superoxide dismutase was not significantly influenced by any of the hydroxylamines tested. However, the activity of glutathione peroxidase (GPX) and glutathione S-transferase (GST) was strongly inhibited by hydroxylamine and its O-derivatives (O-methyl and O-ethyl hydroxylamine). GPX was also inhibited by two $\mathrm{N}$-derivatives of hydroxylamine (i.e. N-dimethyl and N,O-dimethyl hydroxylamine). This indicates that exposure to hydroxylamines not only changes the cellular oxidation-reduction status but also leads to inhibition of the glutathione dependent antioxidant enzymes. GST as well as GPX have cysteine residues at the active site of the enzymes. Such an accessible thiol group is generally susceptible to formation of protein-mixed disulphides or intramolecular disulphides. If these thiol groups are essential for activity this would be accompanied by an increase or decrease in the
\end{abstract}

\section{Introduction}

Under physiological conditions, the red blood cell is continuously exposed to oxidants such as super" oxide radicals and hydrogen peroxide. These reactive oxygen species are also produced under experimental conditions and as a result of occupational exposure to some oxidizing agents such as aniline and hydroxylamines."- However, the red blood cell has a protective mechanism against oxidative damage. The three main antioxidant enzymes, glutathione peroxidase (GPX), catalase and superoxide dismutase (SOD) are part of this protective mechanism. They are assisted by glutathione S-transferase (GST) that acts both as a selenium independent peroxidase and a phase 2 biotransformation enzyme removes reactive products resulting from oxidative activity. Both GPX and GST depend on the availability of sufficient

Correspondenre: Dir CTA Evelo

Recovied 19 /ume 1998: arxpeded 13 July 1998 enzyme activity. In principle this is also true for glutathione reductase (GR), which in this study was only inhibited by N,O-dimethyl and N-methyl hydroxylamines. However, GR is capable to reduce these disulphides by laking up Iwo electrons, either from its substrate NAPDH or from another reductant. Oxidation of these thiol groups in GR would thus not lead to impairment of GR activity. The fact that NODMH and NMH do decrease the (iR activity can therefore only be explained by other modifications. The activity loss of GST and GPX on the other hand, is likely to involve oxidation of critical cysteine residues. The practical consequence of these findings is that the cellular prooxidant state that may arise in erythrocytes exposed to hydroxylamines can be further increased by activity loss of protective enzymes, which may decrease. the average life span of the red blood cell.

Keywords: hydroxylamines; glutathione: puroxidase: superoxide dismutase; catalase; glutathione S-trunsferase; glutathione reduc. tase: human ervthrocytes

levels of reduced glutathione (GSH) to function. Glutathione reductase (GR), is of importance in maintaining this necessary level of GSH. The pentose phosphate shunt provides the NADPH required for GR to convert oxidized glutathione (GSSG) to GSH. Despite this elaborate protective mechanism an imbalance between the formation and removal of radicals can lead to an increase in oxidative damage to the erythrocyte. Such damage might involve consequential damage to the protec. tive enzymes themselves. This would render the erythrocyte more vulnerable to subsequent oxidative exposure, especially since in this type of cells restoration of enzyme activities by the novo synthesis is not possible.

Previously, we described" that hydroxylamine: (HYAM) and some of its derivatives (predominantly O-alkyl amines] are able to induce oxidative damage in erythrocytes. For this reason. we were interested in the possible effects of hydroxylamines on the enzymatic antioxidant defense system in erythrocytes. If is known, and a lso confirmed by our 
own research. that radicals are formed in erythrocyte incubations with different hydroxylamines." ${ }^{10.11}$ Moreover, there are strong indications that hydroxylamines only induce oxidative stress if they are able to react with a haemoprotein.

In the present study, effects of six different hydroxylamines on the activity of human erythrocyte SOD, catalase, GPX, glutathione S-transferase (GST) and GR were investigated. Catalase was of special interest because this enzyme has a haematin nucleus, similar to that of haemoglobin. that is essential for the enzyme activity. ${ }^{12}=$ Since hydroxylamines are predominantly haematotoxic ${ }^{214}$ and hence are able to react with haemoproteins, an inhibitory effect on the catalase activity was expected. Regarding the glutatkione dependent enzymes (GPX. GST and GR), they all have cysteine residues at the active site of the enzyme."isto Such an accessible thiol group is likely to be susceptible to formation of proteinmixed disulphides or intramolecular disulphides. If these thiol groups are essential for activity this would be accompanied by an increase or decrease in the enzyme activity. In this paper, evidence is presented that enzymes bearing an accessible thiol essential for activity (i.e. GPX and GST) are indeed valnerable to oxidative stress induced by hydroxylamines.

\section{Materials and methods}

\section{Chemicals}

$\mathrm{N}$-dimethyl hydroxylamine HCl (NDMH. CAS-no: 16645-06-0). N-methyl hydroxylamine HCl (NMH. CAS-no: 4229-44-2) and O-methyl hydroxylamine HCI (OMH. CAS-no: 593-56-6) were purchased from Fluka Chemika-BioChemika (Buchs, Switzerland). N.O-dimethyl hydroxylamine $\mathrm{HCl}$ (NODMH. CAS-no: 1117-97-1). O-ethyl hydroxy!amine $\mathrm{HCl}$ (OEH. CAS-no: 624-86-2), hydroxylamine $\mathrm{HCl}$ (HYAM, CAS-no: 5470-11-1) and all other biochemicals were obtained from Sigma (St. Louis. USA). Only micro filtrated deionised water was used and all other chemicals were of analytical quality.

\section{Incubation conditions}

Human buffy coats, containing citric acid citrate. phosphate-dextrose (CPD) medium, were obtained from the local center for blood transfusion and stored at $4 \mathrm{C}$ until the next day. Samples were checked for viral infections before use. Erythrocytes. after removal of white blood cells and plasma. were washed twice in saline and resuspended in PBS (phosphate buffered saline: $15 \mathrm{~mm} \mathrm{KH}_{3} \mathrm{PO}_{4}$ / $\left.\mathrm{Na}_{-} \mathrm{HPO}_{4}+130 \mathrm{mM} \mathrm{NaCl}: \mathrm{pH}=7.4\right)$ to the original haematocrit. The cells were incubated with hydroxylamines (final concentration $0,1,2.5,5$ and $7 \mathrm{mM}$ ) in a shaking water bath at 80 r.p.m. for $1 \mathrm{~h}$ at $37 \mathrm{C}$. After incubation, erythrocytes were carefully washed twice with 9 volumes of PBS and packed by centrifugation $(2000 \mathrm{~g})$. The packed erythrocytes were lysed by adding five volumes of ice cold water. After $15 \mathrm{~min}$ storage on ice, cellular debris was removed by centrifugation at $10000 \mathrm{~g}$ for $10 \mathrm{~min}$. All experiments were performed three times on separate days and all incubations were performed in triplicate each day. Haemoglobin concentrations were determined with the haemoglobin cyanide procedure. ${ }^{17}$

\section{Analyses}

Catclase activity Catalase activity in haemolysates was determined as described by Aebi" measuring decomposition of $\mathrm{H}_{2} \mathrm{O}_{2}$ at $240 \mathrm{~nm}$ for $30 \mathrm{~s}$.

Glutathone peroxidase activity (GPX) GPX (EC 1.11.1.9) activity in haemolysates was determined using $\mathrm{H}_{2} \mathrm{O}_{2}(1.5 \mathrm{~mm})$ as substrate in the presence of GR $(2.4 \mathrm{U} / \mathrm{ml})$, GSH (10 mM. NADPH (1.5 mM)

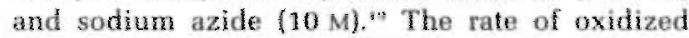
glutathione (GSSG) formation was measured by following the NADPH oxidation at $340 \mathrm{~nm}$ for 3 min. To eliminate NADPH oxidation by NADPHmethaemoglobin reductase in the haemolysate, oxyhaemoglobin is converted to the stable cyanmethaemoglobin form before determination of GPX.

Superoxidase dismutase activity (SOD) Haemo. globin was removed from the hemolysates by an adaptation of the Tsuchihashi chloroform-ethanol treatment." The upper aqueous phase was gently decanted and frozen at $-\mathbf{8 0} \mathrm{C}$ for later analysis. The assay of SOD is performed at $25 \mathrm{C}$ according to McCord and Fridovich. ${ }^{21}$ One unit of SOD activity is defined as the amount of enzyme that inhibits the rate of cytochrome $c$ reduction, generated by a stable xanthine-xanthine oxidase system, by $50 \%$ in a $3 \mathrm{ml}$ reaction volume. The SOD activity was calculated from a semilogarithmic plot as described by L'Abbé and Fisher. ${ }^{22}$

Glutathione S-transferase (GST) and glutathione reductase (GR) activity The assay of GST and GR were carried out as described previously.

\section{Statistical evaluation}

The significance of the concentration dependent change was evaluated using linear regression analysis. The regression model used corrects for inter-experiment variations in control values. For this reason the standard errors shown in the figures are given as the standard error of the mean difference (s.e.m.d.) between the sample value and its control (i.e. the corresponding value at concentration 0). 


\section{Results}

The activity of catalase and SOD was not significantly influenced by any of the six hydroxylamines. NODMH might be a possible exception since it

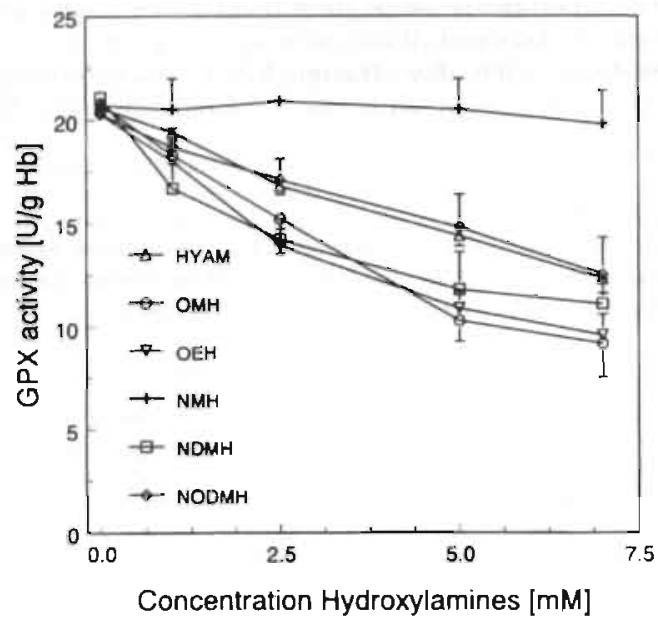

Figure 1 Effect of six hydroxylamines (HYAM, OMH, OEH, NMH. NDMH, and NODMH) on glutathione peroxidase (GPX) activity in human erythrocytes after incubation for $1 \mathrm{~h}$ at $37 \mathrm{C}$ The error bars represent the s.e.m. differences between sample value and control. Regression analyses showed significant decreases in GPX activity with increasing HYAM, OMH. OEH. NDMH and NODMH concentrations $(P<0.0001)$

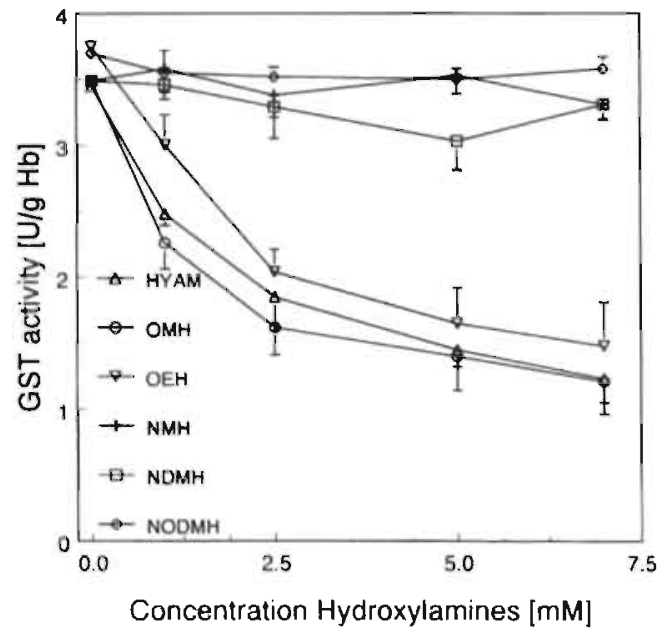

Figurs: 2. Effect of six hudroxvamines (HYAM. OMH. DEH NNH, NDMII, and NOOMH) on gitutathione S-transferase (CST

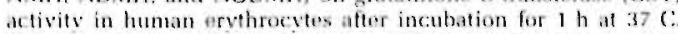
The ror bats represent thes s.e.It. diflerences between simplt value and control. Kegression analyses showed significan decreases in (iST activity with increasing HYAM. OMH and OEH conesentrations $(P<00001$ For HYAM and OEH: $P<0.0002$ for (IMIII] showed a small tendency towards impairment of SOD activity. All hydroxylamines, except $\mathrm{NMH}$. concentration dependently impaired the GPX activity $(P<0.0001$ for all five compounds; Figure 1$)$. $\mathrm{OMHi}$ and $\mathrm{OEH}$ gave the largest GPX inhibition (56\% and $53 \%$ at $7 \mathrm{~mm}$ respectively). inhibitory effects on GPX by NDMH, HYAM and NODMH were about $10 \%$ less $(47,41$ and $39 \%$ at $7 \mathrm{~mm}$ respectively). The GST activity, shown in Figure 2, was strongly impaired by HYAM, OMH and OEH. leading to over $60 \%$ reduction at the highest concentration tested $(P<0.0001$ for HYAM and $\mathrm{OEH} ; \quad P<0.0002$ for $\mathrm{OMH})$. For the other three hydroxylamines (NMH. NDMH and NODMH) no significant changes in the GST activity were found. In contrast, the GR activity was significantly decreased for NODMH $(P<0.0002)$ and NMH $(P<0.0001)$. For these two substances the GR activities in $7 \mathrm{~mm}$ incubations were about $20 \%$ lower than the $6.9 \mathrm{U} / \mathrm{g}$. $\mathrm{Hb}$ found in the control incubations (Figure 3). No GR activity changes were found for HYAM, OMH, OEH and NDMH.

\section{Discussion}

We recently demonstrated that HYAM and its $\mathrm{O}$ alkyl derivatives cause strong oxidative effects in erythrocytes (methemoglobin formation, total glutathione depletion and lipid peroxidation). ${ }^{7 "}$ The potency of NODMH and NMH in this respect was much smaller, and in the case of lipid peroxidation

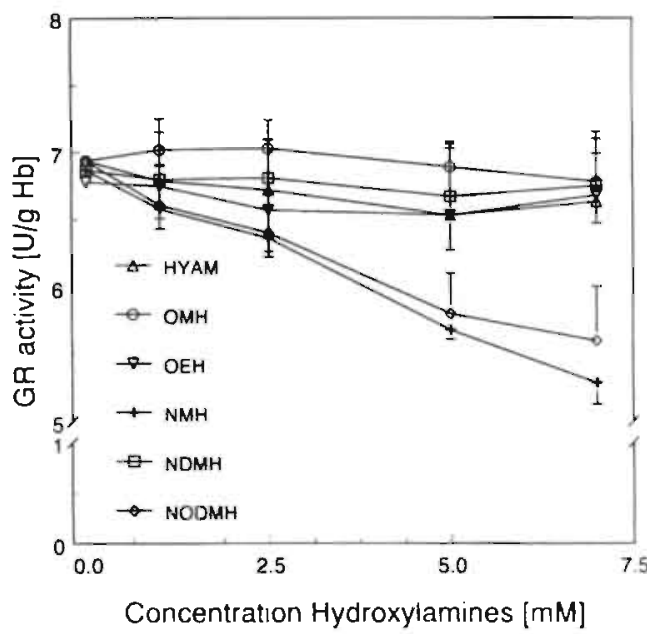

Figure 3 Efeet of sis hodroxilamines fHAM. (NiH, OH:H

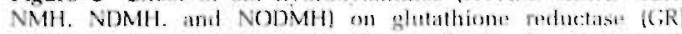
activits in human srothrocytes after incebation for $1 \mathrm{~h}$ at $37 \mathrm{C}$ The error bars represent the s.e.m. differences beswems sample value and control. Regrossion analvses showed significant decreases in CR activity with inseasing NMH and NODMH concentrations $(P<0.0001$ for NMH: $P<0.0002$ for NODMH) 
almost non-existent. These results indicate that the oxidation-reduction status in the erythrocyte changes upon exposure to hydroxylamines. Moreover. Stolze and Nohl' proved the existence of free radicals (nitroxide radicals) in erythrocyte incubations with hydroxylamines. Furthermore, evidence for hydrogen peroxide generation during the reaction of hydroxylamines with oxyhaemoglobin was found in our laboratory. All these findings indicate that hydroxylamines can induce oxidative stress in erythrocytes.

Erythrocytes have several lines of defence against oxidative stress. Antioxidant enzymes, including glutathione related enzymes, act as major scavengers of activated oxygen species in erythrocytes. ${ }^{2}$ Detrimental effects to these enzymes themselves can occur as a consequence of free radical reactivity. The present results show that of the erythrocyte antioxidant enzymes (catalase, SOD and GPX), the activity of SOD and catalase was not affected by any of the six hydroxylamines tested. This implies that the removal of radicals in erythrocytes by these two antioxidant enzymes is not changed through hydroxylamine exposure. The fact that the catalase activity is not impaired. is in contrast to what was expected beforehand. HYAM is known to decrease the catalase activity in liver of mice and forms a catalytically inactive complex with purified catalase. ${ }^{12.1323}$ Furthermore, hydroxylamines are predominantly haematotoxic, ${ }^{214}$ and together this leads to the conclusion that hydroxylamines are able to react with haemoproteins. However, the fact that a very large fraction (about $80 \%$ of the soluble protein) of the erythrocyte consists of a major haemoprotein, haemoglobin, probably explains why hydroxylamines do not impair the catalase activity in erythrocytes to a detectable level.

GST activity was largely decreased in HYAM. OMH and OEH treated samples. Five of the six hydroxylamines strongly inhibited the GPX activity in human erythrocytes. Inhibition of GPX is thought to involve oxidation of the selenocysteine residue at the active site of the enzyme. This is probably a result of the general shift in the cellular oxidationreduction status with concomitant oxidation of thiol groups and is confirmed by a decrease in reduced glutathione and by the concomitant inhibition of GST. another cysteine dependent enzyme tested in this study. It is known that cysteine residues are involved in the inactivation of GST-r by hydrogen peroxide. $z$ in general, any enzyme bearing an accessible thiol group essential for activity is susceptible to formation of proteinmixed disulphides or intramolecular disulphides by reacting with small disulphides, this being accompanied by an increase or decrease in the enzyme activity. The activity loss of GST and GPX occurring under oxidative conditions during hydro- xylamine exposure in erythrocytes is likely to involve such an oxidation of critical cysteine residues.

Catalase and SOD also have cysteine residues, ${ }^{\text {tw.m }}$ but in contrast to GST and GPX, in which thiol groups are essential for the catalytic activity, oxidation of SH-groups or partial alkylation does not affect the specific activity of catalase and SOD. ${ }^{20}$ GR contains fous cysteine residues of which two represent the redox-active dithiol located at the centre of the enzyme's catalytic site." In the oxidized enzyme (often called 'native' enzyme) these two thiols form a disulphide bridge; when the enzyme takes up two electrons, either from its substrate NADPH or from a chemical reductant, this disulphide is opened. Oxidation of these thiols would thus not lead to impairment of GR activity. Nevertheless. GR activity in erythrocyle incubations was impaired by two of the six hydroxylamines tested (NMH and NODMH). This inhibitory effect must therefore be explained by other modifications, possibly as a result of reaction of one or both of these thiols with NODMH or NMH themselves or with reactive intermediates formed during the erythrocyte incubations, yielding stable thioether like structures.

Another possible explanation for the loss of enzyme activity might be that enzyme-proteins participate in the formation of haemichromes. Haemichrome precipitation is part of the process of Heinz Body formation, ${ }^{12}$ that is known to occur in erythrocytes treated with hydroxylamines, ${ }^{n z a n}$ Haemichromes are precipitates of cross-linked haemoglobin that might also involve other proteins. It was previously described that inactivation of GPX activity following entrapment of purified $x$ or $\beta$ haemoglobin chains in human erythrocytes correlated well with the rate of haemoglobin chain oxidation." This enzynne inactivation is mainly present under those conditions where the autoxida= tion of the oxygenated chains is followed by transformation of the oxidised molecule into a haemichrome. This mechanism is likely to lead to decreases in enzyme activities of all enzymes with externally available sulfhydryl groups. The fact that the activities of both SOD, which has sulfhydry! groups on the protein surface, ${ }^{\text {" }}$ and catalase, which most likely also has such free sulhydryl groups, were not affected by any of the hydroxylamines renders this mechanism less plausible.

Under physiological conditions the production and removal of the various oxygen-derived radicals is a dynamic and complex process that results in a steady state with very low concentrations of these reactive molecules in the cell. Additional oxidative capacity introduced by the presence of hydroxylamines leads to increase in oxidative effects, ${ }^{2 n}$ decrease in the activity of the glutathione dependent antioxidant enzymes GPX and GST (probably 
caused by thiol oxidation) and decrease in GR activity (more likely caused by other modifications) which will all add to the development of a cellular prooxidant state, which may endanger the life spañ of the cell.

\section{References}

I Stolze K, Dakak A. Liu Y. Nohl H. Hydroxylamine and phenol-induced formation of methemoglobin and free radical intermediates in erythrocytes. Biochemical Phormacology 1996: 52: 1821-1829.

2 Gross P. Biologic activity of hydroxylamine: A Review. CRC Critical Reviews in Toxicology 1985: 14: $87-99$.

3 Jollow DJ, Grossman SI, Harrison JH. Hydroxylamines and hemolytic anemia. Advances in Experimenta! Medicine and Biology 1986; 573 582.

4 Bradshaw TP. McMillan DC, Crouch RK. Jollow DI. Identification of free radicals produced in rat erythrocytes exposed to hemolytic concentrations of pehnylhydroxylamine. Free Radical Biology and Medicine 1995: 18: $279-285$.

5 Rostorfer $\mathrm{HH}$, Cormier MJ. The formation of hydrogen peroxide in the reaction of oxyhemoglobin with methemoglobin-forming agents. Archives of Biochemistry and Biophysics 1957: 71: 235-249.

6 Mannervik B. Danielson UH. Glutathione transferases - structure and catalytic activity. Clinical Reviews in Biochemistry 1988; 23: 283337.

7 Spooren AAMG, Evelo CTA. In vitro haematotoxic effects of three methylated hydroxylamines. Archives of Toxicology 1997: 71: 299-305.

8 Spooren AAMG, Evelo CTA. Hydroxylamine treatment increases glutathione-protein and protein-protoin binding in human erythrocytes. Blood Cells. Molecules and Diseases 1997; 23: $323-336$,

9 Evelo CTA. Spooren AAMG. Bisschops RAG. Baars LGM. Neis. IM. Two mechanisms for toxic effects of hydroxylamines in human erythrocytes: involvement of free readicals and isk of potentiation. Blood Cells, Molecules and Diseases 1998: 24: $279=293$.

10 Stolze K. Nohl H. Detection of froe radicals as intermediates in the methemoglobin formation fiom oxyhemoglobin induced by hydroxylamine. Biochemical Pharmacology 1989; 38: 3055-3059.

11 Stolze K. Nohl H. Free radical intermediates in the oxidation of $\mathrm{N}$-methylhydroxylamine and N,Ndimethylhydroxylamine by oxyhemoglobin. Free Radical Research Communications 1990: 8: $123-$ 13!.

12 Keilin D. Hartree EF. On some properties of catalase haematiu. Proceedings Roval Sociely of London: Biological Sciences 1936: B121: $173-191$

13 Schombaum GR. Chance B. Catalase. In: The enzrmes Academic Press, London. pp. 363-408. 1976 .

14. Riemann H. On the toxicity of hydroxylamine. Acta Pharmacology 1950; 6: 285-292.

I5 Flohe $L$. The selenoprotein glutathione peroxidase. In: Glutathione chemical. biochemical and medical aspects. I. Wiley \& Sons. New York, pp. $643-731,1989$.

\section{Acknowledgements}

The authors are grateful to the 'Red Cross Bloodbank. South Limburg' for the collection of blood samples.

16 Schulz GE, Schirmer RH. Sachsenheimer W, Pai EF. The structure of the flavoenzyme glutathione reductase. Nalure 1978; 273: $120-124$.

17 van Kampen Ef. Zijlstra WG. Determination of hemoglobin and its derivatives. Advances in Clinical Ghemistry 1965: 8: 141-187.

18 Sinet PM, Barber P. Jerome $\mathrm{H}$. $\mathrm{H}_{2} \mathrm{O}_{2}$ production. modification of the glutathione status and methemoglobin formation in red blood cells exposed to diethyldithiocarbamate in vitro. Biochemical Pharmacology 1982: 31: 521-525.

19 Paglia DE, Valentine WN. Studies on the quantitative and qualitative characierization of erythrocyte glutathione peroxidase. The Journal of Laboratory and Clinical Medicine 1967; 70: $158-$ 169.

20 Tsuchihashi M. Zur Kenntnis der Blutkatalase. Biochemische Zeitschrifl 1923; 140: 63-112.

21 McCord IM. Fridovich I. Superoxide Dismutase: an enzymatic function for erythrocuprein (hemocuprein). Journal of Biological Chemistry 1969: 244: $6049-6055$.

22 L'Abbe MR. Fischer PWF. An automated method for the determination of Ca. Zn-Superoxide dismutase in plasma and erythrocytes using an ABA $-200^{\circ}$ discrete analyzer. Clinical Biochemistry 1986: 19: $175-178$.

23 Sies H. Biochemistry of oxidative stress. Angewandte Chemie. International edition in English 1986: 25: 1058-1071.

24 Adams DH. Roe FI. The action of some chemical substances an mouse liver catalase activity in vivo British Journal of Cancer 1953: 7: 509-518.

25 Blum 1. Fridovich 1. Inactivation of glutathione peroxidases by superoxide radical. Archives of Biochemistry and Biophysics 1985: 240: 500-508.

26 Evelo CTA. Hoorntje TM. Baars LGM. Beesten PD Decreased erythrocyte glutathone S-transferase activity is a useful oxidative siress parameter both in humans and in pigs. Abstract presented at the sth SFRR Biennial Meeting. Barcelona. October i- 5 1995.

27 Shen H. Tsuchida S. Tamai K. Sato K Identification of cysteine residues involved in disulfide formation in the inactivation of glutathione transferase P.form by hydrogen peroxide. Archives of Biochemistry and Biophysics 1993: 300: $137-141$.

28 Sies H. Oxidative stress. Academ ic Press. London. 1985.

29 Hallewell RA, et al. Thermostabilization of recombinant human and bovine CuZn superoxide dismutase by replacemen! of free cysteines. Biochentical and Biophysical Research Communications 1991: 181: 474-480.

30 Mörikofer-Zwuz S. et al. Heterogeneity of erythrocyte catalase. Correlations between sulfhydryl group content. chromatographic and electrophoretic properties. European lournal of Biochemistry 1969: 11: 49-57. 
31 Untucht-Crau R. Schirmer RH. Schrimer I. KrauthSiegol RL. Glutathione reductase from human erythrocytes. Amino-acid sequence of the structurally known FAD-binding domain. European lournal of Biochemistry 1981: 120: 407 419.

32 Peisach I. Blumberg WE, Rachmilewitz EA. The demonstration of ferrichrome intermediates in Heinz body formation following the reduction of oxyhaemoglobin $\mathrm{A}$ by acetylphenylhydrazine. Biochimica et Biophysica Acto 1975; 393: 404418.

33 Sinha D. Sleigh SD. Experimental production of Heinz Bodies in the pig. Toxicology and Applied Pharmacology 1986: 12: $435-439$.
34 Webster SH, Liljegren E). Zimmer DJ. Heinz body formation by certain chemical agents. Journal of Pharmacology and Experimental Therapeutics 1949: 95: $201-211$.

35 Grelloni F. Gabbianelli R. Falcioni G. Inactivation of glutathione peroxidase following hemoglobin oxidation. Biochemistry International 1991: 25: $789-795$.

36 Steinman HM. Superoxide dismutases: protein chemistry and structure-function relationships. In: Superoxide dismutase. CRC Press. Inc. Boca Raton, Florida, pp. 11-89, 1982. 


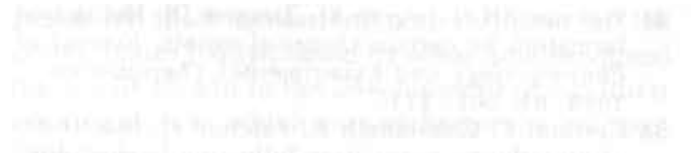


Chapter 5

Hydroxylamine Treatment Increases GlutathioneProtein and Protein-Protein Binding in Human Erythrocytes

Published in: Blood Cells, Molecules, and Diseases, 23: 323-336, 1997 


\title{
Hydroxylamine Treatment Increases Glutathione-Protein and Protein-Protein Binding in Human Erythrocytes
}

\section{Submitted 09/08/97}

(communicated by Ernst R. Jaffé, M.D., 09/09/97)

\author{
Anita A.M.G. Spooren, Chris T.A. Evelo
}

\begin{abstract}
Hydroxylamine is a direct-acting hematotoxic agent leading to hemolytic anemia in animals and man. The effect of hydroxylamine on the morphology, sulfhydryl status and membrane skeletal proteins of human erythrocytes were studied. Loss of reduced glutathione (GSH) from the red blood cells was directly proportional to the hydroxylamine concentration used. This loss of GSH was larger than the sum of the increase in the amounts of extracellular glutathione and intracellular oxidized glutathione (GSSG). The extracellular glutathione is mainly present as GSSG, which is in agreement with the fact that only GSSG is exported from the erythrocytes by membrane bound ATPases. Lack of GSSG export was not limited by decreased ATP levels in the erythrocytes and we concluded that the GSH that disappeared did not become available as intracellular GSSG. After reduction of the erythrocyte incubates the lost GSH was almost completely recovered indicating that the lost GSH is present in the cell as protein-glutathione mixed disulfides. Glutathione thus stored within the cell can be quickly recovered by combined thioltransferase and glutathione reductase activity when conditions become more favorable again. SDS-polyacrylamide gel electrophoresis of membrane ghosts from human red cells revealed changes in skeletal proteins with a smearing of bands 1,2 and 3 to the higher molecular weight end of the gel and the appearance of new monomeric and dimeric hemoglobin bands at about 16 and $30 \mathrm{kD}$. The observed alterations are probably a consequence of disulfide bridge formation between cellular proteins (mainly hemoglobin) and skeletal proteins as well as between hemoglobin monomers. Exposure of hydroxylamine to erythrocytes caused severe Heinz body formation but the outside morphology of the cells was only marginally altered. The described changes in sulfhydryl status of the red blood cells are likely to play a major role in the premature splenic sequestration of hydroxylamine-damaged erythrocytes.
\end{abstract}

Keywords: hydroxylamine, oxidalive damage, erythrocytes, glutathione. Heinz bodies

\section{INTRODUCTION}

Hemolytic anemia, the uncompensated loss of red blood cells from the circulation, is a primary effect of hydroxylamine $\left(\mathrm{H}_{2} \mathrm{NOH}\right)$ exposure in animals and man. This effect of hydroxylamine is commonly associated with methernoglobinemia, sulfhemoglobinemia. Heinz body formation and splenomegaly [for review, see (1)]. This hemolytic activity of hydroxylamine is probably a result of oxidative stress in the erythrocyte as demonstrated by total glutathione depletion and release of lipid peroxidation products from erythrocytes exposed to hydroxylamines in vitro $(2,3)$. This oxidative stress in red cells arises from cyclic oxidationreduction reaction that occurs between hydroxylamine and oxyhemoglobin, yielding a hydronitroxide radical $\left(\mathrm{H}_{2} \mathrm{NO} \bullet\right)$ and methemoglobin $(4,5)$. Apart from this reactive intermediatc, Stolze et al. (6) also observed low-level chemiluminescence resulting from the formation of a compound I type ferryl heme species. The latter is formed by

\footnotetext{
Depurtment of Phurmacology. Toxicslogy Section, University Maasticht, PO Box 616,6200 MD Maastricht. The Netherlands.

Reprint request to: Chris T.A. Evelo, Ph.D., Department of Pharmacology. Toxicology Section, University Maastricht, PO Box 616,6200 MD Maastricht, The Netherlands.

phone 0031433881231 , fax 0031433670940 . emaile evelo@ farmaco unimaas.nl
} 
hydrogen peroxide that is assumed to be the third reaction product in the reaction between hydroxylamine and oxyhemoglobin. Hydrogen peroxide generates other active oxygen species which, together with reactive hydroxylamine products, are capable of causing cellular damage.

Red cells are well equipped with several biological mechanisms to defend against intracellular oxidative stress (7). These biological mechanisms include activity of glutathione peroxidase, superoxide dismutase. and catalase. Glutathione is also an important component of the cell's antioxidant defense, acting both as a substrate for glutathione peroxidase in the removal of peroxides and directly as a free radical scavenger (8). Despite their well developed antioxidant defense system, erythrocytes can be oxidatively damaged. When this damage becomes extensive the cells can be removed from the blood circulation by the spleen. Removal of damaged erythrocytes can be a result of an alteration in the membrane skeletal protein structure and in membrane lipids [for review, see (9)]. These alterations induce a change on the external surface of the red cell, initiating its removal by splenic macrophages $(10,11)$. Incubation of red blood cells with hematotoxic concentrations of the hydroxylamine metabolite of dapsone induced major changes in membrane skeletal proteins which was accompanied by a change in cell morphology in rat (12) and human (13). This change in membrane skeletal proteins was due to formation of protein mixed disulfides and it was proposed that these oxidative changes are involved in the mechanism underlying dapsoneinduced hemolytic anemia. In in vitro studies on the effect of hydroxylamine on human erythrocytes, we observed methemoglobin formation, a loss of total glutathione and a release of lipid peroxidation products $(2,3)$. Since in these experiments the increase in extracellular total glutathione was smaller than the loss of total glutathione from erythrocytes, we suspect that formation of mixed disulfides may have occurred. Formation of mixed disulfides from proteins and glutathione is a general result of glutathione oxidation (14). Formation of disulfides from membrane proteins would lead to changes in electrophoretic behavior of these proteins and there was already some indication in the literature that a shift in electrophoretic pattern may indeed occur (15). Because the ability to deform is crucial to the red cell for performing its function of oxygen delivery, we became interested in the effects of hydroxylamine on red cell morphology and on the sulfhydryl status. Damage endured by red cell membrane proteins was investigated by gel electrophoresis. The results of the present study provide evidence that formation of protein mixed disulfides, does occur in intact erythrocytes when hydroxylamine is added. These oxidative modifications are likely to be a major factor in hydroxylamine-induced hemolytic anemia.

\section{MATERIALS AND METHODS}

\section{Chemicals}

Hydroxylamine $\mathrm{HCl}$ (hydroxylamine, CASno: $5470-11-1$ ) was obtained from Sigma (St. Louis Mo, USA). Molecular weight calibration kits, PhastGel homogeneous media 12.5, PhastGel SDS buffer strips and PhastGel silver kits were obtained from Pharmacia Biotech (Uppsala, Sweden). All other chemicals and reagents were: of analytical grade and purchased from commercial sources. Only micro filtrated deionized water was used.

\section{Incubation Conditions}

Human buffy coats, containing citrate-phosphate-dextrose (CPD) as anticoagulant, were obtained from the local center for blood transfusion and stored at $4 \mathrm{C}$ until the following day. Samples were checked for viral infections before use. Erythrocytes, after removal of white blood cells and plasma, were washed twice in saline and resuspended to the original hematocrit concentration in phosphate buffered saline (PBS) comprising $15 \mathrm{mM} \mathrm{KH}_{2} \mathrm{PO}_{4} / \mathrm{Na}_{2} \mathrm{HPO}_{4}$ and $130 \mathrm{mM} \mathrm{NaCl}$, $\mathrm{pH}$ 7.4. After 5-min preincubation at $37 \mathrm{C}$, various concentrations of hydroxylamine dissolved in phos- 
phate buffer $(0.1 \mathrm{M}$ pH 7.4; $0.2 \mathrm{ml})$ were added to red cell suspensions $(2 \mathrm{ml})$ and allowed to incubate in a shaking water bath at $80 \mathrm{rpm}$ for 1 or $2 \mathrm{hr}$ at $37 \mathrm{C}$. After incubation, the red cell suspension was centrifuged at $2000 \mathrm{Lg}$. The supernatant was used to determine glutathione concentrations and hemoglobin content for the degree of hemolysis. The degree of hemolysis was also used to correct the glutathione values in the supernatant for increases due to hemolysis. Hemoglobin concentrations were determined with the hemoglobin cyanide procedure (16). After removal of the supernatant, erythrocytes were carefully washed twice with 9 volumes of PBS and packed by centrifugation $(2000 \mathrm{~g})$. All experiments were performed three times on separate days and all incubations were performed in triplicate each day.

Assay of ATP

Protein in erythrocytes $(0.3 \mathrm{ml})$ was precipitated by addition of $15 \%$ cold perchluric acid $(0.15 \mathrm{ml})$ and centrifuged at $10,000 \mathrm{~g}$ for $3 \mathrm{~min}$. An aliquot $(0.2 \mathrm{ml})$ of the supernatant was neutralized with $0.1 \mathrm{ml}$ sodium hydroxide $(1.5 \mathrm{M})$ and ATP levels were measured according to Beutler (17).

\section{Assay of Total Glutathione and Oxidized Glutathione (GSSG)}

Erythrocytes $(0.1 \mathrm{ml})$ were lysed with $0.3 \mathrm{ml}$ cold water and after $15 \mathrm{~min}$ on ice protein was precipitated by addition of $10 \%(w / v)$ trichloroacetic acid (TCA; $0.4 \mathrm{ml}$ ). To determine total glutathione in supernatants, $0.5 \mathrm{ml}$ supernatant was precipitated with $0.5 \mathrm{ml} \mathrm{TCA} \mathrm{(10 \% ).} \mathrm{To} \mathrm{estimate} \mathrm{protein-}$ glutathione disulfides levels in incubations with hydroxylamine, erythrocytes $(0.1 \mathrm{ml})$ were lysed with $0.3 \mathrm{ml}$ cold water and after $15 \mathrm{~min}$ on ice. sodium borohydride ( $32 \mathrm{mg}$ ) was added followed by $50 \mu \mathrm{l}$ of $\mathrm{n}$-octanol to release bound glutathione from protein. After $10 \mathrm{~min}$ incubation at room temperature with continuous mixing, protein was precipitated and the surplus sodium borohydride was removed by slow addition of $25 \%(w / v)$ TCA $(0.8 \mathrm{ml})$. After centrifugation total glutathione was measured in the clear TCA supernatant. To measure total glutathione in erythrocytes, in supernatants and in borohydride treated erythrocytes, 0.1 $\mathrm{ml}$ of the clear TCA supernatants was added to 0.8 $\mathrm{ml}$ of phosphate buffer $(0.1 \mathrm{M}, \mathrm{pH} 7.4)$ and stored at minus $20 \mathrm{C}$ until determination. Total glutathione was measured using the cyclic oxidationreduction method essentially as described by Anderson (18). To determine oxidized glutathione (GSSG) levels in supernatant and erythrocytes $1.5 \mathrm{ml}$ blood was treated with an excess of N-ethylmaleimide $(0.25 \mathrm{M} ; 0.3 \mathrm{ml})$ to prevent oxidation of glutathione. After 10 min incubation on ice erythrocytes were separated from supernatant by centrifugation $(2000 \mathrm{~g})$. Protein in supernatant $(0.6 \mathrm{ml})$ and erythrocytes $(0.6 \mathrm{ml})$ was precipitated by addition of $20 \%$ (w/v) trichloroacetic acid $(0.4 \mathrm{ml})$. After centrifugation at $2000 \mathrm{~g}$ for $10 \mathrm{~min}, 0.5 \mathrm{ml}$ of the clear TCA supernatant was extracted three times with about $5 \mathrm{ml}$ of ice-cold ether. Excess ether was removed with a gently stream of nitrogen and GSSG concentrations were determined according to Srivastava and Beutler (19). Reduced glutathione (GSH) levels were calculated by subtracting GSSG concentrations from total glutathione concentrations.

\section{Preparation of Red Cell Ghosts}

Red cell ghost were prepared according to the method of Dodge et al. (20). Packed washed red cells ( $1 \mathrm{ml}$ ) were lysed in $28 \mathrm{ml}$ phosphate buffer (10 $\mathrm{mM} \mathrm{NaH}_{2} \mathrm{PO}_{4}$. $6.65 \mathrm{mM} \mathrm{Na} \mathrm{HPO}_{4} ; \mathrm{pH} \mathrm{7.4).}$ The ghosts were packed by centrifugation at $22,000 \mathrm{~g}$ for $20 \mathrm{~min}$. The supernatant was removed by aspiration and the ghosts were washed two times with the same phosphate buffer and finally two times with a two fold dilution of this buffer. After this the control (i.e., untreated) cells yielded creamy white ghosts.

\section{SDS-Polyacrylamide Gel Electrophoresis (SDS-PAGE)}

Analysis of membrane proteins was performed with a PhastSystem automated electrophoresis and 
staining system (Pharmacia Biotech; Uppsala, Sweden). Red cell ghosts were solubilised by the addition of $100 \mu \mathrm{l}$ solubilisation buffer $(2.5 \%$ SDS, $1 \mathrm{mM}$ EDTA, $10 \mathrm{mM}$ Tris- $\mathrm{HCl}, \mathrm{pH} 7.0$ ) to the ghosts obtained from $1 \mathrm{ml}$ packed erythrocytes. Before resolving the solubilised proteins on the SDS-PAGE gel they were 10 times diluted in solubilisation buffer and heated at $100 \mathrm{C}$ for $5 \mathrm{~min}$. Equal aliquots $(1 \mu \mathrm{l})$ of the solubilised proteins (treated and untreated) were resolved on PhastGel homogeneous media consisting of $12.5 \%$ monomer with $2 \%$ crosslinker as described by Pharmacia separation technique file 111 . Gels were stained with silver according to Pharmacia development technique file 210 . To identify the membrane proteins, SDS-PAGE low and high MW marker proteins (Pharmacia) were also applied.

\section{Assay for Heinz Body Formation}

After 1 hr incubation $0.5 \mathrm{ml} 1 \%(\mathrm{w} / \mathrm{v})$ brilliant cresyl blue in saline was added to $1 \mathrm{ml}$ blood. Heinz bodies were colored during subsequent incubation at room temperature for $1 \mathrm{hr}$. After incubation samples were dried and evaluated by light microscopy $(1000 \mathrm{x})$ under oil immersion (2]).

\section{Preparation of Cells for Scanning Electron Microscopy}

Red blood cells were fixed in a solution consisting of $1 \%$ glutaraldehyde in phosphate buffer $(0.1 \mathrm{M}, \mathrm{pH} 7.4)$ until the red cells have deposited. The cells were then washed twice in micro filtrated deionized water. dehydrated in air and coated with gold. The samples were examined in a Philips 505 scanning electron microscope at $15 \mathrm{kV}$ accelerating voltage.

\section{Statistical Analysis}

The significance of the concentration dependent change caused by hydroxylamine was evaluated using linear regression analysis. The regression model used corrects for inter-experiment variations in control values. For this reason the standard errors shown in the figures are given as the standard error of the mean difference between the sample value and its control (i.e., the corresponding value at concentration 0 ).

\section{RESULTS}

\section{Erythrocyte Sulfhydryl Status}

Changes in intracellular glutathione (total glutathione, GSH and GSSG) by hydroxylamine in human erythrocytes are shown in figure 1. The GSH concentration was significantly decreased from $695 \mathrm{nmol} / \mathrm{ml}$ erythrocyte suspension without hydroxylamine to $450 \mathrm{nmol} / \mathrm{ml}$ erythrocyte suspension at $7.0 \mathrm{mM}$ hydroxylamine $(\mathrm{P}<0.0001)$. Intracellular erythrocyte GSSG was found to increase with higher concentrations of hydroxylamine. This increase $(10 \mathrm{nmol} / \mathrm{ml}$ erythrocyte suspension at $7 \mathrm{mM}$ hydroxylamine) was small compared to the loss of GSH but it was highly significant ( $P<0.005$ ). The loss of intracellular GSH was also not matched by appearance of extracellular total glutathione (Figure 2). The increase in extracellular total glutathione was also very significant $(\mathrm{P}<0.0001)$ but small $(7 \mathrm{nmol} / \mathrm{ml}$ erythrocyte suspension at $7 \mathrm{mM}$ hydroxylamine) when compared with the GSH loss from the erythrocyte and is mainly present as GSSG (Figure 2). From literature it is known that erythrocyte GSSG is exported by an ATP dependent transport system (22). To verify that low ATP levels in one day old washed erythrocytes were not limiting for GSSG export, ATP concentrations also were measured in the hydroxylamine incubations. In these incubations the levels of ATP were not influenced by hydroxylamine and addition of glucose $(20$ $\mathrm{mM}$ ) to the medium also had no effect (Table 1). Moreover, the ATP levels in the incubations with hydroxylamine fell in the normal range for healthy Caucasians (4.23 $\pm 0.29 \mu \mathrm{mol}$ of ATP/g Hb) (17).

To study mixed disulfide formation, erythrocyte incubates were treated with sodium borohydride (Figure 3). The harsh chemical conditions during reduction, borohydride removal and pro- 
tein precipitation, led to a total glutathione loss of about $30 \%$ in the control samples $(0 \mathrm{mM}$ hydroxylamine). The decrease in remaining total glutathione concentrations related to hydroxylamine treatment did almost completely disappear upon reduction. Of the initial $35 \%$ decrease in total glutathione in $7 \mathrm{mM}$ hydroxylamine incubations only $10 \%$ remained after borohydride treatment. The difference in the slope of remaining total glutathione concentrations versus hydroxylamine concentra-tion curves with and without borohydride treatment was statistically different $(\mathrm{P}<0.0001)$.

\section{Erythrocyte Membranes}

Macroscopically, membranes from hydroxylamine treated human erythrocytes were greenishbrown in color and were more adherent to test tubes and to each other in comparison with membranes from untreated human erythrocytes. Membrane protein electrophoresis of erythrocytes incubated with hydroxylamine for $1 \mathrm{hr}$ and normal human erythrocytes are shown in figure 4 (lane 1 and 2 respectively). Equal volumes $(1 \mu \mathrm{l})$ of hydroxylamine treated and untreated solubilised protein fractions were applied to the gel. Since in the hydroxylamine treatment sample extra proteins have adhered to the membrane proteins, the total amount of protein in the two lanes was not equal. The bands were identified by their $\mathrm{MW}$ range and numbered accordingly to Fairbanks et al. (23). The spectrin-ankyrin region (band 1 and 2 , MW ca $250 \mathrm{kD}$ ), the relatively broad band 3 (MW ca $90 \mathrm{kD}$ ), band 4 (MW ca $75 \mathrm{kD})$, band 5 (actin, MW ca $43 \mathrm{kD}$ ) and band 6 (MW ca $35 \mathrm{kD}$ ). Residual hemoglobin ( $\mathrm{Hb}, \mathrm{MW} 16 \mathrm{kD}$ ) was also observed.

Incubation of human erythrocytes with hydroxylamine for $1 \mathrm{hr}$ changed the SDS-PAGE patterns of skeletal membrane proteins. Particularly prominent were increased amounts of hemoglobin monomer $(16 \mathrm{kD})$ and a new broad band at $30 \mathrm{kD}$, probably consisting of hemoglobin dimers. Beside this effect the band 3 region became somewhat broader and a smearing of band 1 and 2 toward the higher molecular weight end of the gel was also visible in erythrocytes incubated with hydroxylamine.

\section{Erythrocyte Morphology}

Occurrence of Heinz bodies in human erythrocytes is shown in figure 5 after 1 hr incubation in the absence (A) and presence (B) of hydroxylamine $(2.5 \mathrm{mM})$. In normal red cells a few Heinz. bodies were visible $(<5 \%)$. Exposure of erythrocytes to hydroxylamine induced extreme formation of Heinz bodies (80-90\%). Hydroxylamine induced Heinz bodies had single foci in most cases but double foci of additional precipitated hemoglobin did also occur. Cell lysis, as measured by release of hemoglobin into the medium, was increased in hydroxylamine treated erythrocytes

Table 1. Cell lysis and ATP levels in human erythrocytes

\begin{tabular}{|c|c|c|c|}
\hline \multirow{2}{*}{$\begin{array}{l}\text { Colkintrution } \\
\text { hydroxylamine (mM) }\end{array}$} & \multicolumn{2}{|c|}{ Without glucose } & \multirow{2}{*}{$\begin{array}{c}\text { With glucose }(20 \mathrm{mM}) \text { ATP } \\
\text { levels }(\mu \mathrm{mol} / \mathrm{g} \mathrm{Hb})\end{array}$} \\
\hline & Cell lysis (mg Hb/l) & ATP leveis $(\mu \mathrm{mol} / \mathrm{g} \mathrm{Hb})$ & \\
\hline 0 & $590 \pm 10$ & $4.47 \pm 0.04$ & $4.40 \pm 0.06$ \\
\hline 1 & $670 \pm 20$ & $4.11 \pm 0.07$ & $4.00 \pm 0.07$ \\
\hline 2.5 & $750 \pm 10$ & n.d. & n.d. \\
\hline$s$ & $880 \div 10$ & n.d. & n.d. \\
\hline 7 & $910 \pm 10$ & $4.42 \pm 0.04$ & $4.34 \pm 0.03$ \\
\hline
\end{tabular}

n.d. $=$ not done

All values were determined after 1 hr incubation of arythrocytes with hydroxylamine a $37 \mathrm{C}$. The values are mean $\pm S E$ and each experiment consisted of incubations in triplicate. Regression analysis showed significane increases in cell lysis with increasing hydroxylamine concentration $(\mathbf{P}<0.0001)$. 


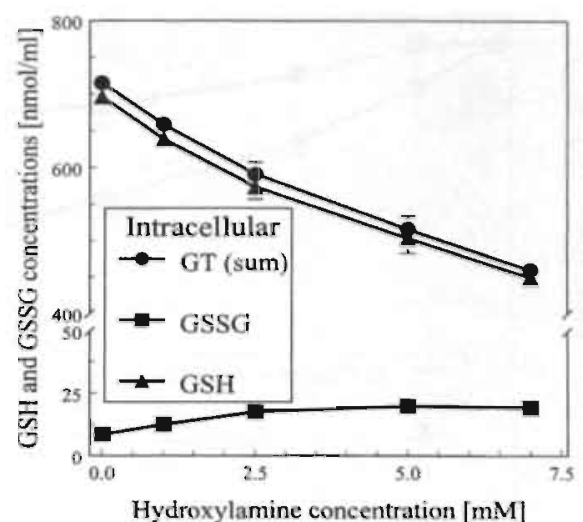

Figure 1. Effects of hydroxylamine on intracellular glutathione concentrations in human erythrocytes after incubation for 1 hr at 37 C. Total glutathione (GT) and oxidized glutathione (GSSG) concentrations were expressed per $\mathrm{ml}$ erythrocyte incubate. Reduced glutathione (GSH) levels were determined by subtraction of GSSG from total glutathione levels. The error bars represent the standard error of the mean differences between sample value and control. The error bars of some of the data fall within the data points. Regression analysis showed significant decreases in total glutathione and GSH levels $(\mathrm{P}<0.0001)$ and significant increases in GSSG levels with increasing hydroxylamine concentrations $(\mathrm{P}<0.005)$.

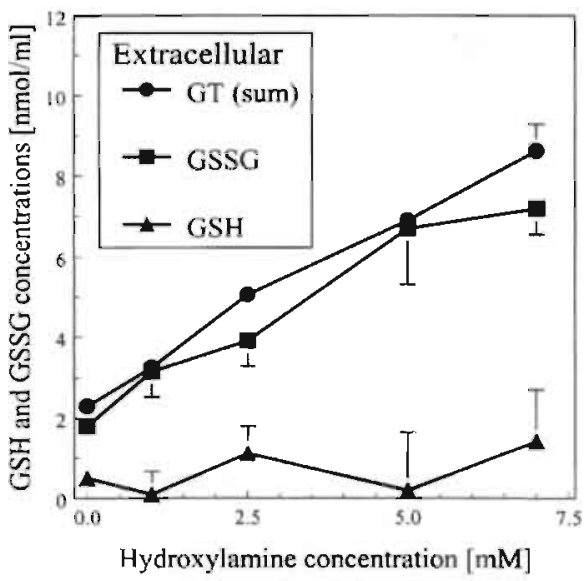

Figure 2. Increases in extracellular glutathione after treatment of human erythrocytes with hydroxylamine for $1 \mathrm{hr}$ at $37 \mathrm{C}$. Total glutathione (GT) and oxidized glutathione (GSSG) concentrations were expressed per ml erythrocyle incubate and were corrected for glutathione loss as a consequence of hemolysis. Reduced glutathione (GSH) levels were determined by subtraction of GSSG from total glutathione levels. The error bars represent the standard error of the mean differences between sample value and control. The error bars of some of the data fall within the data points. Regression analysis showed significant increases in total glutathione and GSSG levels with increasing hydroxylamine concentrations $(\mathbf{P}<0.0001)$. 


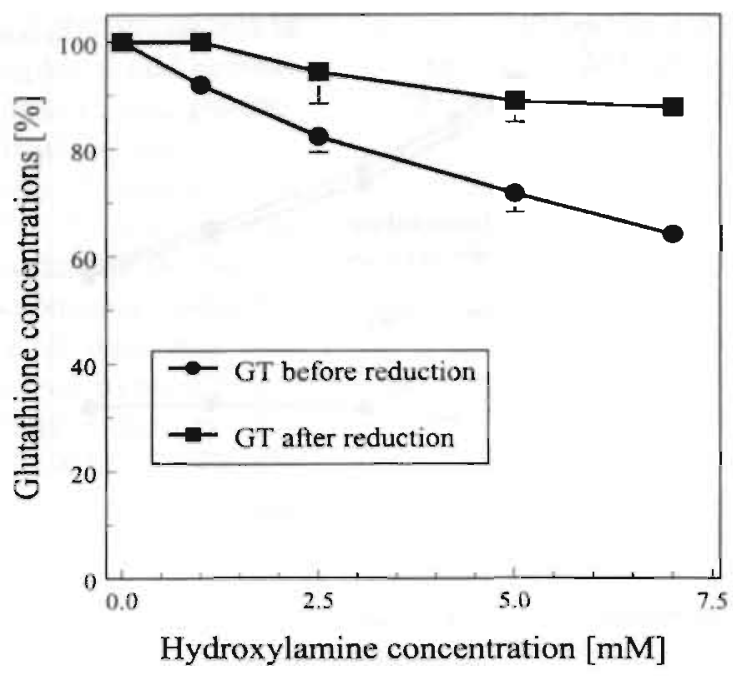

Figure 3. Effect of hydroxylamine on sulfhydryl status in human erythrocytes after incubation for $1 \mathrm{hr}$ at $37 \mathrm{C}$. Total glutathione (GT) levels were determined before and after reduction of protein-glutathione disulfides with sodium borohydride. The control total glutathione value before reduction was $715 \mathrm{nmol} / \mathrm{ml}$ erythrocyte incubate and after reduction the control total glutathione value was $500 \mathrm{nmol} / \mathrm{ml}$ erythrocyte incubate. The error bars represent the standard error of the mean differences between sample value and control. The error bars of some of the data fall within the data points. Regression analysis showed significant decreases in total glutathione levels before and after reduction with increasing concentrations $(\mathrm{P}<0.0001$ and $\mathrm{P}<$ 0.001 respectively) and they were also significant different $(\mathrm{P}<0.0001)$.

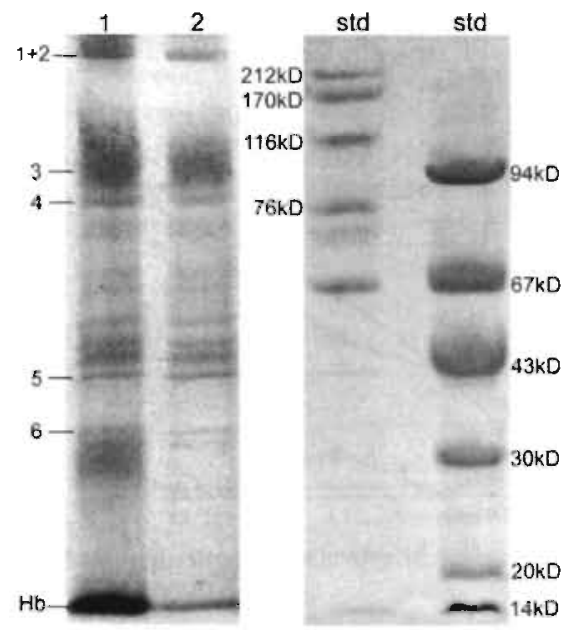

Figure 4. Effects of hydroxylamine on human erythrocyte membrane protcins after I hr incubation at $37 \mathrm{C}$. Lane 1. erythrocytes incubated with $7 \mathrm{mM}$ hydroxylamine: lane 2, control erythrocytes. The cells were washed, and membrane ghosts were prepared and washed exhaustively to remove unbound hemoglobin. The ghosts were then solubilised in SDS and subjected to PAGE. The gels were stained with silver. The protein bands were identified by their molecular weights and are numbered according to the system proposed by Fairbanks et al. (23). 

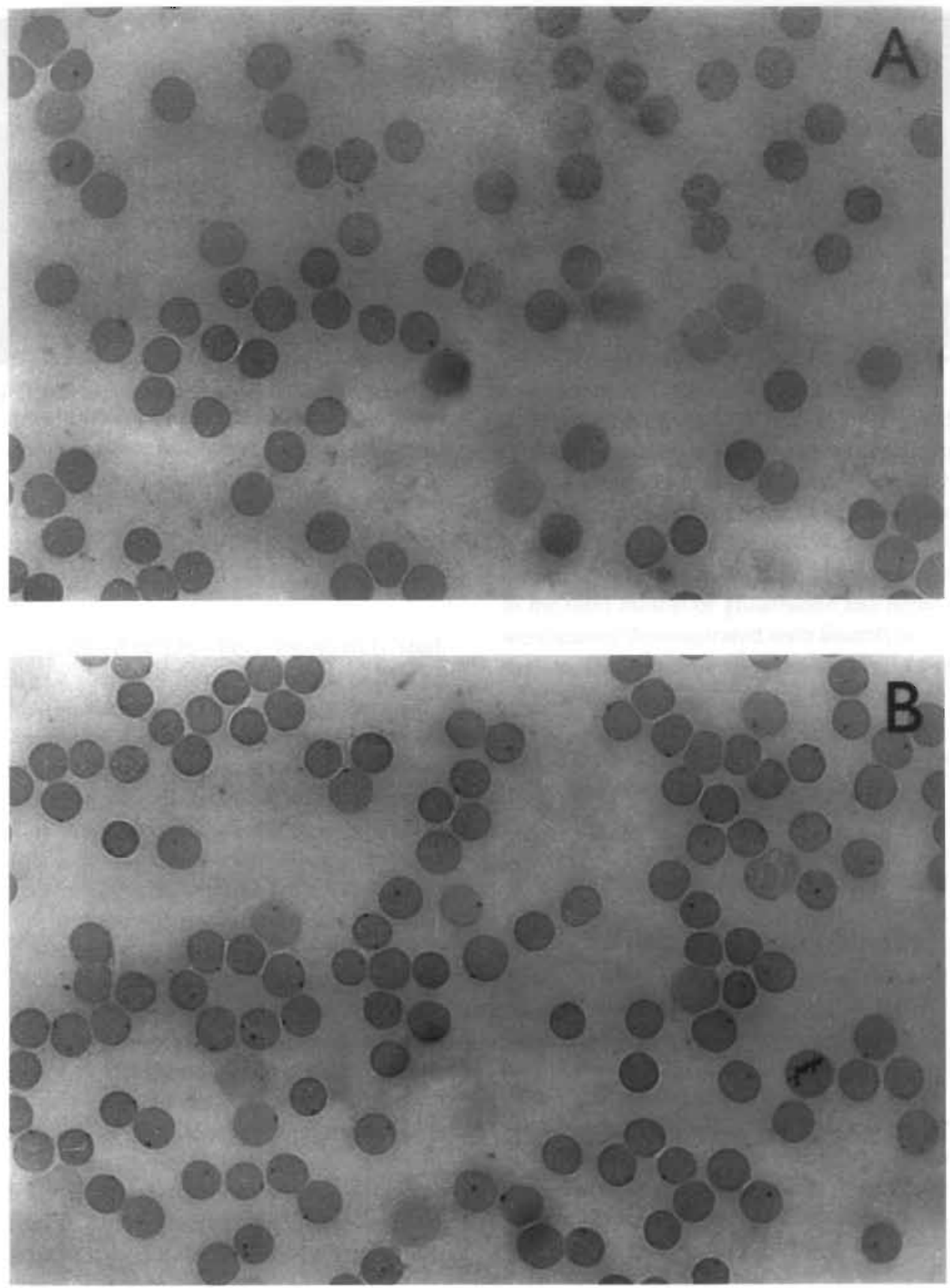

Figure 5. Presence of Heinz bodies in human erythrocytes after incubation for $1 \mathrm{nr}$ at $37 \mathrm{C}$ with hyaroxylamine. Atter addition of brilliant cresyl blue the erythrocytes were incubated at room temperature for $60 \mathrm{~min}$. (A) control erythrocytes (PBS) and (B) erythrocytes in the presence of hydroxylamine $(2.5 \mathrm{mM})$. Magnification $1000 \mathrm{x}$. 

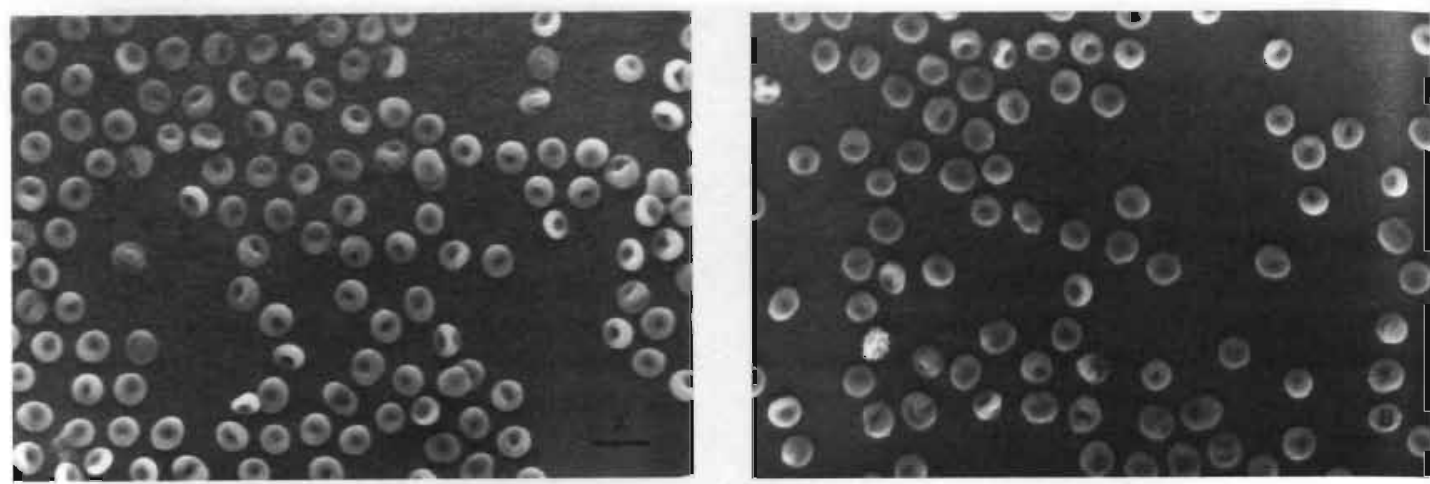

Figure 6. Effect of hydroxylamine on human erythrocyte morphology. Scanning electron micrograph of (A) control erythrocytes (PBS) and (B) erythrocytes exposed to $7 \mathrm{mM}$ hydroxylamine for $2 \mathrm{hr}$ at $37 \mathrm{C}$. The bar represents $10 \mu \mathrm{m}$.

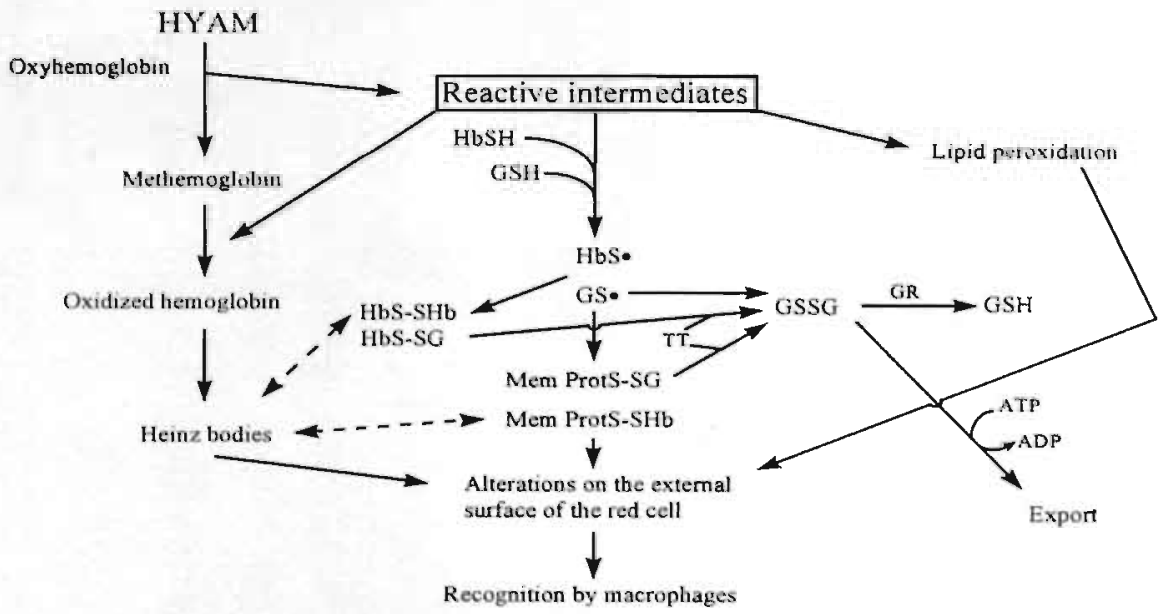

for intrasplenic sequestration

Figure 7. Schematic representation of the proposed mechanisms for hydroxylamine (HYAM) induced hemolytic anemia in man. Hydroxylamine, HYAM: GSH, reduced glutathione: GSSG, oxidized glutathione: HbSH, hemoglobin: Mem ProtS-SHb. membrane protein-hemoglobin mixed disulfides; Mem ProtS-SG, membrane protein-glutathione mixed disulfides: TT, thioltransferase; GR, glutathione reductase. For description see discussion. 
with about $45 \mathrm{mg} \mathrm{Hb} / \mathrm{l}$ for each $\mathrm{mM}$ hydroxylamine added (Table 1; $\mathrm{P}<0.0001$ ). This increase in cell lysis is however not very large. The morphological appearance of human erythrocytes after 2 hr of incubation with $7 \mathrm{mM}$ hydroxylamine were compared with control incubation by scanning electron microscopy (Figure 6). Erythrocytes from control incubations exhibited a normal biconcave appearance (Figure 6A). The morphology of erythrocytes exposed to hydroxylamine was altered but the amount of altered cells was not very high (Figure 6B). This altered morphology is characterized by loss of their biconcave shape. The erythrocytes exhibited moderate protuberances on the surface of the cell and in advanced stages were similar to echinocytes as described by Bessis (24).

\section{DISCUSSION}

The red blood cell has been extensively studicd both as a source of free radicals and as a target for oxidative damage. This is largely becausc a wide varicty of drugs and xenobiotics that can undergo oxidation-reduction reactions have been found to cause red cell destruction and hemolytic anemia. Interaction between the xenobiotic and humoglobin is very important in the process, which is usually characterized by hemoglobin oxidation to methemoglobin and formation of a radical ntermediate. This is also true for the hemolytic compound hydroxylamine, that causes methemoglobin formation with concomitant production of a hydronitroxide radical and hydrogen peroxide $(4,5)$. Methemoglobin formation does not necessarily lead to red blood cell destruction, as evidenced by the absence of hemolysis in patients with methemoglobinemia induced by nitrites or in methemoglobin reductase deficiency (25). The oxidative changes are often accompanied by oxidative denaturation of hemoglobin to give intracellular inclusions or Heinz bodies. This was also the case in human erythrocytes treated with hydroxylamine (Figure 5), indicating that oxidative denaturation of hemoglobin did occur in our experiments. As a consequence of hemoglobin denaturation the porphyrin ring can be opened whereupon release of redox-active iron occurs. Release of iron from hemoglobin in erythrocyte incubations with hydroxylamine was indeed observed by Stolze et al. (5). This free iron, and also heme iñon, can react with reactive oxygen species (like hydrogen peroxide) to generate the highly reactive hydroxyl radical and ferry] heme species (26). As mentioned before such a highly reactive ferryl heme species was indeed observed in incubations with hydroxylamine and oxyhemoglobin (6). When this information is combined, one can conclude that a number of potentially toxic reactive species are generated in erythrocytes exposed to hydroxylamine. These reactive species can react with lipids in the membrane to cause lipid peroxidation or with cellular sulfhydryl groups to generate thiyl radicals, which in turn, can attack the membrane proteins. Secondary radicals such as the thiyl radical of glutathione and hemoglobin were earlier demonstrated with hemolytic concentrations of phenylhydroxylamine (27).

The present study provides experimental evidence that hydroxylamine is able to form mixed disulfides in human erythrocytes. A large amount of intracellular GSH was lost and this loss was not compensated by increases in intracellular GSSG or extracellular total glutathione. This extracellular glutathione was mainly oxidized which is in agreement with the fact that only GiSSG is exported from the erythrocyles by membrane bound ATPases (22). This lack of extracellular glutathone was not due to limiting ATP levels under the assay conditions used. ATP levels were normal during incubations with hydroxylamine and addi. tion of glucose did not increase them (Table 1). We conclude that the GSH that disappears from the erythrocytes did not come available as intracellulat GSSG. The finding that some GSH is also present extracellular can be explained by GSH leakage from cells with damaged membranes. When this damage is marginal GSH leakage may be larger than hemoglobin leakage for which corrections were made. After reduction of the erythrocyte incubates with sodium borohydride the lost glutathione was almost completely recov- 
ered. This indicates that the GSH content of the cells is rapidly lost with concomitant increase in the formation of mixed disulfides between glutathione and the protein of the cell. A small fraction $(10 \%)$ of the glutathione was not recovered. It is possible that this part of the glutathione is converted to sulfonic acid as hypothesized by Winterbourn and Metodiewa (28).

The major feature of the SDS-PAGE patterns was an appearance of hemoglobin dimers and monomers at 30 and $16 \mathrm{kD}$. The occurrence of such monomeric and polymeric forms of hemoglobin in treated cells was not really expected because both treated and control cells were converted to ghosts and were thoroughly washed prior to solubilisation of the membranes with SDS. In accordance with this only low levels of monomeric hemoglobin were present in the control samples while polymeric hemoglobin was completely absent. Grossman et al. (12) also found monomeric and polymeric forms of hemoglobin in membrane fractions of dapsone hydroxylamine treated erythrocytes. They proposed two explanations which are also applicable in this situation. Hemoglobin is the major cytoplasmic protein in the erythrocyte and therefore most of the glutathione will be bound to hemoglobin. Mixed disulfide formation between glutathione and hemoglobin would lead to partial loss of the normal tertiary and quaternary structure of the hemoglobin. As a consequence more lipid-soluble regions come to the surface of the hemoglobin and they generate stronger hydrophobic interactions with the lipid matrix of the membrane and hence form membrane-bound hemoglobin. The alternative is that hemoglobin units bind via disulfide linkage to the skeletal proteins and that noncovalently bound hemoglobin adheres to this covalently linked hemoglobin as a amorphous mass, similar to a Heinz body. Heinz bodies were in fact detected in blood samples treated with hydroxylamine (Figure 5). Moreover, there is evidence that denaturated hemoglobin can become attached to the inner layer of the red cell membrane causing clustering of membrane protein band 3 (29). The precise nature of the binding of Heinz bodies to the internal surface of the membrane is not clear and different mechanisms are suggested including disulfide bonding (30) and hydrophobic bonding (31). Binding of hemoglobin to the region of band 3 could explain the fact that the band 3 region became somewhat broader after treatment with hydroxylamine. Next to the appearance of membrane associated hemoglobin aggregates a smearing of the skeletal membrane protein bands 1 and 2 to the higher molecular weight end of the gel was present. This smearing is probably a consequence of disulfide bridge formation between cellular proteins (mainly hemoglobin) and the skeletal membrane protein bands 1 and 2 causing a broadening of the bands since the molecular weight of hemoglobin is relatively small in comparison to that of bands 1 and 2. Since hemoglobin and membrane protein-hemoglobin dimers with disulfide bridges have modified non-linear quarternary structures, their behavior on SDS-PAGE will not be ideal resulting in smearing.

The current study shows that the glutathione oxidized during treatment with hydroxylamine is mainly converted to glutathione-hemoglobin mixed disulfides. This formation of glutathione-protein mixed disulfides will act as a storage of oxidized glutathione. This is a favorable condition for the cell since it allows the cell to maintain the high GSH/GSSG ratio needed to maintain the redox couple for glutathione peroxidase activity without actual export of most of the GSSG. Oxidized glutathione thus stored within the cell can be recovered by combined thioltransferase [TT, reaction 1, (32)] and glutathione reductase activity (GR, reaction 2) when conditions become more favorable again

$$
\begin{aligned}
& \text { Protein }-\mathrm{SSG}+\mathrm{GSH} \stackrel{\text { TT}}{\longrightarrow} \text { Protein }-\mathrm{SH}+\mathrm{GSSG} \\
& \mathrm{GSSG}+\mathrm{NADPH}+\mathrm{H}^{+} \stackrel{\text { GR. }}{\longrightarrow} 2 \mathrm{GSH}+\mathrm{NADP}^{+}
\end{aligned}
$$

Erythrocytes are not able to import glutathione directly over the membrane (33) and are also not able to recover the glutamic acid or glycine moiety of glutathione from exported S-conjugates or GSSG because they lack $\gamma$-glutamyl transpepti- 
dase activity (34). Moreover, they cannot utilize $\gamma$-glutamyl cycle activity for efficient amino acid uptake since $\gamma$-glutamyl transpeptidase is an important enzyme in this cycle (35). This means that erythrocytes must synthesize new glutathione to compensate for exported glutathione while they will have some difficulty to import the amino acids [especially glutamic acid (36)] needed for this synthesis. The possibility to store GSSG within the cell instead of exporting it, may help to overcome this difficulty. This effect is likely to be a general phenomenon which occurs during oxidative stress as also evidenced by GSH loss in erythrocytes of newborn exposed to hydrogen peroxide with no increase in initial GSSG levels after 30 minutes of incubation (37). So, through formation of glutathione-protein mixed disulfides, erythrocytes are easily and quickly able to restore their glutathione levels under recovered conditions.

Morphological appearance of human red cells exposed to hydroxylamine was only marginally altered (Figure 6) indicating that morphological changes per se are not likely to be responsible for enhanced splenic sequestration of hydroxylaminedamaged red blood cells. Premature removal of hydroxylamine-damaged erythrocytes can result from a combination of different mechanisms that all lead to a change on the external surface of the cell which in turn lead to recognition by splenic macrophages. A schematic representation of the different mechanisms involved in hydroxylamine induced hemolytic anemia is depicted in figure 7 . Hydroxylamine reacts with oxyhemoglobin to form methemoglobin and reactive intermediates. These reactive intermediates can react directly with the membrane to cause lipid peroxidation as was previously shown (2,3). This peroxidative injury may cause a change in the membrane lipid organization (38.39) or may directly alter sulfhydryl groups of spectrin by forming disulfide bridges (40). These alterations can change the external surface of the red cell which lead to premature removal of the cell by the spleen. Beside changes in the external surface, lipid peroxidation may also cause spontaneous cell lysis. However, spontane- ous lysis is not likely to play a crucial role in the hemolytic anemia seen in vivo since in vitro cell. lysis was low, even when high concentrations of hydroxylamine were used. The reactive intermediates can also react with methemoglobin to further oxidize hemoglobin to form Heinz bodies. The altered membrane structure of Heinz bodies is then recognized and they are scavenged by the macrophage system of the spleen. As mentioned before formation of Heinz bodies was found in erythrocytes exposed to hydroxylamine. Alternatively, the reactive intermediates can react with GSH, hemoglobin or other proteins to generate protein-thiyl radicals $(27,41)$. However, existence of secondary radicals such as thiyl radicals of glutathione and hemoglobin in erythrocyte incubations with hydroxylamine remains to be established. These thiyl radicals react with protein in the cytosol and in the membrane to form mixed disulfides causing a distortion in the membrane protein structure leading to premature removal by the spleen.

In summary, hemolytic anemia induced by hydroxylamine is a complex process which involves generation of reactive species during the redox cycling of hydroxylamine with oxy-hemoglobin that interact with cellular thiols and membrane lipids leading to GSH depletion, lipid peroxidation, Heinz body formation and membrane sulfhydryl oxidation. The depleted glutathione is stored within the red cell as protein mixed disulfides and can be liberated by reduction. The oxidative processes induce alterations on the external surface of the red cell initiating premature sequestration of these oxidatively damaged cells by the spleen.

\section{ACKNOWLEDGMENTS}

The authors are grateful to Paul Bomans of the Department of Pathology. Electron Microseopy Unit for his technical suppon on scanning electron microscopy, to Ingrid de Kruijf for her assistance with the analyses and to the Red Cross Blood Bank "Zuid Limburg" for the blood samples used. 


\section{REFERENCES}

1. Gross P. Biologic activity of hydroxylamine: A Review. CRC Crit Rev Toxicol 14:87-99, 1985.

2. Evelo CTA. Toxicological stress indicators in hüman red blood cells: Changes in glutathione and glutathione S-transferase as biological markers for electrophilic and oxidative stress. Ph.D. Thesis, University of Limburg. Maastricht: p 174, 1995.

3. Sprooren AAMG, Evelo C.TA. In vitro haematotoxic effects of three methylated hydroxylamines. Arch Toxicol 71:299-305, 1997.

4. Stolze K. Nohl H. Detection of free radicals as intermediates in the methemoglobin formation from axyhemoglobin induced by hydroxylamine. Biochem Pharmacol 38:3055-3059, 1989.

5. Siolze K, Dadak A, Liu Y, Nohl H. Hydroxylamine and Phenol-induced formation of methemoglobin and free radical intermediates in erythrocytes. Biochem Pharmacol 52:1821-1829, 1996.

6. Nohl H, Stolze K. Chemiluminescence from activated heme compounds detected in the reaction of various xenobiotics with oxyhemoglobin: comparison with several heme/hydrogen peroxide systems. Free Rad Biol Med 15:257-263, 1993.

7. Stern A. Red cell oxidative damage. In: Sies H, eds. Oxidarive Stress. Orlando: Academic Press, Inc., pp. 331-349, 1985.

8. Shan X, Aw TY, Jones DP. Glutathione-dependent protection against oxidative injury. Pharmac Ther 47:61-71, 1990.

9. Clark MR. Senescence of red blood cells: progress and problems. Physiol Rev 68:503-554, 1988.

10. Turrini F, Arese P. Yuan J, Low PS. Clustering of integral membrane proteins of the human erythrocyte membrane stimulates autologus IgG binding, complement deposition, and phagocytosis. J Biol Chem 266:23611-23617, 1991 .

11. Tanaka Y. Schroit AJ. Insertion of fluorescent phosphatidylserine into the plasma membrane of red blood cells: Recognition by autologous macrophages. $J$ Biol Chem 258:11335-11343, 1985.

12. Grossman S.J. Simson J. Jollow DJ. Dapsone-induced hemolytic anemia: effect of $\mathrm{N}$-hydroxy dapsone on the sulfhydryl status and membrane proteins of rat erythrocytes. Toxicol Appl Pharmacol 117:208-217. 1992.

13. McMillan DC. Simson JV, Budinsky RA, Jollow DJ. Dapsone-induced hemolytic anemia: effect of dapsone hydroxylamine on sulfhydryl status, membrane skeletal proteins and morphology of human and rat erythrocytes. J Pharmacol Exp Ther 274:540-547, 1995.

14. Reed DJ. Glutathione: Toxicological implications. Annu Rev Pharmacol Toxicol 30:603-631, 1990.
15. Kotsifopoulos PN. In vitro effect. of oxidizing and analgesic agents on erythrocyte membrane protein electrophoretic pattern. Nouv Rev Fr Hematol 15:141146, 1975 .

16. vart Kampen EJ, Zijlstra WG. Determination of hemoglobin and its derivatives. Adv Clin Chem 8:141-187, 1965.

17. Beutler E. Red Cell Metabolism (A Manual of Biochemical Methods). New York: Grune and Stration, 1975.

18. Anderson ME. Determination of glutathione and glutathione disulphide in biological samples. Meth Enzymol 113:548-555, 1985.

19. Srivastava SK, Beutler E. Accurate measurement of oxidized glutathione content of human, rabbit, and red blood cells. Anal Biochem 25:70-76, 1968.

20. Dodge JT, Mitchell C, Hanahan DJ. The preparation and chemical characteristics of hemoglobin-free ghosts of human erythrocytes. Arch Biochem Biophys 100:119$130,1963$.

21. Hak Hyun B, Gulati GL, Ashron JK. Color Atlas of Clinical Hematology. New York-Tokyo: Igaku-Shoin, 1986.

22. Srivastava SK, Beutler E. The transport of oxidized glutathione from human erythrocytes. $J$ Biol Chem 244:9-16, 1968

23. Fairbanks G, Steck TL, Wallach DFH. Electrophoretic analysis of the major polypeptides of the human erythrocyte membrane. Biochem 10:2606-2617, 1971.

24. Bessis M. Living Blood Cells and Their Ultrastructure. New York: Springer-Verlag, 1973.25.Beutler E. Druginduced hemolytic anemia. Pharmacol Rev 21:73-103. 1969.

26. Halliwell B, Gutteridge JMC. Role of free radicals and catalytic metal ions in human disease: An overview. Meth Enzymol 186:1-85, 1990.

27. Bradshaw TP, McMillan DC. Crouch RK. Jollow DJ Identification of free radicals produced in rat erythrocytes exposed to hemolytic concentratioons of phenylhydroxylamine. Free Rad Biol Med 18:279-285, 1995.

28. Winterbourn CC. Metodiewa D. The reaction of superoxide with reduced glutathione. Arch Biochem Biophys 314:284-290, 1994.

29. Low PS, Waugh SM, Zinke K, Drenckhahn D. The role of hemoglobin denaturation and band 3 clustering in red blood cell aging. Science 227:53i-533, 1985.

30. Jacob HA. Mechanisms of Heinz body formation and attachment to red cell membrane. Semin Hematol 7:341-354, 1970.

31. Winterboum CC, Carrell RW. The attachment of Heinz bodies to the red cell membrane. $B r J$ Haematol 25:585-592, 1973.

32. Wells WW, Yang Y. Deits TL. Thioltransferases. $A d v$ Enzymol Rel Areas Mol Biol 60: 149-201, 1993. 
33. Winter CG, Christensen HN. Migration of amino acids across the membrane of the human erythrocyte. $J$ Biol: Chem 239:872-878, 1964.

34. Srivastava SK. Absence of $\gamma$-glutamyl transpeptidase: and the role of GSSG transport in the tumover of GSH in erythrocytes. Blood 49:668-669, 1977.

35. Deneke SM, Fanburg BL. Regulation of cellular glutathione. Am J Physiol 257:L 163-Li73, 1989.

36. Beuder E. Dale GL. Erythrocyte glutathione: function and metabolism. In: Dolphin D. Avramovic; O. Poulson R, eds. Glutathione Chemical Biochemical and Medical Aspects. Part B. New York: J.Wiley and Sons, Inc., pp. 291-317, 1989.

37. Clahsen PC, Moison RMW, Holtzer CAJ, Berger HM. Recycling of glutathione during oxidative stress in erythrocytes of the newborn. Ped Res 32:399-402. 1992.
38. Arduini A, Stern A, Storto S, Belfiglio M, Mancinelli G, Scurti R, Federici G. Effect of oxidative stress on membrane phospholipid and protein organization in human erythrocytes. Arch Biochem Biophys 273:112120. 1989.

39. Jain SK. In vivo extemalization of phosphatidylserine and phosphatidylethanolamine in the membrane bilayer and hypercoagulability by the lipid peroxidation of erythrocytes in rats. $J$ Clin Invest 76:281-286, 1985.

40. Haest CWM, Kamp D, Plasa G, Deuticke B. Intra- and intermolecular cross-linking of membrane proteins in intact erythrocytes and ghosts by SH-oxidizing agents. Biochim Biophys Acta 169:226-230, 1977.

41. Maples KR, Eyer P. Mason RP. Aniline- , phenylhydroxylamine-, nitrosobenzene-, and nitrobenzene-induced hemoglobin thiyl free radical formation in vivo and in vitĩo. Mol Pharmacol 37:311-318, 1990. 
Chapter 6

\section{A Study on the Interaction between Hydroxylamine Analogues and Oxyhemoglobin in Intact Erythrocytes}

Accepted in: Blood Cells, Molecules, and Diseases 26, 2000 


\title{
A study on the interaction between hydroxylamine analogues and oxyhemoglobin in intact erythrocytes
}

\author{
Anita A. M. G. Spooren and Chris T. A. Evelo ${ }^{1}$
}

Department of Pharmacology, Toxicology Section, Universiteit Maastricht, PO Box 616, 6200 MD Maastricht, The Netherlands

\section{Abstract}

The oxidative potency of hydroxylamine (HYAM) and its O-derivatives (O-methyl- and O-ethyl hydroxylamine) is generally larger than the effects of the $\mathrm{N}$-derivatives ( $\mathrm{N}$-methyl-, $\mathrm{N}$-dimethyl and N,O-dimethyl hydroxylamine). The effects of the two groups of hydroxylamines also differ in a qualitative sense. To elucidate this difference in toxicity profiles we investigated the hemoglobin dependence of the toxicity, the occurrence of cell damaging products like superoxide and $\mathrm{H}_{2} \mathrm{O}_{2}$, and the cellular kinetics of the hydroxylamine analogues. All hydroxylamines were found to depend on the presence and accessibility of oxyhemoglobin to exert their toxicity. This did not provide an explanation for the different toxicity profiles. The interaction of some hydroxylamines with oxyhemoglobin is known to lead to the formation of radical intermediates. Differences in the stability of these radical products are known to occur and in some cases secondary products are formed. This can contribute to the differences in toxicity. In this respect production of superoxide radicals was demonstrated for all hydroxylamines in the reaction with oxyhemoglobin. Evidence for $\mathrm{H}_{2} \mathrm{O}_{2}$ generation during the reaction of HYAM, O-methyl, O-ethyl and $\mathrm{N}$-dimethyl hydroxylamine with oxyhemoglobin was also found. Next to variations in the products formed, differences in cellular kinetics is likely to be among the most important factors that explain the different toxicity patterns seen for the hydroxylamines in erythrocytes. Indeed differences were found to exist for the kinetics of methemoglobin formation in erythrocytes. Not only was the final level of methemoglobin formed much lower for the $\mathrm{N}$-derivatives, but also the reaction rate with oxyhemoglobin was slower than with HYAM and its O-derivatives. Except for N,O-dimethyl hydroxylamine (NODMH) the same pattern was seen in hemolysates. NODMH tripled its effect on hemoglobin in hemolysate compared with incubations in erythrocytes. This implies that cellular uptake is a limiting factor for NODMH. Since formation of $\mathrm{H}_{2} \mathrm{O}_{2}$ is most likely a result of an interaction with hemoglobin, differences in kinetics of methemoglobin formation can be an explanation for the fact that NMH and NODMH did not produce $\mathrm{H}_{2} \mathrm{O}_{2}$ to a detectable level. These results indicate that: (a) the toxicity of all hydroxylamines depends on an interaction with oxyhemoglobin (b) the interaction with hemoglobin produces radical intermediates and concomitantly superoxide radicals and $\mathrm{H}_{2} \mathrm{O}_{2}$ and (c) differences in uptake, reaction rate with hemoglobin, and stability of the intermediates formed do exist for the different hydroxylamines and contribute to their differences in toxicity. 


\section{INTRODUCTION}

Hydroxylamines are industrial compounds used as intermediates in chemical synthesis and are known to produce radical intermediates (nitroxide radicals) in the reaction with oxyhemoglobin $[23,34-36]$. Production of radicals is involved in many pathological processes particularly in the red cell which can reductively activate oxygen, and which is susceptible to damage by redox active compounds.

Recently we described the erythrotoxic effect of hydroxylamine (HYAM) and some of its derivatives; O-methyl hydroxylamine (OMH), O-ethyl hydroxylamine (OEH), N-methyl hydroxylamine (NMH), N-dimethyl hydroxylamine (NDMH) and $\mathrm{N}, \mathrm{O}$-dimethyl hydroxylamine (NODMH) [9,31]. There we proposed two major routes for erythrotoxicity induced by hydroxylamines. In the first route induction of methemoglobin is thought to be the primary effect. HYAM and its O-derivatives react with oxyhemoglobin via a redox mechanism, which eventually can lead to Heinz body formation and red cell hemolysis $[10,26,29,30,40]$. In addition to causing irreversible oxidation of hemoglobin to hemichrome and other denaturated derivatives, these hydroxylamines also give rise to radical intermediates $[23,34$ 36]. These radicals cause lipid peroxidation and together with the lipid peroxides formed lead to impairment of some essential detoxification enzymes like glutathione S-transferase (GST), glutathione peroxidase (GPX) and NADPH methemoglobin reductase (MHbR). The oxidative stress occurring also leads to depletion of glutathione. The other route mainly inhibits the activity of glucose 6-phosphate dehydrogenase (G6PDH) and to a lesser extent glutathione reductase (GR) as seen for the $\mathrm{N}$-substituted hydroxylamines. As a consequence of the effects of the $\mathrm{N}$-alkyl hydroxylamines, glutathione was depleted due to lowered restoring capacity to compensate oxidation in GPX and thiol transferase reactions. Based on these results we hypothesised that HYAM and its O-derivatives are dependent on oxyhemoglobin and that the $\mathrm{N}$-derivatives are independent of the presence of oxyhemoglobin for their erythrotoxic effects. Other evidence for this hypothesis was given by the fact that no effects on hepatocyte glutathione concentrations, formation of lipid peroxidation products or GST activity were found in incubations of hepatocytes with HYAM [25]. This together with the known generation of radicals during methemoglobin formation by HYAM led to the conclusion that HYAM needs oxyhemoglobin to induce lipid peroxidation. This was also confirmed by the observation that no lipid peroxidation was found when HYAM was incubated with washed red blood cell membranes. NDMH, the double $\mathrm{N}$-methylated hydroxylamine, did not fit the simple division in $\mathrm{O}$ - and $\mathrm{N}$-substituted hydroxylamines. This compound did cause effects from both routes and it was therefore expected that only part of the NDMH effects would be dependent on oxyhemoglobin.

The aim of the present study was to investigate whether effects caused by the different hydroxylamines in erythrocytes were dependent or independent on the presence of oxyhemoglobin. In this way it may be possible to elucidate the different toxicity patterns seen for the hydroxylamine derivatives in human red blood cells. Since nitroxide radicals were found in the reaction of hydroxylamines and oxyhemoglobin, we wondered whether cellular 
damaging products like superoxide and $\mathrm{H}_{2} \mathrm{O}_{2}$ also participate in the toxic effects seen for the hydroxylamines in erythrocytes. Superoxide is known to be produced during the autoxidation of oxyhemoglobin [6]. Previously, Stolze and Nohl $[35,36]$ suggested that $\mathrm{H}_{2} \mathrm{O}_{2}$ was formed as a necessary non-radical intermediate in the reaction between hydroxylamines and oxyhemoglobin and they showed that $\mathrm{H}_{2} \mathrm{O}_{2}$ was bound to the heme group in the form of a compound I species $[22,23]$. Beside these aspects of hemoglobin dependence and of occurrence of other hazardous products, differences in cellular kinetics of the hydroxylamine analogues were investigated.

To study these objectives all hydroxylamines were incubated with human erythrocytes, carbon monoxide treated human erythrocytes, diethyldithiocarbamate (DDC) treated human erythrocytes and aminotriazole treated human hemolysates. The kinetics of methemoglobin formation was established in erythrocytes and hemolysates.

\section{MATERIALS AND METHODS}

\section{Materials}

$\mathrm{N}, \mathrm{N}$-dimethyl hydroxylamine $\mathrm{HCl}$ (NDMH, CAS-no: 16645-06-0), N-methyl hydroxylamine $\mathrm{HCl}$ (NMH, CAS-no: 4229-44-2) and O-methyl hydroxylamine $\mathrm{HCl}$ (OMH, CAS-no: 593-56-6) were purchased from Fluka Chemika-BioChemika (Buchs, Switzerland). 2-Thiobarbituricacid (TBA) was obtained from Merck (Darmstadt, FRG) and carbon monoxide was obtained from AGA Gas BV (Amsterdam, Netherlands). 3-Amino-1,2,4-triazole, N,O-dimethyl hydroxylamine $\mathrm{HCl}$ (NODMH, CAS-no: 1117-97-1), N,N-diethyldithiocarbamate (DDC), O-ethyl hydroxylamine $\mathrm{HCl}$ (OEH, CAS-no: 624-86-2), hydroxylamine $\mathrm{HCl}$ (HYAM, CAS-no: $5470-11-1$ ), nonidet $P-40$ and all other biochemicals were obtained from Sigma (St. Louis, USA). Only micro filtrated deionized water was used and all other chemicals were of analytical quality.

\section{Incubation conditions}

Human buffy coats, containing citric acid citrate-phosphate-dextrose (CPD) medium as anticoagulantia, were obtained from the local center for blood transfusion and stored at $4^{\circ} \mathrm{C}$ until the next day. Samples were checked for viral infections before use. Erythrocytes, after removal of white blood cells and plasma, were washed twice in saline and resuspended in PBS (phosphate buffered saline; $15 \mathrm{mM} \mathrm{KH}_{2} \mathrm{PO}_{4} / \mathrm{Na}_{2} \mathrm{HPO}_{4}+130 \mathrm{mM} \mathrm{NaCl} ; \mathrm{pH}=7.4$ ) to the original hematocrit. Hemoglobin concentrations were determined with the hemoglobin cyanide procedure [15].

\section{Effects of hydroxylamines in erythrocytes}

Erythrocytes, containing oxyhemoglobin, were incubated with hydroxylamines (final concentration 0,1 and $7 \mathrm{mM})$ in a shaking water bath $(80 \mathrm{rpm})$ for $1 \mathrm{~h}$ at $37^{\circ} \mathrm{C}$. After incubation, erythrocytes were carefully washed twice with 9 volumes of PBS and packed by centrifugation $(2000 \mathrm{~g})$. 
Hemoglobin dependence of hydroxylamine effects

Erythrocytes, containing carboxyhemoglobin, were prepared by slowly bubbling the chemically pure carbon monoxide ( $\mathrm{CO}$ ) through the washed red cell suspension for $1 \mathrm{~h}$. The CO saturation was calculated from the absorption spectra between 450 and $650 \mathrm{~nm}$ with the equation given by van Kampen and Zijlstra [15]. The $\mathrm{CO}$ saturation in all experiments was at least $90 \%$. These red cells, containing carboxyhemoglobin, were incubated with hydroxylamines (final concentration 0,1 and $7 \mathrm{mM}$ ) in closed tubes containing $\mathrm{CO}$ in a shaking water bath $(80 \mathrm{rpm})$ for $1 \mathrm{~h}$ at $37^{\circ} \mathrm{C}$. After incubation, erythrocytes were carefully washed twice with 9 volumes of helium saturated PBS and packed by centrifugation $(2000 \mathrm{~g})$. As positive controls erythrocytes containing oxyhemoglobin were incubated with $7 \mathrm{mM}$ hydroxylamines for $1 \mathrm{~h}$ at $37^{\circ} \mathrm{C}$ and checked for methemoglobin formation (HYAM, $\mathrm{OMH}, \mathrm{OEH}$ and $\mathrm{NDMH}$ ) or inhibition of glucose 6-phosphate dehydrogenase activity ( $\mathrm{NMH}$, NODMH and NDMH).

\section{Formation of hydrogen peroxide}

The formation of hydrogen peroxide $\left(\mathrm{H}_{2} \mathrm{O}_{2}\right)$ in hemolysates exposed to hydroxylamines was demonstrated by evaluating the aminotriazole-dependent irreversible inhibition of the catalase activity present in the system $[7,18]$. Erythrocytes containing oxyhemoglobin, were lysed with three volumes of ice-cold water and the ionic strength was restored by adding one volume twofold concentrated PBS. This hemolysate was preincubated with $50 \mathrm{mM}$ aminotriazole for $5 \mathrm{~min}$ at $37^{\circ} \mathrm{C}$ in a shaking water bath $(80 \mathrm{rpm})$. Thereafter, $300 \mu \mathrm{l}$ hydroxylamines (final concentrations 0,1 and $3 \mathrm{mM}$ ) was added and incubated for $1 \mathrm{~h}$. Subsequently, catalase activity was determined in the samples $(0.5 \mathrm{ml})$, which were first treated with $2 \mathrm{ml}$ buffered $0.45 \mathrm{M}$ ethanol for $10 \mathrm{~min}$ at room temperature to stop the reaction with aminotriazole [7]. Standard dilutions were then prepared for analysis.

\section{Role of superoxide radicals}

Erythrocytes containing oxyhemoglobin, were incubated with $2.5 \mathrm{mM}$ diethyldithio-carbamate (DDC) in a shaking water bath at $80 \mathrm{rpm}$ for $1 \mathrm{~h}$ at $37^{\circ} \mathrm{C}$ to inactivate superoxide dismutase (SOD) [12,21]. SOD activity was inhibited for more than $90 \%$. After addition of the hydroxylamines (final concentration 0 and $5 \mathrm{mM}$ ) the cells were subsequently incubated for $1 \mathrm{~h}$ at $37^{\circ} \mathrm{C}$. After incubation, the red cells were centrifuged at $2000 \mathrm{~g}$ and washed twice with 9 volumes of PBS.

\section{Kinetics of methemoglobin formation}

Erythrocytes containing oxyhemoglobin were incubated with $5 \mathrm{mM}$ hydroxylamines and the reaction was stopped with the addition of an excess of cold PBS at different time intervals $(0.5,1,2,3,5,10,20,40$ and $60 \mathrm{~min})$. Immediately after addition of PBS the cells were packed by centrifugation $(10.000 \mathrm{~g}$ ) and lysed with the addition of 15 volumes of cold water containing nonidet $\mathrm{P}-40(0.1 \% \mathrm{v} / \mathrm{v})$. In these hemolysates the percentage methemoglobin was instantly determined. To see if lower methemoglobin levels caused by the $\mathrm{N}$-derivatives was not a consequence of limiting cellular absorption, methemoglobin levels were also 
measured in hemolysates (1:7) after incubation with the $\mathrm{N}$-derivatives of hydroxylamine (2 $\mathrm{mM})$ at different time intervals.

\section{Methemoglobin determination}

The percentage methemoglobin present in hemolysates was calculated from the absorbance change occurring after addition of $\mathrm{KCN}$, compared to the same change in a sample fully converted to the methemoglobin form by the addition of $\mathrm{K}_{3}\left[\mathrm{Fe}(\mathrm{CN})_{6}\right][37]$.

\section{Determination of NADPH methemoglobin reductase $(\mathrm{MHBR})$}

NADPH methemoglobin reductase activity in hemolysate was determined by measuring the oxidation of NADPH at $340 \mathrm{~nm}$ for $10 \mathrm{~min}[3,13]$. Methylene blue was used as a substrate.

\section{Lipid peroxide formation}

The formation of lipid peroxidation products in the extracellular medium was assessed by determination of the amount of thiobarbituric acid reactive substances (TBARS) released and was expressed as malondialdehyde equivalents [33]. After incubation and centrifugation $(2000 \mathrm{~g})$, the supernatant was collected and protein was precipitated by the addition of an equal volume of $10 \%(\mathrm{w} / \mathrm{v})$ trichloroacetic acid. Of the supernatant $1.5 \mathrm{ml}$ was added to $1 \mathrm{ml}$ $1 \%(w / v)$ TBA solution in $50 \mathrm{mM} \mathrm{NaOH}$ and heated in a boiling water bath for $15 \mathrm{~min}$. After forced cooling, $1.25 \mathrm{ml}$ butanol was added, and the two phases were thoroughly mixed. The absorbance of the butanol phase at $535 \mathrm{~nm}$ was determined and corrected for the background absorbance at $590 \mathrm{~nm}$.

\section{Determination of total glutathione (GT)}

Protein in erythrocytes was precipitated with an equal volume of $8 \%(\mathrm{w} / \mathrm{v})$ trichloroacetic acid and the clear supernatant was diluted ninefold in $100 \mathrm{mM} \mathrm{KH_{2 }} \mathrm{PO}_{4} / \mathrm{Na}_{2} \mathrm{HPO}_{4}$ buffer $(\mathrm{pH} 7.4)$ and stored $\left(-20^{\circ} \mathrm{C}\right)$ until determination. Total glutathione was measured using the cyclic oxidation-reduction method essentially as described by Anderson [2].

\section{Determination of Glutathione S-transferase (GST)}

GST (EC 2.5.1.18) activity with 1-chloro-2,4-dinitrobenzene as the substrate was determined in hemolysate prepared from erythrocyte incubates by adding three volumes of ice cold water containing $1.4 \mathrm{mM}$ dithiothreitol, using the method of Habig and Jakoby [11] with previously described modifications [4].

\section{Determination of Glutathione peroxidase (GPX)}

GPX (EC 1.11.1.9) activity in hemolysate was determined using $\mathrm{H}_{2} \mathrm{O}_{2}(1.5 \mathrm{mM})$ as substrate in the presence of GR $(2.4 \mathrm{U} / \mathrm{ml}), \mathrm{GSH}(10 \mathrm{mM}), \mathrm{NADPH}(1.5 \mathrm{mM})$ and sodium azide $(10 \mathrm{mM})$ [24]. The rate of oxidised glutathione (GSSG) formation is measured by following the decrease in absorbance of the reaction mixture at $340 \mathrm{~nm}$ for $3 \mathrm{~min}$ as NADPH is converted to $\mathrm{NADP}^{+}$. To eliminate NADPH oxidation by MHbR in the hemolysate, 
oxyhemoglobin is converted to the stable cyanmethemoglobin form before determination of GPX.

\section{Determination of Glutathione reductase (GR)}

GR (EC 1.6.4.2) activity in hemolysate was determined by a modification of the method described by Carlberg and Mannervik [5]. One hundred microliters of hemolysate was added to $2 \mathrm{ml}$ potassium phosphate buffer $(100 \mathrm{mM}), 50 \mu$ EDTA $(80 \mathrm{mM}), 100 \mu$ l NADPH $(2 \mathrm{mM})$ and $100 \mu \mathrm{FAD}(0.3 \mathrm{mM})$. After $2 \mathrm{~min}$ preincubation $\left(37^{\circ} \mathrm{C}\right)$, the reaction was started by adding $100 \mu \mathrm{l}$ GSSG $(7.5 \mathrm{mM})$. After $15 \mathrm{sec}$ the reaction was followed spectrophotometrically at $340 \mathrm{~nm}$ for $2 \mathrm{~min}$. The FAD was added in order to convert the entire enzyme to its holo form.

Determination of Glucose 6-phosphate dehydrogenase (G6PDH)

G6PDH (EC 1.1.1.49) activity in hemolysate was determined using glucose 6-phosphate as substrate in the presence of $\mathrm{NADP}^{+}$and $\mathrm{MgCl}_{2}[3,37]$. The rate of reduction of $\mathrm{NADP}^{+}$was followed spectrophotometrically at $340 \mathrm{~nm}$ for $10 \mathrm{~min}$.

\section{Determination of Catalase}

Catalase activity in hemolysate was determined as described by Aebi [28] measuring decomposition of $\mathrm{H}_{2} \mathrm{O}_{2}$ at $240 \mathrm{~nm}$ for 30 sec.

\section{Determination of superoxide dismutase (SOD)}

Hemoglobin was removed from the hemolysate by an adaptation of the Tsuchihashi chloroform-ethanol treatment [38]. The upper aqueous phase was gently decanted and frozen at $-80^{\circ} \mathrm{C}$ for later analysis. The assay of $S O D$ is performed at $25^{\circ} \mathrm{C}$ according to McCord and Fridovich [19]. One unit of SOD activity is defined as the amount of enzyme that inhibits the rate of cytochrome $c$ reduction, generated by a stable xanthine-xanthine oxidase system, by $50 \%$ in a $3-\mathrm{ml}$ reaction volume. The SOD activity was calculated from a semilogarithmic plot as described by L'Abbé and Fisher [17].

\section{Statistical analysis}

Data are expressed as the mean followed by the standard error of the mean (SE). All experiments were conducted three or six times and were performed in triplicate. The significance of the concentration dependent change was evaluated using linear regression analysis $(p<0.005)$. To test for significance of differences between hydroxylamines effects in untreated and DDC- or aminotriazole- treated erythrocytes, matched pair analyses was performed with the Wilcoxon non-parametric signed rank test. Differences between hydroxylamines effects on blood parameters in oxyhemoglobin and carboxyhemoglobin treated samples were analysed using the Wilcoxon non-parametric signed rank test without matched pair analysis because the experiments were conducted on separate days with different blood samples. In all cases significance was defined as $p<0.05$. 


\section{RESULTS}

\section{Effects of hydroxylamine in erythrocytes}

Methemoglobin formation, release of lipid peroxidation products, glutathione depletion and activity decreases of some enzymes in human erythrocytes after incubation with hydroxylamines are shown in Table 1. HYAM and its O-derivatives induced severe methemoglobin formation, high release of lipid peroxidation products, GST, GPX and MHbR Inhibitions and total glutathione depletion ( $p<0.005$ in all cases). HYAM, OMH and OEH did not affect the activity of $\mathrm{GR}$ and G6PDH. In contrast, all three $\mathrm{N}$-derivatives impaired the G6PDH activity and NMH and NODMH also impaired the GR activity $(p<0.005$ in all cases). This difference in effects of HYAM and its $\mathrm{O}$-derivatives on one side and the $\mathrm{N}$-derivatives on the other side is in accordance with what we previously described $[9,31]$. The effects caused by NMH and NODMH in erythrocyte incubations were comparable (glutathione depletion and G6PDH and GR impairment) except for slight methemoglobin formation and GPX inhibition that were found for NODMH and not for $\mathrm{NMH}$. Although, a very low rate of methemoglobin formation and a small tendency towards impairment of GPX activity was found for $\mathrm{NMH}$. NDMH caused a remarkably different pattern of reactivity. NDMH caused considerable methemoglobin formation with almost no release of lipid peroxidation products, impairment of MHbR and GPX activity but not of GST activity. Furthermore, NDMH did not cause any significant depletion of total glutathione.

Hemoglobin dependence of hydroxylamine effects

To see if methemoglobin formation is the first and critical step leading to all other effects in human erythrocytes, hydroxylamines were incubated with $\mathrm{CO}$ pretreated erythrocytes (Table 1). Pretreatment of erythrocytes with $\mathrm{CO}$ had no significant effect on the tested parameters in control incubations without hydroxylamines. As shown in Table 1, all toxic effects found for hydroxylamines in erythrocytes containing oxyhemoglobin were significantly diminished in the $\mathrm{CO}$ pretreated erythrocytes $(p<0.05)$, although in some cases the decreases were only significant at the higher $(7 \mathrm{mM})$ concentration of hydroxylamines.

\section{Formation of hydrogen peroxide}

We studied the possible formation of $\mathrm{H}_{2} \mathrm{O}_{2}$ in human hemolysate incubations with the different hydroxylamine analogues using the catalase inhibiting reaction of aminotriazole. Since $\mathrm{H}_{2} \mathrm{O}_{2}$ did not accumulate to an extent that permitted direct characterisation, it was necessary to trap the evanescent peroxide by a chemical reaction of high specificity. For this purpose we utilised the catalase inhibiting reaction of aminotriazole. Aminotriazole is an irreversible inhibitor of catalase [18] but inhibition only occurs when the enzyme is in the form of compound I (catalase- $\mathrm{H}_{2} \mathrm{O}_{2}$ complex). $\mathrm{H}_{2} \mathrm{O}_{2}$ activates a histidine residue close to the active site and aminotriazole then binds covalently and inactivates catalase [27]. This latter reaction serves as a detection system for $\mathrm{H}_{2} \mathrm{O}_{2}$ : when irreversible inhibition of catalase by aminotriazole is observed, it may be inferred that $\mathrm{H}_{2} \mathrm{O}_{2}$ had been present in the test system 
Table 1: Methemoglobin formation (MHB), release of lipid peroxidation products (LP), glutathione concentration (GT) and some enzyme activities in human erythrocytes containing oxyhemoglobin or carboxyhemoglobin (+ $\mathrm{CO}$ ) after incubation with hydroxylamines $\left(1 \mathrm{~h}, 37^{\circ} \mathrm{C}\right)$.

\begin{tabular}{|c|c|c|c|c|c|c|c|c|c|c|c|c|c|}
\hline \multirow[t]{2}{*}{ Parameters } & \multirow[b]{2}{*}{ Control } & \multicolumn{2}{|c|}{ Hydroxylamine } & \multicolumn{2}{|c|}{$\begin{array}{c}\text { O-methyl } \\
\text { hydroxylamine }\end{array}$} & \multicolumn{2}{|c|}{$\begin{array}{c}\text { O-ethyl } \\
\text { hydroxylamine }\end{array}$} & \multicolumn{2}{|c|}{$\begin{array}{c}\mathrm{N} \text {-methyl } \\
\text { hydroxylamine }\end{array}$} & \multicolumn{2}{|c|}{$\begin{array}{c}\mathrm{N} \text {-dimethyl } \\
\text { hydroxylamine }\end{array}$} & \multicolumn{2}{|c|}{$\begin{array}{l}\text { N,O-dimethyl } \\
\text { hydroxylamine }\end{array}$} \\
\hline & & $1 \mathrm{mM}$ & $7 \mathrm{mM}$ & $1 \mathrm{mM}$ & $7 \mathrm{mM}$ & $1 \mathrm{mM}$ & $7 \mathrm{mM}$ & $1 \mathrm{mM}$ & $7 \mathrm{mM}$ & $1 \mathrm{mM}$ & $7 \mathrm{mM}$ & $1 \mathrm{mM}$ & $7 \mathrm{mM}$ \\
\hline $\mathrm{MHb}$ & $0.9 \pm 0.1$ & $13.4 \pm 0.7$ & $81.7 \pm$ & $11.3 \pm 0.3$ & $7.9 \pm 3.8 \#$ & $2.8 \pm 0.3$ & $87.9 \pm 5.1 \#$ & $2.0 \pm 0.1$ & $4.2 \pm 0.3 \#$ & $15.1 \pm 0.6$ & $46.2 \pm 1.3 \#$ & $1.3 \pm 0.1$ & $17.4 \pm 0.3 \#$ \\
\hline$+\mathrm{Co}$ & $0.7 \pm 0.1$ & $1.2 \pm 0.2^{*}$ & $7.4 \pm 0.2^{*}$ & $1.1 \pm 0.1^{*}$ & $3.7 \pm 0.2^{*}$ & $1.7 \pm 0.1^{*}$ & $6.1 \pm 0.2^{\star}$ & $0.7 \pm 0.1^{*}$ & $0.9 \pm 0.1^{*}$ & $0.8 \pm 0.1^{*}$ & $0.9 \pm 0.1^{*}$ & $0.7 \pm 0.1^{*}$ & $0.9 \pm 0.1^{*}$ \\
\hline LP (nmot/l) & $79 \pm 9$ & $434 \pm 18$ & $1560 \pm 90 \#$ & $695 \pm 94$ & $2084 \pm 180 \#$ & $511 \pm 16$ & $1815 \pm 156 \#$ & $90 \pm 20$ & $78 \pm 8$ & $94 \pm 25$ & $160 \pm 32 \#$ & $85 \pm 10$ & $100 \pm 25$ \\
\hline$+\mathrm{CO}$ & $55 \pm 13$ & $67 \pm 4^{*}$ & $94 \pm 5^{*}$ & $64 \pm 4^{\circ}$ & $100 \pm 4^{*}$ & $65 \pm 2^{*}$ & $95 \pm 6^{*}$ & n.d. & n.d. & $57 \pm 4$ & $62 \pm 5^{*}$ & n.d. & n.d. \\
\hline $\mathrm{MHbR}(\mathrm{IJ} / \mathrm{g} \mathrm{Hb})$ & $2.8 \pm 0.2$ & $2.0 \pm 0.1$ & $0.7 \pm 0.1 \#$ & $2.0 \pm 0.2$ & $0.6 \pm 0.1 \#$ & $2.3 \pm 0.1$ & $0.6 \pm 0.1 \#$ & $2.9 \pm 0.1$ & $2.7 \pm 0.2$ & $2.6 \pm 0.1$ & $1.7 \pm 0.3 \#$ & $2.7 \pm 0.3$ & $2.5 \pm 0.4$ \\
\hline$+\mathrm{CO}$ & $2.7 \pm 0.1$ & $2.6 \pm 0.1^{*}$ & $2.5 \pm 0.1^{*}$ & $2.6 \pm 0.2^{*}$ & $2.6 \pm 0.1^{*}$ & $2.7 \pm 0.2^{\star}$ & $2.5 \pm 0.2^{*}$ & n.d. & n.d. & $2.6 \pm 0.1$ & $2.5 \pm 0.1^{*}$ & n.d. & nd. \\
\hline GT $(\mu \mathrm{mol} / \mathrm{g} \mathrm{Hb})$ & $5.7 \pm 0.5$ & $5.6 \pm 0.2$ & $4.0 \pm 0.4 \#$ & $5.6 \pm 0.1$ & $3.7 \pm 0.2 \#$ & $5.4 \pm 0.3$ & $3.4 \pm 0.2 \#$ & $5.4 \pm 0.2$ & $4.5 \pm 0.4 \#$ & $5.6 \pm 0.3$ & $5.5 \pm 0.2$ & $5.5 \pm 0.2$ & $4.3 \pm 0.1 \#$ \\
\hline$+\mathrm{C:O}$ & $6.1 \pm 0.7$ & $6.1 \pm 0.2$ & $6.1 \pm 0.2^{*}$ & $6.1 \pm 0.2$ & $5.9 \pm 0.2^{*}$ & $6.0 \pm 0.2$ & $6.0 \pm 0.3^{*}$ & $6.1 \pm 0.2$ & $6.0 \pm 0.1^{*}$ & nd. & n.d. & $5.9 \pm 0.6$ & $6.0 \pm 0.5^{*}$ \\
\hline $\mathrm{GST}(\mathrm{U} / \mathrm{g} \mathrm{Hb})$ & $3.7 \pm 0.4$ & $2.6 \pm 0.1$ & $0.9 \pm 0.3 \#$ & $2.5 \pm 0.2$ & $0.9 \pm 0.2 \#$ & $2.9 \pm 0.2$ & $1.1 \pm 0.3 \#$ & $3.8 \pm 0.2$ & $3.5 \pm 0.1$ & $3.7 \pm 0.1$ & $3.5 \pm 0.2$ & $3.4 \pm 0.3$ & $3.6 \pm 0.3$ \\
\hline$+\mathrm{CO}$ & $4.0 \pm 0.6$ & $3.9 \pm 0.1^{*}$ & $3.3 \pm 0.3^{*}$ & $4.0 \pm 0.1^{*}$ & $3.9 \pm 0.1^{*}$ & $3.8 \pm 0.3^{*}$ & $3.6 \pm 0.2^{*}$ & n.d. & n.d. & n.d. & nd. & n.d. & n.d. \\
\hline GPX (U/G Hb) & $20.2 \pm 1.2$ & $19.4 \pm 0.3$ & $12.3 \pm 0.7 \#$ & $17.8 \pm 0.2$ & $8.8 \pm 2.0$ \#\# & $17.8 \pm 1.0$ & $9.4 \pm 1.0 \#$ & $19.9 \pm 1.5$ & $18.9 \pm 1.6$ & $15.8 \pm 1.2$ & $10.2 \pm 1.3 \#$ & $18.6 \pm 0.9$ & $12.4 \pm 1.8 \#$ \\
\hline$+\mathrm{CO}$ & $18.9 \pm 0.7$ & $18.4 \pm 0.5$ & $18.7 \pm 0.7^{*}$ & $18.9 \pm 0.9^{*}$ & $18.8 \pm 0.7^{*}$ & $18.5 \pm 0.3^{*}$ & $18.6 \pm 0.6^{*}$ & n.d. & n.d & $18.8 \pm 0.6^{*}$ & $18.2 \pm 0.8^{*}$ & $18.7 \pm 0.9$ & $18.4 \pm 0.5^{*}$ \\
\hline $\mathrm{GR}(\mathrm{U} / \mathrm{g} \mathrm{HO})$ & $6.9 \pm 0.8$ & $6.8 \pm 0.5$ & $6.5 \pm 0.5$ & $7.1 \pm 0.2$ & $6.4 \pm 0.4$ & $6.7 \pm 0.4$ & $6.5 \pm 0.2$ & $6.5 \pm 0.1$ & $5.3 \pm 0.2 \#$ & $6.6 \pm 0.1$ & $6.6 \pm 0.2$ & $6.6 \pm 0.3$ & $5.6 \pm 0.4 \#$ \\
\hline$+\mathrm{CO}$ & $6.7 \pm 0.3$ & n.d. & n.d. & n.d. & n.d. & n.d. & n.d. & $6.4 \pm 0.1$ & $6.3 \pm 0.2^{*}$ & n.d. & n.d. & $6.4 \pm 0.4$ & $6.6 \pm 0.3^{*}$ \\
\hline G6PDH (U/g HD) & $7.8 \pm 0.1$ & $7.7 \pm 0.4$ & $7.6 \pm 0.2$ & $7.7 \pm 0.3$ & $7.5 \pm 0.2$ & $8.0 \pm 0.2$ & $7.7 \pm 0.1$ & $7.3 \pm 0.2$ & $6.1 \pm 0.1 \#$ & $7.7 \pm 0.1$ & $6.4 \pm 0.1 \#$ & $7.4 \pm 0.2$ & $5.3 \pm 0.4 \#$ \\
\hline$+\mathrm{CO}$ & $8.0 \pm 0.4$ & n.d. & n.d. & n.d. & n.d. & n.d. & n.d. & $7.9 \pm 0.2^{*}$ & $7.7 \pm 0.2^{*}$ & $7.9 \pm 0.2$ & $8.0 \pm 0.1^{\circ}$ & $7.9 \pm 0.1^{*}$ & $7.6 \pm 0.3^{*}$ \\
\hline
\end{tabular}

n.d. = not done. Values represent the mean \pm SE.

\# Regression analyses showed significant changes with increasing concentrations of the hydroxylamines; $\rho<0.005$.

* Significant difference between hydroxylamine incubations with erythrocytes containing oxyhemoglobin or carboxyhemoglobin; $\rho<0.05$ with corresponding concentration hydroxylamines. 
The activity of catalase was not affected by aminotriazole alone as shown in Fig. 1 (control bars). In the absence of aminotriazole, the six hydroxylamines had no significant effect on the catalase activity in the hemolysate incubations (Fig. 1 open bars). This is in contrast to the literature where hydroxylamines have been reported to form a catalytically inactive complex with purified catalase $[16,27]$. HYAM on itself is also known to inhibit catalase in vivo in liver of mice [1]. HYAM, OMH, OEH and to a lesser extend NDMH led to aminotriazole dependent catalase inhibition at $1 \mathrm{mM}$ concentrations (Fig. 1a). At $3 \mathrm{mM}$ concentrations of the hydroxylamines the effect of HYAM disappeared while it increased for NDMH. NMH and NODMH did not inhibit the catalase activity in hemolysate incubations with aminotriazole.
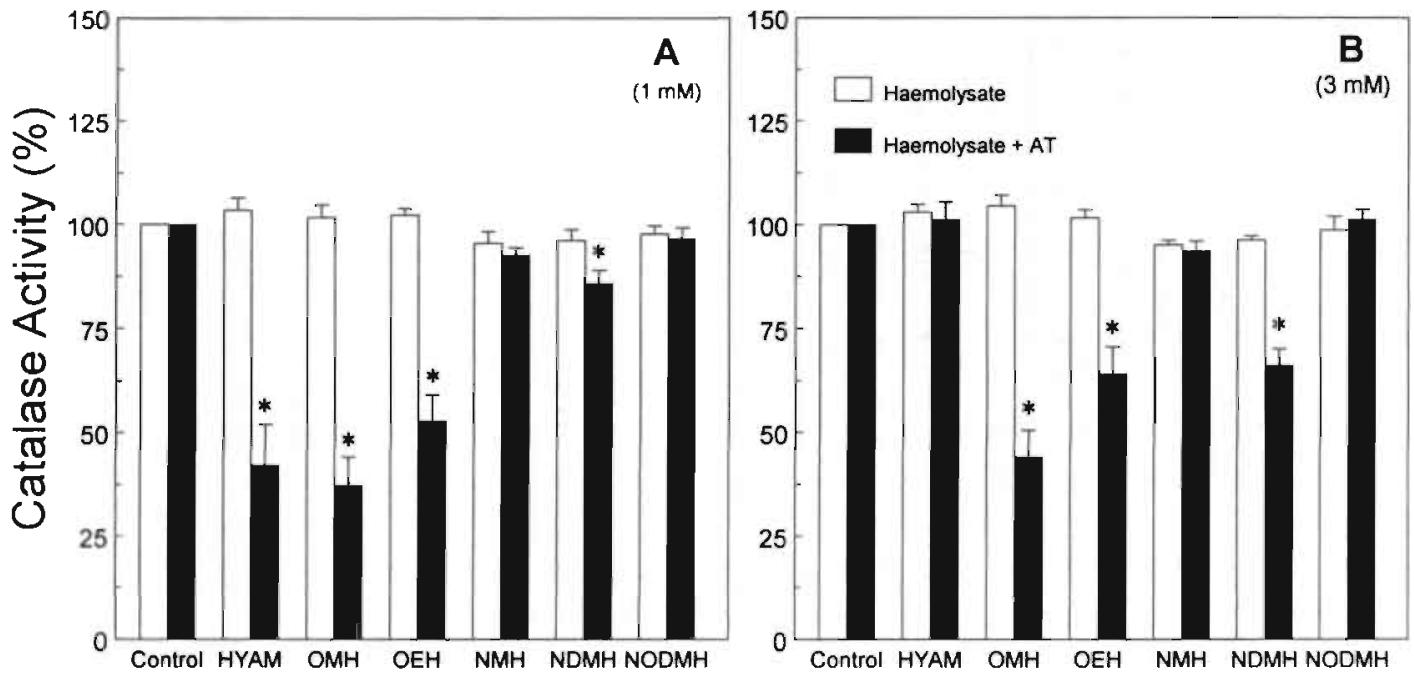

Figure 1: Catalase activity in human hemolysate and in aminotriazole (AT) pretreated hemolysate after incubation with $1 \mathrm{mM}(\mathrm{A})$ or $3 \mathrm{mM}$ (B) concentrations of hydroxylamine (HYAM) or its derivatives for $1 \mathrm{~h}$ at $37^{\circ} \mathrm{C} .100 \%$ catalase activity values in hemolysate and AT pre-treated hemolysate were 315 and $310 \mathrm{k} / \mathrm{g} \mathrm{Hb}$ respectively ( $\mathrm{k}$ : rate constant of the first order reaction as defined by Aebi [28]). "Statistically significant difference between AT pretreated and untreated hemolysates $(p<0.05)$.

\section{Role of superoxide radicals}

Diethyldithiocarbamate (DDC), a reversible inhibitor of SOD [12], was used to examine a possible participation of superoxide radicals in the toxic effects seen for hydroxylamines. Under the described incubation conditions the SOD activity was inhibited by more than $90 \%$. DDC is a copper-chelating agent and inhibits SOD by removing copper from the active site of the CuZn SOD [21]. It is known that DDC does not only inhibit SOD, but can also result in superoxide independent methemoglobin formation and glutathione depletion [28]. With the 
DDC concentration ( $2.5 \mathrm{mM}$ ) used in our experiments only methemoglobin formation was significantly increased in the control samples (Fig. 2A). After correction for this increase, methemoglobin formation was significantly increased in incubations with $\mathrm{NMH}, \mathrm{NDMH}$ and NODMH $(p<0.05)$. Treatment of erythrocytes with DDC did not have any significant influence on the methemoglobin formation caused by HYAM, OMH and OEH. In contrast, DDC significantly decreased the release of lipid peroxidation products in erythrocyte incubations with HYAM and its O-derivatives (Fig. 2B). As shown in Figs. $3 \mathrm{~A}$ and $3 \mathrm{~B}, \mathrm{NDMH}$ had no effect on the total glutathione concentration and GST activity in erythrocytes that were not pretreated with DDC. However, NDMH incubated with DDC pretreated erythrocytes led to a significant depletion of total glutathione and impairment of the GST activity (Figs. 3A and 3B, respectively; $p<0.05$ ). Erythrocytes pretreated with DDC did not change the effects seen for the other five hydroxylamines on total glutathione concentrations and GST activities in normal erythrocytes (Fig. 3). Hydroxylamines tested at a concentration of $5 \mathrm{mM}$ showed the same pattern on the G6PDH activity as shown in Table 1 and pretreatment of erythrocytes with DDC did not significantly change any of these effects.
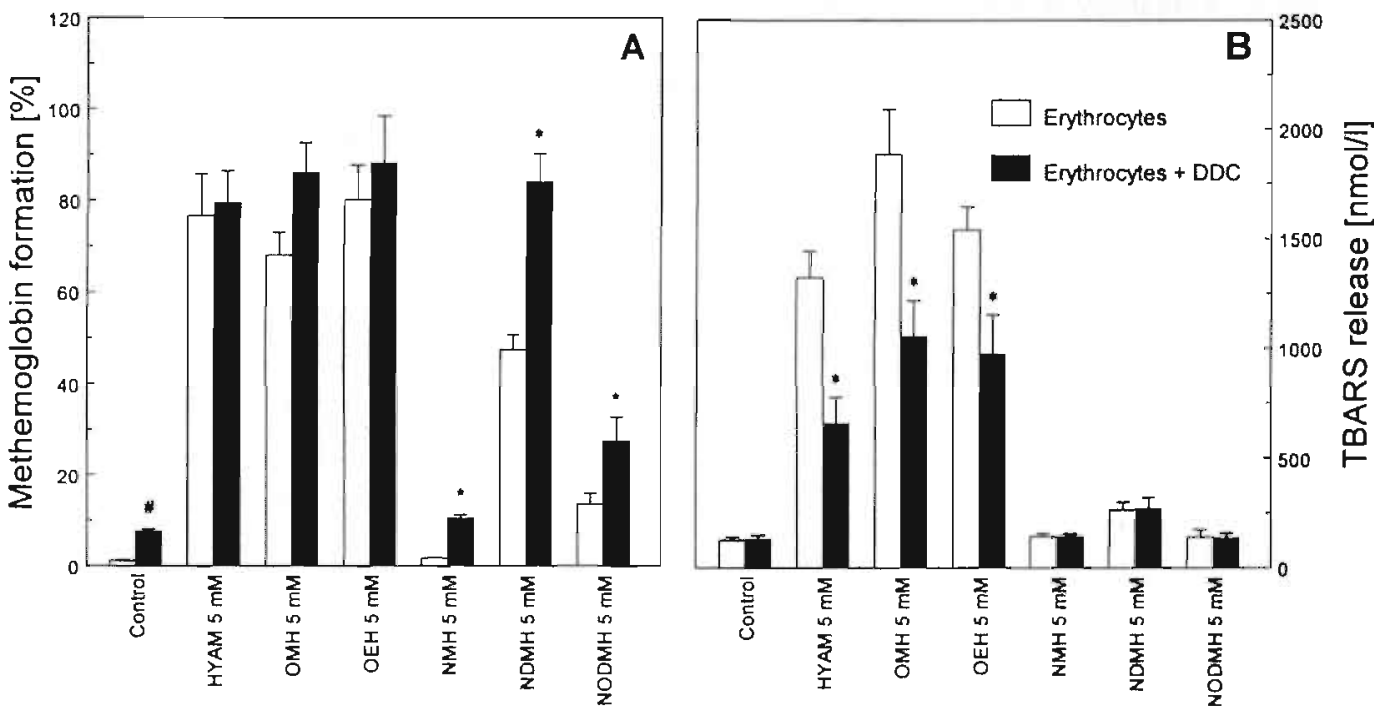

Figure 2: Effects of hydroxylamine (HYAM) and its derivatives on methemoglobin formation (A) and release of lipid peroxidation products $(B)$ in human erythrocytes and in diethyldithiocarbamate (DDC) pretreated erythrocytes after incubation for $1 \mathrm{~h}$ at $37^{\circ} \mathrm{C}$. \#Significant difference between the two controls $(p<0.05)$. *Statistically significant difference between DDC pre-treated and untreated erythrocytes after correction with the corresponding control $(p<0.05)$. 

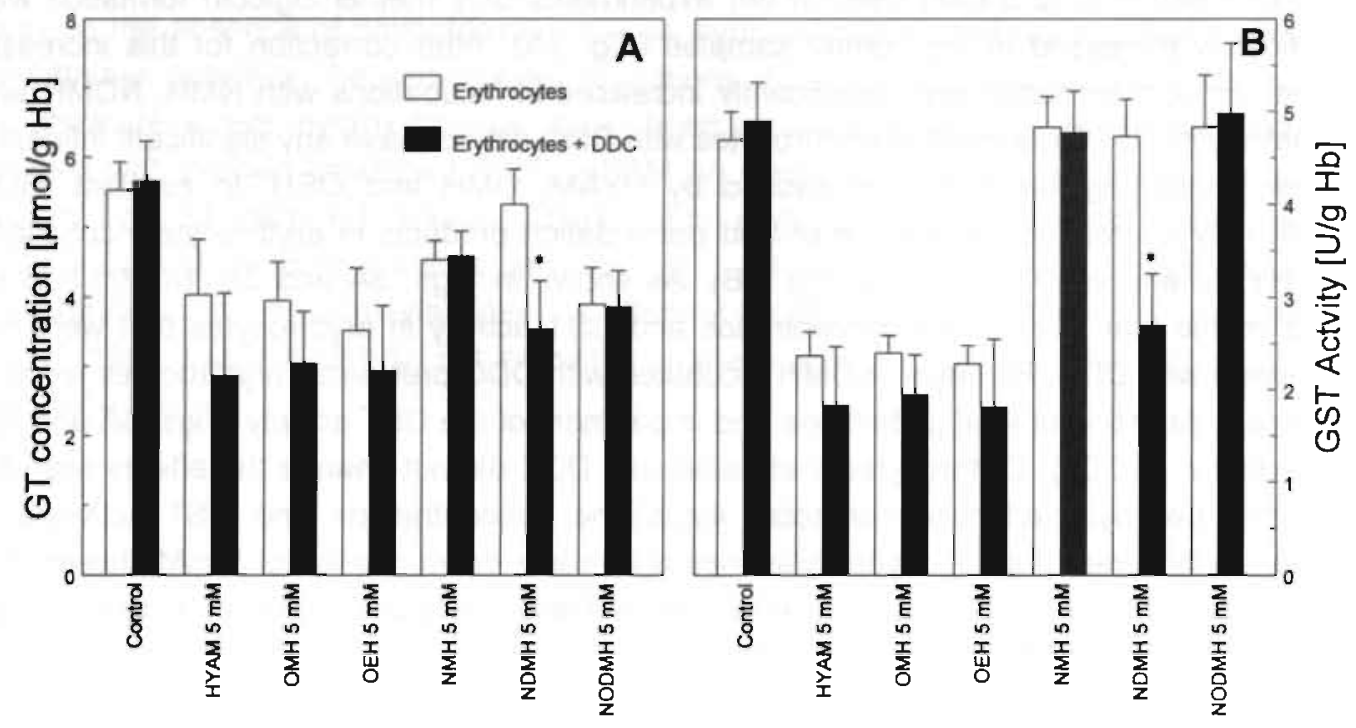

Figure 3: Availability of total (GT) glutathione (A) and effects on glutathione S-transferase (GST) activity $(B)$ in human erythrocytes and in diethyldithiocarbamate (DDC) pretreated erythrocytes after incubation with hydroxylamine (HYAM) and its derivatives for $1 \mathrm{~h}$ at $37^{\circ} \mathrm{C}$. "Statistically significant difference between DDC pretreated and untreated erythrocytes after correction with the corresponding control $(p<0.05)$.

\section{Kinetics of methemoglobin formation}

Figure 4 shows the time course of methemoglobin formation in human erythrocytes and hemolysates with the various hydroxylamines. Again, the highest concentration of methemoglobin in erythrocytes was obtained with HYAM and its O-derivatives. For HYAM the maximum was already reached after $10 \mathrm{~min}$, after which the increase almost completely stopped. For $\mathrm{OMH}$ and $\mathrm{OEH}$ high levels of methemoglobin were also reached after about 10 min, but this was followed by a smooth increase that continued until the end of the incubation. The same pattern was seen for NODMH but with much lower concentrations of methemoglobin. A very low rate of methemoglobin formation was found for $\mathrm{NMH}$ that was already at its maximum after $2 \mathrm{~min}$. In contrast, the formation of methemoglobin in incubations of erythrocytes with NDMH showed an almost linear increase over time. Since the lower effects of $\mathrm{N}$-derivatives on the erythrocytes could be the result of uptake limitations, the time courses were also determined in hemolysates. For $\mathrm{NMH}$ a small increase was found in comparison with the incubations in erythrocytes but the total methemoglobin level was still very low. The effect of NODMH in hemolysate was much stronger than that in erythrocytes. The final methemoglobin level was about tripled and the time course remained linear four till five times longer than in erythrocytes. However, the 
methemoglobin level in incubations with NDMH was somewhat lower than in the incubations with erythrocytes. The course of the methemoglobin curve for NDMH stayed the same.

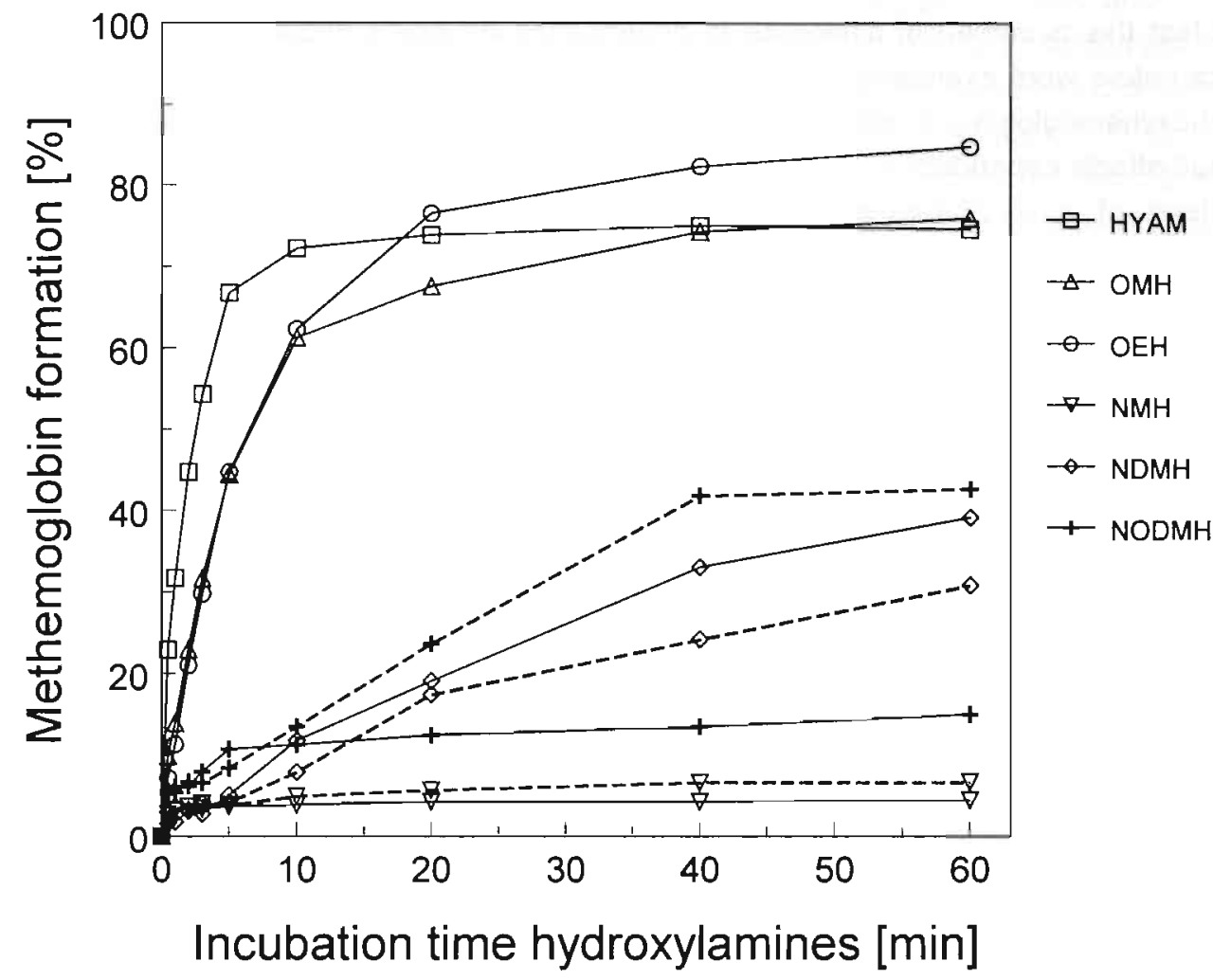

Figure 4: Time course of the reaction between the different hydroxylamines and oxyhemoglobin in human erythrocytes $(-)$ or hemolysates $(---)$. Concentration hydroxylamines were $5 \mathrm{mM}$ in erythrocytes and $2 \mathrm{mM}$ in hemolysates. The oxyhemoglobin content was $158 \pm 8 \mathrm{~g} / \mathrm{l}$ in erythrocytes and $40 \pm 3 \mathrm{~g} / \mathrm{l}$ in hemolysate. The reaction temperature was $37^{\circ} \mathrm{C}$.

\section{DISCUSSION}

In accordance with previously published results $[9,31]$ the oxidative potency of HYAM and its $\mathrm{O}$-derivatives was generally larger than the effects of the $\mathrm{N}$-derivatives (Table 1 ). The effects of the two groups of hydroxylamines also differed in a qualitative sense. HYAM and its O-derivatives caused methemoglobin, lipid peroxidation and a number of other effects that could be related to oxidative stress. The $\mathrm{N}$-derivatives $\mathrm{NMH}$ and NODMH were less active in this respect but did inhibit G6PDH and GR. This and other reasons given in the introduction led us to the postulation that the interaction with oxyhemoglobin is the first and critical step in the erythrotoxicity of HYAM and its O-alkyl derivatives while such an interaction needs not be 
necessary for the effects of the mono $\mathrm{N}$-alkyl hydroxylamines. NDMH, a double $\mathrm{N}$-substituted hydroxylamine showed an intermediate scheme of reactivity, and therefore only part of the NDMH effects was expected to depend on interactions with oxyhemoglobin.

To test this hypothetical difference in dependence on oxyhemoglobin the same biological parameters were evaluated after the oxyhemoglobin content of the cell was transformed to carboxyhemoglobin (i.e. hemoglobin complexed with $\mathrm{CO}$ and therefore not oxidisable). As a result effects dependent on interaction with the heme group in hemoglobin should disappear. Instead of sole disappearance of the erythrotoxic effects caused by HYAM and its O-derivatives, we found that the effects caused by the $\mathrm{N}$-derivatives were also lacking in erythrocytes containing carboxyhemoglobin. In other words, all hydroxylamines are dependent on the presence and accessibility of oxyhemoglobin to exert their toxicity. On the other hand there must be differences in the way the different groups of hydroxylamines interact with oxyhemoglobin. An explanation for the toxic differences may involve electronic or steric hindrance in the reaction with oxyhemoglobin and/or differences in the relative stability of the radical intermediates produced in erythrocytes.

As mentioned before, Stolze and co-workers $[23,34-36]$ have detected nitroxide radicals resulting from the hemoglobin oxidation by HYAM, NMH and NDMH. The nitroxide radicals derived from NMH and NDMH were considerably more stable than the corresponding radical derived from HYAM. The nitroxide radical from $\mathrm{NMH}$ did undergo a rapid degradation with concomitant formation of a secondary product. This difference in radical stability and radical products is likely to contribute to the differences in hydroxylamine toxicity seen in this study. The radical products that may be formed in the reaction of O-substituted hydroxylamines with hemoglobin are unknown. In principle both amino radicals $\left(\mathrm{R}_{1} \mathrm{~N}^{*} O \mathrm{R}_{2}\right)$ and nitroxide radicals $\left(\mathrm{R}_{2} \mathrm{R}_{1} N \mathrm{NO}^{\circ}\right)$ could be formed. $\mathrm{OMH}, \mathrm{OEH}$ and $\mathrm{NODMH}$ can yield amino radicals in organic solvents $[14,39]$. For the formation of nitroxide radicals O-dealkylation is a prerequisite. It is well known that oxyhemoglobin in erythrocytes possesses mixed-function oxidase activity [20] and is able to $\mathrm{N}$-demethylate methylaniline [32]. O-demethylation activity was also reported for oxyhemoglobin [20] but to our knowledge not within erythrocytes. We tried to detect radical intermediates from interaction of O-methyl, O-ethyl and $\mathrm{N}, \mathrm{O}$-dimethyl hydroxylamine with human oxyhemoglobin using ESR. We were able to confirm the formation of the nitroxide radicals for NDMH and —using a flow system—also for HYAM that were previously seen in studies with bovine hemoglobin. Despite extensive variations in experimental conditions (flow rates, time constant, concentration hemoglobin and test compound etc.) we were not able to detect any radical products for $\mathrm{OMH}, \mathrm{OEH}$ and NODMH. The most likely explanation is that the radical products for these compounds are very short living, rapidly producing non-radical intermediates and that these are the cause of the other toxic effects.

Differences in the production of reactive oxygen species like $\mathrm{H}_{2} \mathrm{O}_{2}$ and superoxide can be another cause for the different erythrotoxicity patterns found for the hydroxylamine analogues. Evidence for $\mathrm{H}_{2} \mathrm{O}_{2}$ generation during the reaction of HYAM, NMH and NDMH 
with oxyhemoglobin was reported by Nohl and Stolze [22]; heme-bound hydrogen peroxide was detected with a chemiluminescence technique. Here $\mathrm{H}_{2} \mathrm{O}_{2}$ was detected by demonstration of catalase- $\mathrm{H}_{2} \mathrm{O}_{2}$ complex $\mathrm{I}$ in hemolysates treated with hydroxylamines. Of the six hydroxylamines tested HYAM, OMH, OEH and NDMH produced detectable $\mathrm{H}_{2} \mathrm{O}_{2}$ levels. Higher concentrations ( $3 \mathrm{mM}$ ) of HYAM and the O-derivatives decreased the inhibition of catalase. This does not necessarily mean that less $\mathrm{H}_{2} \mathrm{O}_{2}$ is produced at higher hydroxylamines concentrations since the aminotriazole detectable catalase inhibition is lowered at increased rates of $\mathrm{H}_{2} \mathrm{O}_{2}$ production $[8,18]$. In contrast, higher concentrations of NDMH led to an increase in catalase inhibition. This indicates that more $\mathrm{H}_{2} \mathrm{O}_{2}$ was produced but that the production rate was not overly fast for catalase inhibition by aminotriazole. Nohl and Stolze [22] also proved low levels of heme-bound hydrogen peroxide for $\mathrm{NMH}$. For this reason, it is likely that all hydroxylamines produce $\mathrm{H}_{2} \mathrm{O}_{2}$ when interacting with oxyhemoglobin, but that the levels produced by NMH and NODMH are too low for detection.

The role of superoxide radicals in the reaction of hydroxylamines with oxyhemoglobin was studied by inhibition of SOD with DDC. The most striking effect of this inhibition was that NDMH gave a significant decrease in total glutathione concentration and in GST activity, while it had no effect on these parameters in the absence of DDC (Fig. 3). Production of superoxide radicals was also evident for all other hydroxylamines tested. SOD inhibition lead to increased methemoglobin formation in incubations with $\mathrm{NMH}, \mathrm{NDMH}$ and NODMH (Fig. 2A). Superoxide radicals can oxidise hemoglobin [41], but the rate constant for this reaction is low. Normally only about $0.1 \%$ of the superoxide radical formed is likely to react with hemoglobin before it is scavenged by SOD. In the absence of SOD the fraction able to oxidise hemoglobin will be much higher. This explains the increase in methemoglobin formation seen for NMH, NODMH and NDMH. For NMH and NODMH the amount of extra methemoglobin formation was - although clearly significant- very small and no additional effects on total glutathione and GST activity were seen. This indicates that superoxide radical formation for NMH and NODMH is less important than it is for NDMH. For HYAM, $\mathrm{OMH}$ and $\mathrm{OEH}$ the main effect of SOD inhibition was a decrease in lipid peroxidation. Inhibition of SOD will lead to a slower formation of $\mathrm{H}_{2} \mathrm{O}_{2}, \mathrm{H}_{2} \mathrm{O}_{2}$ is more stable than superoxide and it is therefore more likely to reach the lipid regions and to cause lipid peroxidation. At the normal formation rate (i.e. without SOD inhibition) a smaller fraction of $\mathrm{H}_{2} \mathrm{O}_{2}$ can be detoxified by catalase and GPX and more lipid peroxidation will occur. The same reasoning should of course apply to $\mathrm{NMH}, \mathrm{NDMH}$ and NODMH, but for these compounds the total production of reactive compounds is so low that no or little lipid peroxidation occurs even without SOD inhibition. No increases in methemoglobin formation were found for HYAM, OMH and OEH. The level of methemoglobin was already very high, and it is likely that this obscured the detection of additional methemoglobin resulting from the production of superoxide. The same is probably true regarding the absence of additional effects on total glutathione concentrations and GST activity for these compounds.

The toxicity of all hydroxylamines was thus found to depend on an interaction with oxyhemoglobin that produces radical intermediates and concomitantly superoxide radicals 
and $\mathrm{H}_{2} \mathrm{O}_{2}$. Differences in cellular kinetics —uptake and reaction with oxyhemoglobin- are likely to be among the most important factors that determine the different erythrotoxic patterns. All six hydroxylamines have a small molecular size and are very soluble in water. For this reason they are expected to enter erythrocytes easily. This is confirmed by the fact that each hydroxylamine gave at least one clear effect in erythrocytes (Table 1). Differences in uptake speed will nevertheless exist and will influence the rate at which interaction with hemoglobin can occur. Figure 4 shows that such differences do indeed exist for the kinetics of methemoglobin formation in erythrocytes. Not only was the final level of methemoglobin formed much lower for the $\mathrm{N}$-derivatives but also the reaction rate with oxyhemoglobin was slower than with HYAM and its O-derivatives. Off the six agents tested, NMH reacted slowest with oxyhemoglobin. The rate of hemoglobin oxidation seen for HYAM was estimated to be at least 3600 times that of $\mathrm{NMH}$. Methemoglobin formation by $\mathrm{OMH}$ and $\mathrm{OEH}$ was somewhat slower than for HYAM, but still very rapid. NODMH lead to a somewhat

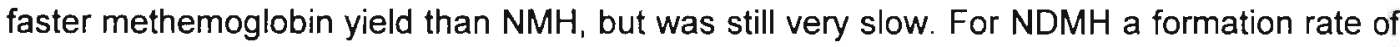
methemoglobin was found that was in between those of the O-derivatives and that of $\mathrm{NMH}$. The substances with the higher formation rates of methemoglobin were the same ones for which production of $\mathrm{H}_{2} \mathrm{O}_{2}$ was demonstrated, another confirmation that the formation of $\mathrm{H}_{2} \mathrm{O}_{2}$ results from hemoglobin oxidation.

To ensure that the low formation rate of methemoglobin found for the $\mathrm{N}$-derivatives are not due to limited cellular uptake, reaction rates for the $\mathrm{N}$-derivatives were also established in hemolysates. For NMH and NDMH no important differences in kinetics were seen between the incubations in erythrocytes and in hemolysates, indicating that cellular uptake is not an important limiting factor for these compounds (Fig. 4). NODMH, on the other hand, tripled its effect on hemoglobin in hemolysates compared with incubations in erythrocytes. This implies that cellular uptake is a limiting factor for NODMH. This is likely to result from constraint uptake due to its lipophilicity but might also be the result of intracellular metabolism or active export.

Based on our results we conclude that the hydroxylamines are dependent on oxyhemoglobin for their toxic effects, which explains why the erythrocyte is the primary target cell in humans. All hydroxylamines enter the erythrocyte where they undergo a coupled redox reaction with oxyhemoglobin to form methemoglobin and radicals (hydroxylamine dependent radical intermediates, superoxide radicals and $\mathrm{H}_{2} \mathrm{O}_{2}$ ). The differences in potency of the different hydroxylamines can be explained by at least three mechanisms. First, the nature of the interaction between hydroxylamines and oxyhemoglobin is different leading to radical intermediates that differ in stability. The fact that $\mathrm{N}$-derivatives have more stable radical intermediates than HYAM [36] can be the reason why these $\mathrm{N}$-derivatives predominantly lead to oxyhemoglobin dependent inhibition of G6PDH and GR. Second, the reaction rate between hydroxylamines and oxyhemoglobin differs, leading to differences in the production rates of reactive species. At lower formation rates -as seen for the $\mathrm{N}$-derivatives - the products can be better detoxified leading to diminished effects on lipid peroxidation, total glutathione concentrations and activity of GST, GPX and MHbR. This is particularly true for 
NMH that gives almost no hemoglobin oxidation. NDMH reacted somewhat faster than the other $\mathrm{N}$-derivatives. It showed only part of the effects that are expected to result from the formation of reactive oxidant species: inhibition of GPX and MHbR but no inhibition of GST and no decreases in total glutathione. This seems to indicate that these two enzymes are more sensitive to oxidative stress in erythrocytes and could provide a more useful detection system than glutathione depletion and GST inhibition. Finally, differences in cellular uptake will also contribute to the differences in hemoglobin oxidation rates and in the resulting toxicity profiles. Uptake limitation is probably one of the major reasons for the limited oxidative potency of NODMH. On the whole, these data support the thesis that interaction with oxyhemoglobin is the key step in the toxicity of all hydroxylamines tested, and that differences in kinetics —uptake, reaction with hemoglobin and product stability - is an important factor to explain the differences in toxicity profiles.

Acknowledgements The authors are grateful to Prof. Dr. A. Bast of the Department of Pharmacochemistry, Faculty of Chemistry, Free University, Amsterdam, The Netherlands, for the opportunity to perform ESR spectroscopy measurements at his department. We thank Ingrid Dekker of the same department for her excellent technical assistance and the "Red Cross Blood-bank, South Limburg" for the blood samples used. 


\section{References}

1 Adams DH and Roe FJ, The action of some chemical substances on mouse liver catalase activity in vivo. Br. J. Cancer 7: 509-18, 1953

2 Anderson ME, Determination of glutathione and glutathione disulphide in biological samples. Meth. Enzymol. 113: 548-55, 1985

3 Beutler E, Red cell metabolism (A manual of biochemical methods). New York: Grune and Stratton, 1975

Brouwer EJ, Evelo CTA, Verplanke AJW, van Welie RTH and de Wolff FA, Biological effect monitoring of exposure to 1,3-dichloropropene: effects on liver and renal function and on glutathione conjugation. Br. J. Ind. Med. 48: 167-72, 1991

5 Carlberg I and Mannervik B, Glutathione reductase. Meth. Enzymol. 113: 484-90, 1985

6 Carrell RW, Winterbourn CC and Rachmilewitz EA, Activated oxygen and haemolysis. $\mathrm{Br}$. J. Haematol. 30: 368-89, 1975

7 Cohen $G$ and Hochstein $P$, Generation of hydrogen peroxide in erythrocytes by hemolytic agents. Biochem. 3: 895-900, 1964

Darr D and Fridovich I, Irreversible inactivation of catalase by 3-amino-1,2,4-triazole. Biochem. Pharmacol. 35: 3642, 1986

9 Evelo CTA, Spooren AAMG, Bisschops RAG, Baars LGM and Neis JM, Two Mechanisms for toxic effects of hydroxylamines in human erythrocytes: Involvement of free radicals and risk of potentiation. Blood Cells, Molecules Diseases 24: 280-95, 1998

10 Gross P, Biologic activity of hydroxylamine: A Review. CRC Crit. Rev. Toxicol. 14: 87-99, 1985

11 Habig WH and Jakoby WB, Assays for the differentiation of glutathione S-transferases. Meth. Enzymol. 77: 398-405, 1981

12 Heikkila RE, Cabbat FS and Cohen G, In vivo inhibition of superoxide dismutase in mice by diethyldithiocarbamate. J. Biol. Chem. 251: 2182-5, 1976

13 Huennekens FM, Caffrey RW, Basford RE and Gabrio BW, Erythrocyte metabolism. IV. Isolation and properties of methemoglobin reductase. J. Biol. Chem. 227: 261-72, 1957

14 Kaba RA and Ingold KU, Kinetic applications of electron paramagnetic resonance spectroscopy. 28. $\mathrm{N}$-alkoxy-N-alkylamino, $\mathrm{N}$-alkoxyamino, and $\mathrm{N}$-alkoxyanilino radicals. J. Am. Chem. Soc. 10: $7375-80,1976$

15 van Kampen EJ and Zijlstra WG, Determination of hemoglobin and its derivatives. Adv. Clin. Chem. 8: 141-87, 1965

16 Keilin D and Hartree EF, On some properties of catalase haematin. Proc. Roy. Soc. Biol. Sci. B121: 173-91, 1936

17 L'Abbé MR and Fischer PWF, An automated method for the determination of Cu,Zn-Superoxide dismutase in plasma and erythrocytes using an ABA-200 ${ }^{\mathrm{TM}}$ discrete analyzer. Clin. Biochem. 19: 175-8, 1986

18 Margoliash E, Novogrodsky A and Schejter A, Irreversible reaction of 3-amino-1,2,4-triazole and related inhibitors with the protein of catalase. Biochem. J. 74: 339-48, 1960

19 McCord JM and Fridovich I, Superoxide Dismutase: an enzymic function for erythrocuprein (hemocuprein). J. Biol. Chem. 244: 6049-55, 1969

20 Mieyal JJ, Monooxygenase activity of hemoglobin and myoglobin. In: Reviews in biochemical toxicology. (eds. Hodgson E, Bend JR and Philpot RM), pp. 1-66. Amsterdam: Elsevier, 1985

21 Misra HP, Reaction of copper-zinc superoxide dismutase with diethyldithiocarbamate. J. Biol. Chem. 254: 11623-8, 1979 
22 Nohl $\mathrm{H}$ and Stolze $\mathrm{K}$, Chemiluminescence from activated heme compounds detected in the reaction of various xenobiotics with oxyhemoglobin: comparison with several heme/hydrogen peroxide systems. Free Rad. Biol. Med. 15: 257-63, 1993

23 Nohl $\mathrm{H}$ and Stolze K, The effects of xenobiotics on erythrocytes. Gen. Pharmac. 31: 343-7. 1998

24 Paglia DE and Valentine $\mathrm{WN}$, Studies on the quantitative and qualitative characterization of erythrocyte glutathione peroxidase. J. Lab. Clin. Med. 70: 158-69, 1967

25 Palmen NGM and Evelo CTA, Oxidative effects in human erythrocytes caused by some oximes and hydroxylamine. Arch. Toxicol. 72; 270-6, 1998

26 Riemann H, On the toxicity of hydroxylamine. Acta Pharmacol. 6: 285-92, 1950

27 Schonbaum GR and Chance B, Catalase. In: The enzymes. (eds. Boyer PD), pp. 363-408 London: Academic Press, 1976

28 Sinet $\mathrm{PM}$, Barber $\mathrm{P}$ and Jerome $\mathrm{H}_{1} \mathrm{H}_{2} \mathrm{O}_{2}$ production, modification of the glutathione status and methemoglobin formation in red blood cells exposed to diethyldithiocarbamate in vitro. Biochem. Pharmacol. 31: 521-5, 1982

29 Sinha D and Sleigh SD, Experimental production of Heinz Bodies in the pig. Toxicol. Appl. Pharmacol. 12: 435-9, 1986

30 Spooren AAMG and Evelo CTA, Hydroxylamine treatment increases glutathione-protein and protein-protein binding in human erythrocytes. Blood Cells, Molecules Diseases 23: 323-36, 1997

31 Spooren AAMG and Evelo CTA, In vitro haematotoxic effects of three methylated hydroxylamines. Arch. Toxicol. 71: 299-305, 1997

32 Stecca $\mathrm{C}$ and Duverger-van Bogaert $\mathrm{M}, \mathrm{N}$-Demethylation reactions in intact erythrocytes and erythrocyte supernatant. Arch. Toxicol. Suppl. 13: 291-3, 1989

33 Stocks $\mathrm{J}$ and Dormandy $\mathrm{TL}$, The autoxidation of human red cell lipids induced by hydrogen peroxide. Br. J. Haematol. 20: 95-111, 1971

34 Stolze K, Dadak A, Liu $Y$ and Nohl $H$, Hydroxylamine and phenol-induced formation of methemoglobin and free radical intermediates in erythrocytes. Biochem. Pharmacol. 52: 18219, 1996

35 Stolze $K$ and Nohl $H$, Detection of free radicals as intermediates in the methemoglobin formation from oxyhemoglobin induced by hydroxylamine. Biochem. Pharmacol. 38: 3055-9, 1989

36 Stolze $\mathrm{K}$ and $\mathrm{Nohl} \mathrm{H}$, Free radical intermediates in the oxidation of $\mathrm{N}$-methylhydroxylamine and N,N-dimethylhydroxylamine by oxyhemoglobin. Free Rad. Res. Comm. 8: 123-31, 1990

37 Tietz NW, Textbook of clinical chemistry. Philadelphia: W.B. Saunders, 1986

38 Tsuchihashi M, Zur Kenntnis der Blutkatalase. Biochem. Z. 140: 63-112, 1923

39 Wardman $\mathrm{P}$ and Smith DR, Electron spin resonance studies of the radiolysis of aliphatic amines adsorbed on silica gel. Can. J. Chem, 49: 1880-7, 1971

40 Webster SH, Liljegren EJ and Zimmer DJ, Heinz body formation by certain chemical agents. J. Pharmacol. Exp. Ther. 95: 201-11, 1949

41 Winterbourn CC, Haemoglobin oxidation and free radical production in the red cell. Biomed. Biochim. Acta 42: s134-8, 1983 

Chapter 7

Occupational Handling of O-methyl Hydroxylamine:

Adoption of an Integrated Strategy for Risk Prevention

Submitted for publication 


\title{
Occupational handling of O-methyl hydroxylamine: adoption of an integrated strategy for risk prevention
}

\author{
Anita A.M.G. Spooren ${ }^{1}$, Leo G.M. Baars ${ }^{1}$, Jan G. Bakker ${ }^{2}$, John M. Neis ${ }^{3}$ and \\ Chris T.A. Evelo ${ }^{1 *}$ \\ ${ }^{\dagger}$ Department of Pharmacology, University Maastricht, P.O. Box 616, 6200 MD Maastricht, \\ The Netherlands \\ ${ }^{2}$ Occupational Health Department, USM, Geleen, The Netherlands \\ ${ }^{3}$ Corporate Department for Safety, Environment, Health and Technology, DSM, Heerlen, \\ The Netherlands
}

\begin{abstract}
Objectives An integrated strategy was adopted to prevent risks related to O-methyl hydroxylamine $(\mathrm{OMH})$ exposure in a recently started $\mathrm{OMH}$ production facility. This strategy consisted of a preopening phase and a check phase.

Pre-opening phase This phase included a toxicological evaluation of available data for two structurally related compounds, hydroxylamine (HYAM) and O-ethyl hydroxylamine (OEH). The hazard assessments made for OEH and HYAM lead to the conclusion that these compounds share their main toxicity pattern (i.e. erythrotoxicity) with about equal potency. Considering the structure analogy, we assumed that the main toxicity hazard for $\mathrm{OMH}$ would also be erythrotoxicity and that the potency of $\mathrm{OMH}$ would be about equal to that of HYAM and OEH. This was confirmed by the marginal data on toxicity of $\mathrm{OMH}$ itself present in the literature. Next to this toxicological evaluation an in vitro study with human erythrocytes was carried out that confirmed the erythrotoxic potency of $\mathrm{OMH}$. Based on all these data an advised maximum exposure level for $\mathrm{OMH}$ was set at $0.1 \mathrm{ppm}$. Furthermore, this phase consisted of development of a production design that would minimise exposure risk and adoption of a lay-out of work regulations that would almost exclude exposure.

Check phase In the check phase environmental monitoring was performed to verify that the advised maximum exposure level for $\mathrm{OMH}$ was not exceeded and biochemical effect monitoring was performed to verify that no adverse health effects occurred in workers during the production process. Environmental monitoring showed that the $\mathrm{OMH}$ exposure was clearly below the advised maximum exposure level of $0.1 \mathrm{ppm}$. In the biological effect monitoring study no detectable adverse biochemical effects that related to $\mathrm{OMH}$ exposure were found.

Conclusions We conclude that the strategy used ensures an acceptable situation for workers with regard to $\mathrm{OMH}$ exposure. This study illustrates the value of in vitro techniques in hazard assessment for structurally related compounds.
\end{abstract}




\section{INTRODUCTION}

O-Methyl hydroxylamine (OMH, $\mathrm{H}_{2} \mathrm{NOCH}_{3}$; CAS-no 593-56-6) is a chemical belonging to the family of alkoxyamines and it is a derivative of hydroxylamine (HYAM, $\mathrm{H}_{2} \mathrm{NOH}$ ). Hydroxylamines are used as intermediates in the production of pharmaceuticals and pesticides, as reducing agents in the dye-, perfume- and photographic industry, in aldehyde and ketone purification, as oxidants for fatty acids and soaps, or as tanning agents $[7,11]$. In animals hydroxylamine exposure has resulted in hemolytic anemia accompanled by methemoglobinemia, sulfhemoglobinemia, Heinz body formation and splenomegaly $[14,19,21,22,33,34]$. In man mild hemolytic anemia was reported following the inhalation of three hydroxylamine-compounds (O-methyl, N,O-dimethyl and trimethyl hydroxylamine) without detectable formation of Heinz bodies and methemoglobin [16]. Hydroxylamine sulphate is known to have also skin sensitising properties. In former days handling of HYAM sulphate resulted occasionally in allergic skin reactions, caused by difficult to control skin contact with the dust of this salt. Despite periodically repeated medical investigations, effects on the blood have never been found. Improved occupational hygiene conditions nowadays have banned this kind of skin problems. Exposure to hydroxylamine derivatives in liquid (and vaporous) form, e.g. alkoxyamines, can present an other kind of danger to the exposed workers since systemic effects might occur at low exposure levels.

Experimental data describing the toxicity of $\mathrm{OMH}$ as such is not available in abundance. To our knowledge only one chronic study is described by Yamamoto et al [34] where OMH as well as HYAM did not cause tumour formation after long-term administration in mice. In this study the principal toxic effects were anemia and splenomegaly. For this reason an integrated strategy was adopted for risk prevention with regard to $\mathrm{OMH}$ exposure in a production facility for $\mathrm{OMH}$. During the pre-opening phase this procedure consisted of: a) a toxicological evaluation of the available data for the related compounds HYAM and O-ethyl hydroxylamine $\left(\mathrm{OEH}, \mathrm{H}_{2} \mathrm{NOC}_{2} \mathrm{H}_{5}\right) ;$ b) an in vitro study towards the erythrotoxic potency of $\mathrm{OMH}$ intended to confirm the hazard assessment made on the basis of the analogy evaluation and the scarce adequate $\mathrm{OMH}$ in vivo data. This in vitro study was also intended to provide biochemical parameters that would be useful for biochemical effect monitoring; $c$ ) a plant design based on a closed reaction system to minimise exposure risk; d) a lay-out of work regulations that would in principle almost exclude exposure during normal production while full protective clothing with clean-air supply is to be worn during any work (e.g. maintenance, sampling) that might involve higher exposures.

Immediately after the start of the $\mathrm{OMH}$ production this was followed by a check phase in which it was verified that: e) the intended advised maximum exposure levels were not exceeded using environmental monitoring with personal air sampling and spot measurements; f) no detectable adverse biochemical effects were present in the blood of the workers using biochemical effect parameters based on the results of the earlier in vitro study. Finally this was followed by a normal production phase during which work regulations remain 
effective and a scheme of air-sampling measurements is continued to ensure commitment to the exposure limit value.

\section{PRE-OPENING PHASE}

As described above a multistage strategy was adopted to prevent risks during the $\mathrm{OMH}$ production. First a toxicological evaluation took place of the available data of the two related hydroxylamines HYAM and OEH. In vitro HYAM and OEH cause oxidative effects in human erythrocytes [8]. In contrast $\mathrm{N}, \mathrm{O}$ dimethyl hydroxylamine (NODMH) causes only inactivation of two protective enzymes, glutathione reductase (GR) and glucose 6-phosphate dehydrogenase (G6PDH) [8]. In vivo HYAM causes methemoglobinemia, sulfhemoglobinemia, formation of Heinz bodies and splenomegaly which all results in hemolytic anaemia $[14,19,21,22,33,34]$. Methemoglobinemia, splenomegaly and anemia were also found in vivo for OEH (data not published). Based on these in vivo OEH data, the maximum advised exposure level for $\mathrm{OEH}$ was set at $0.1 \mathrm{ppm}$. Taking the structural analogy into account, one would expect that exposure to $\mathrm{OMH}$ results in the same kind of toxicological effects as exposure to HYAM and $\mathrm{OEH}$. Moreover, the structural properties of $\mathrm{OMH}$ are likely to result in physicochemical properties that lie in between those of HYAM and OEH (Figure 1). The results of the in vivo $\mathrm{OMH}$ study by Yamamoto et al [34] provided evidence that the main target for OMH toxicity is indeed the red blood cell as was found for HYAM and OEH. The hazard assessments made for HYAM and OEH lead to the conclusion that these compounds share their main toxicity pattern (i.e. erythrotoxicity) with about equal potency. Taken together this lead to the conclusion that the main toxicity hazard of $\mathrm{OMH}$ would also be erythrotoxicity and that maximum exposure levels should be preliminary set equal to that adopted for OEH (0.1 ppm).

Next an in vitro study was carried out to confirm the erythrotoxic potency of $\mathrm{OMH}$. This study indicated that $\mathrm{OMH}$ is equally potent in oxidative effects as OEH and HYAM in human erythrocytes [24]. OMH caused methemoglobin formation, release of lipid peroxidation products, depletion of total glutathione (GT), inhibition of glutathione S-transferase (GST) and NADPH methemoglobin reductase activity but no inhibition of GR and G6PDH activity. Previously, we showed that the latter two enzymes were only inactivated by NODMH, an $\mathrm{N}$-derivative of HYAM [8], they were all the same measured in erythrocyte incubations with $\mathrm{OMH}$ to rule out the occurrence of this kind of effects. The main conclusion of this in vitro study was that the biochemical effects caused by $\mathrm{OMH}$ in human erythrocytes do indeed correspond to what was found for HYAM and OEH and not to the effects caused by $\mathrm{N}$-derivatives. The finding that the potency of $\mathrm{OMH}$ to cause erythrotoxic effects is about equal to that of HYAM and $\mathrm{OEH}$ underlined the hazard assessments made for $\mathrm{OMH}$ on the basis of the expected structure activity relationship. 


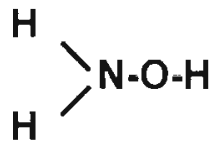

Hydroxylamine

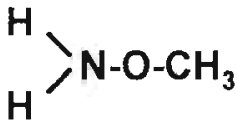

O-Methyl Hydroxylamine

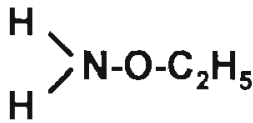

O-Ethyl Hydroxylamine

Figure 1: Structures of three hydroxylamine analogues. The parent compound hydroxylamine (HYAM; left), the earlier produced O-ethyl hydroxylamine (OEH; right) and the main compound in this study O-methyl hydroxylamine (OMH; in the middle).

The information obtained mainly from the comparative study and from the $\mathrm{OMH}$ in vitro study was integrated and used to obtain an advised maximum exposure value for $\mathrm{OMH}$. Using this structure analogy evaluation, the advised maximum exposure value of $0.1 \mathrm{ppm}$ for $\mathrm{OEH}$ based on experimental $\mathrm{OEH}$ data, was also suggested for $\mathrm{OMH}$. From the in vitro data a tentative advised maximum exposure level for $\mathrm{OMH}$ could be calculated on the conservative assumption that all inhaled $\mathrm{OMH}$ reaches the blood and remains there long enough to react with hemoglobin. Extrapolation of the in vitro data for methemoglobin formation by $\mathrm{OMH}$ shows that about $1 \%$ methemoglobin formation will occur at $0.1 \mathrm{mM} \mathrm{OMH}$ per litre blood [24]. Since in healthy persons about 3\% methemoglobin is formed per day [4], $1 \%$ extra methemoglobin formation is not likely to lead to effects. The conservative assumption that all $\mathrm{OMH}$ will react with red blood cells before it is transported to other organs leads to a "volume of distribution" of 5 litres. This corresponds to inhalation of $0.5 \mathrm{mM} \mathrm{OMH}$ per day. In a working day $(8 \mathrm{~h})$ workers may inhale about 10,000 litre air (assumed ventilation rate of 21 $\mathrm{l} / \mathrm{min}$ ) this is equal to inhalation of $0.05 \mu \mathrm{M} \mathrm{OMH}$ per litre air which is equivalent to $1 \mathrm{ppm}$. This conservatively calculated maximum exposure level of $1 \mathrm{ppm}$ did not indicate a necessity to decrease the suggested exposure limit of $0.1 \mathrm{ppm}$ based on the structure analogy. Therefore, the advised maximum accepted exposure level for $\mathrm{OMH}$ was provisionally set at $0.1 \mathrm{ppm}$ at the start of the $\mathrm{OMH}$ production. An extra consideration was that this limit value is so low that even if the current procedures had missed some important toxic effects of $\mathrm{OMH}$ other than erythrotoxicity, this other effect would have been unlikely to result in further decrease of the derived advised limit value.

Apart from this, the in vitro study provided some useful parameters for biochemical effect monitoring. Hydroxylamines react with hemoglobin resulting in hemoglobin oxidation and liberation of free radical species which leads to lipid peroxidation $[24,28,29]$. Lipid peroxidation products together with the radical species then cause disturbance of erythrocyte membrane structures, consumption of antioxidant factors like reduced glutathione and inhibition of some important protective enzymes like GST and glutathione peroxidase (GPX) $[23,25]$. In the present study methemoglobin formation and release of lipid peroxidation products were analysed despite the fact that they presumably will not accumulate due to the activity of methemoglobin reductases which reduce methemoglobin to hemoglobin $[32,35]$ and due to the short life span of lipid peroxides [5]. As antioxidant systems, GT 
concentrations, GST, GPX and NADPH methemoglobin reductase activities were measured. Accumulation of activity loss of the enzymes is to be expected since the erythrocyte has no protein synthesis to compensate for this loss. Glutathione is the most important non-protein thiol and may be oxidised to GSSG (oxidised glutathione) [6]. Therefore, GT and GSSG concentrations were measured in blood and GSSG levels were also measured in the plasma because GSSG is exported from the erythrocyte to the plasma when the reductive capacity of the cell is insufficient [1]. In other words, GSSG levels in plasma are an indication for glutathione oxidation in the erythrocyte. People who are deficit in $\mathrm{G6PDH}$ activity are considerably more vulnerable to oxidative damage. In this in vivo study the subjects were screened for G6PDH activity to rule out sensitive subjects in the population. Besides these parameters some hematological effect parameters were measured to screen for hemoglobin degradation (bilirubin levels) and cell damage (total hemoglobin and haptoglobin concentrations).

The third part of the pre-opening stage strategy consisted of developing a plant design based on a closed reaction system to minimise exposure risk. Finally, a lay out of work regulations was adopted to exclude exposure during normal production. Full protective clothing with clean-air supply is worn during any work that might involve higher exposures.

\section{CHECK PHASE}

In this phase environmental monitoring was performed to verify that the advised maximum exposure level of $0.1 \mathrm{ppm}$ for $\mathrm{OMH}$ was not exceeded and biochemical effect monitoring was performed to verify that no adverse biochemical health effects occurred in workers during the production process

\section{Population and study design}

Apparently healthy male workers from the OMH plant ( $n=16, D S M$ Limburg bv) and from a control production facility that did not produce OMH ( $n=12$, DSM Limburg bv) and from the University of Maastricht ( $n=13)$ participated in the study. Twelve workers of the 16 workers exposed to $\mathrm{OMH}$ completed the study (OMH group). The other 12 workers of whom 10 completed the study worked in a production facility but not at the $\mathrm{OMH}$ plant (non-OMH group). All 13 workers of the University of Maastricht, whom were not exposed to OMH or any other chemical compound, completed the study (non-industrial group). By means of a questionnaire, completed on the first sampling day, information was obtained from each subject on age, smoking and drinking habits, and medication. These demographic characteristics are shown in Table 1.

The workers from the chemical plant work in three shifts: a morning shift (07.00-15.00 h), an afternoon shift (15.00-23.00 h) and a night shift (23.00-07.00 h). They work three or four days in a row and in between the different shifts they have two or three days off. Volunteers from the university work daily from 09.00 till $17.00 \mathrm{~h}$. To evaluate the effect of $\mathrm{OMH}$ exposure, blood samples were taken before and after occupational handling of $\mathrm{OMH}$. The 
first blood sample from the $\mathrm{OMH}$ and the non-OMH group was collected at random between 7.00 and 8.00 a.m. before the start of the $\mathrm{OMH}$ production. At this time subjects were always working in the morning shift. In the same period but on different days samples were taken at 09.00 a.m. from the non-industrial group. The second blood sample from the OMH and the non-OMH group was collected at random between 7.00 and 8.00 a.m. on the last day of every morning shift after handling $\mathrm{OMH}$. This means that the subjects had worked with $\mathrm{OMH}$ for two or three consecutive days before the blood samples were taken. It took three weeks to collect all blood samples from the workers and the average total working time at the $\mathrm{OMH}$ plant during this whole period was $5.8 \pm 3.4$ days (range $2-11$ ). Samples from the nonindustrial group were again collected on different days but in the same period.

Table 1: Demographic characteristics of the three groups studied

\begin{tabular}{|c|c|c|c|}
\hline Parameter (unit) & $\begin{array}{l}\text { OMH group } \\
(n=12)\end{array}$ & $\begin{array}{l}\text { Non-OMH group } \\
\qquad(n=10)\end{array}$ & $\begin{array}{c}\text { Non-industrial } \\
\text { group } \\
(n=13)\end{array}$ \\
\hline Age (years) & $37 \pm 7(25-46)$ & $36 \pm 5(30-46)$ & $34 \pm 9(24-53)$ \\
\hline $\begin{array}{l}\text { Smoking habit } \\
\text { (cigarettes/day) }\end{array}$ & $10 \pm 9(4-25)(3)$ & $13 \pm 7(4-25)(6)$ & $11 \pm 8(3-25)(6)$ \\
\hline $\begin{array}{l}\text { Alcohol intake } \\
\text { (glasses/week) }\end{array}$ & $10 \pm 5(5-20)(8)$ & $8 \pm 5(3-17)(8)$ & $9 \pm 5(3-21)(13)$ \\
\hline
\end{tabular}

Data are mean $\pm \mathrm{SD}$ and (range) and (total number of consumers)

Possible effects of exposure to $\mathrm{OMH}$ on blood were studied by measuring total hemoglobin, methemoglobin, GSSG and GT levels, release of lipid peroxidation products, NADPH methemoglobin reductase, GST (EC 2.5.1.18), GPX (EC 1.11.1.9) and G6PDH (EC 1.1.1.49) activities, and by measuring total bilirubin and haptoglobin concentrations in serum. Within one month after the study all workers were informed by the occupational physician about the personal outcome of the measurements.

\section{Analytical Methods}

At each sample point three blood samples were collected from every individual. Blood samples for measurement of GSSG and release of lipid peroxidation products in plasma were collected in $10 \mathrm{ml}$ vacuum tubes containing heparin as anticoagulant. For the measurement of bilirubin and haptoglobin blood was collected in $5 \mathrm{ml}$ vacuum tubes and was allowed to clot and transported within two hours to the laboratory for Clinical Chemistry and Hematology, Maasland Hospital, Sittard. For all other determinations blood was collected in $10 \mathrm{ml}$ vacuum tubes containing $\mathrm{K}_{3}$ EDTA as anticoagulant. After collection of the blood, the $K_{3} E D T A$ blood tube was kept on ice and the heparin blood tube was centrifuged to separate plasma from erythrocytes $(2000 \mathrm{~g})$. To measure GSSG, whole blood and plasma were immediately treated with an excess of $\mathrm{N}$-ethylmaleimide (NEM) to prevent oxidation of glutathione. After 10 minutes incubation at room temperature, protein was denaturated with 
$10 \%$ (w/v) trichloroacetic acid (TCA). To measure release of lipid peroxidation products, plasma from the heparin blood tube was immediately denaturated with $10 \%$ TCA (w/v). Blood samples were transported in a cool box to the Department of Pharmacology, University Maastricht, and analysed on the same day. Enzyme activities in whole blood were determined spectrophotometrically, according to the methods of Habig and Jakoby [12] (GST), Beutler [3] (G6PDH), Huennekens et al [13] (NADPH methemoglobin reductase), and Paglia and Valentine [18] (GPX). GT concentrations were determined according to the protocol described by Anderson [2] and GSSG concentrations were determined according to Srivastava and Beutler [26]. Methemoglobin levels and plasma lipid peroxidation product levels were measured spectrophotometrically according to Tietz [31] and Stocks and Dormandy [27] respestively. Serum bilirubin and haptoglobin concentrations were analysed within 24 hours using standardised clinical protocols. The concentration of hemoglobin $(\mathrm{Hb})$ was determined with the hemoglobin cyanide procedure [15].

\section{Exposure assessment}

Stationary monitoring was done at three different sampling places selected by the occupational hygiene department from the standard inventory of monitoring spots. Sampling took place once a week at head height (usually the day before blood sampling took place). Personal air monitoring was done by workers exposed to $\mathrm{OMH}$ during the morning, afternoon and night shift the day before blood sampling took place. Samples were collected using an explosion safe sample pump with a maximum sample volume of $50 \mathrm{I}$. Absorption tubes were filled with silica gel that was pre-treated with concentrated hydrochloric acid fumes during sixteen hours. Liquid desorption was done with $0.5 \mathrm{M}$ sulphuric acid. The samples were derivatized with heptanon, extracted with methyl tertiary butyl ether and analysed by gas chromatography with a flame ionisation detector.

\section{Statistical Analyses}

To test for significance of differences between blood parameters before and after the exposure, matched pair analyses was performed with the Wilcoxon non-parametric signed rank test. Changes in the $\mathrm{OMH}$ group were compared with changes in the non-OMH group with a paired Wilcoxon test after correction of the changes in the $\mathrm{OMH}$ group for changes in the mean values in the non-OMH group. Changes in the non-OMH group were compared with changes in the non-industrial group in the same way after correction of the changes in the non-OMH group for changes in the mean values in the non-industrial group. Differences in parameter values between the three groups were tested by analysis of variance. 
Table 2: Blood parameters before and after occupational handling of $\mathrm{OMH}$

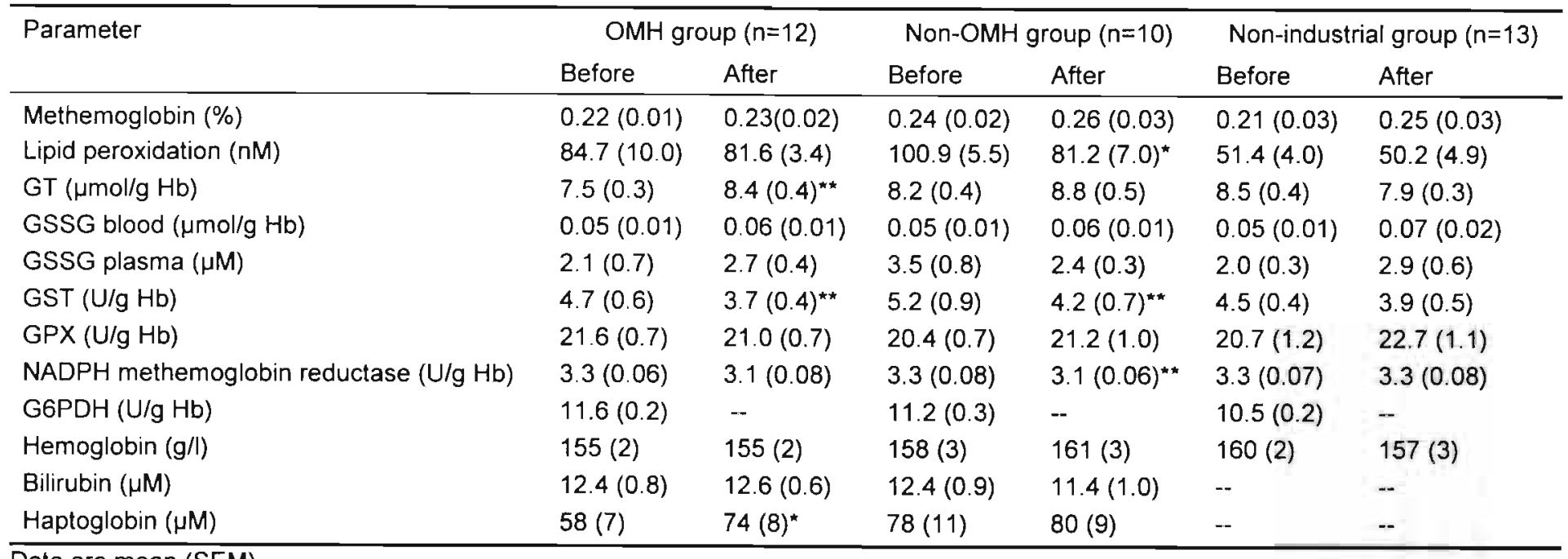

Data are mean (SEM)

Significant difference between before and after occupational handling of $\mathrm{OMH}$ : ${ }^{*} p<0.05,{ }^{* *} \rho<0.01$ 


\section{RESULTS}

\section{Exposure}

During stationary monitoring the sample time ranged from 5.3 to $6.7 \mathrm{~h}$ with a mean of $6.3 \mathrm{~h}$. The sample time during personal air monitoring ranged from 2.5 to $8.2 \mathrm{~h}$ with a mean of $6.5 \mathrm{~h}$. In the stationary monitoring study the $\mathrm{OMH}$ exposure was found to be extremely low: the concentration of $\mathrm{OMH}$ in the air ranged from 0.013 to $0.024 \mathrm{ppm}$ (mean $0.016 \mathrm{ppm}$ SD $0.003 ; n=11$ ). The concentration of $\mathrm{OMH}$ measured with personal air monitoring was also very low and ranged from 0.012 to $0.036 \mathrm{ppm}$ (mean $0.015 \mathrm{ppm}$ SD $0.005 ; \mathrm{n}=23$ ).

\section{Blood parameters}

The G6PDH activity, that was determined as a sensitivity marker, was normal in all individuals with a mean of $10.8 \mathrm{U} / \mathrm{g} \mathrm{Hb}$ (SE 0.3). Significant difference in pre-exposure values between the three groups was only found for release of lipid peroxidation products in plasma which were lowest in the non-industrial group and highest in the industrial non-OMH group ( $p<0.0001$; ANOVA). With the exception of GST, GT and haptoglobin, no significant differences were found for the blood parameters of the $\mathrm{OMH}$ group in the samples taken before and after occupational handling of $\mathrm{OMH}$ (Table 2). Concentrations of GT and haptoglobin were significantly increased after the exposure from 7.50 to $8.35 \mathrm{U} / \mathrm{g} \mathrm{Hb}$ $(p<0.001)$ and from 58 to $74 \mu \mathrm{mol} / /(p<0.02)$ respectively. GST activity after OMH exposure was $1 \mathrm{U} / \mathrm{g} \mathrm{Hb}$ lower than the $4.7 \mathrm{U} / \mathrm{g} \mathrm{Hb}$ found in the pre-exposure phase $(p<0.005)$. In the industrial non-OMH group significant differences between the two samples were found for release of lipid peroxidation products, GST activity and NADPH methemoglobin reductase activity all of which showed some decrease (Table 2). As noted before the pre-exposure sample for release of lipid peroxidation products was relatively high in this group and the decrease led to equal average values in the post-exposure samples for the two industrial groups. Comparing the changes in the $\mathrm{OMH}$ group with the changes in the non-OMH group, no differences were found in the blood parameters except for haptoglobin levels in plasma where the increase in the $\mathrm{OMH}$ group was significantly stronger than in the non-OMH group $(p<0.02)$. In the non-industrial group no significant differences in blood parameters were found between the early samples and the late samples (Table 2). Comparing the changes in the industrial non-OMH group with the changes in the non-industrial group the minor decreases remained significant for NADPH methemoglobin reductase activity $(p<0.006)$ and release of lipid peroxidation products $(p<0.05)$ while the GT concentrations showed a relative increase $(p<0.02)$ and GSSG levels in plasma a relative decrease $(p<0.03)$ in the industrial non-OMH group in contrast with the non-industrial controls.

\section{CONCLUSIONS AND FOLLOW UP}

In this study we adopted a multistage strategy for risk prevention with regard to $\mathrm{OMH}$ exposure at an $\mathrm{OMH}$ production facility. This strategy included two phases; a pre-opening phase and a check phase. The pre-opening phase consisted of a toxicological evaluation of available data for $\mathrm{OMH}$ and for two structurally related compounds, an in vitro study in 
human erythrocytes with $\mathrm{OMH}$, development of a plant design that would minimise exposure risk and adoption of a lay out of work regulations that would exclude exposure. In this phase the exposure limit value for $\mathrm{OMH}$ was set at $0.1 \mathrm{ppm}$. This limit was based on the toxicological evaluation of in vivo $\mathrm{OMH}, \mathrm{HYAM}$ and $\mathrm{OEH}$ data and on data from the OMH in vitro study, as described above. We choose to derive the exposure limit value for $\mathrm{OMH}$ from structure activity relationships and in vitro data rather than from an extra in vivo animal study with extrapolation of the data to the human situation. The main consideration for this was the structure analogy between OMH, OEH and HYAM (Figure 1). Based on this analogy it was logical to assume that the physicochemical properties of OMH would lie in between these of HYAM and OEH. Since in vitro and in vivo studies were carried out with HYAM and OEH it was possible to make a good toxicological evaluation of these available data. The main conclusion from this evaluation was that HYAM as well as OEH are erythrotoxic compounds with similar potency. Considering the structure analogy, we assumed that the main toxicity hazard for $\mathrm{OMH}$ would also be erythrotoxicity and that the potency of $\mathrm{OMH}$ would be about equal to that of HYAM and OEH. Moreover, Yamamoto et al [34] showed that the main target organ for $\mathrm{OMH}$ is indeed the erythrocyte. This taken into account, it was reasonable to set the maximum exposure levels for $\mathrm{OMH}$ at the same level as that adopted for $\mathrm{OEH}$

To base a maximum exposure level for a newly produced compound predominantly on structure analogy with other known compounds can be risky. For this reason an in vitro study was carried out to confirm if OMH was indeed equally potent in erythrotoxic effects as HYAM and OEH. In the previous [8] in vitro study with HYAM and OEH also a third structure analogue was tested, NODMH. It appeared that this structure analogue was far less potent than HYAM and OEH in erythrotoxic effects and only affected the two protective enzymes G6PDH and GR. These latter two parameters were also measured in the OMH in vitro study primarily to see if OMH exposure correspond to toxic effects seen for HYAM and OEH or correspond to that seen for NODMH. The OMH in vitro study [24] showed that OMH was just as potent as HYAM and OEH in erythrotoxic effects and accordingly the hazard assessments made for $\mathrm{OMH}$ based mainly on the toxicological evaluation of data from HYAM and OEH was confirmed.

An other reason for proceeding this multistage strategy is the fact that the maximum accepted exposure level for $\mathrm{OMH}$ is very low $(0.1 \mathrm{ppm})$. As stated before, animal in vivo studies with the structural related compounds HYAM and OEH showed that erythrotoxic effects are by far the most important and occur with relative low exposure levels. From the $\mathrm{OMH}$ in vitro [24] and animal in vivo [34.] study it appeared that this kind of erythrotoxic effects are also expected for $\mathrm{OMH}$ at comparable low exposure levels. Therefore, absence of erythrotoxic effects must mean that the exposure levels are low and occurrence of other toxicological effects (i.e. in other organs) at these exposure levels is unlikely, especially since no other toxicological effects were found in in vivo animal studies with HYAM, OEH and $\mathrm{OMH}[14,19,21,22,33,34]$. 
Next to these toxicological considerations to determine a maximum exposure level for $\mathrm{OMH}$, we found it also very important to improve the production process at the chemical plant to minimise exposure. For this reason a plant design with a closed reaction system was developed. Furthermore, a lay out of work regulations was set up to protect the workers as much as possible for $\mathrm{OMH}$ exposure. To check if indeed all these precautionary measurements succeeded to minimise exposure and to verify if the maximum exposure level for $\mathrm{OMH}$ was not exceeded, environmental monitoring was performed immediately after the start of the $\mathrm{OMH}$ production. To verify that no detectable adverse biochemical effects were present in blood of workers, an in vivo study was also carried out in the same period. This biological effect monitoring study was also intended to rule out the possibility of effects occurring at extremely low exposure as a result of higher in vivo potency compared to in vitro.

Environmental monitoring (spot measurements and personal air sampling) showed that the $\mathrm{OMH}$ exposure was clearly below the advised maximum exposure level of $0.1 \mathrm{ppm}$. Moreover, during the whole study no complaints from workers of the $\mathrm{OMH}$ plant were registered by the occupational physician and no incidents with accidentally high exposures were registered by the plant management. We concluded that the safety precautions taken regarding the plant design and the work regulations were effective in minimising the occupational exposure.

In the biological effect monitoring study significant difference was found in pre-exposure values between the three groups for release of lipid peroxidation products. This difference seems to be mainly due to lower values in the group of the non-industrial workers. Although this may have been caused by a background in exposure to oxidative compounds in the overall industrial facility it can also be the result of differences in other working conditions (e.g. physical activity). The design of the current study does not allow conclusions about the cause of this difference. Haptoglobin levels in the $\mathrm{OMH}$-group were significantly increased after handling $\mathrm{OMH}$ and this change was significantly different from the change in the non$\mathrm{OMH}$ group. However, this increase was small and in between the normal range of haptoglobin levels in plasma (38-102 $\mu \mathrm{M}$ according to the clinical laboratory). Moreover, occurrence of hemolysis which would be a logical result after $\mathrm{OMH}$ exposure, leads to decreased levels of haptoglobin in plasma and not to increased levels [17,31]. Based on this we concluded that no additional hemolysis occurred due to occupational handling of $\mathrm{OMH}$. The GST activity in the OMH-group was significantly decreased after exposure to $\mathrm{OMH}$. Since the GST activity was decreased in all three groups this means that the decrease can not be the result of OMH exposure but is probably due to intra-individual erythrocyte GST variability $[9,10,20,30]$. Some minor differences were found between the non-OMH group and the non-industrial group. These differences are significant but are most likely due to different working conditions (e.g. physical activity) and due to local (e.g. different oxidative background exposure) and analytical variation. 
On the whole occupational handling of $\mathrm{OMH}$ did not lead to detectable adverse health effects in blood of workers and the maximum exposure level of $0.1 \mathrm{ppm}$ for $\mathrm{OMH}$ was not exceeded under the working conditions described above (i.e. a closed reaction system in open-air and good work regulations). Based on these results the check phase was followed by a normal production phase during which work regulations remain effective and a scheme of airsampling measurements was continued to ensure commitment to the maximum exposure value. This scheme of air sampling consisted of six personal air sampling measurements a year (two series of measurements in three successive shifts) and of spot measurements at three different places at head height once a week. Looking at the results of these spot air sampling measurements $(0.012 \mathrm{ppm}$ SD $0.002 ; n=36)$ as collected during the first 4 months after the check phase one can conclude that during this period the $\mathrm{OMH}$ exposure was always below the limit exposure value of $0.1 \mathrm{ppm}$. Besides this scheme of air sampling measurements, workers are medically checked every year as a routine, before and during certain batch processes and immediately after accidental exposure. Finally, a biological effect monitoring protocol was developed for accidental exposures. This protocol describes when and how blood samples must be drawn, who has to be notified and that the situation, the possible exposure and the medical complaints from workers has to be registered.

Considering the above one can conclude that the followed strategy ensured a acceptable situation for workers with regard to $\mathrm{OMH}$ exposure. Furthermore, this study emphasised the use of in vitro techniques in hazard assessment. In other words the biological blood parameters measured in the in vitro and in vivo study are useful tools in the future for potency ranking of newly produced hydroxylamine derivatives. Screening new derivatives of hydroxylamine with the in vitro methods described provides a good insight in the toxicological properties and enables us to estimate the requirements for further toxicological research, for the nature and extent of occupational hygiene and for medical screening. On the whole, the overall strategy prevents unreasonable risks and ensures a good insight in the toxicological properties of the compound used and is cost effective with regard to money spent and animals used.

Acknowledgements The authors are indebted to all workers for their participation in this study and wish to thank the department of Clinical Chemistry and Hematology, Maasland Hospital, Sittard for their assistance with the analyses. The study was financially supported by DSM Special Products b.v., Geleen, The Netherlands. 


\section{References}

1 Akerboom $\mathrm{T}$ and Sies $\mathrm{H}_{1}$ Glutathione transport and its significance in oxidative stress. In: Glutathione: metabolisme and physiological functions. (eds. Vina J), pp. 45-55. Boca Raton: CRC Press, 1990

2 Anderson ME, Determination of glutathione and glutathione disulphide in biological samples. Meth. Enzymol. 113: 548-55, 1985

3 Beutler E, Red cell metabolism (A manual of biochemical methods). New York: Grune and Stratton, 1975

4 Carrell RW, Winterbourn CC and Rachmilewitz EA, Activated oxygen and haemolysis. Br. J. Haematol. 30: 368-89, 1975

5 Chiu D, Kuypers F and Lubin B, Lipid peroxidation in human red cells. Semin. Hematol. 26: 257-76, 1989

6 Deneke SM and Fanburg BL, Regulation of cellular glutathione. Am. J. Physiol. 257: L163-73, 1989

7 Derelanko MJ, Gad SC, Gavigan FA, Babich PC and Rinehart WE, Toxicity of hydroxylamine sulfate following dermal exposure: Variability with exposure method and species. Fund. Appl. Toxicol. 8: 583-94, 1987

8 Evelo CTA, Spooren AAMG, Bisschops RAG, Baars LGM and Neis JM, Two Mechanisms for toxic effects of hydroxylamines in human erythrocytes: Involvement of free radicals and risk of potentiation. Blood Cells, Molecules Diseases 24: 280-95, 1998

Gidlow BA, Church JF and Clayton BE, Seasonal variations in haematological and biochemical parameters. Ann. Clin. Biochem. 23: 310-6, 1986

Gidlow DA, Church JF and Clayton BE, Haematological and biochemical parameters in an industrial workforce. Ann. Clin. Biochem. 20: 341-8, 1983

Gross P. Biologic activity of hydroxylamine: A Review. CRC Crit. Rev. Toxicol. 14: 87-99, 1985

Habig WH and Jakoby WB, Assays for the differentiation of glutathione S-transferases. Meth. Enzymol. 77: 398-405, 1981

3 Huennekens FM, Caffrey RW, Basford RE and Gabrio BW, Erythrocyte metabolism. IV. Isolation and properties of methemoglobin reductase. J. Biol. Chem. 227: 261-72, 1957

Jacobson E, Plum CM and Milwertz I, Experimental anemias with hydroxylamine and their relation to human pernicious anemia. Nord. Med. 3: 2851-8, 1939

van Kampen EJ and Zijlstra WG, Determination of hemoglobin and its derivatives. Adv. Clin. Chem. 8: 141-87, 1965

Martin $H$, Wörner $W$ and Rittmeister $B$, Hämolytische anämie durch inhalation von hydroxylaminen. Zugleich ein beitrag zur frage der Heinz-Körper-Bildung. Klin. Wochenschr. 15 : 725-31, 1964

17 McCormick DJ and Atassi MZ, Hemoglobin binding with haptoglobin: delineation of the haptoglobin binding site on the alpha-chain of human hemoglobin. J. Prot. Chem. 9: 735-42, 1990

18 Paglia DE and Valentine WN, Studies on the quantitative and qualitative characterization of erythrocyte glutathione peroxidase. J. Lab. Clin. Med. 70: 158-69, 1967

Riemann H, On the toxicity of hydroxylamine. Acta Pharmacol. 6: 285-92, 1950

Scott EM and Wright RC, Variability of glutathione S-transferase of human erythrocytes. Am. J. Hum. Genet. 32: 115-7, 1980 
21 Sinha D and Sleigh SD, Experimental production of Heinz Bodies in the pig. Toxicol. Appl. Pharmacol. 12: 435-9, 1986

22 Smith RP and Layne WR, A comparison of the lethal effects of nitrite and hydroxylamine in the mouse. J. Pharmacol. Exp. Ther. 165: 30-5, 1969

23 Spooren AAMG and Evelo CTA, Hydroxylamine treatment increases glutathione-protein and protein-protein binding in human erythrocytes. Blood Cells, Molecules Diseases 23: 323-36, 1997

24 Spooren AAMG and Evelo CTA, in vitro haematotoxic effects of three methylated hydroxylamines. Arch. Toxicol. 71: 299-305, 1997

25 Spooren AAMG and Evelo CTA, Only the glutathione dependent antioxidant enzymes are inhibited by haematotoxic hydroxylamines. hum. exp. toxicol. 17: 554-9, 1998

26 Srivastava SK and Beutler E, Accurate measurement of oxidized glutathione content of human, rabbit, and red blood cells. Anal. Biochem. 25: 70-6, 1968

27 Stocks $\mathrm{J}$ and Dormandy $\mathrm{TL}$, The autoxidation of human red cell lipids induced by hydrogen peroxide. Br. J. Haematol. 20: 95-111, 1971

28 Stolze $\mathrm{K}$, Dadak $\mathrm{A}$, Liu $\mathrm{Y}$ and Nohl $\mathrm{H}$, Hydroxylamine and phenol-induced formation of methemoglobin and free radical intermediates in erythrocytes. Biochem. Pharmacol. 52: 1821-9, 1996

29 Stolze $\mathrm{K}$ and Nohl $\mathrm{H}$, Detection of free radicals as intermediates in the methemoglobin formation from oxyhemoglobin induced by hydroxylamine. Biochem. Pharmacol. 38: 3055-9, 1989

30 Strange RC, Johnson PH, Lawton A, Moult JA, Tector MJ, Tyminski RJ and Cotton W, Studies on the variability of glutathione S-transferase from human erythrocytes. Clin. Chim. Acta 120: 251-60, 1982

31 Tietz NW, Textbook of clinical chemistry. Philadelphia: W.B. Saunders, 1986

32 Tomoda A, Imoto M, Hirano M and Yoneyama $Y$, Analysis of met-form haemoglobins in human erythrocytes of normal adults and of a patient with hereditary methemoglobinaenemia due to deficiency of NADH-cytochrome $b_{5}$ reductase. Biochem. J. 181: 505-7, 1979

33 Winter AJ and Hokanson JF, Effects of long-term feeding of nitrate, nitrite, or hydroxylamine on pregnant dairy heifers. Am. J. Vet. Res. 25: 335-61, 1964

34 Yamamoto RS, Weisburger EK and Korziz J, Chronic administration of hydroxylamine and derivatives in mice. Pro. Soc. Exp. Biol. Med. 124: 1217-20, 1967

35 Yubisui $T$, Takeshita $M$ and Yoneyama $Y$, Reduction of methemoglobin through flavin at the physiological concentrations by NADPH-flavin reductase of human erythrocytes. J. Biochem. 87: $1715-20,1980$ 



\section{Chapter 8}

\section{General Discussion and Conclusions}

The main objective of industrial toxicology is the prevention of health impairments in workers that may be exposed to industrial chemicals. This objective can only be reached if conditions of exposure or work practices are defined that do not entail unacceptable health risks [14]. With the possible exception of carcinogenic substances, for which it is still debatable whether "safe" conditions of exposure can presently be defined, this implies in practice that permissible levels of exposure to industrial chemicals have to be defined. These levels are most often expressed as acceptable atmospheric concentrations: e.g. maximum accepted concentrations (Dutch: MAC) or threshold limit values (US: TLV). Both values can also be defined as worktime weighted averages (TWA) and peak values like threshold limit value ceiling (TLV-C) or short-term exposure limits (STEL). Permissible biologic levels of the chemicals or their metabolites (biological TLV) can also be used. To evaluate with some degree of confidence the level of exposure at which the risk of health impairment is negligible, a body of toxicological information is required that derives from two main sources: experimental investigations on animals and/or human tissues, and surveillance of exposed workers. Animal and/or human tissue testing can only provide an estimate of the toxicity of a chemical for humans. Thus, when the compound is actually handled in industry, monitoring of the workplaces and careful surveillance of the workers are essential. The main objectives of the surveillance work are (1) to test the validity of the provisional permissible level of exposure based on animal and/or human tissue experiments; (2) to detect as early as possible reactions unpredictable from animal and/or human tissue investigations. Experimental studies on animals and/or human tissue and surveillance studies on workers are closely related, and this thesis illustrates how integration of these two approaches helps to accomplish an acceptable situation for workers in a production facility for one of the studied hydroxylamines. In addition, the experimental in vitro studies described in this thesis also give an insight into mechanistic aspects of hydroxylamine induced adverse effects in man.

In the first in vitro study effects of three industrially used hydroxylamines on human red blood cells were studied (chapter 2). The parent compound hydroxylamine (HYAM) is known for its hematotoxic potency, with a strong ability to induce methemoglobin [3]. Strong methemoglobin formation was also found for O-ethyl hydroxylamine (OEH). Both compounds also induced lipid peroxidation. This is probably a result of the formation of free radicals during the oxidation of hemoglobin. The reaction of HYAM with hemoglobin involves a twostep reaction in which hemoglobin cycles between deoxyhemoglobin and methemoglobin leading to decomposition of HYAM into ammonia, nitrogen gas and small amounts of nitrous oxide $[2,5]$. Since the heme iron is a one-electron reactant and two electrons are required to form nitrogen gas, it is assumed that free radical intermediates are involved. Moreover, 
Stolze and Nohl [24-26] reported the existence of radical products, $R_{2} R_{1} N^{*}$, as intermediates in the formation of methemoglobin induced by hydroxylamines. In parallel with methemoglobin formation and lipid peroxidation, strong decreases in glutathione S-transferase (GST) and NADPH methemoglobin reductase activity in red blood cells were found. Total glutathione (GT) depletion was also found but the relative magnitude of this effect was much smaller than methemoglobin formation or the induction of lipid peroxidation. Only a small fraction of the GT that disappeared from the red blood cells could be recovered as oxidised glutathione (GSSG) in the plasma. This phenomenon was studied more extensively in chapter 5 . The third compound used in the first in vitro study was N,O-dimethyl hydroxylamine (NODMH). This compound was found to have much less oxidative potency. The methemoglobin formation was much lower than that for HYAM or OEH, there was hardly any lipid peroxidation detectable and we found no GST or NADPH methemoglobin reductase inhibition. On the other hand NODMH addition did result in some GT depletion in the red blood cells, and the increase in plasma GSSG was even somewhat higher than for the other two hydroxylamines. NODMH pre-treated red blood cells also had a decreased resistance to hydrogen peroxide induced lipid peroxidation. A likely explanation of this phenomenon was found, when it appeared that NODMH treatment resulted in a strong inhibition of G6PDH. In the erythrocyte this enzyme is crucial for the production of NADPH. NADPH is needed for many reductive reactions, including GR and NADPH methemoglobin reductase activity. GR itself was also, but to a lesser extent, inhibited by NODMH. The reduced availability of NADPH will render the erythrocytes more vulnerable to a subsequent oxidative stress, as was found in the experiments with hydrogen peroxide. These results indicate the existence of two different routes of hematotoxicity induced by hydroxylamines (see figure 8.1). HYAM as well as $\mathrm{OEH}$ primarily induce methemoglobin, a process involving radical formation. The radical stress occurring is probably responsible for most other effects. NODMH primarily leads to inhibition of the protective enzymes G6PDH and GR. Since these enzymes play a key role in the protection of erythrocytes against oxidative stress a risk for potentiation during mixed exposure does exist.

This first study led to some ideas about structure-activity-relationships. The oxidative potency of HYAM and its O-derivative $(\mathrm{OEH})$ was larger than the potency of the N,O-derivative (NODMH), In other words, it seemed that the reactivity of hydroxylamines decreases when an alkyl group is attached to the nitrogen atom. To explore this idea and consequently gain more insight into the structure-activity-relationship of hydroxylamines another in vitro study was conducted (chapter 3). In this follow-up study three methylated hydroxylamines were tested: $\mathrm{N}$-methyl hydroxylamine (NMH), N-dimethyl hydroxylamine (NDMH) and O-rnethyl hydroxylamine (OMH). Methemoglobin formation, high release of lipid peroxidation products and depletion of GT were observed with $\mathrm{OMH}$, indicating that $\mathrm{OMH}$ is able to give rise to strong oxidative effects. These oxidative effects seen with $\mathrm{OMH}$ are similar to the effects previously seen with HYAM and OEH (chapter 2). NADPH methemoglobin reductase and GST impairment was also found for $\mathrm{OMH}$; the reductive enzymes G6PDH and GR were not impaired by this compound. The latter two enzymes 
were inactivated by NMH and only the activity of G6PDH was decreased by NDMH. The activity of the protective enzymes NADPH methemoglobin reductase and GST were not influenced by the addition of $\mathrm{NMH}$. The potency of $\mathrm{NMH}$ in achieving oxidative effects (methemoglobin formation, GT depletion) was small and this is consistent with the effects previously seen for NODMH (chapter 2). NDMH not only decreased the activity of G6PDH but also decreased the NADPH methemoglobin reductase activity. Furthermore, NDMH caused severe methemoglobin formation with very little release of lipid peroxidation products. GST activity and GT levels were not decreased by NDMH.

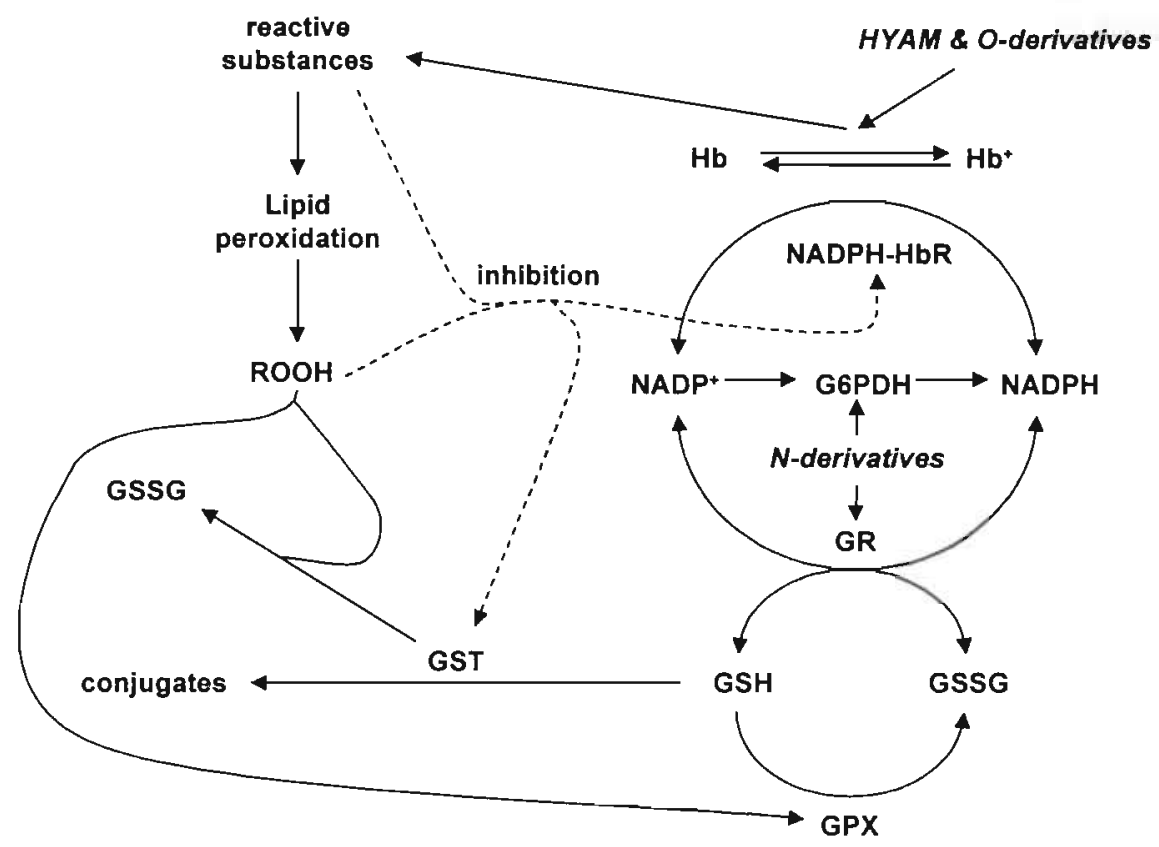

Figure 8.1: Schematic representation of the proposed hematotoxic routes for hydroxylamines. Hydroxylamine (HYAM) and its O-derivative $(\mathrm{OEH})$ induce formation of methemoglobin. During this process free radicals are formed that induce lipid peroxidation. The free radicals plus the lipid peroxides (ROOH) formed lead to inhibition of glutathione S-transferase (GST) and NADPH methemoglobin reductase (NADPH-Hbr). N-derivatives (NODMH) inhibit glucose 6-phophate dehydrogenase $(\mathrm{G} 6 \mathrm{PDH})$, and to a lesser extend glutathione reductase (GR). The oxidative stress occurring leads to depletion of glutathione (GSH) by various routes. Other abbreviations used: GPX = glutathione peroxidase, $\mathrm{GSSG}=$ oxidised glutathione, $\mathrm{Hb}^{+}=$methemoglobin formation

The findings for $\mathrm{OMH}$ are consistent with the proposed mechanism for O-derivatives where methemoglobin formation is the primary and critical step leading to the liberation of free radicals, which cause lipid peroxidation, inhibition of NADPH methemoglobin reductase activity 
and GST activity, and GT depletion. The effects seen for NMH (G6PDH and GR inhibition, and GT depletion) are fully in line with the effects seen for the N-derivatives (see figure 8.1). This supports the idea that the main oxidative activity of hydroxylamine derivatives is dependent on the availability of the nitrogen atom. Masking this atom with a single methyl group was found to decrease the oxidative potency (NMH and NODMH). The presence of an alkyl group attached to the oxygen atom (OEH and $\mathrm{OMH}$ ) does not have qualitative effects. However, the disubstituted compound, NDMH, does not behave similarly to the mono substituted compounds (i.e. $\mathrm{NMH}$ and NODMH). This finding indicates that, despite the simple structures, the structure-activity-relationship is not so straightforward as was initially suggested and that classification of hydroxylamines in O-derivatives and $\mathrm{N}$-derivatives has to be extended with double N-substituted compounds.

From the above, it is clear that hydroxylamines are able to induce oxidative damage in erythrocytes. Moreover, it is known that radicals are formed in erythrocyte incubations with different hydroxylamines [24]. For this reason, and in view of the fact that hydroxylamines react with hemoproteins, we were interested in the possible effects of hydroxylamines on the enzymatic antioxidant defence system in human erythrocytes (chapter 4). The activity of superoxide dismutase (SOD) and catalase was not affected by the hydroxylamines. This indicates that removal of oxygen radicals in erythrocytes by these two antioxidant enzymes is not changed through hydroxylamine exposure. The fact that catalase, a hemoprotein, was not inhibited by hydroxylamines is thought to be largely due to the abundance of hemoglobin present in erythrocytes (about $80 \%$ of the soluble protein).

Under oxidative stress conditions, accessible thiol groups are susceptible to formation of protein-mixed disulphides or intramolecular disulphides that eventually can lead to impairment of enzyme activities if these thiol groups are essential for its activity or if the induced changes in the protein conformation hamper the normal functioning of the enzyme [21]. It appeared that the glutathione peroxidase (GPX) activity was inhibited after exposure to all studied hydroxylamines, except for NMH. GST activity was only impaired by HYAM, OMH and OEH (as was also seen in chapters 2 and 3 ). Since both enzymes have an accessible thiol group essential for activity, it is likely that the activity loss occurring under oxidative conditions during hydroxylamine exposure in erythrocytes involves such an oxidation of critical cysteine residues. Especially since cysteine residues are involved in the inactivation of GST- $\pi$ and GPX by hydrogen peroxide and superoxide radicals, respectively $[4,20]$. GR also contains cysteine residues at its active site [29]. However, oxidation of these thiols would never lead to impairment of GR activity since this enzyme is able to take up electrons from its substrate NADPH or from a chemical reductant to reduce possible disulphide bridge formation. Nevertheless, GR activity was impaired by $\mathrm{NMH}$ and NODMH, which must therefore be explained by other modifications of the enzyme. These results indicate that beside an increase in oxidative effects by hydroxylamines (chapter 2 and 3), the decrease in the activity of the glutathione dependent enzymes GPX, GST and GR may contribute to a cellular prooxidant state in the erythrocyte, which may endanger the life span of the cell. 
A primary effect of hydroxylamine exposure in man and animals is hemolytic anemia [12]. This hemolytic activity is probably a result of oxidative stress within erythrocytes as demonstrated in chapters 2 to 4 . The in vitro study described in chapter 5 was directed to the effect of HYAM on the sulfhydryl status, morphology and membrane skeletal proteins of human erythrocytes. Loss of reduced glutathione (GSH) from the red blood cells was directly proportional to the HYAM concentration used. This loss of GSH was larger than the sum of the increase in the amounts of extracellular glutathione and intracellular oxidised glutathione (GSSG). In other words, the GSH that disappears from the erythrocytes did not come available as intracellular GSSG and was also not exported from the cell. After reduction of the erythrocyte incubates with sodium borohydride the lost glutathione was almost completely recovered. This indicates that the lost GSH is present in the cell as protein-glutathione mixed disulphides. This formation of mixed disulphides will act as a storage of oxidised glutathione. This is a favourable condition for the cell since it allows the cells to maintain the high GSH/GSSG ratio without the necessity to export and thus loose GSSG. Erythrocytes have difficulties to import glutathione directly over the membrane or to synthesise new glutathione $[9,22,30]$. So, through formation of glutathione-protein mixed disulphides, erythrocytes are easily and quickly able to restore their glutathione levels under recovered conditions.

The major features of the SDS-polyacrylamide gel electrophoresis patterns of erythrocyte membrane skeletal proteins were a smearing of bands 1, 2 (spectrin-ankyrin region; MW appr. $250 \mathrm{kD}$ ) and 3 (MW appr. $90 \mathrm{kD}$ ) to the higher molecular weight end of the gel and the appearance of new monomeric and dimeric hemoglobin bands at about 16 and $30 \mathrm{kD}$. The observed alterations are probably a consequence of disulphide bridge formation between cellular proteins (mainly hemoglobin) and skeletal proteins as well as between hemoglobin monomers. Exposure of HYAM to erythrocytes caused severe Heinz body formation and some hemolysis but the outside morphology of the cells was only marginally altered. From this it is concluded that hemolytic anemia induced by HYAM is a complex process which involves generation of reactive species during the redox cycling of HYAM with hemoglobin that interact with cellular thiols and membrane lipids leading to GSH depletion, lipid peroxidation, Heinz body formation and membrane sulfhydryl oxidation. These oxidative processes induce alterations on the external surface of the red cell initiating premature sequestration of these oxidatively damaged cells by the spleen. In other words, the oxidative modifications occurring in erythrocytes are the actual cause for HYAM-induced hemolytic anemia.

The oxidative potency of HYAM and its $\mathrm{O}$-derivatives (OMH and $\mathrm{OEH})$ is generally larger than the effects of the $\mathrm{N}$-derivatives (NMH, NODMH and $\mathrm{NDMH}$ ). The effects of the two groups of hydroxylamines also differ in a qualitative sense. To elucidate this difference in toxicity profiles we investigated the hemoglobin dependence of the toxicity, the occurrence of cell damaging products like superoxide and hydrogen peroxide, and the cellular kinetics of the hydroxylamine analogues (chapter 6). From the results described above it is concluded that HYAM and its O-derivatives cause severe oxidative effects. The $\mathrm{N}$-derivatives of HYAM were less active in this respect. This led us to the postulation that the interaction with oxyhemoglobin is the first and critical step in erythrotoxicity of HYAM and its O-alkyl derivatives whereas such an 
interaction was thought to be unnecessary for the effects of the $\mathrm{N}$-alkyl hydroxylamines (see figure 8.1). However, instead of exclusive disappearance of the erythrotoxic effects caused by HYAM and its O-derivatives, we found that the effects caused by the $\mathrm{N}$-derivatives were lacking in erythrocytes containing carboxyhemoglobin as well. This indicates that all hydroxylamines are dependent on the presence and accessibility of oxyhemoglobin to exert their toxicity. Based on these results the schematic representation of the proposed hematotoxic routes for hydroxylamines (figure 8.1) needs to be adjusted. Figure 8.2 is a more appropriate representation of the hematotoxic properties of the different hydroxylamines.

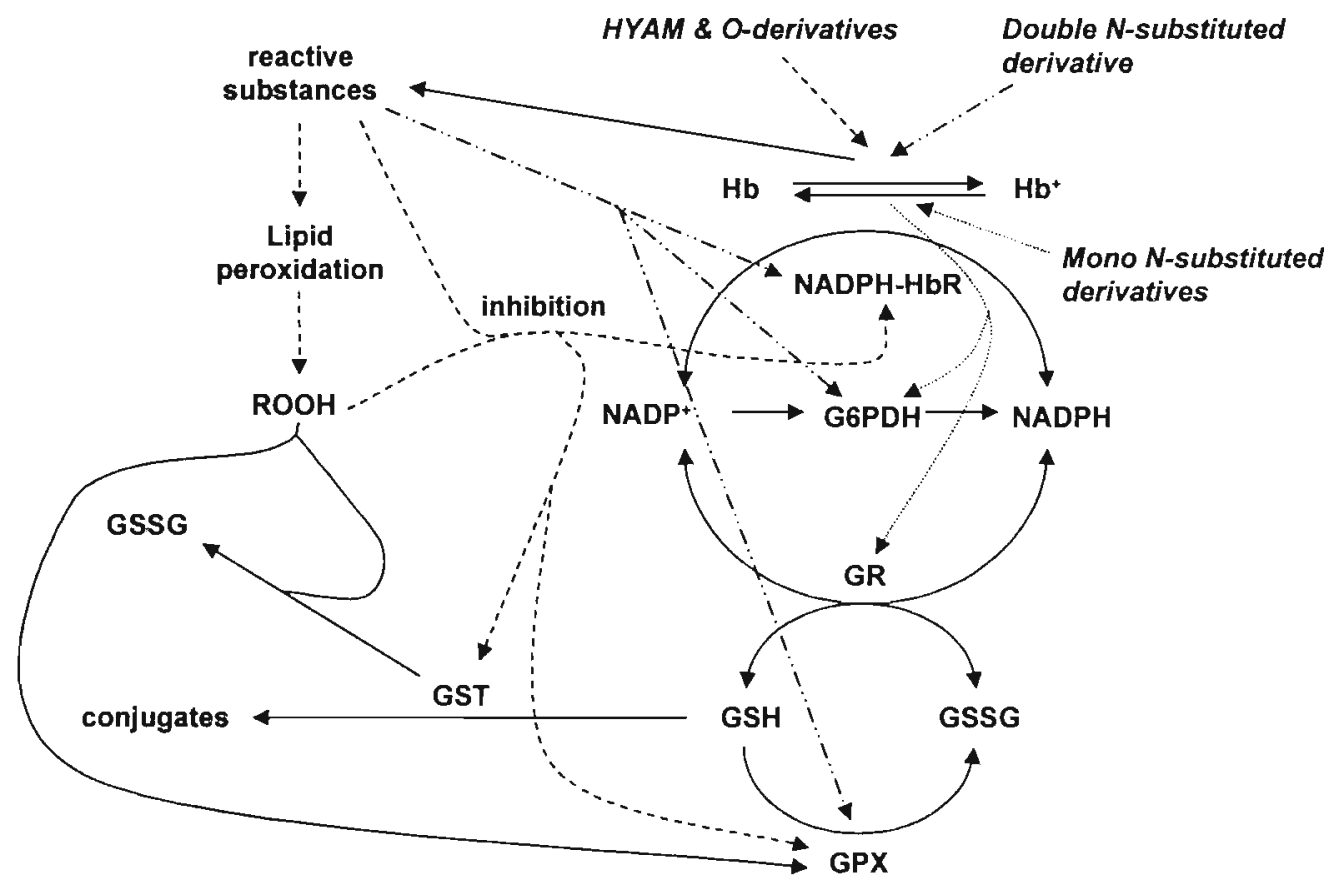

Figure 8.2: Schematic representation of the hematotoxic properties of hydroxylamines. All hydroxylamines are dependent on hemoglobin for their toxicity. HYAM and its O-derivatives form methemoglobin which lead to free radicals and cause lipid peroxidation. These products plus the radicals cause enzyme inhibitions. Mono $\mathrm{N}$-derivatives (NMH and NODMH) are also dependent on hemoglobin but cause only inhibition of glucose 6-fosfaat dehydrogenase (G6PDH) and glutathione reductase (GR) without visible effects on hemoglobin. Double $\mathrm{N}$-substituted compounds (NDMH) causes methemoglobin formation without simultaneous lipid peroxidation, inhibition of NADPH methemoglobin reductase (NADPH-HbR), glutathione peroxidase (GPX) and G6PDH. The oxidative stress occurring leads to depletion of glutathione (GSH) by various routes. 
The fact that all hydroxylamines are dependent on hemoglobin to exert their toxicity, did not provide an explanation for the different toxicity profiles seen for the hydroxylamines. Since it is demonstrated that radical intermediates are formed in the reaction of hydroxylamines with oxyhemoglobin [24-26], and that these radical intermediates are not identical and differ in stability will contribute to the differences in hydroxylamine toxicity seen in erythrocytes. Differences in the production of reactive oxygen species like hydrogen peroxide and superoxide can be another cause for the different erythrotoxicity patterns found for the hydroxylamine analogues. In this respect production of superoxide radicals was demonstrated for all hydroxylamines in the reaction with oxyhemoglobin. Evidence for hydrogen peroxide generation during the reaction of HYAM, OMH, OEH and $\mathrm{NDMH}$ with oxyhemogiobin was also found. The toxicity of hydroxylamines was thus found to depend on an interaction with oxyhemoglobin that produces radical intermediates and concomitantly superoxide radicals and hydrogen peroxide.

Differences in cellular kinetics - uptake and reaction with oxyhemoglobin-is therefore likely to be among the most important factors that determine the different erythrotoxic patterns. Indeed differences were found to exist for the kinetics of methemoglobin formation in erythrocytes. Not only was the final level of methemoglobin formed much lower for the $\mathrm{N}$-derivatives but the reaction rate with oxyhemoglobin was also slower than with HYAM and its O-derivatives. Except for NODMH the same pattern was seen in hemolysates. NODMH tripled its effect on hemoglobin in hemolysate compared with incubations in erythrocytes. This implies that cellular uptake is a limiting factor for NODMH. These results indicate that all hydroxylamines are dependent on oxyhemoglobin for their toxic effects which explains why the erythrocyte is the primary target cell in humans. Hydroxylamines enter the erythrocyte where they undergo a coupled redox reaction with oxyhemoglobin to form methemoglobin and radicals (hydroxylamine dependent radical intermediates, superoxide radicals and hydrogen peroxide). The differences in potency of the different hydroxylamines can be explained by at least three mechanisms. First, the nature of the interaction between hydroxylamines and oxyhemoglobin is different leading to radical intermediates that differ in stability. Second, the reaction rate between hydroxylamines and oxyhemoglobin differs, leading to differences in the production rates of reactive species. Finally, differences in cellular uptake will also contribute to the differences in hemoglobin oxidation rates and in the resulting toxicity profiles. These three mechanisms are important factors to explain the differences in hydroxylamine toxicity.

From the above in vitro studies, it can be concluded that hydroxylamines are predominantly hematotoxic, that they are dependent on oxyhemoglobin to exert their toxic effects, and that production of radicals occurs. Hydroxylamines are also capable to form mixed disulphides and to cause severe Heinz body formation. These last two effects play a major role in the premature splenic sequestration of hydroxylamine-damaged erythrocytes. On the whole, this suggest that erythrotoxicity is probably also the most important effect after occupational exposure. For this reason, apart from hematological effects, determinations of 
NADPH methemoglobin reductase, GPX, and GST activities are likely to be useful biomarkers to monitor human exposure to compounds of this class. The primary oxidative effects (methemoglobin formation, lipid peroxidation and GT depletion) seem most promising for the purpose of ranking the biological activity potency of new hydroxylamines.

\section{Perspectives for further research}

The occurrence of various free radical intermediates and lipid peroxidation in erythrocytes exposed to hydroxylamines is a trigger for further research. The presence of such active species in vivo is assuciated with increased cancer risks and accelerated ageing $[1,6,10,27,28]$. It should be noted however that radical production in this case is linked to the presence of hemoglobin. Since erythrocytes do not contain a nucleus, direct DNA damage is excluded. On the other hand reactive products formed in erythrocytes might be able to leave the erythrocytes and interact with biological plasma-components or reach other cells to provoke damage there. Moreover, such radical mechanisms might also be induced by hydroxylamines at hemoproteins elsewhere (e.g. cytochrome $P_{450}$ ). In the carcinogenicity studies performed so far $[13,16,17,31]$, no clear carcinogenic effects were found. However, the quality of these studies is insufficient to decide whether hydroxylamines are animal carcinogens [3].

In a preliminary study it was suggested that peroxides originating from the membrane of hydroxylamine pre-treated erythrocytes are responsible for LDL (low-density lipoproteinparticles) oxidation $[7,8]$. This is a strong indication that indeed hydroxylamine induced oxidative intermediates are able to cross the erythrocyte membrane. In pilot studies we tried to investigate whether oxidative intermediates, originated from hydroxylamines, are able to induce a response in other neighbouring cells. To study this we incubated erythrocytes with increasing concentrations of hydroxylamines (up to $7 \mathrm{mM}$ ). The cell-free supernatant obtained after centrifugation was used as incubation medium for T-lymphocytic cell lines. In these lymphocytic cell lines we measured the activation of nuclear factor $\kappa B(N F-\kappa B)$. NF- $\mathrm{kB}$ is among the most important transcription factors shown to respond directly to oxidative stress (preferentially peroxides) and plays a key role in the regulation of numerous genes involved in pathogen responses and cellular defence mechanisms $[11,18,19]$. We were not able to show a hydroxylamine dependent NF-KB response. However, with the future use of more sensitive test systems (e.g. cytokine release, oncogene activation or DNA oxidation) it might still be possible to demonstrate effects of reactive substances originating from hydroxylamine treated erythrocytes in other cells. The hypothetical concept that hydroxylamine induced oxidative intermediates might be able to reach biological plasma-components (like $L D L$ ) or to reach other cells to provoke damage there, illustrates the significance of this kind of studies. Especially since oxidatively modified LDL plays a critical role in the onset of artherosclerosis [23] while oxidative damage to other cells could lead to a large number of pathological changes [15]. 


\section{Real life situation in a production facility}

In the last chapter, an occupational health study was carried out for $\mathrm{OMH}$. In this study an integrated strategy was adopted to prevent risks related to $\mathrm{OMH}$ exposure in a recently started $\mathrm{OMH}$ production facility. During the pre-opening phase a toxicological evaluation of the available data for two structurally related compounds, HYAM and $\mathrm{OEH}$, was carried out. The hazard assessments made for OEH and HYAM lead to the conclusion that these compounds share their main toxicity pattern (i.e. erythrotoxicity) with about equal potency. Taking the structural analogy into account, we assumed that exposure to $\mathrm{OMH}$ results in the same kind of toxicological effects as exposure to HYAM and $\mathrm{OEH}$. The marginal data in the literature on toxicity of $\mathrm{OMH}$ itself confirmed this assumption. Furthermore, the in vitro studies described above also confirm that the erythrotoxic potency of $\mathrm{OMH}$ is equal to that of HYAM and OEH. Based on these data an advised maximum exposure level for $\mathrm{OMH}$ was set at $0.1 \mathrm{ppm}$. Next to this, a plant design based on a closed reaction system to minimise exposure risks was chosen and a lay-out of work regulations was developed that would almost exclude exposure during normal production while full protective clothing with clean-air supply was to be worn during any work that might involve higher exposures.

Immediately after the start of the $\mathrm{OMH}$ production this pre-opening phase was followed by a check phase in which it was verified that: 1) the intended advised maximum exposure level was not exceeded using environmental monitoring with personal air sampling and spot measurements; 2) no detectable adverse biochemical effects were present in the blood of the workers using biochemical effect parameters derived from the in vitro studies described above. Furthermore, some classical hematological parameters were used (i.e. haptoglobin, bilirubin and hemoglobin levels). Environmental monitoring showed that the $\mathrm{OMH}$ exposure was clearly below the advised maximum exposure level of $0.1 \mathrm{ppm}$. In the biological effect monitoring study no detectable adverse biochemical effects, related to $\mathrm{OMH}$ exposure, were found.

Based on these results the check phase was followed by a normal production phase during which work regulations remain effective and a scheme of air sampling measurements was continued to ensure commitment to the maximum exposure value. The measurements performed during the 4 months following the check phase showed that the $\mathrm{OMH}$ exposure was always below the limit exposure value of $0.1 \mathrm{ppm}$.

From this occupational health study it can be concluded that the followed strategy ensures an acceptable situation for workers with regard to $\mathrm{OMH}$ exposure.

Considering the above we face an intriguing dilemma. As occupational toxicologists we would decide that no further mechanistic toxicological research with hydroxylamines is necessary at this moment. After all, production of $\mathrm{OMH}$ under the conditions described above (i.e. closed reaction system with a lay out of work regulations) ensures an acceptable situation for 
workers. The actual level of exposure is too low to induce adverse health effects, even after chronic exposure. However, hydroxylamine induced oxidative intermediates could be able to provoke damage outside erythrocytes at levels above the current actual exposure but possibly below the advised maximum exposure level.

On the whole, it can be concluded that the studies provided in this thesis give an insight into mechanistic aspects of hydroxylamine induced adverse effects in man, and furthemore, illustrate the value of in vitro techniques in hazard assessment for structurally related compounds. 


\section{References}

1 Bandy B and Davison AJ, Mitochondrial mutations may increase oxidative stress: implications for carcinogenesis and aging? Free Rad. Biol. Med. 8: 523-39, 1990

Bazylinski DA, Arkowitz RA and Hollocher TC, Decomposition of hydroxylamine by hernoglobin. Arch. Biochem. Biophys. 259: 520-6, 1987

BG Chemie: Hydroxylamin und seine salze. (Berufsgenossenschaft der Chemischen Industrie. Toxikologische bewertung Ausgabe 05/91 Nr 62, Heidelberg ISSN-0937-4248), 1991

Blum J and Fridovich I, Inactivation of glutathione peroxidases by superoxide radical. Arch. Biochem. Biophys. 240: 500-8, 1985

Colter JS and Quastel JH, Catalytic decomposition of hydroxylamine by hemoglobin. Arch. Biochem. 27: 368-89, 1950

Dadak A and Nohl H (1996): Oxidative modification of LDL via hydroxylamine-pretreated erythrocytes. Abstract presented at the 8th SFRR Biennial Meeting, Barcelona, p. 329.

Dadak $A$, Stolze $K$ and Nohl $H$, The relation between hydroxylamine-induced formation of methemoglobin and prooxidants in erythrocytes and the modification of low density lipoproteinparticles. Naunyn-Schmiedeberg's Arch. Pharmacol. Supplement 353 No. 4: R127, 1996

Deneke SM and Fanburg BL, Regulation of cellular glutathione. Am. J. Physiol. 257: L163-73, 1989

10 Farber $\mathrm{JL}$, Kyle ME and Coleman JB, Biology of disease. Mechanisms of cell injury by activated oxygen species. Lab. Invest. 62: 670-9, 1990

11 Flohé L, Brigelius-Flohé R, Saliou C, Traber MG and Packer L, Redox regulation of NF-kappa B activation. Free Rad. Biol. Med. 22: 1115-26, 1997

12 Gross P, Biologic activity of hydroxylamine: A Review. CRC Crit. Rev. Toxicol. 14: 87-99, 1985

13 Harman D, Prolongation of the normal lifespan and inhibition of spontaneous cancer by antioxidants. J. Gerontol. 16: 247-54, 1961

14 Henderson PT, Borm PJA and Kant IJ, Basisboek arbeidstoxicologie. Risico-inventanisatie en evaluatie. Zeist: Uitgeverij Kerckebosch bv, 1995

15 Janssen YMW, Van Houten B, Borm PJA and Mossman BT, Biology of disease. Cell and tissue responses to oxidative damage. Lab. Invest. 69: 261-74, 1993

16 Poukka Evarts R and Brown CA, Morphology of mammary gland, ovaries and pituitary gland of hydroxylamine-fed C3H/HeN mice. Lab. Invest. 37: 53-63, 1977

17 Poukka Evarts R, Brown CA and Atta GJ, The effect of hydroxylamine on the morphology of the rat mammary gland and on the induction of mammary tumors by 7,12-dimethylbenz(a)anthracene. Exp. Mol. Pathol. 30: 337-48, 1979

18 Schreck R, Albermann $K$ and Baeuerle PA, Nuclear factor kappa B: An oxidative stress responsive transcription factor of eukaryotic cells (A Review). Free Rad. Res. Comm. 17: 221-37, 1992

19 Schreck R, Rieber $P$ and Baeuerle PA, Reacative oxygen intermediates as apparently widely used messengers in the activation of the NF-kappa B transcription factor and HIV-1. EMBO J. 10: 2247-58, 1991

20 Shen H, Tsuchida S, Tamai $\mathrm{K}$ and Sato $\mathrm{K}$, Identification of cysteine residues involved in disulfide formation in the inactivation of glutathione transferase P-form by hydrogen peroxide. Arch. Biochem. Biophys. 300: 137-41, 1993

21 Sies H, Oxidative stress. London: Academic Press, 1985 
22 Srivastava SK, Absence of gamma-glutamyl transpeptidase and the role of GSSG transport in the turnover of GSH in erythrocytes. Blood 49: 668-9, 1977

23 Steinberg D, Parthasarathy S, Carew TE, Khoo JC and Witztum JL, Beyond cholesterol. Modifications of low-density lipoprotein. N. Engl. J. Med. 320: 915-24, 1989

24 Stolze $\mathrm{K}$, Dadak $\mathrm{A}$, Liu $\mathrm{Y}$ and Nohl $\mathrm{H}$, Hydroxylamine and phenol-induced formation of methemoglobin and free radical intermediates in erythrocytes. Biochem. Pharmacol. 52 : $1821-9,1996$

25 Stolze $\mathrm{K}$ and Nohl $\mathrm{H}$, Detection of free radicals as intermediates in the methemoglobin formation from oxyhemoglobin induced by hydroxylamine. Biochem. Pharmacol. 38: 3055-9, 1989

26 Stolze $\mathrm{K}$ and $\mathrm{Nohl} \mathrm{H}$, Free radical intermediates in the oxidation of $\mathrm{N}$-methylhydroxylamine and N,N-dimethylhydroxylamine by oxyhemoglobin. Free Rad. Res. Comm. 8: 123-31, 1990

27 Sun Y, Free radicals, antioxidant enzymes, and carcinogenesis. Free Rad. Biol. Med. 8: 583-99, 1990

28 Trush MA and Kensler TW, An overview of the relationship between oxidative stress and chemical carcinogenesis. Free Rad. Biol. Med. 10: 201-9, 1991

29 Untucht-Grau R, Schirmer RH, Schrimer I and Krauth-Siegel RL, Glutathione reductase from human erythrocytes. Amino-acid sequence of the structurally known FAD-binding domain. Eur. J. Biochem. 120: 407-19, 1981

30 Winter CG and Christensen HN, Migration of amino acids across the membrane of the human erythrocyte. J. Biol. Chem. 239: 872-8, 1964

31 Yamamoto RS, Weisburger EK and Korziz J, Chronic administration of hydroxylamine and derivatives in mice. Pro. Soc. Exp. Biol. Med. 124: 1217-20, 1967 


\section{Chapter 9}

\section{Summary}

The working environment will always present the risk of workers' overexposure to various chemicals. It is self-evident that the control of these risks cannot wait until epidemiological studies have defined the no-adverse-effect level directly in man. However, extrapolation from animal data has its limitations. A combination of experimental studies on animals and/or human tissue and surveillance studies on workers is more effective to evaluate the potential risks of industrial chemicals. This thesis illustrates how integration of these two approaches helps to accomplish an acceptable situation for workers in a production facility for one of the studied hydroxylamines (i.e. O-methyl hydroxylamine).

The toxic potency of six industrially used hydroxylamines was studied in human blood cells in vitro in chapter 2 and 3. The parent compound hydroxylamine and the O-ethyl and O-methyl derivative gave very similar results. All three compounds induced methemoglobin, leading to liberation of free radicals which cause lipid peroxidation, inhibition of glutathion S-transferase (GST) and NADPH methemoglobin reductase (MHbR), and depletion of glutathion (GSH). Other enzyme activities like glutathion reductase (GR) and glucose 6-phosphate dehydrogenase (G6PDH) were not or only slightly impaired by hydroxylamine, O-ethyl hydroxylamine or O-methyl hydroxylamine. Hydroxylamine and O-ethyl hydroxylamine had also no effect on the glucose phosphate isomerase and NADH methemoglobin reductase activity. By contrast, a different scheme of reactivity was found for $\mathrm{N}, \mathrm{O}$-dimethyl hydroxylamine and $\mathrm{N}$-methyl hydroxylamine, two single $\mathrm{N}$-substituted derivatives of hydroxylamine. These compounds gave much less methemoglobin formation, lipid peroxidation was not detectable and GST and MHbR activity was not decreased. On the other hand GR and G6PDH activities were inhibited. These results indicate the existence of two different routes of hematotoxicity induced by hydroxylamines. Hydroxylamine as well as its O-derivatives primarily induce methemoglobin, a process involving radical formation. The radical stress occurring is probably responsible for most other effects. $\mathrm{N}$-derivatives like $\mathrm{N}, \mathrm{O}$-dimethyl and $\mathrm{N}$-methyl hydroxylamine primarily lead to inhibition of the protective enzymes G6PDH and GR. In other words, the oxidative potency of hydroxylamine and its O-derivatives is larger than the potency of single $\mathrm{N}$-substituted derivatives. This indicates that the attachment of an alkyl group to the nitrogen atom of hydroxylamine leads to decreased reactivity. However, $\mathrm{N}$-dimethyl hydroxylamine, a double $\mathrm{N}$-substituted compound, caused a strikingly different scheme of reactivity: inhibition of G6PDH but not of GR, severe methemoglobin formation, only little lipid peroxidation and some impairment of $\mathrm{MHbR}$ but not of GST. These results for $\mathrm{N}$-dimethyl hydroxylamine indicate that a simple classification in $\mathrm{O}$-derivatives and $\mathrm{N}$-derivatives of hydroxylamine is to simplistic and that this classification has to be extended for double $\mathrm{N}$-substituted compounds which give a mixture of effects. 
In chapter 4 the effects of hydroxylamines on the enzymatic antioxidant defence system in human erythrocytes was investigated. The activity of catalase and superoxide dismutase was not significantly decreased by any of the six hydroxylamines tested. However, the activity of glutathion peroxidase (GPX) was strongly inhibited by hydroxylamine itself and its O-derivatives (O-methyl and O-ethyl hydroxylamine). GPX was also inhibited by $\mathrm{N}$-dimethyl and $\mathrm{N}, \mathrm{O}$-dimethyl hydroxylamine. GST activity was decreased by hydroxylamine, O-methyl, and O-ethyl hydroxylamine (as was also seen in chapter 2 and 3). This activity loss of GST and GPX is likely to involve oxidation of critical cysteine residues, since GST as well as GPX have cysteine residues at the active site of the enzymes. These cysteine residues are susceptible to formation of protein-mixed disulphides or intramolecular disulphides which can lead to an increase or decrease in the enzyme activity. In principle this is also true for GR, which in this study was only inhibited by the single $\mathrm{N}$-substituted hydroxylamines (i.e. $\mathrm{N}$-methyl and N,O-methyl hydroxylamine). However, GR is capable to reduce these disulphides by taking up two electrons, either from its substrate NADPH or from another reductant. In other words, the activity loss of GR, induced by single N-substituted hydroxylamines, must probably be explained by other modifications than oxidation of cysteine residues. The practical consequence of these findings is that the cellular prooxidant state that may arise in erythrocytes exposed to hydroxylamines can be further increased by activity loss of protective enzymes, which may decrease the average life span of the red blood cell.

The effect of hydroxylamine on the morphology, sulfhydryl status and membrane skeletal protein of human erythrocytes were studies in chapter 5. A large amount of intracellular GSH was lost and this loss was not compensated by increases in intracellular oxidised glutathion (GSSG) or extracellular total glutathion. This extracellular glutathion was mainly oxidised which is in agreement with the fact that only GSSG is exported from the erythrocytes. These results indicated that the GSH that disappeared did not become available as intracellular GSSG. After reduction of the erythrocyte incubates the lost GSH was almost completely recovered indicating that the lost $\mathrm{GSH}$ is present in the cell as protein-glutathion mixed disulphides. Under favourable conditions this stored GSH can be quickly recovered by thioltransferase and GR activity. SDS-polyacrylamide gel electrophoresis of membrane ghosts from human red cells revealed changes in skeletal proteins with a smearing of bands 1,2 and 3 to the higher molecular weight end of the gel and the appearance of new monomeric and dimeric hemoglobin monomers. Hydroxylamine induced severe Heinz body formation but the outside morphology of the red cell was only marginally altered. Therefore, it is concluded that the described changes in the sulphydryl status of erythrocytes are likely to play a major role in the premature splenic sequestration of hydroxylamine-damaged red cells.

The hemoglobin dependence of the toxicity, the occurrence of cell damaging products like superoxide and hydrogen peroxide, and the cellular kinetics of hydroxylamine analogues is investigated in chapter 6 to elucidate the difference in toxicity profiles. All hydroxylamine 
were found to depend on the presence and accessibility of oxyhemogiobin to exert their toxicity. This did not provide an explanation for the different toxicity profiles. It is known that radical intermediates are formed in the reaction with hydroxylamines and oxyhemoglobin. Differences in the stability of these radical products are known to occur and this can contribute to the difference in toxicity. In this respect production of superoxide radicals was demonstrated for all hydroxylamines in the reaction with oxyhemoglobin. Evidence for hydrogen peroxide generation during the reaction of hydroxylamine, O-methyl, O-ethyl and $\mathrm{N}$-dimethyl hydroxylamine with oxyhemoglobin was also found. Next to variations in the products formed, difference in cellular kinetics is likely to be among the most important factors that can explain the different toxicity patterns seen for the hydroxylamines in erythrocytes. Beside the fact that the final methemoglobin level in erythrocytes after exposure to $\mathrm{N}$-derivatives is much lower, the reaction rate with oxyhemoglobin was also slower than with hydroxylamine and its O-derivatives. The same pattern was also seen in hemolysates, except for $\mathrm{N}, \mathrm{O}$-dimethyl hydroxylamine which tripled its effects on hemoglobin. This latter effect implies that cellular uptake is a limiting factor for N,O-dimethyl hydroxylamine. Altogether, this indicates that: (1) the toxicity of all hydroxylamines depends on an interaction with oxyhemoglobin, (2) the interaction with hemoglobin produces radical intermediates and concomitant superoxide radicals and hydrogen peroxide, and (3) differences in uptake, reaction rate with hemoglobin and stability of the intermediates formed do exist for the different hydroxylamines and contribute to their differences in toxicity.

In the last chapter (chapter 7 ) an integrated strategy was adopted to prevent risks related to O-methyl hydroxylamine exposure in a recently started O-methyl hydroxylamine production facility. The pre-opening phase consisted of a toxicological evaluation of available data for two structurally related compounds, hydroxylamine and O-ethyl hydroxylamine. Considering the structure analogy, we assumed that the main toxicity hazard for O-methyl hydroxylamine would also be erythrotoxicity and that the potency of O-methyl hydroxylamine would be about equal to that of hydroxylamine and O-ethyl hydroxylamine. This was confirmed by the marginal data on toxicity of O-methyl hydroxylamine itself present in the literature and the in vitro studies carried out in the previous chapters. Based on these data an advised maximum exposure level for O-methyl hydroxylamine was set at $0.1 \mathrm{ppm}$. This phase also consisted of development of a production design that would minimise exposure risk and adoption of a lay-out of work regulations that would almost exclude exposure. In the check phase environmental and biochemical effect monitoring was performed which showed that the O-methyl exposure was clearly below the level of $0.1 \mathrm{ppm}$ and no detectable adverse biochemical effects, related to O-methyl hydroxylamine, were found. As such, it was concluded that the strategy used ensures an acceptable situation for workers exposed to O-methyl hydroxylamine.

Altogether, it can be concluded that the described studies give an insight into mechanistic aspects of hydroxylamine induced adverse effects in man, and illustrate the value of in vitro techniques in hazard assessment for structurally related compounds. 


\section{Hoofdstuk 10}

\section{Samenvatting}

In de arbeidsomgeving kunnen werknemers langdurig blootgesteld worden aan verschillende chemicaliën. Het is duidelijk dat men voor het in de hand houden van deze risico's niet kan wachten tot dat epidemiologische studies een 'no-adverse-effect level' in de mens hebben gedefinieerd. Extrapolatie van dierexperimentele gegevens naar de mens heeft echter ook zijn beperkingen. Een combinatie van experimenteel onderzoek bij dieren en/of weefsels van mensen en monitoringstudies bij werknemers op de arbeidsplek is een effectievere manier om de potentiële gevaren van industriële chemicaliën te evalueren. Dit proefschrift laat zien hoe integratie van deze twee benaderingen kan leiden tot het tot stand komen van een acceptabele situatie voor werknemers in een productie-faciliteit van een van de geteste hydroxylamines (O-methyl hydroxylamine).

In hoofdstuk 2 en 3 werd de toxische potentie van zes industrieel gebruikte hydroxylamines in vitro bestudeerd in humane rode bloedcellen. De moederstof hydroxylamine (HYAM) en de O-ethyl en O-methyl derivaten gaven overeenkomende effecten. Alle drie de stoffen zorgen voor de vorming van methemoglobine, hetgeen leidt tot het vrijkomen van vrije radicalen die vervolgens lipide peroxidatie, afname van glutathion (GSH) en remming van NADPH methemoglobine reductase (MHbR) en glutathion S-transferase (GST) veroorzaken. Andere enzym activiteiten zoals glutathion reductase (GR) en glucose 6-fosfaat dehydrogenase (G6PDH) werden niet of nauwelijks geremd door HYAM, O-methyl hydroxylamine $(\mathrm{OMH})$ en O-ethyl hydroxylamine $(\mathrm{OEH})$. HYAM en OEH hadden evenmin een effect op de glucose isomerase en $\mathrm{NADH}$ methemoglobine reductase activiteit. In tegenstelling tot HYAM, OEH en $\mathrm{OMH}$ vertoonden $\mathrm{N}, \mathrm{O}-$ dimethyl hydroxylamine (NODMH) en $\mathrm{N}$-methyl hydroxylamine $(\mathrm{NMH})$, twee enkel $\mathrm{N}$-gesubstitueerde verbindingen, een geheel ander patroon van reactiviteit. Deze verbindingen veroorzaakten aanzienlijk minder methemoglobine vorming, nauwelijks lipide peroxidatie, en in het geheel geen GST of $\mathrm{NADPH}$ MHbR activiteit remming. Wel bleken deze verbindingen een remmend effect te hebben op de GR en G6PDH activiteit. De resultaten van deze studies wijzen erop dat twee verschillende routes bestaan aangaande de hematotoxiciteit van hydroxylamines. HYAM en de O-derivaten induceren voornamelijk methemoglobine, een proces waarbij radicalen betrokken zijn. Deze radicalen zijn hoogstwaarschijnlijk verantwoordelijk voor alle andere effecten die optreden in de rode bloedcel. Daarentegen veroorzaken NODMH en NMH met name remming van de beschermende enzymen G6PDH en GR. Met andere woorden, de oxidatieve potentie van HYAM en de O-derivaten is groter dan de potentie van de enkel $\mathrm{N}$-gesubstitueerde derivaten. Dit impliceert dat de reactiviteit van hydroxylamines blijkt af te nemen wanneer er een alkyl groep gebonden zit aan het stikstof atoom. De aanwezigheid van een alkyl groep aan het zuurstof atoom heeft geen invloed op de oxidatieve potentie van 
de hydroxylamines (OEH en $\mathrm{OMH}$ ). N-dimethyl hydroxylamine (NDMH), een dubbel $\mathrm{N}$-gesubstitueerde verbinding, vertoonde echter een geheel ander patroon van reactiviteit: remming van G6PDH maar niet van GR, sterke methemoglobine vorming en remming van NADPH MHbR activiteit maar bijna geen lipide peroxidatie, GST activiteit remming en glutathion afname. De effecten van NDMH geven dan ook aan dat de structuuractiviteitsrelatie niet zo makkelijk is als men in eerste instantie zou verwachten op basis van de eenvoudige structuren. Indeling van hydroxylamines in O-derivaten en $\mathrm{N}$-derivaten is dus niet zonder meer mogelijk en deze indeling moet uitgebreid worden met dubbel $\mathrm{N}$-gesubstitueerde verbindingen.

In hoofdstuk 4 werd het effect van de verschillende hydroxylamines op de antioxidant enzymen in de rode bloedcel bestudeerd. Alle zes de hydroxylamines hadden geen invloed op de activiteit van superoxide dismutase (SOD) en catalase. Alle hydroxylamines behalve NMH remden het enzym glutathion peroxidase (GPX). De GST activiteit werd geremd door HYAM, OEH en OMH (zoals ook al eerder aangetoond in hfdst 2 en 3). Aangezien zowel GST als GPX een cysteine-thiol groep bezitten die essentieel is voor de enzymactiviteit, is het zeer waarschijnlijk dat oxidatie van deze kritische cysteïne groepen verantwoordelijk is voor het verloren gaan van de enzymactiviteit na blootstelling aan hydroxylamines. Deze cysteïne groepen zijn gevoelig voor vorming van eiwitbruggen en intramoleculaire disulfide bruggen, hetgeen in principe kan leiden tot remming of verhoging van de enzym activiteit. GR bezit ook cysteïne groepen. Remming van deze groepen zal echter nooit leiden tot remming van de activiteit van GR omdat dit enzym in staat is om elektronen op te nemen van NADPH of een andere reductor om de eventuele gevormde disulfide bruggen te reduceren. Desondanks, is de activiteit van GR geremd door NMH en NODMH. Deze remming is dan ook alleen te verklaren door andere modificaties aan het enzym. De praktische consequentie van deze bevindingen is dat naast een toename in oxidatieve stress door blootstelling aan hydroxylamines ook de activiteit van de glutathion afhankelijke enzymen GPX, GST en GR geremd wordt. Dit zal uiteindelijk leiden tot een cellulair prooxidant situatie wat de levensduur van de rode bloedcel in gevaar zal brengen.

De effecten van HYAM op de sulfhydryl status, morfologie en membraaneiwitten van humane rode bloedcellen werd bestudeerd in hoofdstuk 5 . Verlies van gereduceerd glutathion concentraties was proportioneel aan de gebruikte HYAM concentratie. Dit verlies was groter dan de som van de toename in extracellulair glutathion en het intracellulaire geoxideerde glutathion (GSSG). Het extracellulair glutathion was voornamelijk aanwezig als GSSG hetgeen in overeenstemming is met het feit dat alleen GSSG geëxporteerd wordt door de rode bloedcel. Deze resultaten indiceerden dat het verdwenen glutathion in de rode bloedcel niet geheel uit de cel getransporteerd werd en ook niet beschikbaar kwam als intracellulair geoxideerd glutathion. Na reductie van de hydroxylamine behandelde rode bloedcellen werd het "verdwenen" glutathion bijna geheel teruggevonden. Dit duidt op vorming van glutathion-eiwitbruggen, ook wel aangeduid met mixed-disulfides. Aangezien 
GSSG toxisch is voor de rode bloedcel, is opslag van GSSG als mixed-disulfides gunstig voor de cel. Door de vorming van glutathion-eiwitbruggen kan de rode bloedcel, wanneer de condities weer gunstig zijn, snel en gemakkelijk de glutathion concentraties op peil brengen met behulp van thiol transferases en GR.

De SDS-polyacrylamide gel elektroforese patronen van membraan eiwitten van rode bloedcellen laten een smering van de banden 1 en 2 (spectrine-ankyrine regio; MW ca $250 \mathrm{kD}$ ) en band 3 ( $\mathrm{MW} 90 \mathrm{kD}$ ) zien en het ontstaan van nieuwe mono- en dimeren hemoglobine banden op ongeveer 16 en $30 \mathrm{kD}$. Blootstelling aan HYAM veroorzaakte Heinz Bodies en hemolyse, maar de morfologie van de rode bloedcel werd maar marginaal veranderd. Concluderend kan dan ook gesteld worden dat de beschreven veranderingen op de sulfhydryl status in de rode bloedcel een rol spelen bij de vroegtijdige verwijdering van de door hydroxylamine beschadigde cel door de milt.

Om meer inzicht te krijgen in de verschillende toxiciteitsprofielen van hydroxylamine analogen werd de hemoglobine-afhankelijkheid, het ontstaan van celbeschadigende producten zoals waterstofperoxide en superoxide, en de cellulaire kinetiek van de hydroxylamines bestudeerd in hoofdstuk 6 . Alle hydroxylamines bleken afhankelijk te zijn van oxyhemoglobine om hun toxiciteit uit te oefenen. Hemoglobine-afhankelijkheid is dus geen verklaring voor het optreden van de verschillende toxiciteitsprofielen van hydroxylamines.

In eerder onderzoek is aangetoond dat radicaal-tussenproducten gevormd worden in de reactie met hydroxylamines en hemoglobine. Deze radicaal-tussenproducten zijn niet allemaal hetzelfde en verschillen in stabiliteit, hetgeen een belangrijke factor kan zijn voor de verschillende toxische effecten aangetoond in rode bloedcellen na blootstelling aan de verschillende hydroxylamines. Verschillen in de productie van vrije radicalen zoals superoxide en waterstofperoxide kan een andere verklaring zijn voor de verschillende toxiciteitsprofielen van de hydroxylamine anaiogen. Superoxide radicalen werden aangetoond bij de reactie van oxyhemoglobine met alle hydroxylamine analogen. Waterstofperoxide werd in ieder geval aangetoond in rode bloedcel incubaties met HYAM, $\mathrm{OMH}, \mathrm{OEH}$ en $\mathrm{NDMH}$.

Verschillen in de cellulaire kinetiek -opname en de reactie met oxyhemoglobine- is waarschijnlijk de meest belangrijke factor om de verschillende toxische profielen van hydroxylamines te verklaren. Bij de $\mathrm{N}$-derivaten werd niet alleen aangetoond dat het uiteindelijke gehalte aan methemoglobine lager is maar de reactie snelheid met oxyhemoglobine is ook langzamer dan met HYAM en zijn O-derivaten. Dit zelfde patroon was ook te zien in hemolysaten, behalve voor NODMH dat een verdrievoudigd effect te zien gaf in hemolysaten ten opzichte van rode bloedcellen. Dit betekent dat cellulaire opname een beperkende factor is voor NODMH. Concluderend kan gesteld worden dat: (1) alle hydroxylamines afhankelijk zijn van oxyhemoglobine om hun toxiciteit uit te oefenen, (2) de 
interactie met oxyhemoglobine radicaal-tussenproducten produceert en tegelijkertijd ook superoxide radicalen en waterstofperoxide, en (3) verschillen in cellulaire opname, in de reactie snelheid met oxyhemoglobine en in de stabiliteit van de gevormde radicalen optreden bij de verschillende hydroxylamines en dat deze aspecten mede zullen leiden tot de uiteindelijke verschillen in de hydroxylamine toxiciteitsprofielen.

In het laatste hoofdstuk (hoofdstuk 7) is een geïntegreerde strategie gebruikt om risico's, gerelateerd aan $\mathrm{OMH}$ blootstelling in een recent opgestarte $\mathrm{OMH}$ productie faciliteit, te voorkomen. De pre-start fase bestond uit een toxicologische evaluatie van beschikbare gegevens van twee structuur-verwante analogen, HYAM en OEH. Op basis van de structuuranalogie werd aangenomen dat het belangrijkste toxische gevaar van $\mathrm{OMH}$ toxische effecten op de rode bloedcel zouden zijn en dat de potentie van OMH vergelijkbaar is met HYAM en OEH. Dit werd bevestigd door de marginale toxische gegevens die voorhanden zijn in de literatuur over $\mathrm{OMH}$ zelf en de uitgevoerde in vitro studies zoals beschreven in de voorgaande hoofdstukken. Op basis van deze gegevens werd voorgesteld de maximale blootstellingconcentratie van $\mathrm{OMH}$ vast te stellen op $0,1 \mathrm{ppm}$. Deze fase bestond eveneens uit het ontwikkelen van een productie plan waarbij de blootstelling tot een minimum werd beperkt en het opzetten van werkvoorschriften die blootstelling bijna uitsluiten. In de check-fase werd omgevings- en biologische effect monitoring uitgevoerd. Deze monitoringstechnieken toonden aan dat de blootstellingconcentratie van $\mathrm{OMH}$ beduidend lager was dan 0,1 ppm en dat geen detecteerbare biochemische effecten, gerelateerd aan $\mathrm{OMH}$, werden aangetoond. Geconcludeerd werd dan ook dat de gevolgde strategie een acceptabele situatie verzekerde voor werknemers in de $\mathrm{OMH}$ fabriek.

Samenvattend, kan geconcludeerd worden dat de beschreven studies een inzicht geven in de mechanistische aspecten van hydroxylamine-geïnduceerde toxische effecten in de mens, en bovendien laten zien wat de waarde van in vitro technieken bij 'hazard' karakterisering kan zijn. 


\section{Dankwoord}

Zoals al zo vaak gezegd is, is een proefschrift nooit het product van één persoon. Aangezien velen na de titel en mijn naam, dit dankwoord waarschijnlijk zo'n beetje als eerste zullen lezen is het goed om te weten dat ik er ongetwijfeld een paar zal vergeten, niet omdat zij niet belangrijk zijn geweest, maar omdat ik er nu even niet bij stil sta. Daarvoor mijn welgemeende excuses.

Op de eerste plaats wil ik mijn co-promotor dr. ir. Chris Evelo bedanken. Beste Chris, tijdens mijn promotie onderzoek heb je me op je eigen speciale manier op een fijne wijze begeleid. Je introduceerde mij in het fascinerende gebied van de toxicologie en zorgde keer op keer dat ik vertrouwen in mezelf bleef houden. Zelfs op het gebied van computers leerde je me dat er naast het "eenvoudig gebruik" ook een soms alles overheersende hobby kan ontstaan, die je jammer genoeg op Rob moest overdragen. Het zij je vergeven, aangezien hij ondertussen ook weet dat er meer is in het leven dan computers alleen. Dus Chris, probeer er zo nu en dan vanaf te blijven!

Leo, zonder jou zouden de dagen vaak eentonig geweest zijn. Je wist me binnen enkele seconden zowel ontzettend vrolijk als ontzettend gedesillusioneerd te maken. Wat dat betreft doe je me denken aan mijn kleine lieve meisje dat mij zowel ontzettend gelukkig, als ontzettend kwaad kan maken, en dat ook binnen enkele seconden. Het waren gezellige tijden en via jou heb ik geleerd hoe je snel iets, binnen een zo traag instituut als de Universiteit, voor elkaar kunt krijgen. Mijn eeuwige dank daarvoor. Daarnaast heb je me op het lab menig maal de niet in boeken beschreven tips gegeven waardoor ik vaak sneller iets onder de knie had dan bij voorbaat gedacht.

Aangezien ik grotendeels aangewezen was op hulp in het lab van studenten en stagiaires van de studie Gezondheidswetenschappen te Maastricht, en de Middelbare Laboratoriumschool te Sittard, wil ik deze grote groep mensen niet allemaal bij naam noemen, maar wil ik bij deze iedereen heel hartelijk danken voor zijn of haar inzet.

Tevens wil ik mijn promotores prof. dr. Harry Struijker Boudier en prof. dr. Aalt Bast bedanken. Harry, met name in de laatste fase van het promoveren gaf je mij vele goede tips die zeer welkom waren. Aalt, naast mijn dank voor je suggesties, mijn dank voor het uitvoeren van ESR bepalingen bij de faculteit Scheikunde aan de Vrije Universiteit Amsterdam, waar je in die tijd nog werkzaam was. Bij deze wil ik ook Ingrid Dekker bedanken van dezelfde afdeling voor haar technische assistentie.

John Neis en Jan Bakker van DSM waren niet alleen als opdrachtgever betrokken bij veel van de uitgevoerde studies in dit proefschrift, maar hun ervaring uit de praktijk en hun tomeloze inzet zorgden voor een plezierige en prettige samenwerking. Natuurlijk kan ik een groot aantal mensen van DSM, omwille van privacy, niet bij naam noemen, terwijl hoofdstuk 7 niet geschreven had kunnen worden zonder hun bijdrage. Bij deze wil ik jullie 
dan ook allemaal bijzonder bedanken voor jullie deelname aan het onderzoek. In een woord, GEWELDIG!!!

Jacques Piette and Bernard Piret van de afdeling Virologie, faculteit Pathologie van de Universiteit Luik, wil ik graag bedanken voor hun inzet bij het meten van de NF-kB respons in lymfocyten. Te allen tijde was ik welkom in hun laboratorium om onder begeleiding van Bernard de praktische bepalingen uit te voeren. Fantastisch!

Nicole, nogmaals bedankt voor de waardevolle discussies in het begin van mijn promotie onderzoek.

Mijn dank gaat ook uit naar Yvonne, Lilian en Dorette. Yvonne voor je altijd luisterende oor en je hartverwarmende vriendschap. Menig uurtje hebben we samen gespendeerd om daarna weer met frisse moed aan de gang te gaan. Dat we in de toekomst nog vaak met elkaar kunnen lachen. Lilian en Dorette voor jullie luisterend oor in de trein. Vaak waren jullie een uitlaatklep voor mij en hebben we heel wat afgelachen in al die uurtjes die we gereisd hebben. Natuurlijk gebied de eerlijkheid mij te zeggen dat we ook heel wat geslapen hebben, maar de interne rust die dit uitstraalde was de volgende dag zeker zichtbaar. Waarschijnlijk hebben we allemaal ook een aversie tegen treinreizen gekregen, maar ondanks dat is het vaak toch beter dan uren in de file staan. Dorette en Lilian blijf vooral zoals jullie zijn, twee spontane meiden die genieten van het leven.

Last but not least, bedank ik mijn familie en vrienden omdat ik nou eenmaal iedere dag weer met plezier naar huis ging. Rob en Lieke, en zeker ook niet te vergeten onze twee poezen Henkie en Lotje, nog eens extra bedankt omdat jullie mij er telkens aan herinneren, ieder op zijn eigen manier natuurlijk, dat er nog zoveel meer in het leven is.

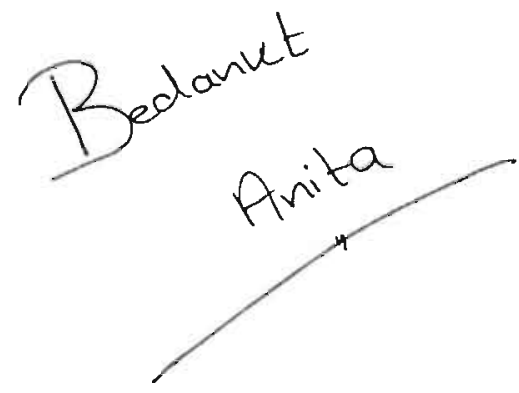




\section{Curriculum Vitae}

Zoals velen van mijn leeftijdgenoten werd ik thuis geboren, en wel te Vught op 1 april 1968 , wat zeker geen grapje was! Dit dorp, gelegen bij 's-Hertogenbosch, is eveneens de plek waar ik opgroeide en nog vaak met liefdevolle herinneringen aan terugdenk. Na het doorlopen van de lagere school besloot ik in 1980 naar het Maurick-College te gaan, gevestigd precies op die plek waar mijn vader een groot deel van zijn jeugd had gewoond. $\mathrm{Na}$ het ondertekenen van het Atheneum B diploma in 1987, ging ik Gezondheidswetenschappen studeren aan de Universiteit Maastricht (destijds nog Rijksuniversiteit Limburg geheten), waar ik na het propedeuse jaar voor Biologische Gezondheidkunde koos. $\mathrm{Na}$ onder meer stages bij achtereenvolgens de vakgroep Arbeidsgeneeskunde, Milieugezondheidkunde en Toxicologie (AMT) en de vakgroep Farmacologie van de Universiteit Maastricht, studeerde ik in 1992 af als Gezondheidswetenschapper. Als echte liefhebber van een Belgisch biertje met een goede maaltijd op een lekker zonnig terrasje in een Zuidelijke Bourgondische omgeving, kon ik het niet over mijn hart verkrijgen Maastricht te verlaten. Ik kon dan ook al snel beginnen als Assistent in Opleiding bij de vakgroep Farmacologie, sectie Toxicologie van de Universiteit Maastricht. Tijdens dit promotie onderzoek werden diverse cursussen in het kader van de postdoctorale opleiding Toxicologie gevolgd. Aangezien deze cursussen verspreid door Nederland werden gegeven, werd al snel duidelijk dat Bourgondische gezelligheid overal in Nederland te vinden is, als je maar zoekt! In 1995 werd Maastricht dan ook verlaten, weliswaar maar gedeeltelijk, want mijn werkzaamheden waren nog steeds in Maastricht, maar de eerste stap was gezet. Sinds 1998 ben ik in dienst bij TNO Nutrition and Food Research Institute te Zeist als toxicoloog bij de afdeling Toxicologische Risicobeoordeling. Vanaf die tijd is Maastricht een stad waar ik nog vaak aan terugdenk en regelmatig probeer te vertoeven. 


\section{List of Publications}

\section{Articles}

- Anita A.M.G. Spooren and Chris T.A. Evelo, Modulation of glutathione and glutathione Stransferase levels by cyclophosphamide and cisplatin. In: Evelo CTA. Toxicological stress indicators in human red blood cells: changes in glutathione and glutathione S-transferase as biological markers for electrophilic and oxidative stress. PhD Thesis, University of Limburg, Maastricht: 55-76, 1995

- Anita A.M.G. Spooren and Chris T.A. Evelo, In vitro haematotoxic effects of three methylated hydroxylamines. Archives in Toxicology 71: 299-305, 1997

- Anita A.M.G. Spooren and Chris T.A. Evelo, Hydroxylamine treatment increases glutathione-protein and protein-protein binding in human erythrocytes. Blood Cells, Molecules, and Diseases 23: 323-336, 1997

- Anita A.M.G. Spooren and Chris T.A. Evelo, Only the glutathione dependent antioxidant enzymes are inhibited by haematotoxic hydroxylamines. Human and Experimental Toxicology, 17: 554-559, 1998

- Chris T.A. Evelo, Anita A.M.G. Spooren, Rob A.G. Bisschops, Leo G.M. Baars and John $M$. Neis, Two mechanisms for toxic effects of hydroxylamines in human erythrocytes; involvement of free radicals and risk of potentiation. Blood Cells, Molecules, and Diseases 24: 280-295, 1998

- Anita A.M.G. Spooren and Chris T.A. Evelo, A study on the interaction between hydroxylamine analogues and oxyhemoglobin in intact erythrocytes. Accepted for publication in: Blood Cells, Molecules, and Diseases 26: 2000

- Anita A.M.G. Spooren, Leo G.M. Baars, Jan G. Bakker, John M. Neis and Chris T.A. Evelo, Occupational handling of O-methyl hydroxylamine: adoption of an integrated strategy for risk prevention. Submitted for publication

\section{Abstracts}

- Anita A.M.G. Spooren, Nicole G.M. Palmen and Chris T.A. Evelo, Influence of cyclophosphamide on the glutathione S-transferase activity and glutathione concentration in rat liver fractions and human erythrocytes. Hum. Exp. Toxicol. 12: 53-84, 1993

- Anita A.M.G. Spooren, Vivian E.A.P. Geelen and Chris T.A. Evelo, Is (re)activation of soluble glutathione $\mathrm{S}$-transferase by cyclophosphamide in incubations with microsomes caused by a reduction of reactive oxygen species? Hum. Exp. Toxicol. 12: 343-354, 1993

- Rob A.G. Bisschops, Anita A.M.G. Spooren, Leo G.M. Baars, John M. Neis en Chris T.A. Evelo, Structure activity relations in hematotoxic effects of hydroxylamines. Hum. Exp. Toxicol. 12: 343-354, 1993

- Chris T.A. Evelo, Rob A.G. Bisschops, Anita A.M.G. Spooren and John M. Neis, Toxic effects of some hydroxylamines in human erythrocytes. European ISSX workshop 1994. Toxicology of Industrial Compounds. Sluchsee: June 12-15, 1994 
- Anita A.M.G. Spooren, Ingrid J.M. de Kruijf and Chris T.A. Evelo, What happens to glutathione in human erythrocytes after oxidative stress? Hum. Exp. Toxicol. 14: 679-694, 1995

- Anita A.M.G. Spooren and Chris T.A. Evelo, Effects of hydroxylamines on the antioxidant enzymes in human erythrocytes. Hum. Exp. Toxicol. 14: 679-694, 1995

- Anita A.M.G. Spooren and Chris T.A. Evelo, Hydroxylamines only affect the glutathione dependent antioxidant enzymes in human erythrocytes. International ISSX workshop on glutathione S-transferases. Noordwijkerhout: April 22-25, Abstract no. p83, 1995

- Anita A.M.G. Spooren and Chris T.A. Evelo, In vitro erythrotoxic effects of hydroxylamine analogues. Hum. Exp. Toxicol. 15: 925-944, 1996

- Anita A.M.G. Spooren and Chris T.A. Evelo, Only the glutathione dependent antioxidant enzymes are affected by the hematotoxic hydroxylamines. International workshop on Oxidative stress and redox regulation: Cellular signalling. Aids, Cancer and Other diseases. Institut Pasteur - Paris: May 21-24, Abstract no. p141, 1996

- Anita A.M.G. Spooren and Chris T.A. Evelo, Hemoglobin dependent toxicity of hydroxylamines. $3^{\text {rd }}$ Symposium for PhD students in toxicology. Doonwerth, November $14-15,1996$

\section{Publications in Dutch}

- Rob A.G. Bisschops, Leo G.M. Baars, Anita A.M.G. Spooren en Chris T.A. Evelo, Diagnostiek voor de hemolyserende werking van hydroxylamines. Rapport opgesteld in opdracht van DSM Special Products, 1992

- Rob A.G. Bisschops, Anita A.M.G. Spooren, Leo G.M. Baars en Chris T.A. Evelo, In vitro hematotoxische effecten van hydroxylamines. Rapport opgesteld in opdracht van DSM Special Products, 1993

- Anita A.M.G. Spooren, Leo G.M. Baars en Chris T.A. Evelo, In vitro hematotoxische effecten van O-methyl hydroxylamine. Rapport opgesteld in opdracht van DSM Special Products, 1995 



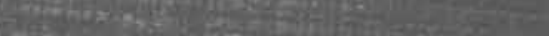

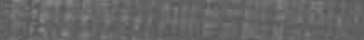

sing 